(C) 2013

GOUTHAM VISWANADAM

ALL RIGHTS RESERVED 


\title{
WATER-DIESEL SECONDARY DISPERSION SEPARATION USING SUPERHYDROPHOBIC TUBES OF NANOFIBERS
}

\author{
A Dissertation \\ Presented to \\ The Graduate Faculty of The University of Akron
}

\author{
In Partial Fulfillment \\ of the Requirements for the Degree
}

Doctor of Philosophy

Goutham Viswanadam

August, 2013 


\title{
WATER-DIESEL SECONDARY DISPERSION SEPARATION USING SUPERHYDROPHOBIC TUBES OF NANOFIBERS
}

\author{
Goutham Viswanadam
}

\section{Dissertation}

Approved:

Advisor

Dr. George G. Chase

Committee Member

Dr. Gang Cheng

Committee Member

Dr. Lingyun Liu

Committee Member

Dr. Kevin L. Kreider
Accepted:
Department Chair

Dr. Lu-Kwang Ju

Dean of the College

Dr. George K. Haritos

Dean of the Graduate School

Dr. George R. Newkome

Committee Member

Dr. S. I. Hariharan 


\begin{abstract}
In diesel engines, sulfur and nitrogen compounds present in the fuel forms oxides during combustion. In the presence of water, these oxides form acidic products which leads to corrosion of engine parts. Hence, it is desired to remove water from diesel fuel before it enters the engine. In this work, superhydrophobic nanofiber mat filters are fabricated in flat sheet and cylindrical geometries by the process of electrospinning and are tested for separation of water dispersions in diesel fuel. Superhydrophobic surfaces are oleophilic due to their low surface energy. The superhydrophobic nanofiber mat acts as a barrier in restricting water droplets while allowing the nonaqueous phase to easily flow through it. The cylindrical nanofiber filters performed with separation efficiency as high as $98 \%$ on a total mass basis for water drops in the range of 7-50 microns in ultra low sulphur diesel fuel (ULSD) with a face velocity of $1.55 \mathrm{~cm} / \mathrm{min}$. The flat filter geometry performed at about $92 \%$ separation efficiency at a similar face velocity. This work shows practical water-diesel separation filters can be constructed in tubular geometries.
\end{abstract}

Keywords: wettability, contact angle, nanofiber, electrospinning, superhydrophobic 


\section{ACKNOWLEDGEMENTS}

I would like to express my deepest gratitude to my advisor, Dr. George G. Chase, for his valuable guidance, caring, tremendous patience, and inspiration throughout this study. I would like to thank my committee members, Dr. Gang Cheng, Dr. Lingyun Liu, Dr. Kevin L. Kreider and Dr. S. I. Hariharan for their guidance and for agreeing to be on my doctoral committee.

I would like to thank Dr. Saru Dawar, Dr. Barry Mark Verdegan and Dr. Mark T. Wieczorek for guiding me in my project. This work has been supported by Cummins Filtration.

I would like to thank Mr. Frank Pelc, for his technical expertise and for helping me in fabricating equipment required for my research. I would like to thank Mallory Barker for helping me with electric field modeling. I would like to thank all my friends in Multiphase group for their help. I would like to thank Mrs. Nancy Chase for all the love and support.

Last but not the least, I would like to thank my family for their love, support and encouragement during my study. 


\section{DEDICATION}

My beloved grandfather

Late Mr. Venkata Subramanya Sarma Viswanadham

And

My beloved parents

Mr. Surya Narayana Murthy Viswanadham

Mrs. Padmavathi Viswanadham 


\section{TABLE OF CONTENTS}

Page

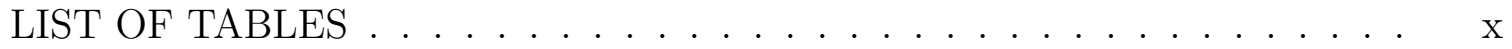

LIST OF FIGURES . . . . . . . . . . . . . . . . . . xi

\section{CHAPTER}

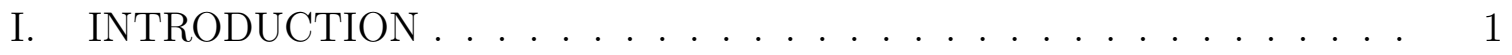

1.1 Motivation ............................ 1

1.2 Problem statement . . . . . . . . . . . . . . . . . 4

1.3 Hypothesis . . . . . . . . . . . . . . . . . 7

1.4 Research objectives . . . . . . . . . . . . . . . . . 9

1.5 Benefits of work . . . . . . . . . . . . . . . . 10

1.6 Dissertation outline . . . . . . . . . . . . . . . . 11

II. LITERATURE REVIEW . . . . . . . . . . . . . . . . . . . . . . . . . 14

2.1 Wettability ......................... 14

2.2 Young's equation . . . . . . . . . . . . . . . . . 15

2.3 Surface models . . . . . . . . . . . . . . . . . . . . . . 16

2.4 Superhydrophobic surfaces . . . . . . . . . . . . . . . . . 18

2.5 Fabrication of superhydrophobic surfaces . . . . . . . . . . . . 19 
2.6 Electrospinning . . . . . . . . . . . . . . . . . . 22

2.7 Charecterization of superhydrophobic surfaces . . . . . . . . . 26

2.8 Effect of surface curvature on hydrophobicity . . . . . . . . . . 28

2.9 Emulsions . . . . . . . . . . . . . . . . . . 30

2.10 Surface filtration . . . . . . . . . . . . . . . 31

III. CONTACT ANGLES OF DROPS ON CURVED SUPERHY-

DROPHOBIC SURFACES . . . . . . . . . . . . . . . . . . . 32

3.1 Comparison of theoretical data to reported data for drops on spheres 32

3.2 Experimental Description for Drops on Cylindrical Surfaces . . . . . 34

3.3 Materials ........................... 34

3.4 Electrospinning setup . . . . . . . . . . . . . . 35

3.5 Contact angle measurement . . . . . . . . . . . . . . . . 36

3.6 Experimental challenges . . . . . . . . . . . . . . . . . 36

3.7 Results and discussion . . . . . . . . . . . . . . . . . . . 38

3.8 Conclusion . . . . . . . . . . . . . . . . . . . . . 42

IV. LENGTH OF THREE PHASE CONTACT LINE OF DROPS ON FLAT AND SPHERICAL SURFACES . . . . . . . . . . . . 43

4.1 Introduction . . . . . . . . . . . . . . . . 43

4.2 Materials ........................... 44

4.3 Electrospinning setup . . . . . . . . . . . . . . . 44

4.4 Dip coating setup . . . . . . . . . . . . . . . 45

4.5 Contact angle measurement . . . . . . . . . . . . . . 46

4.6 Experimental challenges . . . . . . . . . . . . . . . . 46 
4.7 Results and discussion . . . . . . . . . . . . . . . 47

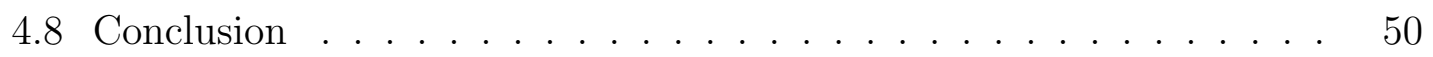

V. MODIFIED ELECTRIC FIELDS TO CONTROL THE DIRECTION

OF ELECTROSPINNING JETS . . . . . . . . . . . . . . . 51

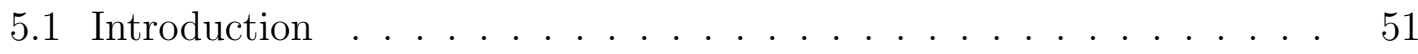

5.2 Simulation work $\ldots \ldots \ldots \ldots \ldots \ldots$

5.3 Experimental work . . . . . . . . . . . . . . . . 61

5.4 Results and discussion . . . . . . . . . . . . . . 65

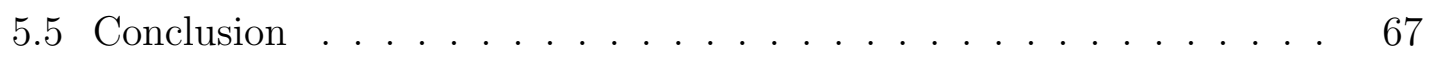

VI. MATERIAL AND METHOD FOR THE FABRICATION OF TUBU-

LAR AND PLANAR NANOFIBER MATS . . . . . . . . . . 69

6.1 Materials . . . . . . . . . . . . . . . . . 69

6.2 Fabrication of tubular nanofiber mats $\ldots \ldots \ldots \ldots$

6.3 Preparation of planar nanofiber mats . . . . . . . . . . 72

VII. WATER-DIESEL SEPARATION EXPERIMENT AND PROCEDURE . 74

7.1 Filter holder design and description $\ldots \ldots \ldots \ldots . \ldots 74$

7.2 Interfacial tension measurements $\ldots \ldots \ldots \ldots \ldots$

7.3 Water-diesel separation experiment . . . . . . . . . . 78

7.4 Experimental procedure $\ldots \ldots \ldots \ldots \ldots$. . . . . . . 81

VIII. EXPERIMENTAL RESULTS _ . . . . . . . . . . . . . . 84

8.1 Comparison of separation efficiency of a flat filter and a tubular filter 84

8.2 Dependence of separation efficiency on the curvature of tubular filter 90

8.3 Dependence of separation efficiency of tubular filter on face velocity . 92 
8.4 Conclusion . . . . . . . . . . . . . . . . . . . 95

IX. CONCLUSIONS . . . . . . . . . . . . . . . . . . . . 97

X. FUTURE WORK . . . . . . . . . . . . . . . . . . . . . . . 101

BIBLIOGRAPHY . . . . . . . . . . . . . . . . . . . . . . 104

APPENDICES . . . . . . . . . . . . . . . . . . . . . 112

APPENDIX A. RELATION BETWEEN INTRINSIC CONTACT ANGLE, DROP SIZE AND RADIUS OF CURVATURE TO THE APPARENT CONTACT ANGLE . . . 113

APPENDIX B. EQUATION TO CALCULATE THE LENGTH OF THREE PHASE CONTACT LINE OF A DROP ON A HYDROPHOBIC PLANAR SURFACE . . . . 117

APPENDIX C. EQUATION TO CALCULATE THE LENGTH OF THREE PHASE CONTACT LINE OF A DROP ON A HYDROPHOBIC SPHERE . . . . . . . . . . . . 119

APPENDIX D. FORTRAN CODE TO CALCULATE THE THEORETICAL LENGTH OF THREE PHASE CONTACT LINE OF A DROP ON A SPHERE . . . . . . . 123

APPENDIX E. EQUATION TO CALCULATE THE POTENTIAL AT EACH POINT IN THE GRID . . . . . . . . . . . 129

APPENDIX F. FORTRAN CODE FOR ELECTRIC FIELD MODELLING WITH TWO PERPENDICULAR ELEC-

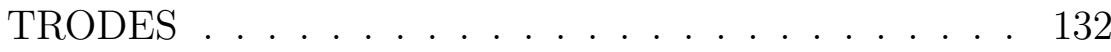




\section{LIST OF TABLES}

Table

Page

$5.1 \quad$ Experimental results . . . . . . . . . . . . . . . 67

8.1 Comparison of parameters and results for the two nanofiber filter geometries. . . . . . . . . . . . . . . . . . . . . . 90 


\section{LIST OF FIGURES}

Figure

Page

1.1 Schematic diagram of the filtration method commonly used to separate emulsified water in diesel fuel . . . . . . . . . . . . . . . . 4

2.1 Equilibrium contact angle of liquid on a flat surface (Young's equation) 16

2.2 Schematic diagram of the electrospinning setup . . . . . . . . . . . . . 22

3.1 Graphical comparison of WCA on PTFE and PC spherical surfaces calculated theoretically and measured experimentally (data from Extrand and Moon, [93] ). ' $R$ ' is the radius of curvature of the spherical surfaces and ' $r$ ' is the radius of the drop in $\mathrm{mm}$. . . . . . . . . 33

3.2 Electrospinning setup to make SPP cylindrical surfaces. . . . . . . . . . 35

3.3 Close-up view of motor and the steel rod collector. . . . . . . . . . . . 36

3.4 Drop shape analyzer . . . . . . . . . . . . . . . 36

3.5 A $4 \mu$ l water droplet on a stainless steel rod coated with SPP nanofiber mat . . . . . . . . . . . . . . . . . . . . . . 38

3.6 Sample SEM images of SPP electrospun fibers on (A) flat surface (B) $3.96 \mathrm{~mm}$ OD steel rod (C) $7.57 \mathrm{~mm}$ OD steel rod . . . . . . . . 39

3.7 DSA photographs of water droplets of different volumes on flat SPP surface. (A) $4 \mu \mathrm{l}(\mathrm{r}=0.985 \mathrm{~mm}),(\mathrm{B}) 5 \mu \mathrm{l}(\mathrm{r}=1.061 \mathrm{~mm}),(\mathrm{C}) 6 \mu \mathrm{l}$ $(\mathrm{r}=1.128 \mathrm{~mm})$, (D) $7 \mu \mathrm{l}(\mathrm{r}=1.187 \mathrm{~mm})$. The images are at different magnifications and hence are not comparable in scale . . . . . . . . . . 39 
3.8 WCA on flat SPP electrospun fiber surface. The larger drops have contact angles exceeding 150 degrees indicating superhydrophobic behavior . . . . . . . . . . . . . . . . . .

3.9 DSA photographs of axial views of water droplets of different volumes on 0.156 Inch outer diameter SPP cylindrical surface. (A) 4 $\mu \mathrm{l}(\mathrm{r}=0.985 \mathrm{~mm}),(\mathrm{B}) 5 \mu \mathrm{l}(\mathrm{r}=1.061 \mathrm{~mm}),(\mathrm{C}) 6 \mu \mathrm{l}(\mathrm{r}=1.128 \mathrm{~mm})$, (D) $7 \mu \mathrm{l}(\mathrm{r}=1.187 \mathrm{~mm})$. The images are at different magnifications and hence are not comparable in scale . . . . . . . . . . . .

3.10 DSA photographs of side view of water droplets of different sizes on cylindrical surfaces $(\mathrm{R}=1.98 \mathrm{~mm})(\mathrm{A}) 4 \mu \mathrm{l}(\mathrm{r}=0.985 \mathrm{~mm}),(\mathrm{B})$ $5 \mu \mathrm{l}(\mathrm{r}=1.061 \mathrm{~mm}),(\mathrm{C}) 6 \mu \mathrm{l}(\mathrm{r}=1.128 \mathrm{~mm}),(\mathrm{D}) 7 \mu \mathrm{l} \quad(\mathrm{r}=1.187$ $\mathrm{mm})$. The images were at different magnifications and hence are not comparable in scale . . . . . . . . . . . . . . . .

3.11 Comparison of WCA on SPP cylindrical surfaces calculated using Equation A.9 (Appendix A) and experimentally measured. $\mathrm{R}$ is the radius of the cylindrical surface and $\mathrm{r}$ is the radius of the drop . . . . . 42

4.1 Dip coating setup . . . . . . . . . . . . . . . 46

4.2 DSA photographs of water drops on (A) flat and (B) spherical surfaces. Both the surfaces are coated with fluoropel $(\mathrm{CA}=120$ degrees) by the process of dip coating . . . . . . . . . . . . . . . . . 47

4.3 DSA photographs of water drops on (A) flat and (B) spherical surfaces. Both the surfaces are coated with polypropylene $(\mathrm{CA}=142$ degrees) nanofibers by the process of electrospinning . . . . . . . . . . 48

4.4 Plot showing theoretical and experimental values of length of contact line of drops of varying volume on sphere $(\mathrm{D}=6.35 \mathrm{~mm})$ with $\mathrm{CA}=120$ degrees and $\mathrm{CA}=142$ degrees . . . . . . . . . . . 48

4.5 Comparison of experimental values of length of contact line of drops on flat and spherical $(\mathrm{D}=6.35 \mathrm{~mm})$ surface with intrinsic contact angle of 142 degrees . . . . . . . . . . . . . . . . .

4.6 Comparison of experimental values of length of contact line of drops on spherical $(\mathrm{D}=4.76 \mathrm{~mm}$ and $\mathrm{D}=6.35 \mathrm{~mm})$ surfaces with intrinsic contact angle of 120 degrees . . . . . . . . . . . . . . . . . . 50

5.1 Case 1. (A) Schematic diagram showing the locations of the source and the collector. (B) Top view of the setup . . . . . . . . . . 56 
5.2 Case 1. (A) Electric field current density vectors for the $Y=0.5$ plane in the absence of an intruding object. (B) Contour plot showing the potential profile for $\mathrm{Y}=0.5$ plane . . . . . . . . . . 56

5.3 Case 2. (A) Schematic diagram showing the location of source, object and collector. (B) Top view of the setup . . . . . . . . 57

5.4 Case 2. (A) Electric field current density vectors for the $\mathrm{Y}=0.5$ plane with an intruding object present. (B) Contour plot showing the potential profile for $\mathrm{Y}=0.5$ plane $\ldots \ldots \ldots \ldots . \ldots \ldots$

5.5 Case 3. (A) Schematic diagram showing the location of source, object, collector and secondary electrodes. (B) Top view of the setup . 58

5.6 Case 3. (A) Electric field current density vector directions for $Y=0.5$ plane in the presence of an intruding object and secondary electrodes. (B) Contour plot showing the potential profile for $\mathrm{Y}=0.5$ plane . . . . . . . . . . . . . . . . . . 58

5.7 Case 4. (A) Schematic diagram showing the location of source, object, collector and secondary electrodes. (B) Top view of the setup .

5.8 Case 4. (A) Electric field current density vector directions for $Y=0.5$ plane in the presence of an intruding object and secondary electrodes. (B) Contour plot showing the potential profile for $\mathrm{Y}=0.5$ plane . . . . . . . . . . . . . . . . . .

5.9 (A) Schematic diagram showing the location of source, object, collector and secondary electrodes (hemi-sphere) (B) Schematic diagram showing the location of source, object, collector and secondary electrodes (cylinder) (C) Schematic diagram showing the location of source, object, collector and secondary electrodes (conical frustum) . .

5.10 (A) Electric field current density vector directions for $\mathrm{Y}=0.5$ plane in the presence of an intruding object and secondary electrodes (Hemi sphere). (B) Electric field current density vector directions for $\mathrm{Y}=0.5$ plane in the presence of an intruding object and secondary electrodes (Cylinder). (C) Electric field current density vector directions for $\mathrm{Y}=0.5$ plane in the presence of an intruding object and secondary electrodes (Cone) . . . . . . . . . . . . .

5.11 (A) Contour plot showing the potential profile for $\mathrm{Y}=0.5$ plane (Hemi sphere). (B) Contour plot showing the potential profile for $\mathrm{Y}=0.5$ plane (Cylinder). (C) Contour plot showing the potential profile for $\mathrm{Y}=0.5$ plane $($ Cone $) \ldots \ldots \ldots \ldots$ 
5.12 Electrospinning setup corresponding to model Case 2 . . . . . . . .

5.13 (A) Experimental setup for Case 3 with secondary flat electrodes positioned perpendicular to each other. (B) Photograph of experimental setup for Case 3 a cardboard collector positioned between the needle and the grounded aluminum foil at a particular Z plane location to collect fibers . . . . . . . . . . . . . . . . .

5.14 (A) Photograph of the cardboard collectors with fibers for Case 2 overlaid on top of each other to show the locations of where the fibers collected on the cardboard in the XY space at the different $\mathrm{Z}$ planes. (B) Photograph of the overlaid cardboard collectors with fibers for Case 3. The locations of the Z-planes were $0.2,0.5$ and 0.8 , as labeled . . . . . . . . . . . . . . . .

5.15 Plots showing superimposed experimental data over theoretical data for (A) Case 2 and (B) Case 3. The arrows show the general direction of electric field current density vectors at predicted by the model and the dots represent the centers of masses where fibers were collected on the cardboard collectors experimentally . . . . . . . . .

5.16 Photographs showing the secondary flat electrode and collector (A) before electrospinning and (B) after electrospinning. No nanofibers were observed to collect on the secondary electrode nor the intruding object (motor) . . . . . . . . . . . . . . . .

6.1 Stainless steel compression spring was used as collector to make tubular nanofiber mat . . . . . . . . . . . . . . . . . 70

6.2 Electrospinning setup to make SPP tubular nanofiber mats . . . . . . 71

6.3 Close-up view of the spring collector $(\mathrm{OD}=2.4 \mathrm{~mm}) \ldots . . . . . \quad 72$

6.4 A thin SPP layer electrospun on the stainless steel compression spring of OD $2.4 \mathrm{~mm} \ldots \ldots$. . . . . . . . . . . . . 72

6.5 Water droplets attached to the cylindrical surface of a spring (OD $=2.4 \mathrm{~mm}$ ) covered with SPP nanofiber layer in air. The droplet repellency is similar to that commonly reported for planar nanofiber mat surfaces . . . . . . . . . . . . . . . . . . 72

6.6 DSA photograph of a $4 \mu$ l drop sitting on a tubular filter . . . . . . . 72 
6.7 The nanofiber mats turn transparent when wetted by diesel fuel and opaque when dry in air. A $4 \mathrm{l}$ water droplet placed by a syringe sits on the SPP fiber mat surface on the tube while submerged in the diesel fuel showing repellency similar to that when the tube is in air . . 72

6.8 Planar nanofiber mat . . . . . . . . . . . . . . . . . . 73

7.1 Exploded diagram of the tubular filter holder . . . . . . . . . . 76

7.2 Inlet (A) and Outlet (B) parts of the tubular nanofiber filter holder . . 76

7.3 Center part of the tubular filter holder. The two open ends of the compression spring, covered with the nanofiber mat, were inserted into holes drilled into the $6.4 \mathrm{~mm}(0.25 \mathrm{inch})$ thick sheet of Plexiglas of the center part. The holes in the Plexiglas were sealed around the nanofiber mat with epoxy $\ldots \ldots \ldots \ldots . \ldots . \ldots 76$

7.4 Assembled tubular filter holder . . . . . . . . . . . . . . . 76

7.5 Exploded diagram of the planar filter holder . . . . . . . . . . . 77

7.6 Inlet (A) and Outlet (B) parts of the planar nanofiber filter holder . . . 77

7.7 Assembled planar filter holder . . . . . . . . . . . . . . . . . 77

7.8 Drop shape analyzer for interfacial tension measurement $\ldots \ldots \ldots 78$

7.9 Flow diagram of the experimental apparatus for filter testing . . . . . 79

7.10 Particle size analyzer (Accusizer 780/SIS) … . . . . . . . . 80

7.11 Experimental setup used to test the separation efficiency of tubular filter 83

8.1 SEM pictures of nanofibers in the flat (A) and tubular (B) filter geometries 85

8.2 Comparison of length weighted log-normal frequency distribution of fiber diameters of the tubular and planar filters . . . . . . . . . 86

8.3 Magnified view of water droplets accumulated on the surface of the tubular nanofiber filter oriented with the axis vertical . . . . . . 86

8.4 Comparison of inlet and outlet stream water droplet size distributions of the planar filter . . . . . . . . . . . . . . . . 89 
8.5 Comparison of inlet and outlet stream water droplet size distributions of the tubular filter . . . . . . . . . . . . . . . . 89

8.6 Comparison of separation efficiency by drop size . . . . . . . . . . 90

8.7 Change of efficiency with face velocity for tubular and flat filter . . . . 90

8.8 Effect of curvature on the separation efficiency of filter media. The average separation efficiency is reported and the error bar corresponds to one standard deviation . . . . . . . . . . . . . . . 91

8.9 Comparison of inlet and outlet stream water droplet size distributions of the tubular filter with spring outer diameter $2.4 \mathrm{~mm}$. . . . . 91

8.10 Comparison of inlet and outlet stream water droplet size distributions of the tubular filter with spring outer diameter $4.7 \mathrm{~mm} \ldots$. . . 92

8.11 Comparison of separation efficiency by drop size . . . . . . . . . . . 92

8.12 Effect of face velocity on separation efficiency for tubular filter (filter area is constant $\ldots \ldots \ldots \ldots \ldots \ldots$. . . . . . . . . . . . 94

8.13 Effect of face velocity on separation efficiency for tubular filter (upstream flow rate is constant) . . . . . . . . . . . . . 94

8.14 Comparison of inlet and outlet stream water droplet size distributions of the tubular filter at a face velocity of $1.55 \mathrm{~cm} / \mathrm{min} \ldots \ldots 9$

8.15 Comparison of inlet and outlet stream water droplet size distributions of the tubular filter at a face velocity of $3 \mathrm{~cm} / \mathrm{min} \ldots \ldots . . .94$

8.16 Comparison of inlet and outlet stream water droplet size distributions of the tubular filter at a face velocity of $4.6 \mathrm{~cm} / \mathrm{min} \ldots \ldots . .95$

8.17 Comparison of inlet and outlet stream water droplet size distributions of the tubular filter at a face velocity of $6 \mathrm{~cm} / \mathrm{min} \ldots \ldots \ldots$

8.18 Comparison of inlet and outlet stream water droplet size distributions of the tubular filter at a face velocity of $8 \mathrm{~cm} / \mathrm{min} \ldots \ldots . . .95$

8.19 Comparison of inlet and outlet stream water droplet size distributions of the tubular filter at a face velocity of $12.5 \mathrm{~cm} / \mathrm{min} \ldots \ldots 9$

8.20 Comparison of inlet and outlet stream water droplet size distributions of the tubular filter at a face velocity of $25 \mathrm{~cm} / \mathrm{min} \ldots \ldots$

A.1 Schematic diagram of a liquid droplet sitting on top of a solid sphere . 113 
B.1 Schematic diagram of a liquid droplet on a planar surface . . . . . . . . 117

C.1 Schematic diagram of a liquid droplet on a solid sphere . . . . . . . . . 119

E.1 Notation showing voltage potential at a local point in a rectangular grid and the surrounding points . . . . . . . . . . . . . . 131 


\section{CHAPTER I}

\section{INTRODUCTION}

\subsection{Motivation}

In 1974 the United States Environmental Protection Agency (EPA) first issued emission standards for heavy duty diesel engines [1]. Since then, emission targets have been incrementally decreased. To meet the emission standards, diesel engine manufacturers started using electronic fuel injection systems instead of carburetted engines [2]. High operating pressure makes fuel injection system vulnerable to contaminants.

Water is a fuel contaminant of concern and it can be present in the fuel as dissolved water and free water [3]. While the dissolved water can affect the stability of the fuel, free water is more strongly associated with corrosion concerns. Diesel is a mixture of hydrocarbons, Nitrogen and Sulfur. Sulfur in the fuel is oxidized in the engine during combustion to produce sulfur dioxide.

$$
\mathrm{S}+\mathrm{O}_{2} \rightarrow \mathrm{SO}_{2}
$$


In the gas phase, sulfur dioxide is oxidized to form sulfur trioxide

$$
\begin{gathered}
\mathrm{SO}_{2}+\mathrm{OH}^{-} \rightarrow \mathrm{HOSO}_{2}^{-} \\
\mathrm{HOSO}_{2}^{-}+\mathrm{O}_{2} \rightarrow \mathrm{HO}_{2}^{-}+\mathrm{SO}_{3}
\end{gathered}
$$

In the presence of water, sulfur trioxide is converted to sulfuric acid

$$
\mathrm{SO}_{3}(\mathrm{~g})+\mathrm{H}_{2} \mathrm{O} \rightarrow \mathrm{H}_{2} \mathrm{SO}_{4}
$$

Similarly Nitrogen dioxide forms nitric acid

$$
\mathrm{NO}_{2}(\mathrm{~g})+\mathrm{OH}^{-} \rightarrow \mathrm{HNO}_{3}
$$

Sulfuric acid and nitric acids cause corrosion of engine components [4][5][6]. In addition, the presence of water reduces heat of combustion of the fuel and promotes microbiological growth [7]. Hence, effective water removal from fuel is of high priority to preserve fuel injection systems and thus, attaining emission standards.

Water gets into the fuel mainly through condensation of atmospheric moisture [8]. Water can exist as free water or emulsified water. Free water can be separated using simple techniques like gravity settling. Emulsified water consists of droplets of size less than $100 \mu \mathrm{m}$ and needs special separation techniques like centrifuges, electric 
fields, membrane processes or flow through fibrous filters [9]. Separation of emulsified water from fuel has been of concern since many years.

Water is removed from diesel fuel by a fuel-water separator installed in the engine fuel system. Filtration methods by which the filter media operates in these separators can be classified into surface filtration or depth filtration [10]. In surface filtration, water droplets bead up on the surface of a hydrophobic media which acts as barrier, enlarge in size due to coalescence and drain on the upstream side of the media due to gravity. In depth filtration, water droplets are captured in the fibrous hydrophilic media, enlarge in size due to coalescence and the enlarged droplets migrate through the filter due to drag by the fuel and drain on the downstream side of the filter media due to gravity. A schematic diagram of the filtration processes is shown in Figure 1.1.

Fibrous filter media show high efficiency in removing secondary dispersions of water droplets in oil with low pressure drop. Because of the high surface to volume ratio and resulting high surface cohesion, tiny water droplets can be easily trapped in the nanofibrous structured filters [11].

The demand for finer filtration and longer service life of the filter gives an opportunity to explore new ways to separate secondary dispersions. Most of the 
previous studies were done on flat fibrous filter media [12][13][14][15] but different filter media geometries are seldom investigated.

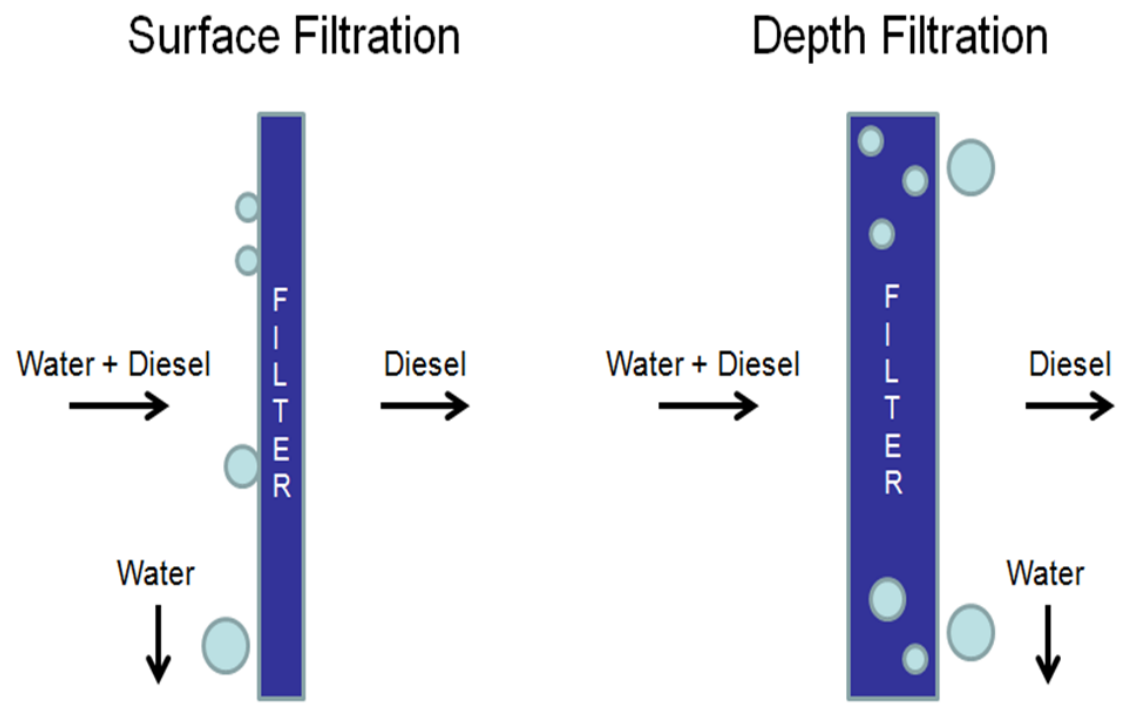

Figure 1.1: Schematic diagram of the filtration method commonly used to separate emulsified water in diesel fuel

\subsection{Problem statement}

In order to meet mandated sulfur levels, diesel fuel is subjected to hydrodesulphurization, a refining step which not only removes sulfur but also non-wax type species from it. The result is ultra low sulphur diesel (ULSD) fuel that has been stripped of its natural lubricity. Fuel lubricity is important since it protects fuel injector systems from catastrophic wear. Chronic failure of ULSD to pass diesel wear resistance 
requirements led the industry to add fuel additives also known as surfactants such as lubricity enhancers, rust inhibitors, and anti-wear agents to ULSD to restore required lubricity.

Fuel and water normally do not dissolve into one another. If forced to coexist, they are most stable as separate layers, with the fuel layer on top of the water layer. The degree to which the layers repel is measured in terms of interfacial tension (IFT). If mixed, an emulsion is formed, where water transiently exists as suspended drops in the fuel.

The root cause of fuel-water separator failure with ULSD is because of addition of surfactants to the fuel. Surfactants create sufficiently small water drops that pass through the media without encountering it. Surfactants also stabilize the emulsion because of which, drops are less likely to partition out of the fuel onto the media even upon interaction. Also, drops that impact other drops resist coalescing into the larger drops necessary for successful separation. Hence there is a need to explore ways to separate tiny water droplets.

Superhydrophobic surfaces can be used as barriers to separate secondary dispersions of water from organic liquids. These surfaces are oleophilic due to their low surface energy. The superhydrophobicity helps in the accumulation of tiny water 
droplets while the oleophilicity allows the non-aqueous phase to easily flow through it [16].

Coalescing filters with hydrophobic/hydrophilic layers are proved to be effective in separating secondary dispersions [17] but they are prone to get saturated after a period of time. The performance of coalescing filters is measured in terms of separation efficiency and pressure drop across the filter media [11]. Saturation results in an increased pressure drop that is not desired since the power $(\mathrm{P})$ required to pump the fuel through the filter media increases with increase in pressure drop across the filter media (Equation 1.6).

$$
\mathrm{P}=\Delta P \cdot Q
$$

Where $\Delta \mathrm{P}=$ pressure drop and $\mathrm{Q}=$ flow rate

In this work, superhydrophobic surface filter media are fabricated out of electrospun fiber mats. Separation performances of the electrospun fiber mats constructed in tubular geometries are compared with electrospun fiber mats constructed in planar geometries. 


\subsection{Hypothesis}

In many industrial applications water-in-oil dispersions are separated for safety, ecological and economic reasons [18]. Water droplets with diameters greater than 100 $\mu \mathrm{m}$ are normally easy to separate using gravity settling. Separation of secondary dispersion with droplets smaller than $100 \mu \mathrm{m}$ are more difficult. The primary goal of this research work is to study the effect of surface curvature on water contact angle and use tubular fibrous mats as filters to separate secondary dispersions of water droplets from diesel fuel.

The process of electrospinning is known for the production of continuous fibers from solutions of different polymers and polymer blends to form non-woven fibrous mats [19]. Electrospun nanofibers are of interest in many applications [20] like filtration [21], biomedical applications [22], tissue engineering [23], catalysis [24] and fuel cells [25]. During electrospinning, most of the electrospun fibers collect on the grounded collector, but depending on the design of the electrospinning apparatus and the environment, some of the fibers drift away from the collector and are captured on other objects. Control of where the fibers collect is of significant interest when the polymer solution is expensive or may be chemically hazardous. For continuous large scale operations the accumulation of fibers other than on the desired collector may be problematic from an operational perspective. The secondary goal of this research work was to modify the electric field with secondary electrodes to prevent the fibers 
from collecting in undesired locations. The electric field is modeled with secondary electrodes placed at locations between the needle and the collector to direct the current density lines away from an intruding object such as a motor.

This work has two hypothesis and are as following

\section{Hypothesis one}

Superhydrophobic surfaces can be used as barriers to separate secondary dispersions of water from organic liquids. Water droplets accumulate on the surface and coalesce into larger drops. Once they become large enough, gravity pulls the drop down vertical surfaces and uncovers surface area for organic fluid flow and capture of additional water droplets. The surface tension force that holds a drop to the surface is proportional to the length of the three phase contact line [26][27][28][29]. Our hypothesis is that curved surfaces result in shorter contact lines when compared to a planar surface. Hence, the force holding a drop to a vertical curved surface (such as a cylinder) will be less than the force holding a drop to a planar surface. This reduction in force should allow smaller drops to roll off of curved surfaces than flat surfaces. This is expected to increase the efficiency of water - oil separation.

\section{Hypothesis two}

Electrospinning is a well known process for fabricating sub-micron size fibers. A high voltage potential is used in electrospinning to launch a polymer jet 
from a droplet of polymer solution towards a grounded collector. Most of the electrospun fibers collect on the grounded collector, but depending on the design of the electrospinning apparatus and the environment, some of the fibers drift away from the collector and are captured on other objects. In this work we apply the hypothesis that the electrospinning jet follows the path of the electric fields current density lines. By controlling the direction of the current density lines one can control the path of the electrospinning jet and hence can control the location of where the fibers are collected.

\subsection{Research objectives}

The primary objectives of the research work are:

1. Fabricate and characterize superhydrophobic surfaces.

2. Derive an equation to relate apparent contact angle of a water drop to its intrinsic contact angle on hydrophobic curved surfaces.

3. Study the behavior of water drops on hydrophobic flat and curved surfaces.

4. Derive an equation to calculate the length of three phase contact line of a water drop on hydrophobic flat and spherical surface.

5. Theoretically show that drops on curved surfaces have smaller contact line than same volume drops on flat surfaces. 
6. Validate theoretical results by experimentally calculating the length of three phase contact line of drops on spherical and flat surfaces.

7. Model static electric fields by numerically solving Laplaces equation for potential field.

8. Develop a technique to control the path of electrospinning jet by modifying the electric field using charged electrodes.

9. Develop a technique to fabricate superhydrophobic tubes of nanofibers.

10. Design a filter holder for assembling tubular filters.

11. Evaluate the performance of tubular filters in separating water dispersion from diesel fuel.

12. Study the effect of surface curvature on the separation efficiency of tubular filters.

13. Study the effect of face velocity on the separation efficiency of tubular filters.

\subsection{Benefits of work}

There are several companies involved in filter media manufacturing, design and distribution for many different applications. The approach of this research which includes filter media design, development, characterization and testing can have significant impact on the economy of the filter industry. 
The benefits of this research are as following:

1. The results of this work will directly impact the automotive industry, especially the fuel filter design. It might help the industry to manufacture compact fuel filters than those currently available in the market.

2. The results of this work might also impact the fuel filter design in the field of aviation.

3. The results of this work might be useful for liquid-liquid separations in petrochemical industry.

4. Similar approach can be applied to separate water droplets from air or gas stream.

5. The principle and approach can also be applied to separate oil from water which would help in the separation of oils and hydrocarbons from produced water, industrial water and waste water.

\subsection{Dissertation outline}

The outline of this dissertation is as follows:

- CHAPTER I explains the motivation behind the work, problem statement, hypothesis, research objectives and benefits of the work. 
- CHAPTER II reviews literature on wetting theory, superhydrophobic surfaces, electrospinning, effect of curvature on hydrophobicity, and surface filtration theory. - CHAPTER III describes the calculation of the apparent water contact angle of drops on hydrophobic spherical and cylindrical surfaces.

- CHAPTER IV describes the calculation of length of three phase contact lines of water drops on hydrophobic spherical and flat surfaces.

- CHAPTER V describes the modeling of electric fields current density lines using secondary electrodes to control the direction of electrospinning jets, experimental setup and results.

- CHAPTER VI describes the material and method used to fabricate tubular as well as planar nanofiber mats.

- CHAPTER VII describes the filter holder design and the experimental setup used for water-diesel separation experiments.

- CHAPTER VIII presents the experimental results of tubular filter media tested for water-diesel separation.

- CHAPTER IX presents the conclusions of the research work.

- CHAPTER X presents the recommendations for future work on separation of water dispersion from diesel fuel using superhydrophobic tubes of nanofibers.

- APPENDIX A presents the relation between intrinsic contact angle, drop size and radius of curvature to the apparent contact angle.

- APPENDIX B presents the derivation of equation to calculate the length of three phase contact line of a drop on a hydrophobic planar surface. 
- APPENDIX C presents the derivation of equation to calculate the length of three phase contact line of a drop on a hydrophobic spherical surface.

- APPENDIX D presents the FORTRAN code to calculate the length of three phase contact line of a drop on a sphere.

- APPENDIX E presents the equation to calculate the potential at each point in the grid.

- APPENDIX E presents the FORTRAN code for electric field modeling with two perpendicular electrodes. 


\section{CHAPTER II}

\section{LITERATURE REVIEW}

A review of literature on wetting theory, superhydrophobic surfaces, electrospinning, effect of curvature on hydrophobicity, and surface filtration theory is summarized in this chapter.

\subsection{Wettability}

Wettability is a fundamental property which describes how a liquid behaves when it interacts with a solid surface. When a liquid drop is placed on a solid surface, three interfaces are observed, namely, solid-liquid, solid-vapor and liquid-vapor. Whether the drop wets the surface of the solid or not is quantified by the spreading parameter (S). The spreading parameter is defined as the difference between the free energy of a bare solid surface, directly in contact with the vapor and the free energy of the same surface when covered by a liquid layer [30]. It relates the interfacial tensions corresponding to the three interfaces as shown in Equation 2.1.

$$
\mathrm{S}=\gamma_{S V}-\left(\gamma_{\mathrm{SL}}+\gamma_{L V}\right)
$$


Where,

$\gamma_{S L}=$ solid-liquid interfacial tension

$\gamma_{S V}=$ solid-vapor interfacial tension

$\gamma_{L V}=$ liquid-vapor interfacial tension

When $\mathrm{S}>0$, the drop spreads and covers the solid surface. This situation is known as total wetting. When $\mathrm{S}<0$, the liquid remains as a drop on the solid surface and reaches an equilibrium shape. This situation is referred to as partial wetting.

In the case of partial wetting, the drop retains approximately a spherical shape characterized by the contact angle between the liquid-vapor interface and the solid-liquid interface at the contact line where the two interfaces meet. The equilibrium contact angle is determined by the values of the surface tensions between the phases.

\subsection{Young's equation}

Consider a liquid drop sitting on an ideal solid surface as shown in Figure 2.1. Young's equation relates the thermodynamic equilibrium contact angle $(\theta)$ of the drop to the specific energies of the solid-liquid, solid-gas and liquid-gas interface [31][32] as shown in Equation 2.2, where $(\gamma)$ is a function of the chemical structure of the respective interface. 


$$
\cos (\theta)=\frac{\gamma_{S V}-\gamma_{S L}}{\gamma_{L V}}
$$

Equation 2.2 may also be interpreted as equilibrium of forces at the three phase contact line. From Young's equation, the spectrum of possible contact angles ranges from 0 degrees (complete wetting) to 180 degrees (complete non-wetting). Superhydrophobic surfaces are those surfaces with contact angles greater than 150 degrees.

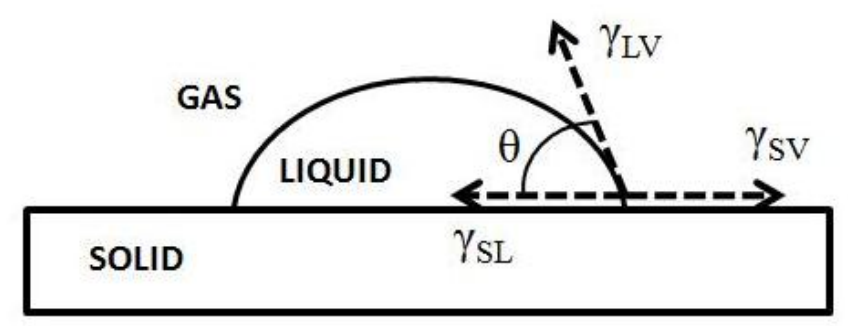

Figure 2.1: Equilibrium contact angle of liquid on a flat surface (Young's equation)

\subsection{Surface models}

The principles of superhydrophobicity were first outlined by Wenzel in 1936 and then by Cassie and Baxter in 1944. Wenzel model [33] predicted that roughness can improve wetting properties of a smooth material if a drop wets the surface in such a way that it follows the roughness features. In this situation, the area of the drop's 
solid-liquid interface is enlarged by a factor $r$ called the roughness factor. Roughness factor is defined as the ratio of actual surface area to the planar area.

$$
\mathrm{r}=\text { roughness factor }=\frac{\text { actual surface area }}{\text { planar surf ace area }}
$$

Wenzel proposed that the contact angle on the rough surface $\left(\theta_{w}\right)$ would be

$$
\cos \left(\theta_{\mathrm{w}}\right)=\operatorname{rcos}(\theta)
$$

According to the Equation 2.4, a hydrophobic surface will become more hydrophobic with increase in roughness while a hydrophilic surface will become more hydrophilic with increase in roughness.

The Cassie-Baxter model [34] considers the interaction of a liquid drop with the surface in terms of interface areas and the interfacial energies. According to this model, when a water droplet sits on top of protrusions of a surface, air is trapped underneath the droplet between these protrusions. Cassie-Baxter proposed that the contact angle on the rough surface $\left(\theta_{c}\right)$ would be

$$
\cos \left(\theta_{\mathrm{c}}\right)=\sum_{i} \phi_{i} \cos \left(\theta_{\mathrm{i}}\right)
$$


Where, $\theta_{c}$ is the equilibrium contact angle on the heterogeneous surface, $\theta_{i}$ is the angle belonging to the area fraction $\mathrm{I}$ and $\phi_{i}$ is the area fraction.

\subsection{Superhydrophobic surfaces}

Superhydrophobicity, a unique property of materials, has been investigated excessively in the past few years because of its applications in various fields [16] such as anti bio fouling paints for boats, anti stick coatings on antennas and windows [35], self cleaning windshields for automobiles, stain resistant textiles and oil-water separation $[36]$.

Research on superhydrophobic surfaces did not receive much attention before the mid-1990's, which mainly focused on the relations between contact angles and surface geometry. It received considerable interest after the explanation of 'lotus effect' by Neinhuis and Barthlott in 1997 [37]. They have revealed that the epicuticular wax crystalloids of the plant surface are responsible for their self-cleaning properties. Selfcleaning is a property of the leaf surface where the dust particles adhere to the surface of water droplets and can be removed easily from the leaves when the droplets roll off.

Other examples of superhydrophobic surfaces in nature include water strider legs [38], which have a highly defined microstructure that is coated by a layer of secreted wax. The wings of few insects also show superhydrophobic properties because 
of surface microstructure and composition [39]. Butterflies have a network of micro structured scales on their wings which help them in directional rolling of water away from the body.

Since then, nature-inspired artificial superhydrophobic surfaces are fabricated with lotus leaf as the classical example. Surface roughness is used to enhance the intrinsic hydrophobic nature of the surface, producing highly non-wetting surfaces.

\subsection{Fabrication of superhydrophobic surfaces}

Techniques to fabricate superhydrophobic surfaces can be classified into two categories: making a rough surface from a low surface energy material and modifying a rough surface with a material of low surface energy [40][41].

\subsubsection{Roughening a low surface energy material}

Fluorinated polymers are of great interest due to their extremely low surface energy. Roughening these polymers leads to superhydrophobicity [42]. Due to their limited solubility, many fluorinated polymers have not been used directly but linked [43] or blended [44] with other materials. Silicones are also known to have low surface energy. Well known polymer which comes in this category is polydimethylsiloxane (PDMS). Because of its intrinsic deformability and hydrophobic property, PDMS can readily 
be made into superhydrophobic surfaces. Although fluorocarbons and silicones are known as hydrophobic materials, several researchers focused on fabricating superhydrophobic surfaces from organic materials such as polyamide [45], polycarbonate [46] and alkylketene dimer [47] since nature achieves non-wetting and self-cleaning properties using paraffinic hydrocarbons.

\subsubsection{Modifying a rough substrate with a low surface energy material}

Methods to make superhydrophobic surfaces by roughening low surface energy materials are mostly one-step processes and have the advantage of simplicity but they are always limited to a small set of materials. A commonly used strategy to overcome this problem is to roughen the material surface and then modify the surface chemistry with hydrophobic treatments. There are several ways to make rough surfaces. Few commonly used methods are chemical etching, lithography, sol-gel processing and electrospinning.

Etching is a straight forward method to make rough surfaces [48]. Polycrystalline metal surfaces can be easily roughened by chemical etching. Organic polymers like polytetrafluoroethylene and polypropylene can be etched and roughened by plasma processes. 
Photo-lithography and electron beam lithography techniques developed in semi-conductor processing have been widely used to create periodic topographic patterns. The use of lithographic patterning allows precise control of topographic features like dimensions and shapes. Another fast growing patterning technique is nanosphere lithography. In this method, mono-dispersed polystyrene or silica nanoparticles are deposited in a close-packed lattice array by controlling the drying process of nanoparticle containing solutions on flat substrate surfaces. Combined with proper surface modification chemistry, the ordered nanoparticle arrays produced in this method can generate superhydrophobic properties.

Another widely used approach is sol-gel process [49]. In this method, a secondary component is used to create surface roughness after deposition of thin films. The secondary component is removed later by dissolution in hot water or sublimation which gives porous structures. Subsequent fluorinated silane coating can render these sol-gel processed films superhydrophobic.

Electrospinning is a simple and cost effective technique to make ultrafine fibers. This process can simultaneously produce rough geometry and hydrophobic chemistry in a single step. Several groups found out that electrospinning technique provides sufficient surface roughness for superhydrophobicity [50]. 


\subsection{Electrospinning}

Electrospinning is a well known process for fabricating micron and submicron sized polymer fibers. The first attempt closest to electrospinning process was made by J. F. Cooley in 1902 [51]. From 1934 till 1943, A. Formals produced continuous fine fibers for use in textile industry and patented several different electrospinning setups [52][53][54][55] [56][57][58]. Electrospinning was rediscovered in 1995 as a potential and easy technique to fabricate nanostructures. The term electrospinning was first coined by Reneker and Doshi in 1995 [59]. Since then, a lot of research papers related to electrospinning have been published symbolizing the growing interest in this field.

A simple electrospinning apparatus consists of a high voltage source, a syringe pump to deliver the polymer solution from a syringe to a charged needle, and a grounded collector as shown in Figure 2.2. The collector may be a flat surface, a rotating cylindrical drum, or some other shape depending on the application.

Initially, the polymer solution is held at the tip of the needle by its surface tension. When a voltage potential is applied to the needle, it charges the droplet of polymer solution. The hemispherical surface of the droplet at the tip of the needle elongates to form a cone shaped structure known as the Taylor cone. When the voltage potential reaches a critical value, the electrical forces exceed the surface tension of the droplet and a charged jet is initiated from the tip of the Taylor cone. As the jet 


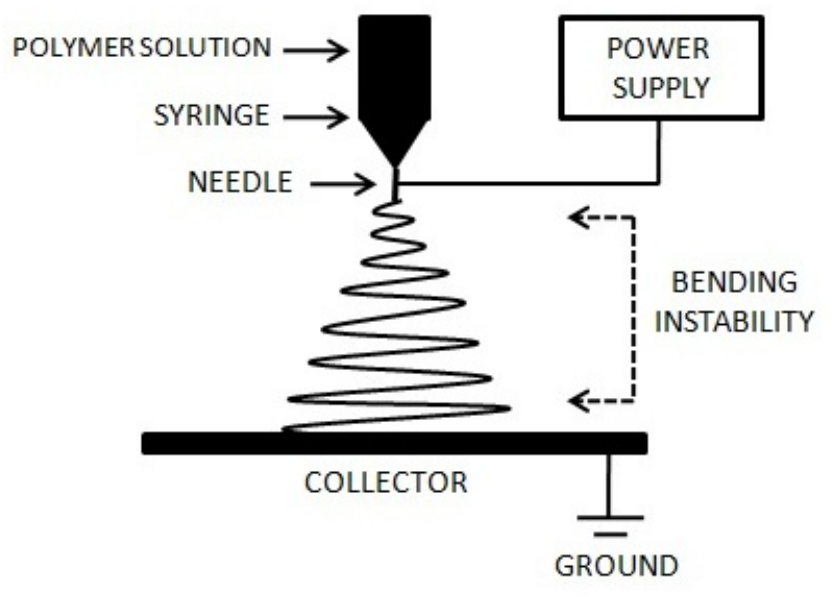

Figure 2.2: Schematic diagram of the electrospinning setup

travels from the needle to the collector, it experiences bending instabilities [60][61]. The bending instabilities cause the jet to stretch and loop onto itself, resulting in jet diameters in the submicron range. Meanwhile, the solvent in the polymer solution evaporates from the jet and the jet hardens into a solid fiber. The high voltage is maintained on the polymer drop to sustain the continuous flow of polymer solution to the jet.

Electrospinning process is governed by several parameters which are broadly classified into solution parameters, process parameters and ambient parameters EM2004. Solution parameters include viscosity, conductivity, molecular weight and surface tension. Process parameters include applied electric field, tip to collector distance and flow rate of the polymer solution. Ambient parameters include humidity and tem- 
perature. Each of these parameters significantly affects the fiber morphology [62] and their manipulation allows achieving desired morphology and diameters [63].

The solvent used in preparing polymer solutions has a significant influence on its spinnability. The first step of the electrospinning process is dissolution of polymer in a suitable solvent. Solvents should posses properties like good volatility, vapor pressure, boiling point and should maintain the integrity of the polymer solution. Hence for successful electrospinning of a polymer, the selection of an appropriate solvent to dissolve the respective polymer is required.

During the electrospinning process, electrostatic repulsion between charged ions within the polymer jet causes the loops of the jet to move away from each other while the collective center of mass of the loops of the jet moves towards the grounded collector surface. The time-averaged path of the loops of the jet travels through a three dimensional volume from the needle to the grounded surface that resembles the shape of a right circular cone having its vertex at the needle. The general motion (i.e. center) of this cone follows the local current density lines. The current density lines [64] are analogous to fluid flow streamlines that pass through a unit area of space.

In most electrospinning applications, objects other than those shown in Figure 1 are positioned at sufficient distances away that the current density lines towards such objects in the surrounding environment are negligible compared to the current 
density lines towards the grounded collector. However, in some applications objects may intrude into the electrospinning space in close enough proximity to attract current density lines from the needle that interfere with the jet movement towards the grounded surface. This latter situation generally results in some fibers collecting on the intruding objects as well as on the grounded collector surface. Examples of these intruding objects are motors used to rotate a collector drum [65] or to rotate devices for collecting nanofiber yarns [66].

Control of where the fibers collect is of significant interest when the polymer solution is expensive or may be chemically hazardous. For continuous large scale operations the accumulation of fibers other than on the desired collector may be problematic from an operational perspective. In prior studies the electric fields had been modified, such as through the application of secondary electrodes, to control the motion of the electrospinning jet to align the electrospun fibers. Carnell et al. produced highly aligned electrospun fibers by incorporating an auxiliary counter electrode to create an electric field of controlled geometry and magnitude [67]. Pan et al. produced continuous, well-aligned electrospun fibers by placing two oppositely charged metallic needles [68]. Wu et al. produced aligned electrospun fibers by creating a converged electric field through the use of auxiliary counter electrodes [69]. Teo et al. produced diagonally aligned electrospun fibers through the use of knife edges to control the electrostatic field forces [70]. Theron et al. demonstrated an approach for aligning nanofibers on a tapered and grounded wheel-like bobbin by controlling 
the electrostatic field [71]. Li et al. demonstrated a simple method for generating uniaxially aligned nanofibers by collecting the nanofibers over a gap formed between two conductive substrates [72]. In other applications, secondary electrodes, such as ring electrodes, were used to aid in the launch and stretching of the jets [73][74][75].

\subsection{Charecterization of superhydrophobic surfaces}

Characterization of the surface is one of the key issues in the research of superhydrophobic surfaces. Many methods and techniques have been developed to characterize the superhydrophobic nature of a surface, such as tilt angle method, multi resonance thickness shear mode sensors and sessile drop method.

The tilt angle refers to the critical angle between the substrate and the horizontal, below which the water droplet begins to move upon elevating one end of the substrate. When the tilt angle is less than 10 degrees, the superhydrophobic surface is considered to have self cleaning properties.

Kwoun et al. [76] introduced the method of multi resonance thickness shear mode sensors to characterize superhydrophobic surfaces. The technique on which this method works is based on high frequency shear acoustic waves generated by a piezoelectric quartz resonator thickness shear mode sensor. For the thickness shear mode operating in the frequency range of 1 to $100 \mathrm{MHz}$, the depth of penetration is of 
the order of tens to thousands of nanometers. When a superhydrophobic surface has a low contact angle hysteresis, the water layer can only wet the top of the surface and is almost unable to penetrate into the interspaces of the rough structure. Therefore the harmonic frequency shift of such a surface is much smaller than surfaces with higher contact angle hysteresis.

Sessile drop method is the most commonly used technique to characterize superhydrophobic surfaces [77]. In this method, a small drop of liquid is placed on the surface and is observed in the side view using a camera. Modern equipment uses computer software to extract contact angle by detecting the shape of the droplet.

The drop size in sessile drop method should be selected in such a way that it satisfies two criteria. Firstly, the effect of evaporation on the drop shape can be neglected on the time scale of the experiment. This condition limits the minimum size of the drop. Secondly, the drop should be small enough so that the effect of gravitational force on the shape of the drop can be neglected. This condition limits the maximum size of the drop. The effect of gravitational force on the shape of the drop can be neglected if the diameter of the drop is less than the capillary length of the respective liquid. The capillary length is defined as (Equation 2.6)

$$
K_{c}=\sqrt{\frac{\gamma}{\rho g}}
$$


Where $\theta$ is the surface tension at the liquid-gas interface, $\rho$ is the density of the liquid and $\mathrm{g}$ is the gravitational acceleration. For drop diameters below the capillary length, surface tension forces are assumed dominant. The capillary length for water is $2.7 \mathrm{~mm}[31]$.

Due to gravitational forces on the drop, the contact angle changes with volume [78]. Hence, droplets measured by the same analysis method and the same droplet volume can be directly compared. These factors should be taken into consideration while comparing the results because a difference in the contact angle might not be solely due to differences in surface hydrophobicity but may be also due to the methods used to collect the results [77][79].

\subsection{Effect of surface curvature on hydrophobicity}

Water repellency is important in many applications [16]. The wettability of a liquid on a solid surface can be evaluated by measuring the liquid's contact angle. A few studies consider the effect of curvature on the hydrophobicity of the surface [80][81][82][83] but most only consider planar or low curvature surfaces. Alarcon et al. [84] studied water molecular orientations on curved surfaces and Choi et al. [85] investigated the superhydrophobicity of silicon nanowires, suggesting strong curvature has an effect 
on hydrophobicity. Tools to assist interpretation of experimental observation of drops on curved surfaces are needed.

Superhydrophobic surfaces are of interest for a number of applications. As an example, fibrous depth filter media are used to separate secondary dispersions of water droplets from oil [12]. Media are typically constructed as pleated flat sheets or as cylindrical cartridges. If the hydrophobicity is enhanced by small radius of curvature, then media designers may take advantage of this via small diameter tubular media to achieve greater separation efficiency.

In a second example, superhydrophobic surfaces exhibit low fluid drag on aquatic surfaces [86] and protect aquatic devices from marine fouling [87]. Instead of applying coatings, which may be toxic, to repel marine organisms, these surfaces may be enhanced via surface curvature in an environment friendly way to resist biofouling on the underwater parts of ships.

A third example application is corrosion prevention. Water is responsible for most corrosion that occurs on materials. Superhydrophobic coatings to protect surfaces from corrosion are of current research interest [88]. Electrospun nanofiber coatings are reported for imparting superhydrophobicity and corrosion resistance to surfaces [89].Surface curvature may affect the hydrophobic interaction between water droplets and the surfaces in all of these example applications. 
The interpretation of the observed contact angles is important. In the extreme case of a sharp edge of a surface, Gibbs proposed a simple geometric relation which describes the interaction of liquids with sharp edges [90]. When a liquid droplet is placed on a flat surface with sharp edges, an intrinsic contact angle of $\theta_{o}$ is observed. As liquid is added to this drop, the drop advances to the edge of the surface. With the addition of more liquid, the contact angle relative to the horizontal plane at the edge increases. Eventually, the drop reaches a critical apparent advancing contact angle $(\theta)$ at the edge that any further liquid added to the drop causes the drop to collapse. According to Gibbs, the apparent advancing contact angle $(\theta)$ increases due to the interaction with the sharp edge according to the equation

$$
\theta=\theta_{o}+(\pi-\phi)
$$

Where $\phi$ is the edge angle. In the late 1970's, Mason et al. performed experiments using conical frusta which proved the above expression correct [91].

\subsection{Emulsions}

An emulsion is a mixture of two or more liquids which are immiscible. Emulsion has two phases, dispersed phase and continuous phase with the boundary between them 
called the interface. Emulsion stability refers to the ability of an emulsion to resist change in its properties over time [92]. The interfacial tension has a significant effect on the stability of emulsions. Liquids with interfacial tensions below $20 \mathrm{mN} / \mathrm{m}$ tend to form stable emulsions. The liquid viscosity also has a significant impact on droplet coalescence. The droplets must overcome high drag forces exerted by the continuous phase to reach and colloid with another droplet.

\subsection{Surface filtration}

In recent years, water in oil emulsion separation has received greater attention. In many applications, dispersions of water droplets of size less than $100 \mu \mathrm{m}$ are very difficult to separate. Fibrous filter media provide the advantage of high separation efficiency at economical energy costs. Coalescence filters are known for effective separation of secondary dispersions. Parameters used to evaluate the performance of a filter are pressure drop across the filter media and its separation efficiency. Usually, coalescer filters get saturated with water droplets after a period of time and these droplets cannot be removed since there is no opportunity for back flow. The demand for longer filter life is increasing and this would be a disadvantage since coalescer filter is onetime usable filter. In addition, the pressure drop across the filter media increases when it gets saturated with water droplets. 
Filtration can occur on the surface of the filter medium or within the depth of the medium. Surface filtration is used when the capture of water droplets within the filter media is not desired. When an organic liquid containing suspended water droplets is passed through a surface filter, water droplets which are larger than the pore size are retained. The retained droplets grow in size due to coalescence and roll down off the surface of the filter media due to gravity and hence exposing the filter area to fresh water droplets. 


\section{CHAPTER III}

\section{CONTACT ANGLES OF DROPS ON CURVED SUPERHYDROPHOBIC SURFACES}

In this chapter, we derived an equation to calculate the water contact angle on curved spherical and cylindrical surfaces as described in Appendix A. The derived equation relates the drop size and radius of curvature of the surface to the apparent contact angle on the curved surfaces. Experiments are conducted with drops on superhydrophobic curved surfaces fabricated from mats of electrospun fibers. The theoretical predicted angles are compared with measured angles as a function of drop volume. In most cases the experimental results are in good agreement with the predictions.

\subsection{Comparison of theoretical data to reported data for drops on spheres}

The Gibbs equation is a consequence of the geometry and is immaterial of the intrinsic nature of the edge. A curved surface can be treated as a continuous edge surface with a varying angle. To check the validity of the Equation A.9 (Appendix A), we compare the calculated water contact angle (WCA) with the experimental data reported by Extrand and Moon [93] of drops of varying volumes on spherical surfaces of Polytetrafluoroethylene (PTFE) and Polycarbonate (PC). The intrinsic water con- 
tact angle on flat surfaces of PTFE and PC are reported as $\theta_{o}(\mathrm{PTFE})=108$ degrees and $\theta_{o}(\mathrm{PC})=89$ degrees [93]. The experimental data and values predicted by Equation A.9 (Appendix A) are plotted in Figure 3.1 for PTFE and SPP spherical surfaces.

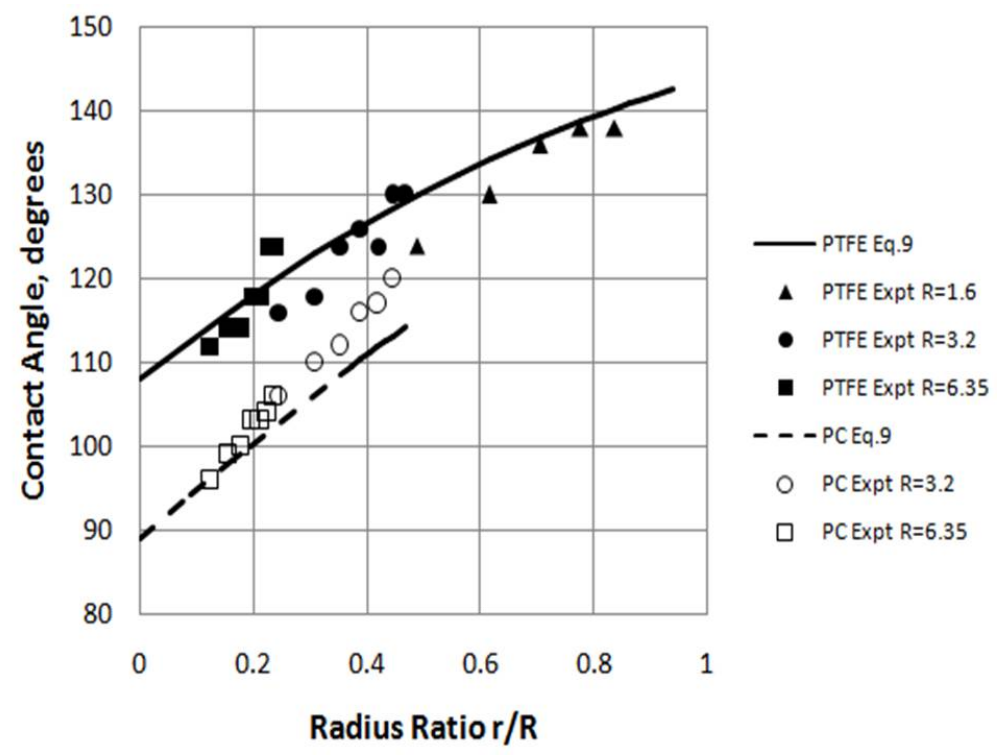

Figure 3.1: Graphical comparison of WCA on PTFE and PC spherical surfaces calculated theoretically and measured experimentally (data from Extrand and Moon, [93] ). ' $\mathrm{R}$ ' is the radius of curvature of the spherical surfaces and ' $r$ ' is the radius of the drop in $\mathrm{mm}$.

The plots in Figure 3.1 show theoretical values have the same trend as the experimental values. For a given radius of the spherical surface the apparent contact angles relative to the horizontal axis increase with increasing drop size (or radius ratio). As the drop size increases, the drops cover more of the sphere surface resulting in a decrease in the observed edge angle. The reasons for a deviation of the experimental results from the calculated angles may be due to variation in drop symmetry 
relative to the vertical axis through the center of the sphere. It may also be due to our assumed spherical drop shape in deriving Equation A.9 (Appendix A) where physically the drop might not be truly spherical in shape. Because Equation A.9 (Appendix A) is derived from geometrical analysis, in principle it should apply to any liquid material of the sphere.

The theoretical results for both PTFE and PC agreed reasonably well with the experimental results reported by Extrand and Moon [93]. Equation A.9 (Appendix A) accounts for both the effect of the radius ratio and the WCA for a flat surface.

\subsection{Experimental Description for Drops on Cylindrical Surfaces}

To extend this work to cylindrical superhydrophobic surfaces, we experimentally observed WCA on Syndiotactic Polypropylene (SPP) sub-micron fiber mat surfaces. Cylindrical surfaces were made by electrospinning SPP onto stainless steel rods of different diameters whereas for flat surfaces the fibers were spun onto flat glass slides. 


\subsection{Materials}

Syndiotactic Polypropylene (SPP, melt index: $2.20 \mathrm{~g} / 10 \mathrm{~min}$ at $230 \mathrm{C}$ with a load 2.16 Kg, ASTM D 1238) used in this study was purchased from Aldrich (Sigma Aldrich, St. Louis, MO). The weight average $\left(M_{W}\right)$ and number-average molecular weight $\left(M_{N}\right)$ were 174000 and $75000 \mathrm{~g} / \mathrm{mol}$, respectively $\left(\frac{M_{W}}{M_{N}}=2.32\right)$. SPP was dissolved in a solvent mixture of cyclohexane $(99 \%+)$, acetone and dimethylformamide (DMF) in a weight ratio of $80 / 10 / 10$ at $70 \mathrm{C}$ at a weight concentration of $2 \%$ of SPP to solvent mixture [94]. This polymer mixture was electrospun to produce fiber mats. All of the chemicals were purchased from Thermo Fisher Scientific Inc. (Waltham, MA) and used without further modification.

\subsection{Electrospinning setup}

Stainless steel rods were chosen as collectors to make the curved surfaces of electrospun fiber mats. As shown in Figure 3.2, one end of the steel rod is fixed to a motor and rotated at $10 \mathrm{rpm}$ while the other end is suspended horizontally in the air in front of a grounded sheet of aluminum foil. The polymer solution was loaded into a $5 \mathrm{ml}$ syringe. The needle of the syringe was positioned horizontally on the syringe pump such that the needle was oriented perpendicular to the rod at a distance of about 25 cm. A high voltage power supply (Gamma High Voltage, Ormond Beach, FL) was used to generate a potential difference of about $25 \mathrm{kV}$ between the syringe needle and 
the grounded aluminum foil. The flat surfaces of sub-micron fiber mats were made by electrospinning SPP onto a glass slide with similar electrospinning conditions as that of the curved surface.

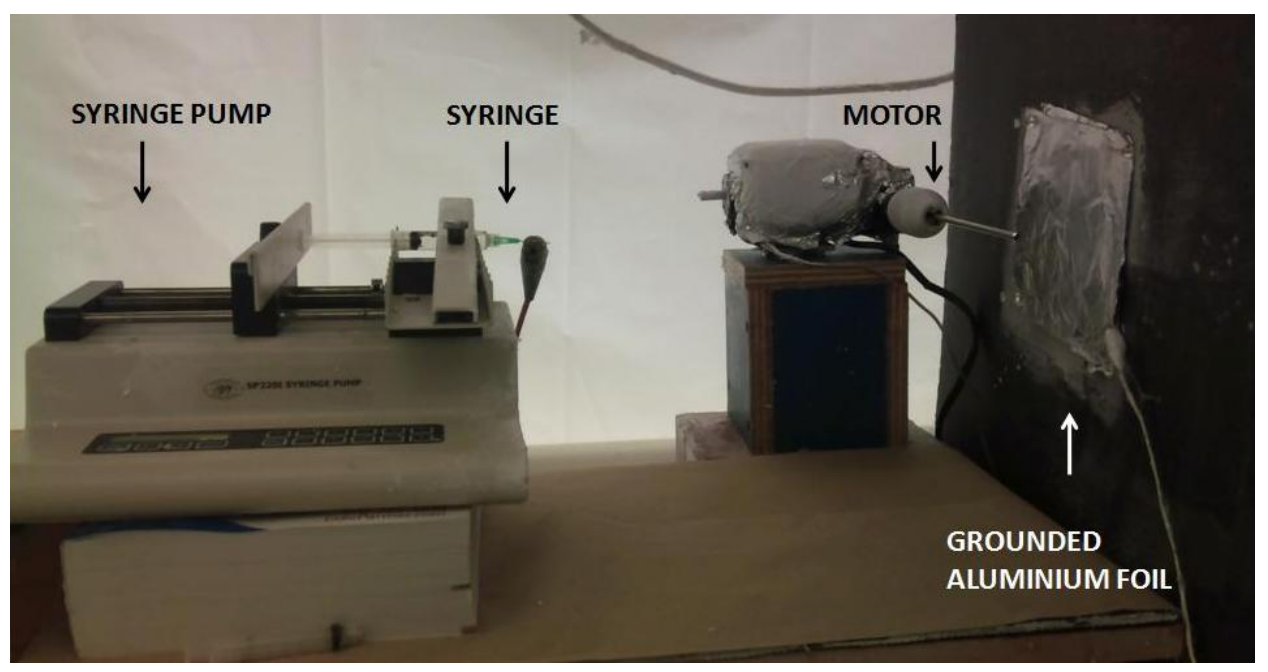

Figure 3.2: Electrospinning setup to make SPP cylindrical surfaces.

\subsection{Contact angle measurement}

Contact angles were measured using a Drop Shape Analyzer (DSA20E, KrssUSA, Matthews, NC) (Figure 3.4). In The sessile drop fitting method was used for both flat and curved surfaces. The water drops were placed using a micro-syringe pointed vertically downward onto the sample surfaces. 


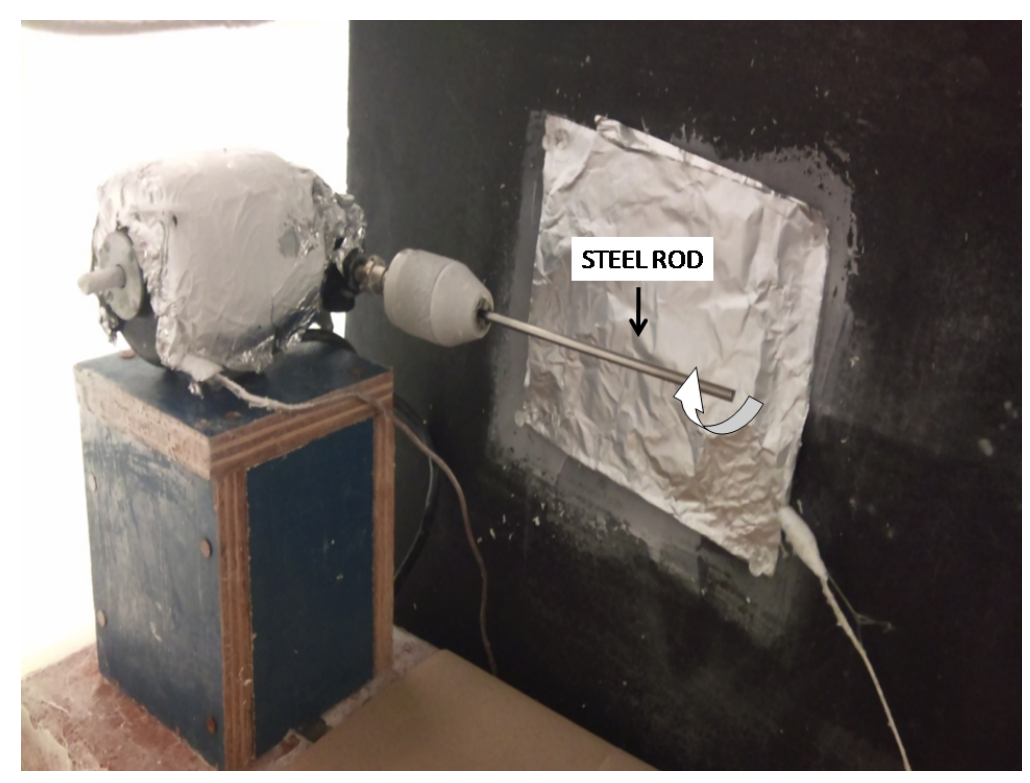

Figure 3.3: Close-up view of motor and the steel rod collector.

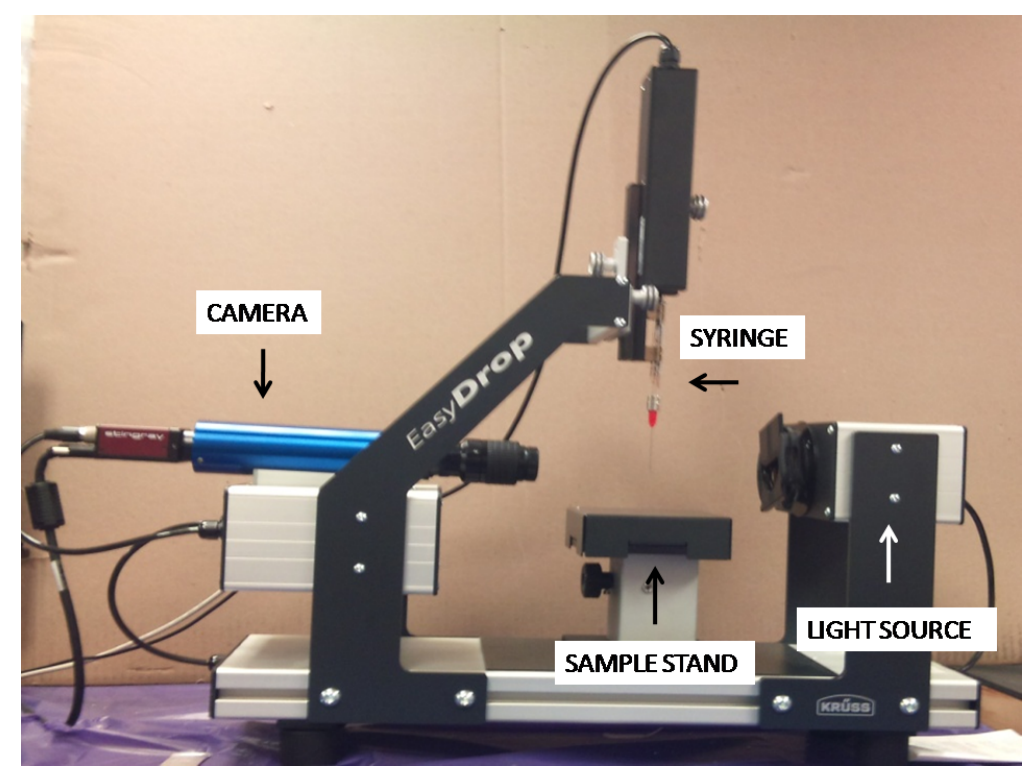

Figure 3.4: Drop shape analyzer 


\subsection{Experimental challenges}

Measurements on curved surfaces were experimentally challenging. One challenge was to attach drops to the superhydrophobic surface. The most common way to attach drops of a measured volume to a surface is to produce the drop on the tip of a syringe needle and to touch the drop to the surface. For most materials the drop detaches from the needle and attaches to the surface due to the attractive forces between the drop and the surface being larger than the attractive forces between the drop and the needle. However, with superhydrophobic surfaces the smaller drops preferred to stay attached to the needle. Only when the drop exceeded a certain volume (about $4 \mu \mathrm{l}$ ) could the drop be shaken off of the tip of the needle with help of gravity and inertial forces. A second challenge was to obtain symmetry of the drop about the vertical axis shown in Figure 3.5. Once a water drop was positioned on the cylindrical surface, the orientation of the cylinder had to be rotated to orient the vertical axis through the centre of the liquid drop, without the drop rolling off. This was difficult for the larger drops because the larger the drop the greater the ratio of gravity force to the interface force holding the drop on the surface. Hence, many experimental attempts were made to obtain the images for contact angle measurements. 


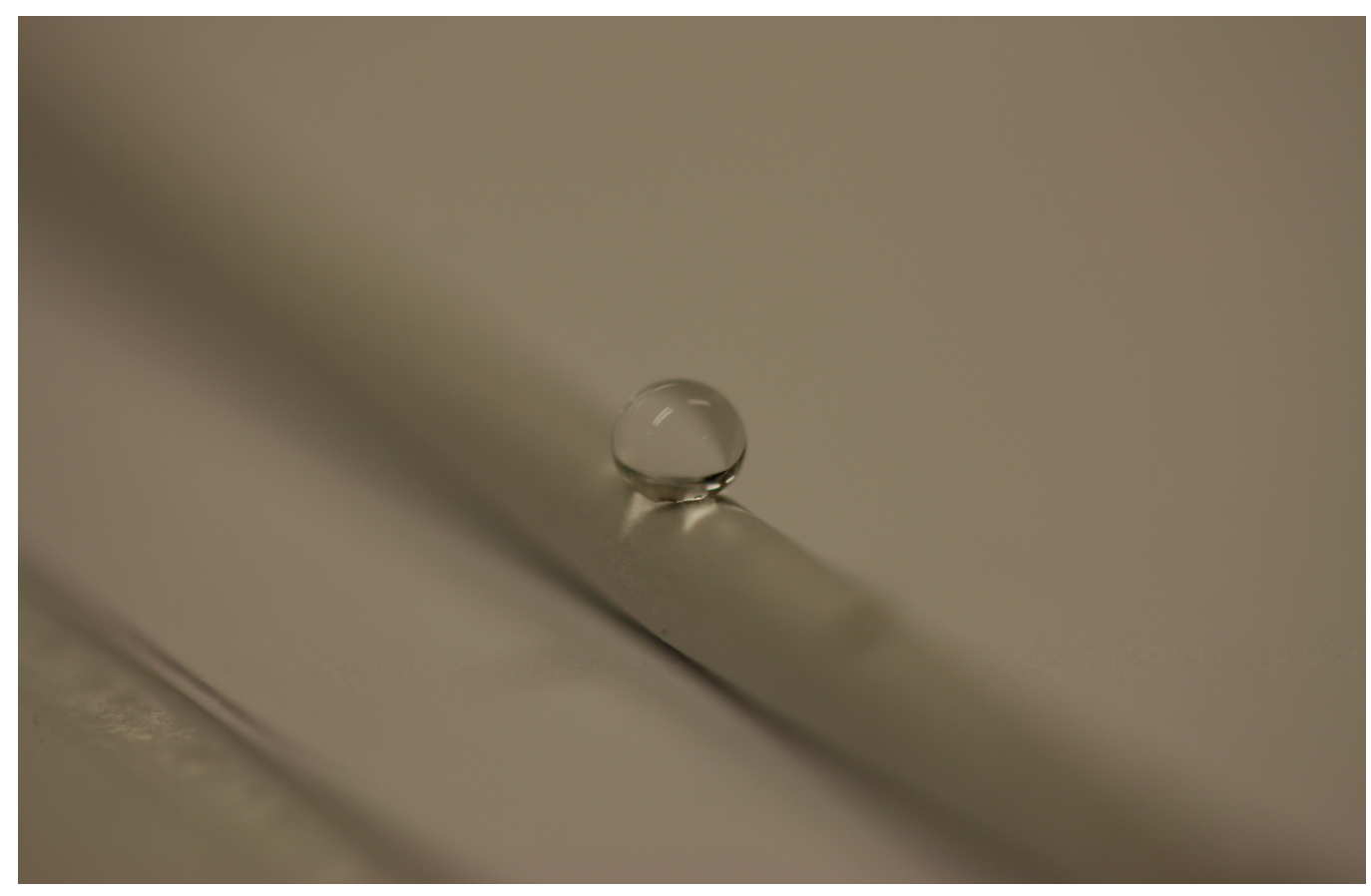

Figure 3.5: A $4 \mu \mathrm{l}$ water droplet on a stainless steel rod coated with SPP nanofiber mat

\subsection{Results and discussion}

The flat surfaces of sub-micron fiber mats were made by electrospinning SPP onto a glass slide with similar electrospinning conditions as that of the curved surface. Example SEM images of fibers produced by electrospinning are shown in Figure 3.5. From the SEM images, we observed beads as well as fibers for both flat and curved surfaces. The average diameters of the fibers were calculated using length weighted method [95]. The Flat surface had an average fiber size of 0.534 microns, the $3.96 \mathrm{~mm}$ OD rod had fibers with an average diameter of 0.450 microns, and the $7.57 \mathrm{~mm}$ rod 
had 0.561 microns diameter fibers, indicating the fiber size ranges were similar due to the similar electrospinning conditions. The beads contribute to the hydrophobic nature of the fiber mat surface but because of their irregular sizes and shapes there is not a convenient way to characterize their coverage on the electrospun fiber mats.

WCA for different drop sizes were measured on flat SPP electrospun fiber surfaces using the DSA20E. Example images of drops on the surfaces are shown in Figure 3.7. We do not have data for WCA of drops less than $4 \mu \mathrm{l}$ as they could not be detached from the syringe. The WCA on the fiber surfaces depends upon the fiber diameter and pore size due to surface roughness as described by Cassie-Baxter theory [96], hence the contact angle varies with the size of the drop, especially for small drops [78]. Figure 3.7 shows the variation of the measured WCA for the water droplets on the flat SPP surface. The drops with WCA greater than 150 degrees show the surface has superhydrophobic properties. 

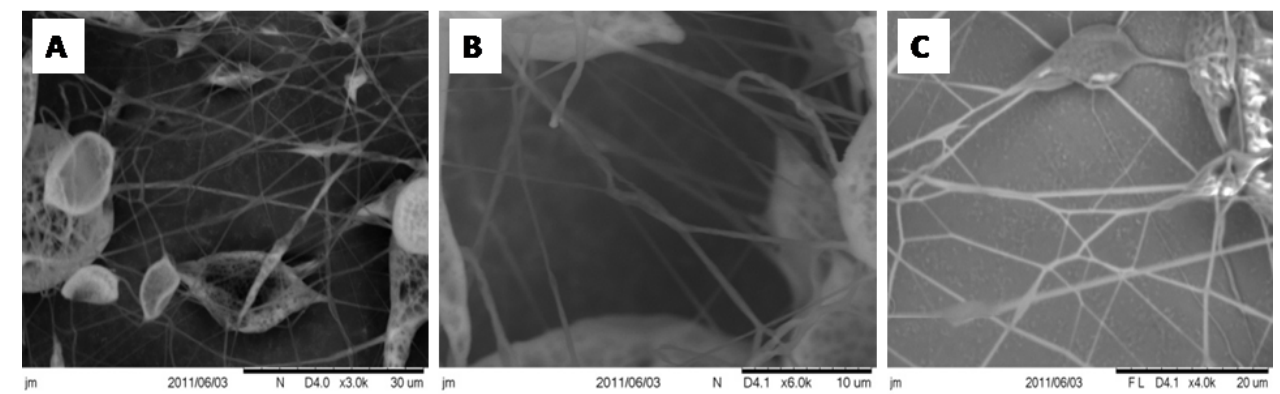

Figure 3.6: Sample SEM images of SPP electrospun fibers on (A) flat surface (B) $3.96 \mathrm{~mm}$ OD steel rod (C) $7.57 \mathrm{~mm}$ OD steel rod

A

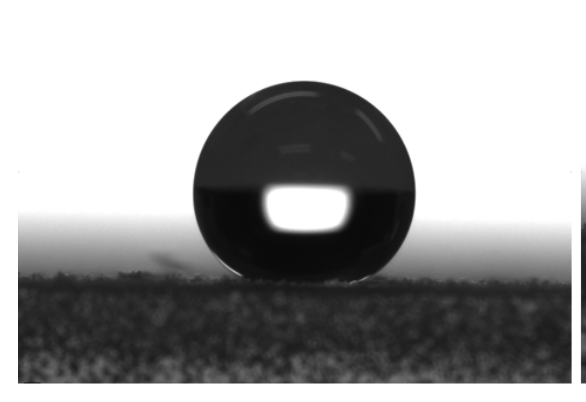

C

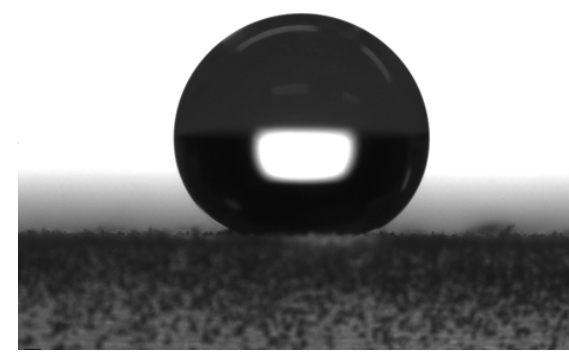

B

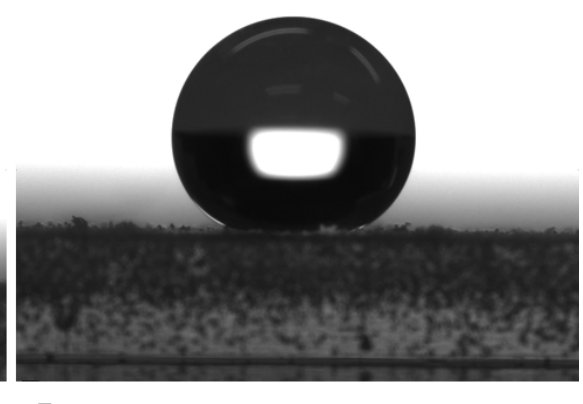

D

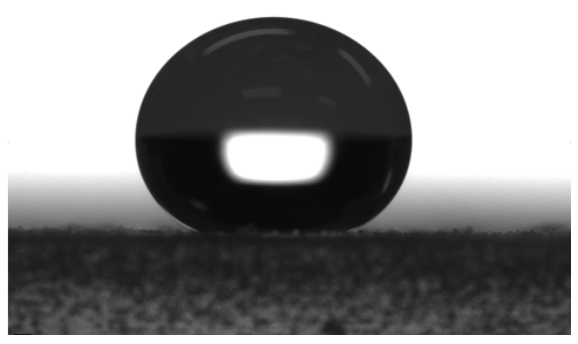

Figure 3.7: DSA photographs of water droplets of different volumes on flat SPP surface. (A) $4 \mu \mathrm{l}(\mathrm{r}=0.985 \mathrm{~mm})$, (B) $5 \mu \mathrm{l}(\mathrm{r}=1.061 \mathrm{~mm}),(\mathrm{C}) 6 \mu \mathrm{l}(\mathrm{r}=1.128 \mathrm{~mm})$, (D) $7 \mu \mathrm{l}(\mathrm{r}=1.187 \mathrm{~mm})$. The images are at different magnifications and hence are not comparable in scale 


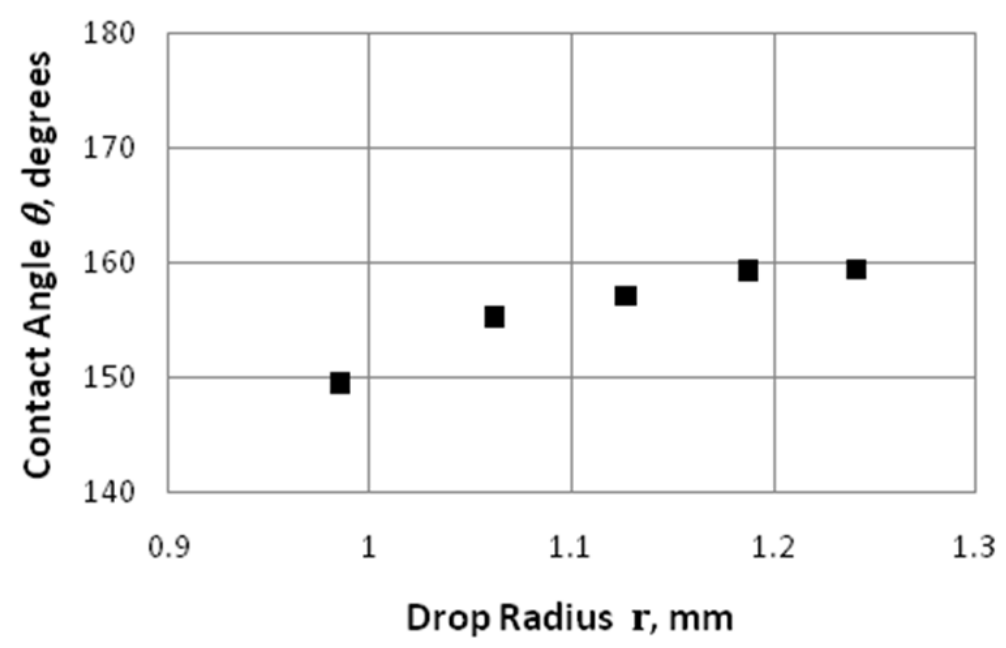

Figure 3.8: WCA on flat SPP electrospun fiber surface. The larger drops have contact angles exceeding 150 degrees indicating superhydrophobic behavior

The images in Figure 3.9 are examples of axial views of drops of different sizes on the curved cylindrical surfaces. Figure 3.10 shows examples of the side views of drops sitting on the cylindrical surfaces. The axial view shows the drops look similar to those sitting on the spherical surfaces and we expect Equation A.9 (Appendix A) to give an estimate of the apparent contact angle. Measurement of WCA for the side views do not give the same values as for drops on flat surfaces, indicating the cylindrical curvature affects the drop shape from the side view. 
A

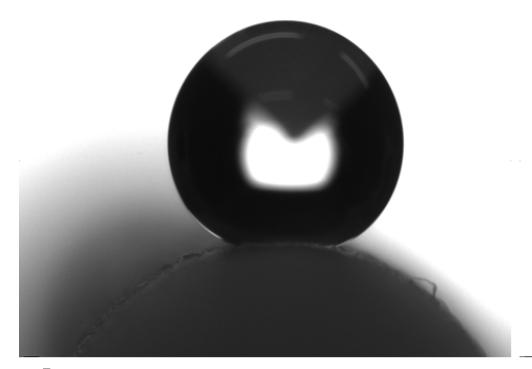

C

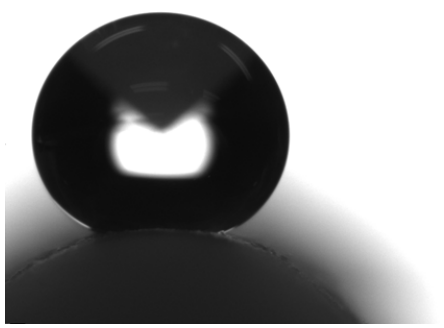

B

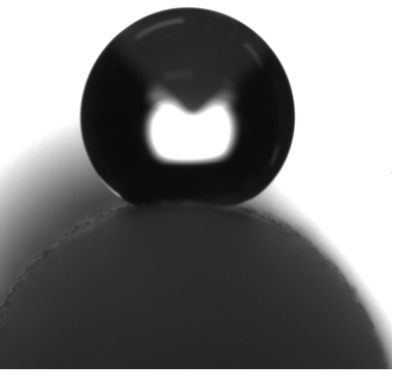

D

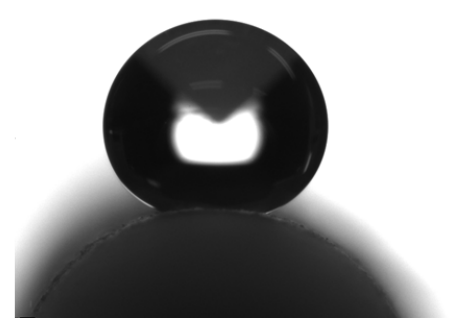

Figure 3.9: DSA photographs of axial views of water droplets of different volumes on 0.156 Inch outer diameter SPP cylindrical surface. (A) $4 \mu \mathrm{l}(\mathrm{r}=0.985 \mathrm{~mm})$, (B) $5 \mu \mathrm{l}$ $(\mathrm{r}=1.061 \mathrm{~mm}),(\mathrm{C}) 6 \mu \mathrm{l}(\mathrm{r}=1.128 \mathrm{~mm}),(\mathrm{D}) 7 \mu \mathrm{l}(\mathrm{r}=1.187 \mathrm{~mm})$. The images are at different magnifications and hence are not comparable in scale

The calculated angles for the axial view and observed apparent angles are plotted in Figure 3.11. The experimental results agree reasonably well with the calculations of Equation A.9 (Appendix A). They show the same trend of increasing contact angles with increasing drop to cylinder radius ratio. However, unlike the data plotted in Figure 3.1, the data for different cylindrical radii do not collapse into one curve because the flat surface contact angles vary with drop radius, hence the contact angles are dependent on both drop size $(\mathrm{r})$ and the radius ratio $(\mathrm{r} / \mathrm{R})$. Unlike Figure 3.1, the curves in Figure 3.11 calculated for Equation A.9 (Appendix A) are not extended to zero drop radius because the flat surface contact angles for the smaller drop sizes are not known. 
A

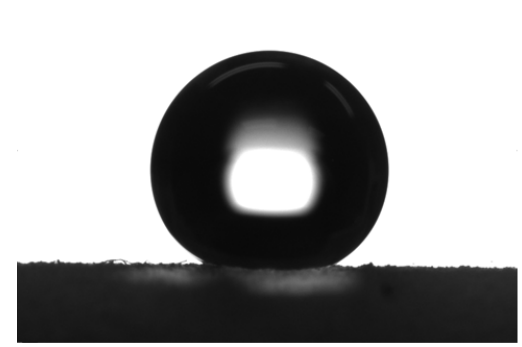

C

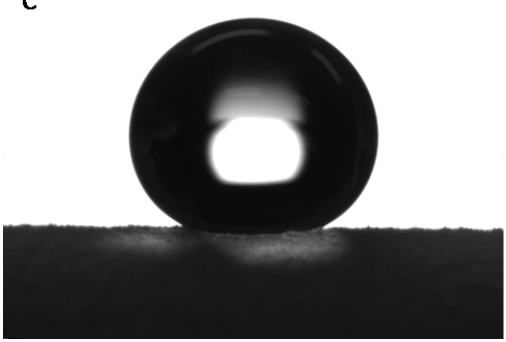

B

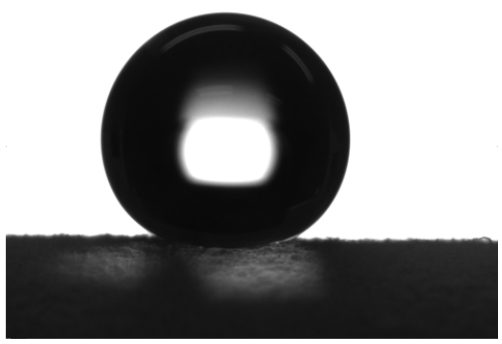

D

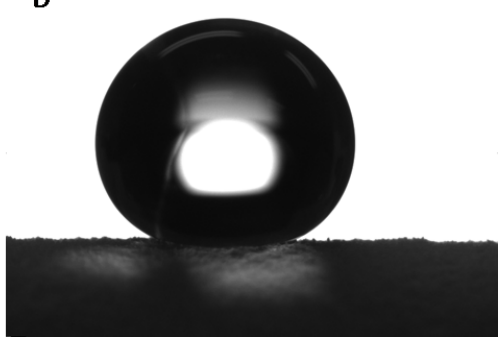

Figure 3.10: DSA photographs of side view of water droplets of different sizes on cylindrical surfaces $(\mathrm{R}=1.98 \mathrm{~mm})(\mathrm{A}) 4 \mu \mathrm{l}(\mathrm{r}=0.985 \mathrm{~mm}),(\mathrm{B}) 5 \mu \mathrm{l}(\mathrm{r}=1.061 \mathrm{~mm}),(\mathrm{C}) 6 \mu \mathrm{l}$ $(\mathrm{r}=1.128 \mathrm{~mm}),(\mathrm{D}) 7 \mu \mathrm{l}(\mathrm{r}=1.187 \mathrm{~mm})$. The images were at different magnifications and hence are not comparable in scale

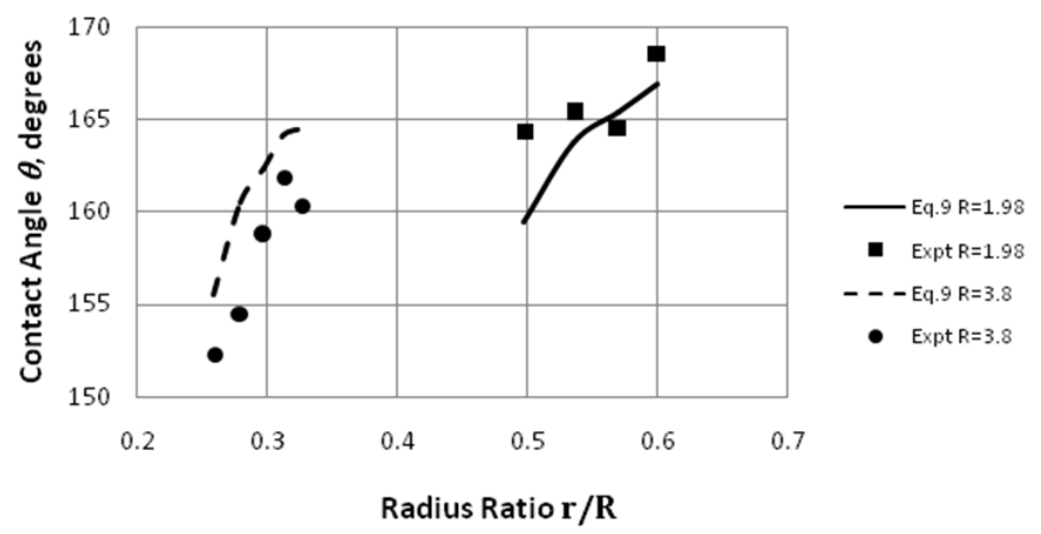

Figure 3.11: Comparison of WCA on SPP cylindrical surfaces calculated using Equation A.9 (Appendix A) and experimentally measured. $\mathrm{R}$ is the radius of the cylindrical surface and $\mathrm{r}$ is the radius of the drop 


\subsection{Conclusion}

The derived Equation A.9 (Appendix A) agrees reasonably well with the experimental data for both cylindrical and spherical surfaces and can be used to study the effect of curvature on contact angle. The effect of liquid drop volume on the contact angle

for a curved surface can also determined. Equation A.9 (Appendix A) can be useful to estimate the effects of surface curvature on apparent contact angles. 


\section{CHAPTER IV}

\section{LENGTH OF THREE PHASE CONTACT LINE OF DROPS ON FLAT AND SPHERICAL SURFACES}

In this chapter, equations are derived geometrically to calculate the length of three phase contact line of drops on planar and spherical surfaces. Experiments are conducted with drops on hydrophobic spherical and planar surfaces fabricated from mats of electrospun fibers. The derived equations agree reasonably well with the experimental data for both planar and spherical surfaces.

\subsection{Introduction}

Superhydrophobic surfaces can be used as barriers to separate secondary dispersions of water from organic liquids. Water droplets accumulate on the surface and coalesce into larger drops. Once they become large enough, gravity pulls the drop down vertical surfaces and uncovers surface area for organic fluid flow and capture of additional water droplets. The surface tension force that holds a drop to the surface is proportional to the length of the three phase contact line. In this work, the hypothesis 
that curved surface result in shorter contact line when compared to a planar surface is applied.

Equations are derived to calculate the length of three phase contact line of a drop on planar as well as spherical surface. Experiments are conducted with drops on hydrophobic spherical and planar surfaces fabricated from mats of electrospun fibers. The derived equations agree reasonably well with the experimental data for both planar and spherical surfaces. Results show that similar drops have shorter contact lines on curved surfaces when compared to planar surfaces. Hence, this work shows that the force holding a drop to a vertical curved surface (such as a cylinder) will be less than the force holding a drop to a planar surface. This reduction in force should allow smaller drops to easily roll off of curved surfaces than flat surfaces. This is expected to increase the efficiency of water - oil separation.

\subsection{Materials}

\subsection{Electrospinning setup}

Solid stainless steel spheres were chosen as collectors to make spherical surfaces of electrospun fiber mats. Spheres of diameter $4.76 \mathrm{~mm}$ and $6.35 \mathrm{~mm}$ were used. The polymer solution was loaded into a $5 \mathrm{ml}$ syringe and is pumped at a flow rate of $25 \mathrm{ml} / \mathrm{hr}$. The needle is placed vertically at a distance of $25 \mathrm{~cm}$ from the grounded 
sphere and is connected to the syringe using Teflon tube. A high voltage power supply (Gamma high voltage, Ormond Beach, FL) generated a potential difference of about $25 \mathrm{kV}$ between the syringe needle and the grounded sphere. Flat surfaces of sub-micron fiber mats were made by electrospinning SPP onto a glass slide with similar electrospinning conditions as that of the spherical surface.

\subsection{Dip coating setup}

Dip coating is a simple and easy technique to coat thin films of polymer on a surface. Dip coating setup consists of a motor, sample holder and a stand to hold the polymer solution as shown in Figure 4.1. Substrate which is to be coated is fixed to the sample holder. The sample holder is mounted on a rail that permits vertical movement. The holder is held in place by one end of a polymer cord (fishing line). The other end of the cord is wrapped around a spool connected to a stepper motor. The motor rotates the spool to unwind or wind up the cord to lower or raise the sample holder. The sample is immersed in the polymer solution at a constant speed with the help of the motor. It is made to remain in the solution for few seconds and is pulled up. A thin layer of polymer deposits on the substrate as it is pulled up. The speed determines the thickness of the coating. Once the substrate is pulled out of the solution, it is air dried for 24 hours for the solvent to evaporate. 


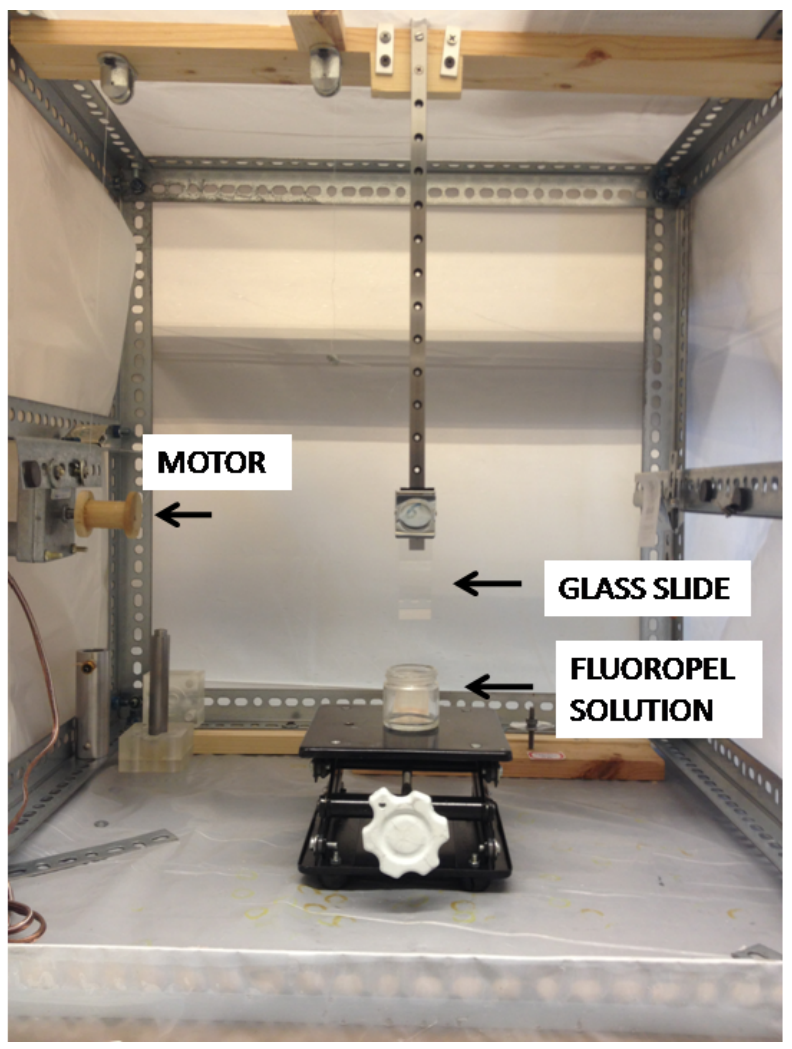

Figure 4.1: Dip coating setup

\subsection{Contact angle measurement}

Contact angles were measured using a Drop Shape Analyzer (DSA20E, KrssUSA, Matthews, NC) (Figure 3.3). Sessile drop fitting method was used for the measurements. Water drops were placed using a micro-syringe pointed vertically downward onto the sample surface. 


\subsection{Experimental challenges}

Measurements on spherical surfaces were experimentally challenging. One challenge was to attach drops to the superhydrophobic surface. The most common way to attach drops of a measured volume to a surface is to produce the drop on the tip of a syringe needle and to touch the drop to the surface. For most materials the drop detaches from the needle and attaches to the surface due to the attractive forces between the drop and the surface being larger than the attractive forces between the drop and the needle. However, with superhydrophobic surfaces the smaller drops preferred to stay attached to the needle. Only when the drop exceeded a certain volume (about $4 \mu \mathrm{l}$ ) could the drop be shaken off of the tip of the needle with help of gravity and inertial forces. A second challenge was to obtain symmetry of the drop about the vertical axis. Once a water drop was positioned on the spherical surface, the orientation of the sphere had to be rotated to orient the vertical axis through the center of the liquid drop, without the drop rolling off. This was difficult for the larger drops because the larger the drop the greater the ratio of gravity force to the interface force holding the drop on the surface. Hence, many experimental attempts were made to obtain images of drops on spheres for measuring the length of three phase contact line. 


\subsection{Results and discussion}

The length of three phase contact line of drops was measured on hydrophobic spheres as well as flat surfaces. Drop size, contact angle (CA) and radius of the sphere were varied during the experiments. Example images of drops on flat and spherical surfaces are shown in Figure 4.2 and Figure 4.3. Images of drops on these surfaces were captured using DSA.
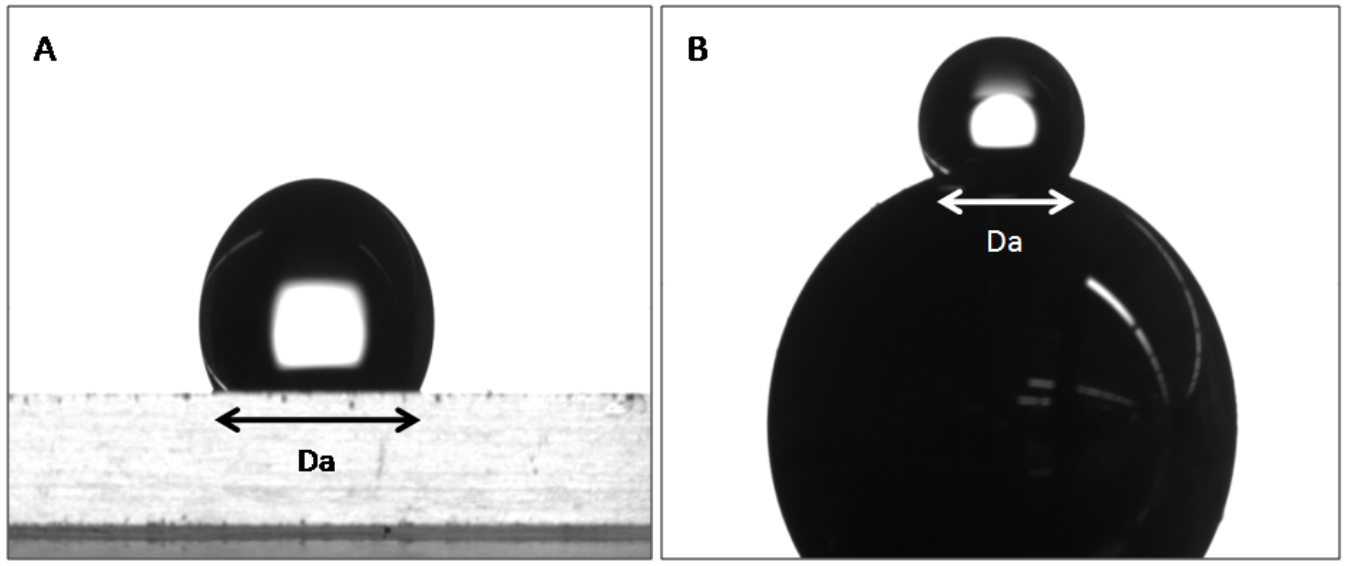

Figure 4.2: DSA photographs of water drops on (A) flat and (B) spherical surfaces. Both the surfaces are coated with fluoropel ( $\mathrm{CA}=120$ degrees) by the process of dip coating

To check the validity of Equation C.8 (Appendix C), we compared the calculated values of length of three phase contact line of drops on spheres with the experimental values. The plot in Figure 4.4 shows that theoretical values have similar trend as the experimental values. 


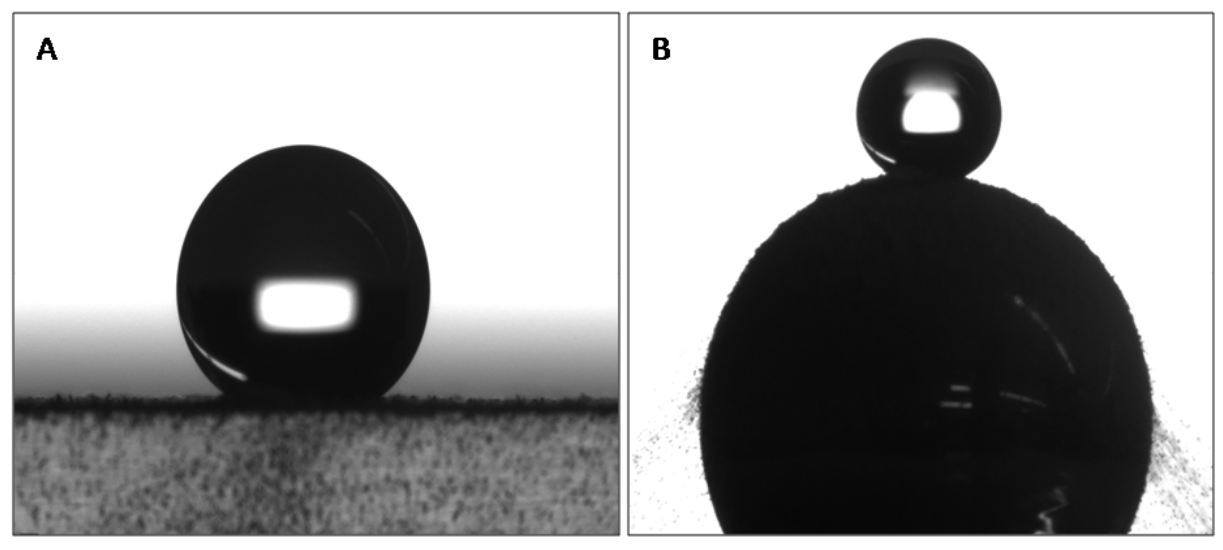

Figure 4.3: DSA photographs of water drops on (A) flat and (B) spherical surfaces. Both the surfaces are coated with polypropylene ( $\mathrm{CA}=142$ degrees) nanofibers by the process of electrospinning

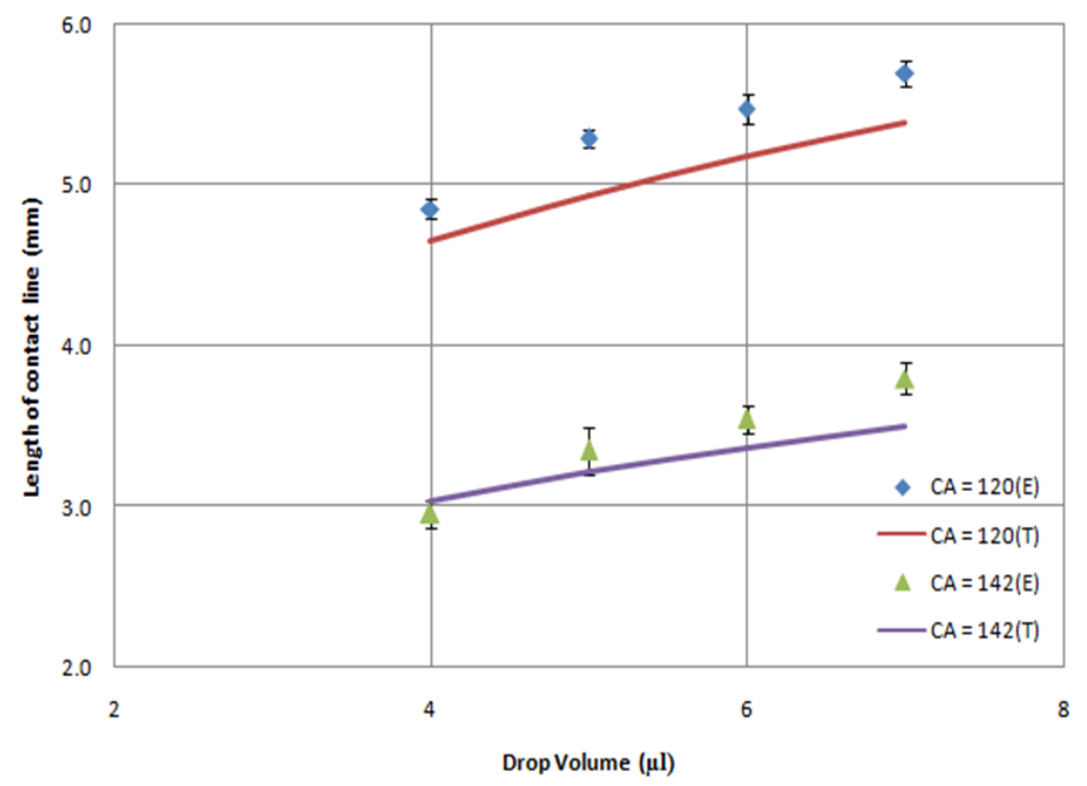

Figure 4.4: Plot showing theoretical and experimental values of length of contact line of drops of varying volume on sphere $(D=6.35 \mathrm{~mm})$ with $C A=120$ degrees and $\mathrm{CA}=142$ degrees 
To compare the length of three phase contact line of drops on flat and spherical surfaces, images of drops on these surfaces were captured using DSA and the diameter of circular contact area $\left(D_{a}\right)$ was measured. Flat surface was fabricated by electrospinning Polypropylene onto a glass slide and spherical surface was fabricated by electrospinning Polypropylene onto a sphere of diameter $6.35 \mathrm{~mm}$ under similar electrospinning conditions. The intrinsic water contact angle on the flat surface was 142 degrees. Because of the hydrophobic nature of the surface, drops of volume less than $4 \mu \mathrm{l}$ did not detach from the syringe needle of the DSA while drops of volume greater than $8 \mu \mathrm{l}$ rolled off of the sphere. Hence, the data obtained was limited. Results are summarized in Figure 4.5. Experiments were run in triplicate and the error bar in Figure 4.5 corresponds to one standard deviation. Results show that similar drops have shorter three phase contact line on spherical surface than on planar surface.

To study how the three phase contact line of drops varies with surface curvature, Polypropylene was electrospun onto spheres of diameters $6.35 \mathrm{~mm}$ and $4.75 \mathrm{~mm}$ under similar electrospinning conditions. Multiple attempts were made to capture images of drops on the sphere of diameter $4.75 \mathrm{~mm}$ but due to high contact angle and smaller diameter, drops rolled off of the sphere. Hence, the spheres are coated with Fluoropel by the process of dip coating and the intrinsic contact angle is reduced to 120 degrees from 142 degrees. Images of drops on spheres of two different diameters were captured using DSA and the diameter of circular contact area $\left(D_{a}\right)$ was 
measured. Results are summarized in Figure 4.6. Experiments were run in triplicate and the error bar in Figure 4.6 corresponds to one standard deviation. Results show that the length of three phase contact line of similar drops decreased with increase in curvature. A $25 \%$ decrease in the diameter of the sphere decreased the length of contact line of a $5 \mu \mathrm{l}$ drop by $6.6 \%$.

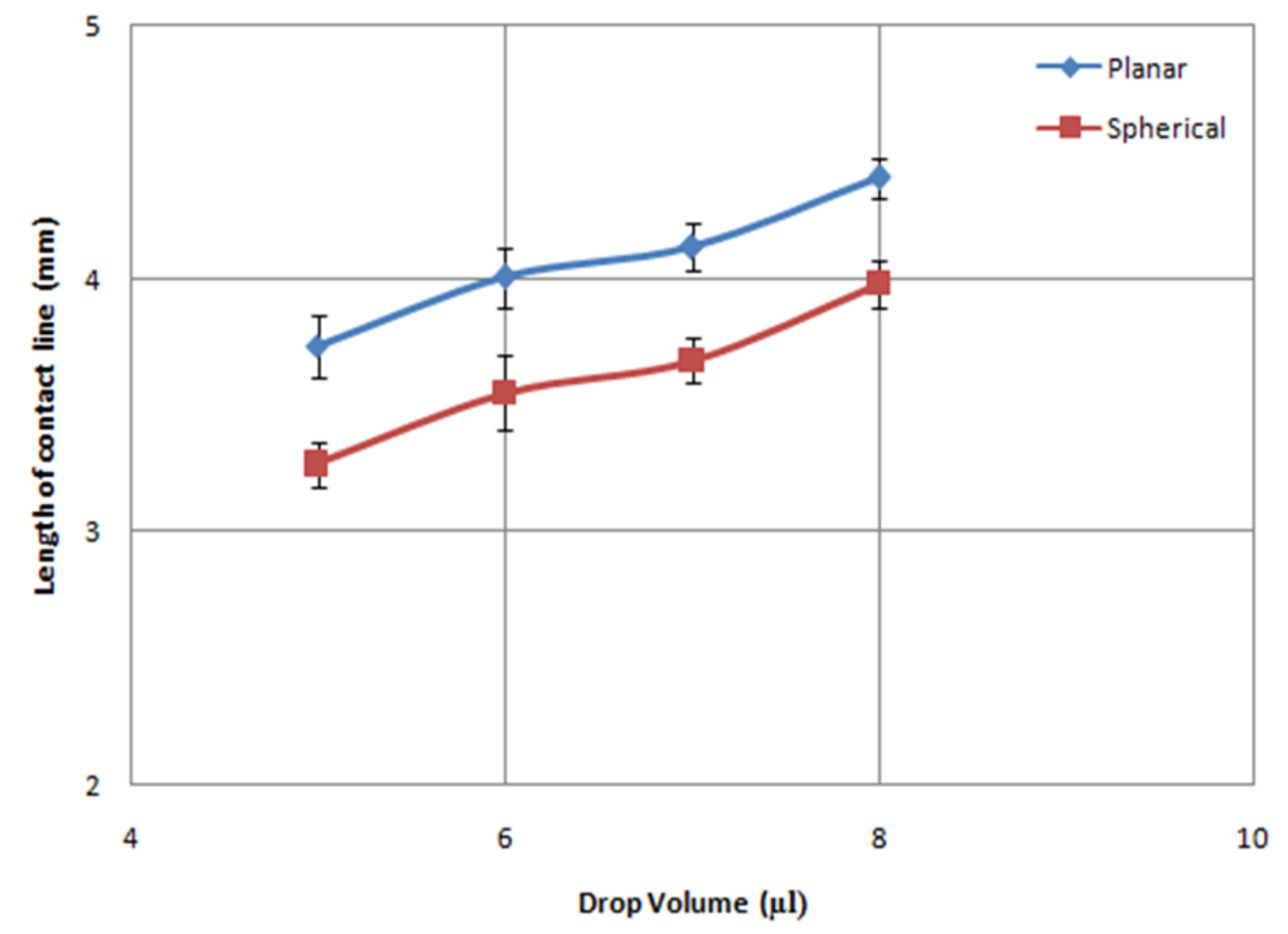

Figure 4.5: Comparison of experimental values of length of contact line of drops on flat and spherical $(\mathrm{D}=6.35 \mathrm{~mm})$ surface with intrinsic contact angle of 142 degrees 


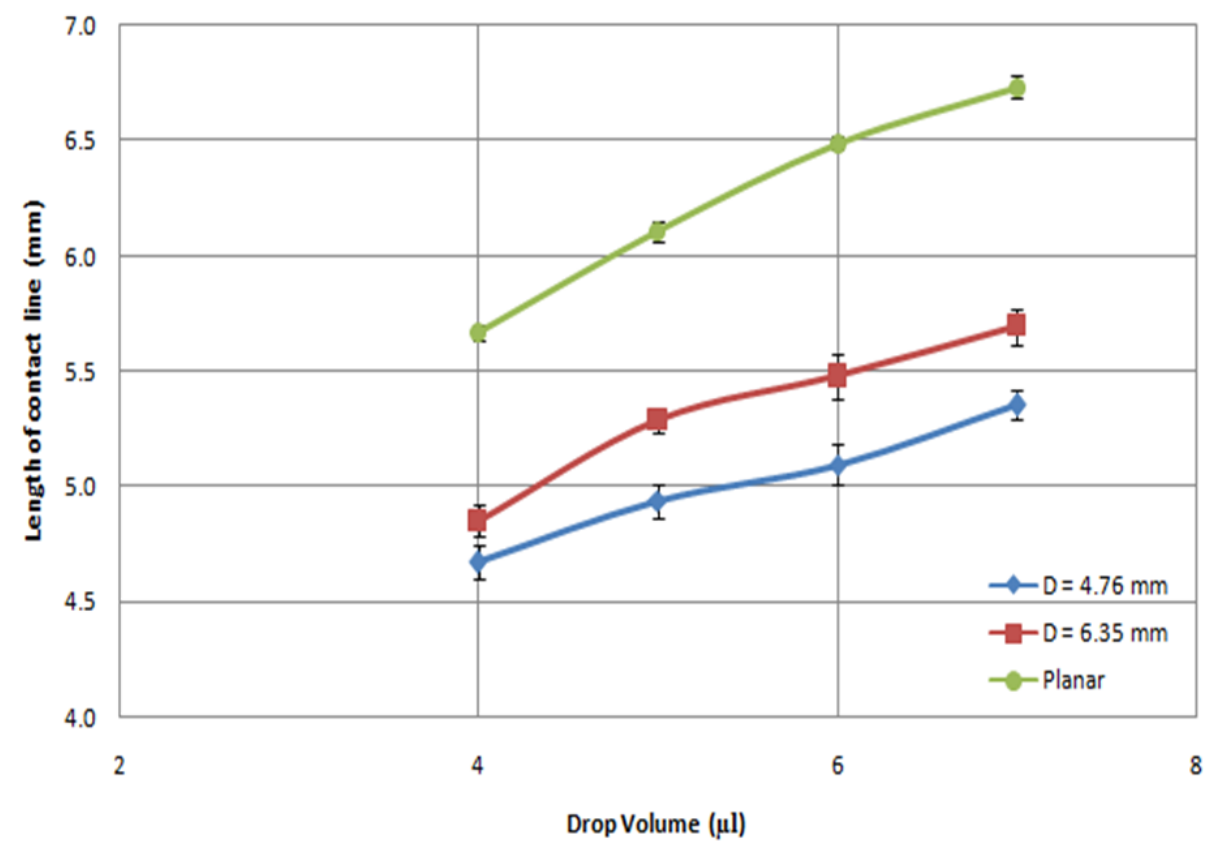

Figure 4.6: Comparison of experimental values of length of contact line of drops on spherical $(\mathrm{D}=4.76 \mathrm{~mm}$ and $\mathrm{D}=6.35 \mathrm{~mm})$ surfaces with intrinsic contact angle of 120 degrees

\subsection{Conclusion}

Equations are derived to calculate the length of three phase contact line of a drop on a planar and a spherical surface. Experiments are conducted with drops on hydrophobic planar and spherical surfaces fabricated from mats of electrospun fibers as well as from dip coating technique. The theoretical predicted values are compared with experimentally measured values. In most cases the experimental results are in good agreement with the predictions. Results show that similar drops have shorter three phase contact line on a curved surface when compared to a flat surface. 


\section{CHAPTER V}

\section{MODIFIED ELECTRIC FIELDS TO CONTROL THE DIRECTION OF ELECTROSPINNING JETS}

In this chapter, the electrospinning electric field is modified with secondary electrodes to prevent the fibers from collecting in undesired locations. The electric field is modeled with secondary electrodes placed at locations between the needle and the collector to direct the current density lines away from an intruding object such as a motor.

\subsection{Introduction}

Electrospinning is a well known process for fabricating sub-micron size fibers. A high voltage potential is used in electrospinning to launch a polymer jet from a droplet of polymer solution towards a grounded collector. Most of the electrospun fibers collect on the grounded collector, but depending on the design of the electrospinning apparatus and the environment, some of the fibers drift away from the collector and are captured on other objects. 
Control of where the fibers collect is of significant interest when the polymer solution is expensive or may be chemically hazardous. For continuous large scale operations the accumulation of fibers other than on the desired collector may be problematic from an operational perspective.

In this work we apply the hypothesis that the electrospinning jet follows the path of the electric fields current density lines. By controlling the direction of the current density lines one can control the path of the electrospinning jet and hence can control the location of where the fibers are collected.

The current density lines are determined by the gradient of the static electric potential field. The electric field is modified in this work by positioning charged electrodes that change the potential field and hence change the potential gradient and the path of the current density lines. In this way, the jet, following the current density lines, can be directed towards desired locations and away from undesired locations. The static electric field was modeled by numerically solving Laplaces equation for the potential field. Electrospinning experiments were conducted with the same geometric arrangement of electrodes for comparison. The results show the center of mass of the electrospinning jets generally followed the current density lines. This work shows it is possible to direct the electrospinning jets away from undesired objects by use of secondary electrodes. 


\subsection{Simulation work}

The volume around the electrospinning system is assumed to be a rectangular cuboid. The volume is divided into a rectangular grid. The boundaries of the grid are assumed to behave as insulators. The potential at each point is calculated using Equation E.7 (Appendix E) or is set to a constant if the potential location corresponds to an electrode. The Gauss - Siedel iterative method is used to reach convergence [97]. The potentials and distances are normalized by dividing by the corresponding (maximum - minimum) and thus are dimensionless values between 0 and 1 . Hence, the source at the normalized position at $Z=0$ has normalized potential 1 and the grounded surface at normalized position $\mathrm{Z}=0.9$ has zero potential.

The model is applied to a large enough volume surrounding the electrospinning system that the effects of objects external to the volume are assumed negligible. The boundaries of the cuboid volume that do not coincide with a constant potential electrode are assumed to behave as insulators with zero potential gradient normal to the surface. For example, at an X-Y planar boundary for a constant position of the $\mathrm{Z}$ coordinate, the gradient in the Z-direction is set to zero by setting $\phi_{i j k+1}=\phi_{i j k-1}$ in Equation 5.1 for all insulator points on that plane.

The dimensionless current density components are calculated in each coordinate direction by the central difference formula 


$$
\begin{aligned}
& \mathrm{j}_{\mathrm{x}}=-\left[\frac{\phi_{i+1 j k}-\phi_{i-1 j k}}{2 h}\right] \\
& \mathrm{j}_{\mathrm{y}}=-\left[\frac{\phi_{i j+1 k}-\phi_{i j-1 k}}{2 h}\right] \\
& \mathrm{j}_{\mathrm{z}}=-\left[\frac{\phi_{i j k+1}-\phi_{i j k-1}}{2 h}\right]
\end{aligned}
$$

Where $\phi$ and $\mathrm{h}$ are the normalized potentials and the position step values. The cuboid volume is divided into a rectangular grid of spacing size h.

In the calculations, the total dimensionless current passing through a plane (at $\mathrm{Z}=0.3$ ) between source electrode and the remainder of the volume is calculated to determine the step size $\mathrm{h}$ that is required to ensure the numerical method converges to an accurate solution. The total current is obtained by numerically integrating the current over the surface area of the $\mathrm{Z}=0.3$ plane. The spacing size, $\mathrm{h}$, was reduced in successive calculations until the calculated total current became a constant to ensure the model calculations were independent of the grid size.

To visualize the current density path in the cuboid volume, the current density components of the converged solution are plotted via a vector- plotting software. The most revealing current density paths were observed for the $\mathrm{Y}=0.5$ plane. The 
$\mathrm{Y}=0.5$ plane contains the electrospinning needle and passes through all of the electrodes. The $\mathrm{Y}=0.5$ plane plots are included in discussion of several case studies below.

\subsubsection{CASE 1 - No intruding object}

In this first case study the electric current density lines are observed in the absence of an intruding object. The schematic diagram of the experimental set up is shown in Figure 5.1. The source is a single point placed at XYZ co-ordinates $(0.6,0.5,0.0)$ and the collector is a flat surface with an area of $0.4 \times 0.4$ at $\mathrm{Z}=0.9$ plane located with opposing corners at points $(0.4,0.3,0.9)$ and $(0.8,0.7,0.9)$. As expected, the current density vector arrows generated at the source follow paths that terminate at the collector. The electric current density vector arrow directions and the potential field profile are mapped for the $\mathrm{Y}=0.5$ plane in Figure 5.2. The $\mathrm{Y}=0.5$ plane was selected because the point source is in this plane and this plane shows the greatest variation in the current density vectors. Only a fraction of the grid points are plotted, otherwise the density of points would be too large to visually see the arrows.

The current density vectors and the potential field are almost but not quite symmetric due to the source and collector being off center. Figure 5.2(A) shows the direction arrows but not the magnitudes of the vectors. Inspection of the magnitudes of the vector components shows that the asymmetric part of the current density lines in the $\mathrm{Y}=0.5$ plane to the left of the collector in Figure 5.2 is negligible compared to 
the current density lines near the source and collector. Hence the asymmetry does not affect the numerical solution.
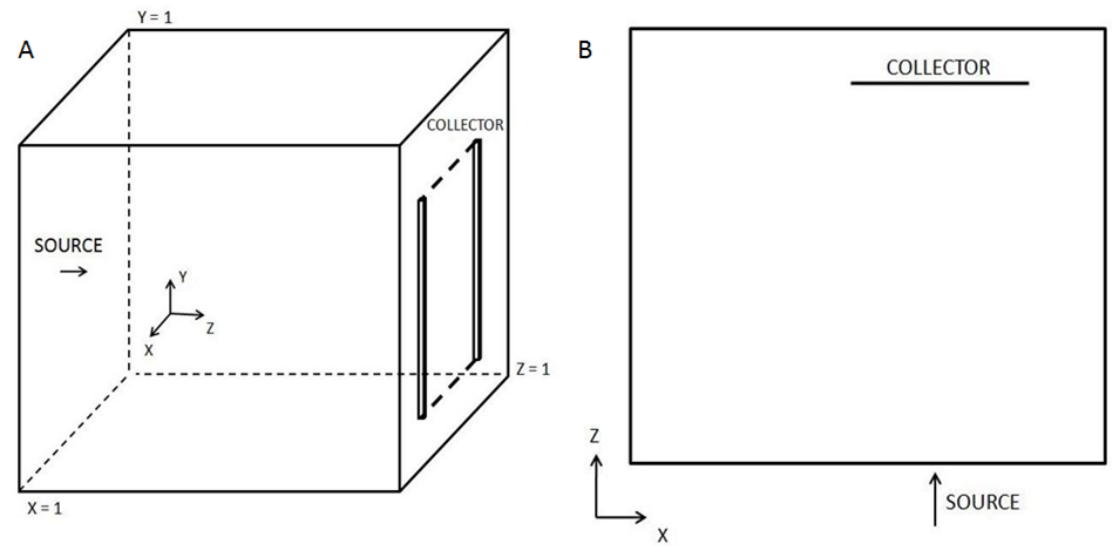

Figure 5.1: Case 1. (A) Schematic diagram showing the locations of the source and the collector. (B) Top view of the setup
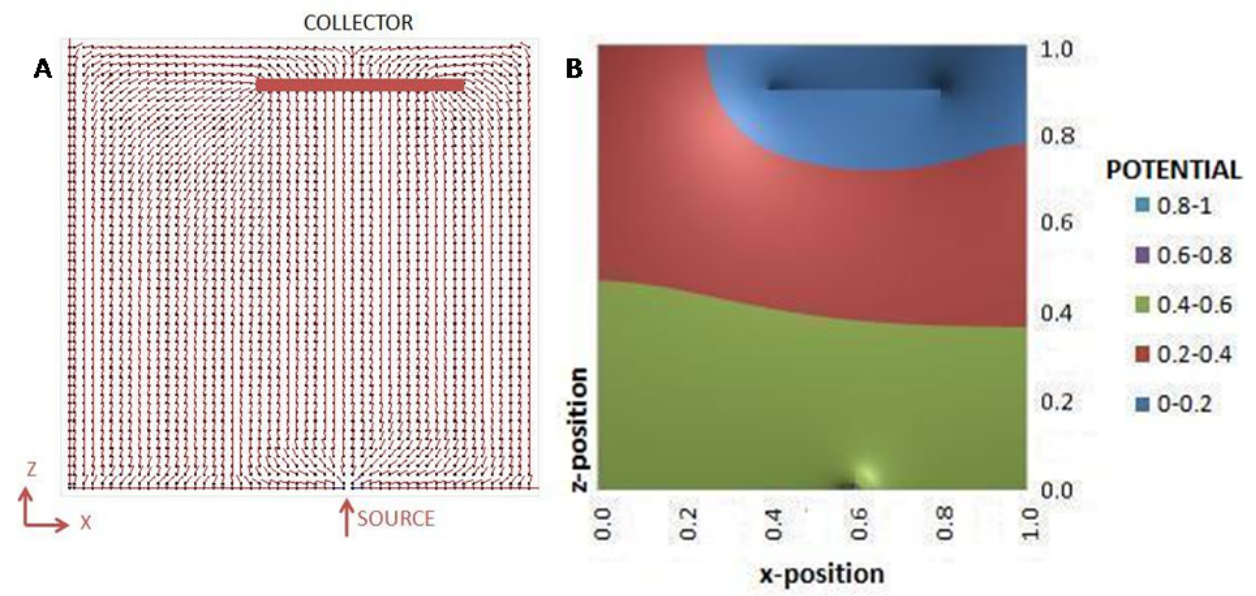

Figure 5.2: Case 1. (A) Electric field current density vectors for the $Y=0.5$ plane in the absence of an intruding object. (B) Contour plot showing the potential profile for $\mathrm{Y}=0.5$ plane 


\subsubsection{CASE 2 - Intruding object}

In Case 2 the current density lines are calculated with the presence of an intruding object. The schematic diagram of the experimental set up is shown in Figure 5.3. The intruding object is assumed to be a cuboid with its nearest corner from the origin and opposing corner co-ordinates $(0.1,0.3,0.4)$ and $(0.3,0.6,0.8)$. The intruding object is grounded (ie., has zero potential). The current density vectors and the potential field for the $\mathrm{Y}=0.5$ plane are plotted in Figure 5.4. The presence of the intruding object causes significant changes to the current density vector plot and potential field as compared to Figure 5.2. Many of the current density vectors are directed towards the grounded intruding object.
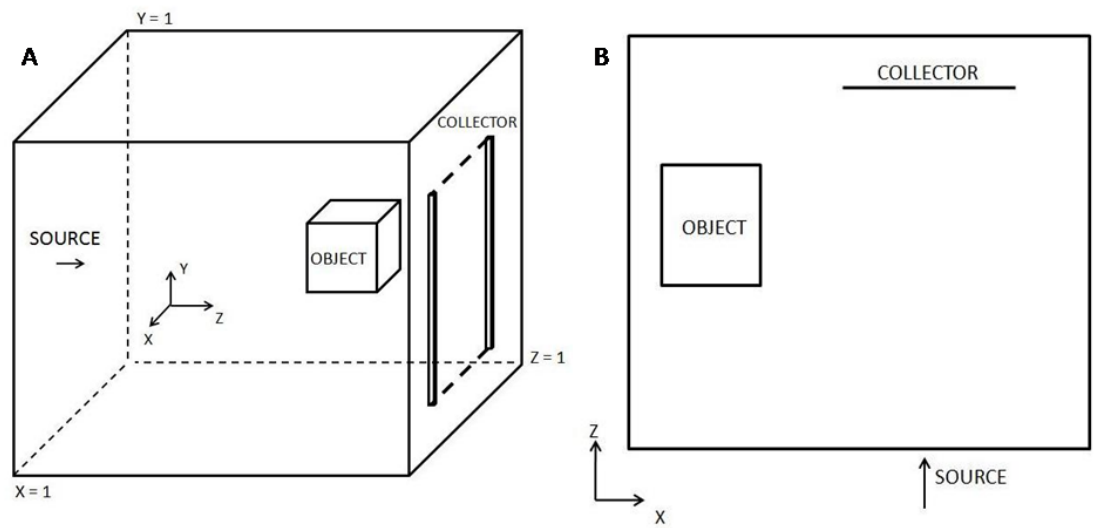

Figure 5.3: Case 2. (A) Schematic diagram showing the location of source, object and collector. (B) Top view of the setup 

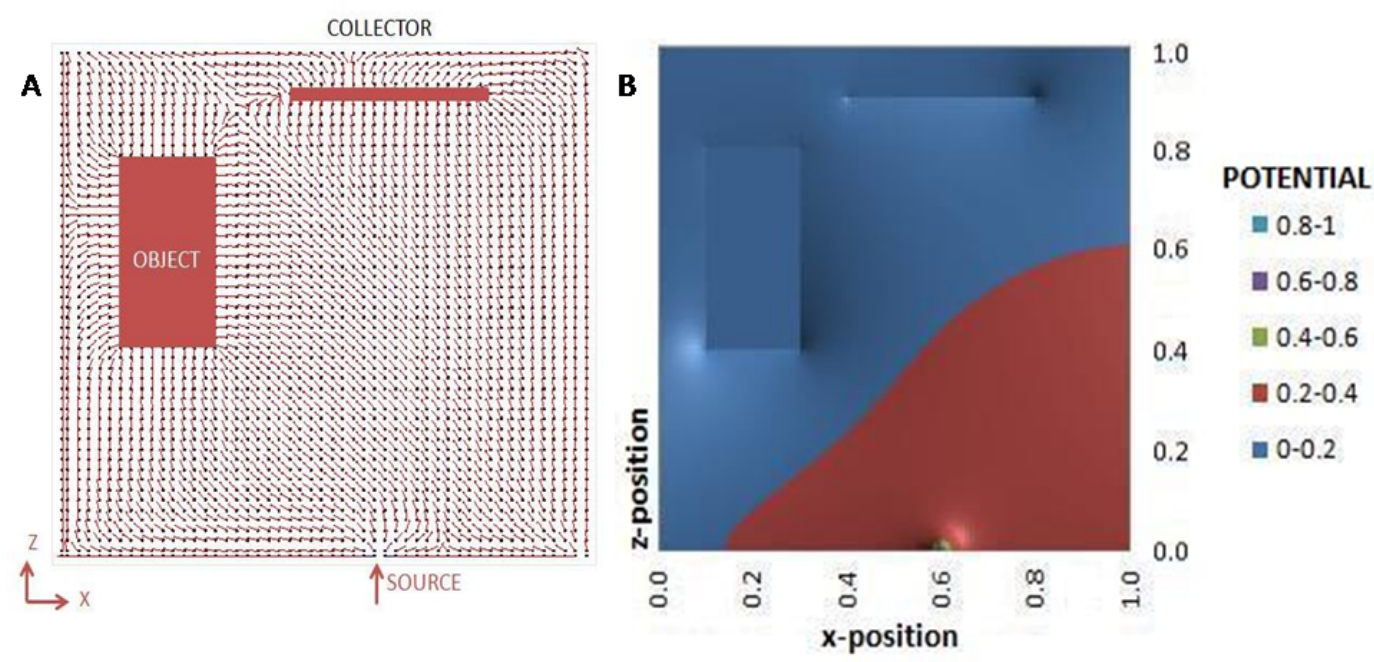

Figure 5.4: Case 2. (A) Electric field current density vectors for the $\mathrm{Y}=0.5$ plane with an intruding object present. (B) Contour plot showing the potential profile for $\mathrm{Y}=0.5$ plane

\subsubsection{CASE 3 - Intruding object and two perpendicular secondary electrodes}

In Case 3 the current density lines are calculated in the presence of an intruding object as well as two secondary electrodes that are arranged perpendicular to each other. The schematic diagram of the experimental set up is shown in Figure 5.5. The first electrode is placed in front of the intruding object as a flat surface with an area of $0.3 \times 0.4$ at $\mathrm{X}=0.4$ plane located with opposing corners at points $(0.4,0.3,0.3)$ and $(0.4,0.6,0.7)$ and is given a potential of 0.6 . The second electrode is placed perpendicular to the first electrode as a flat surface with an area of $0.2 \times 0.3$ at the $\mathrm{Z}=$ 0.2 plane located with opposing corners at points $(0.2,0.3,0.2)$ and $(0.4,0.6,0.2)$ and is given a potential of 0.9 . The current density vectors and the potential field for the $\mathrm{Y}=0.5$ plane are plotted in Figure 5.6(A). The presence of secondary electrodes 
modified the potential field and most of the current density vectors are directed away from the grounded intruding object.

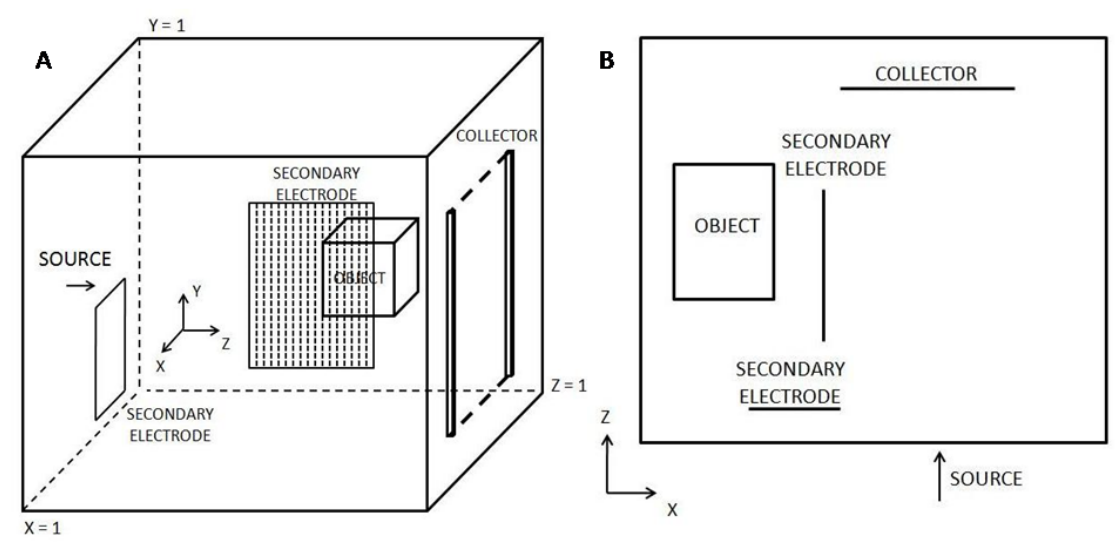

Figure 5.5: Case 3. (A) Schematic diagram showing the location of source, object, collector and secondary electrodes. (B) Top view of the setup
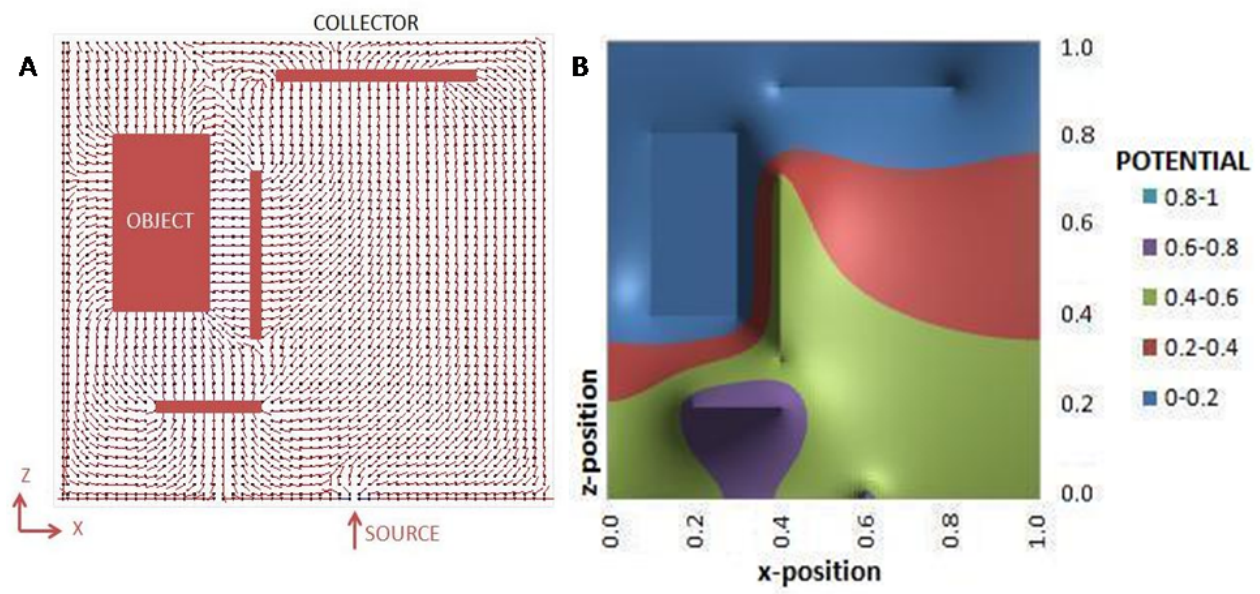

Figure 5.6: Case 3. (A) Electric field current density vector directions for $\mathrm{Y}=0.5$ plane in the presence of an intruding object and secondary electrodes. (B) Contour plot showing the potential profile for $\mathrm{Y}=0.5$ plane 


\subsubsection{CASE 4 - Intruding object and two parallel secondary electrodes}

In Case 4 the current density lines are calculated in the presence of an intruding object and two parallel secondary electrodes. The schematic diagram of the experimental set up is shown in Figure 5.7. The first electrode is placed in front of the intruding object as a flat surface with an area of $0.3 \times 0.4$ at $\mathrm{X}=0.4$ plane located with opposing corners at points $(0.4,0.3,0.3)$ and $(0.4,0.6,0.7)$ and is given a potential of 0.6. The second electrode is placed parallel to the first electrode as a flat surface with an area of $0.3 \times 0.2$ at $\mathrm{X}=0.2$ plane located with opposing corners at points $(0.2,0.3,0.1)$ and $(0.2,0.6,0.3)$ and is given a potential of 0.9 . The current density vectors and the potential field for the $\mathrm{Y}=0.5$ plane are plotted in Figure 5.8. The presence of the secondary electrodes modified the potential field and most of the current density vectors are directed away from the grounded intruding object, similar to Case 3. 

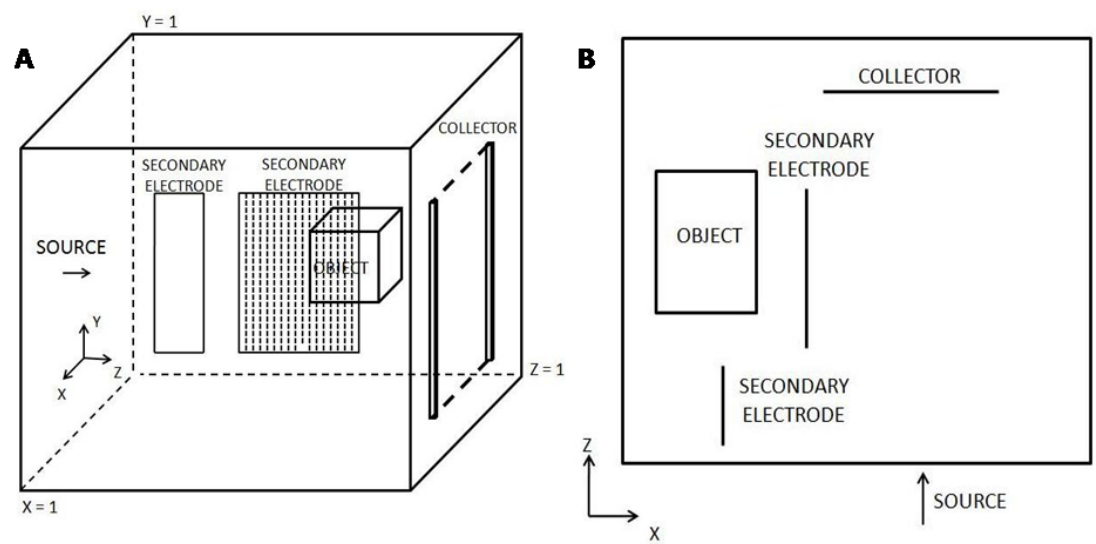

Figure 5.7: Case 4. (A) Schematic diagram showing the location of source, object, collector and secondary electrodes. (B) Top view of the setup
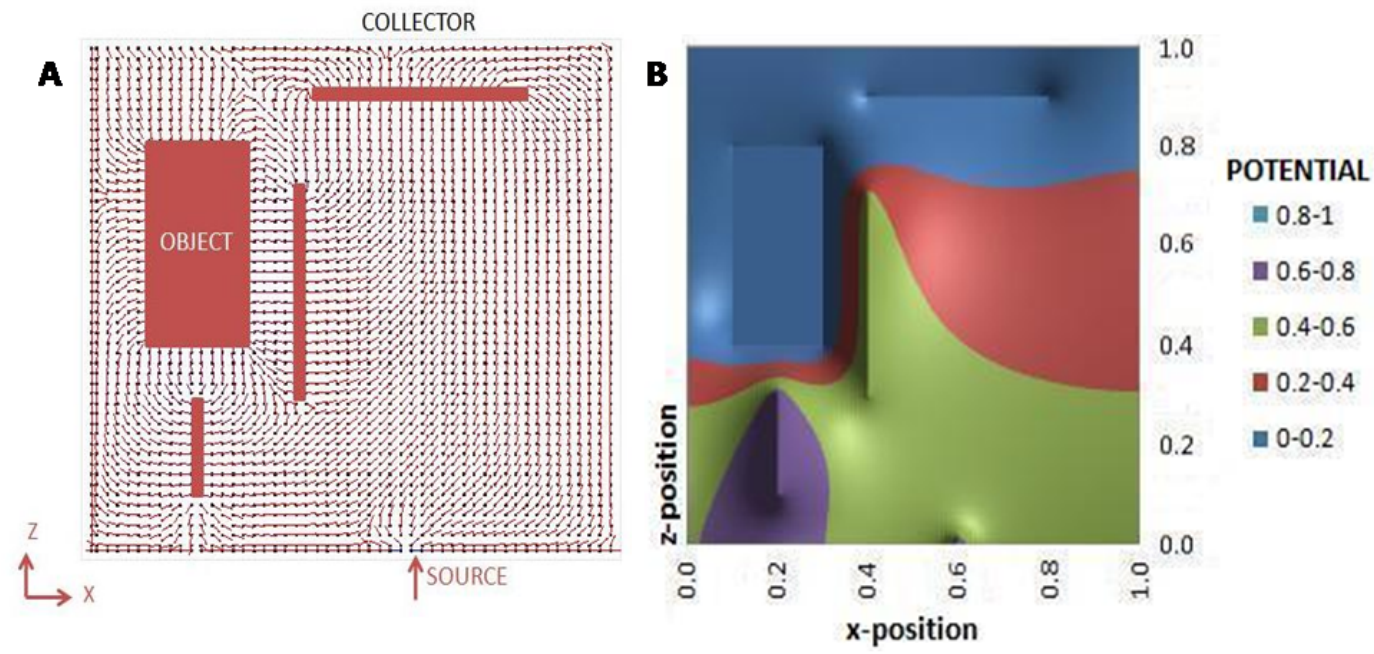

Figure 5.8: Case 4. (A) Electric field current density vector directions for $\mathrm{Y}=0.5$ plane in the presence of an intruding object and secondary electrodes. (B) Contour plot showing the potential profile for $\mathrm{Y}=0.5$ plane 
5.2.5 CASE 5 - Intruding object, a secondary electrode surrounding the source and a planar secondary electrode

To study if using a secondary electrode of a different geometry would modify the current density lines better than Case 3 and Case 4, three different geometries, i.e hemi-sphere, cylinder and a cone are placed as shown in Figure 5.9.

In Case 5 the current density lines are calculated in the presence of an intruding object, a secondary electrode surrounding the source and a planar secondary electrode. The schematic diagram of the experimental set up is shown in Figure 5.9. The first electrode is placed in front of the intruding object as a flat surface with an area of $0.3 \times 0.4$ at $\mathrm{X}=0.4$ plane located with opposing corners at points $(0.4,0.3,0.3)$ and $(0.4,0.6,0.7)$ and is given a potential of 0.6. The second electrode surrounds the source and is given a potential of 0.9 . The current density vectors for the $\mathrm{Y}=0.5$ plane are plotted in Figure 5.10. The potential field for the $Y=0.5$ plane are plotted in Figure 5.11. The presence of the secondary electrodes modified the potential field and most of the current density vectors are directed away from the grounded intruding object, similar to Case 3 and Case 4 . 

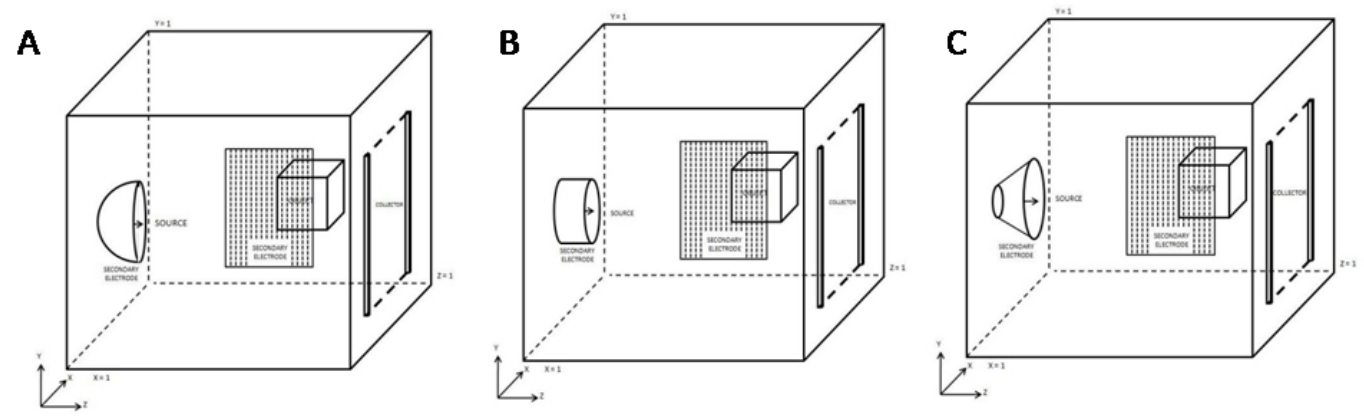

Figure 5.9: (A) Schematic diagram showing the location of source, object, collector and secondary electrodes (hemi-sphere) (B) Schematic diagram showing the location of source, object, collector and secondary electrodes (cylinder) (C) Schematic diagram showing the location of source, object, collector and secondary electrodes (conical frustum)
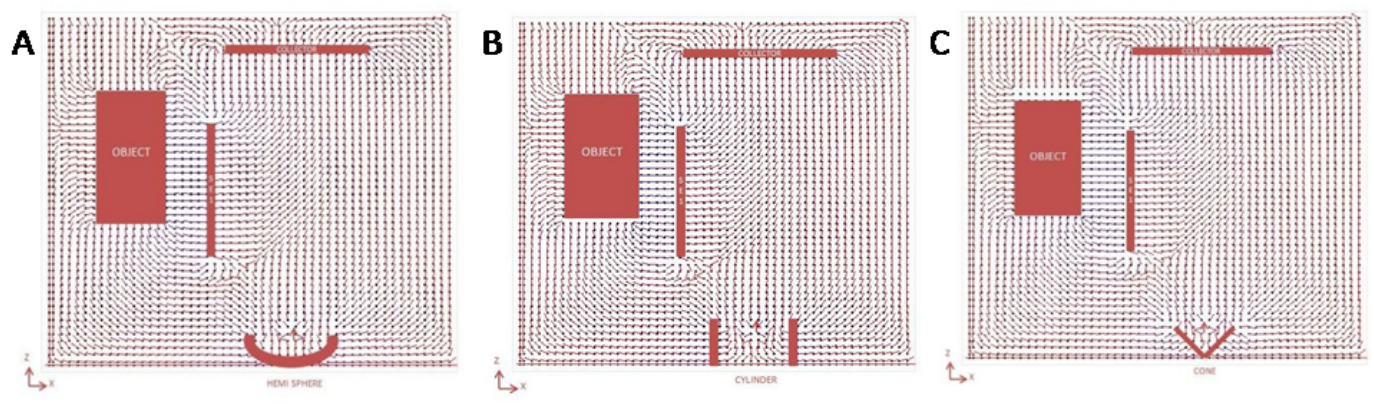

Figure 5.10: (A) Electric field current density vector directions for $Y=0.5$ plane in the presence of an intruding object and secondary electrodes (Hemi sphere). (B) Electric field current density vector directions for $\mathrm{Y}=0.5$ plane in the presence of an intruding object and secondary electrodes (Cylinder). (C) Electric field current density vector directions for $\mathrm{Y}=0.5$ plane in the presence of an intruding object and secondary electrodes (Cone) 

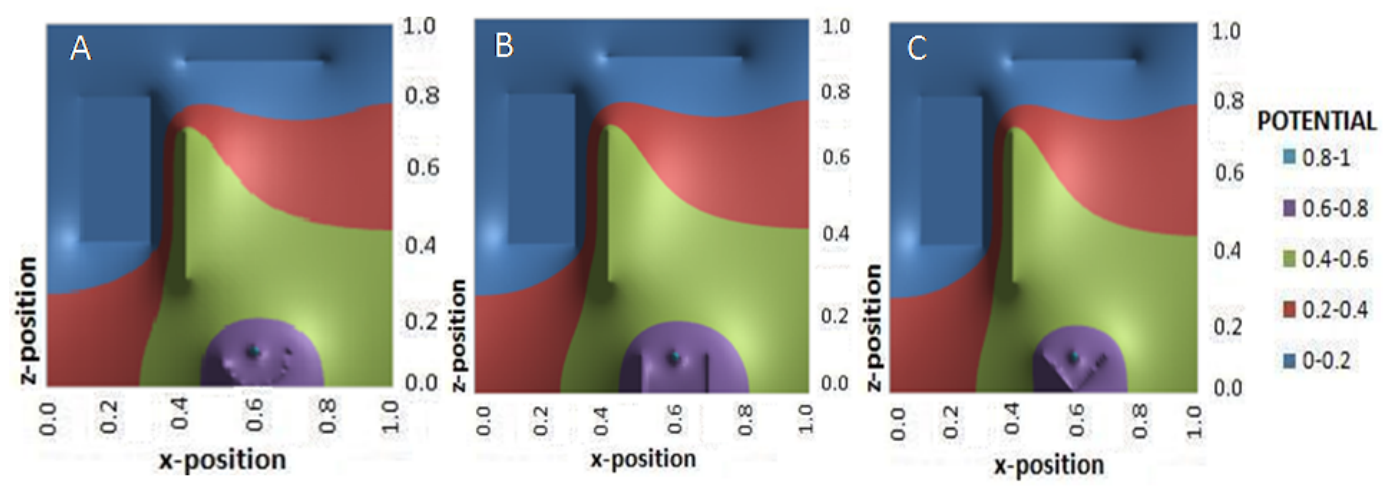

Figure 5.11: (A) Contour plot showing the potential profile for $\mathrm{Y}=0.5$ plane (Hemi sphere). (B) Contour plot showing the potential profile for $\mathrm{Y}=0.5$ plane (Cylinder). (C) Contour plot showing the potential profile for $\mathrm{Y}=0.5$ plane (Cone)

\subsection{Experimental work}

Our interest in the experimental work is to compare the effects of secondary electrodes to divert the electrospinning jets away from the intruding object (an electric motor). The current density lines patterns observed in Cases 3, 4 and 5 were very similar. Hence experiments are conducted to compare Cases 2 and 3 only.

\subsubsection{Materials}

Syndiotactic Polypropylene (SPP, melt index: $2.20 \mathrm{~g} / 10 \mathrm{~min}$ at $230 \mathrm{C}$ with a load 2.16 Kg, ASTM D 1238) used in this study was purchased from Aldrich (Sigma Aldrich,

St. Louis, MO). The weight average $\left(M_{W}\right)$ and number-average molecular weight 
$\left(M_{N}\right)$ were 174000 and $75000 \mathrm{~g} / \mathrm{mol}$, respectively $\left(\frac{M_{W}}{M_{N}}=2.32\right)$. SPP was dissolved in a solvent mixture of cyclohexane $(99 \%+)$, acetone and dimethylformamide (DMF) in a weight ratio of $80 / 10 / 10$ at $70 \mathrm{C}$ at a weight concentration of $2 \%$ of SPP to solvent mixture [94]. This polymer mixture was electrospun to produce fiber mats. All of the chemicals were purchased from Thermo Fisher Scientific Inc. (Waltham, MA) and used without further modification.

\subsubsection{Electrospinning setup}

The experimental setup corresponding to the model Case 2 is shown in the photograph in Figure 5.12. The physical dimensions are in proportion to the dimensionless distances in Case 2. The experimental set up is an approximation to the model because some of the geometric details vary. For example, the intruding object (a grounded electric motor) in the experiment was cylindrical in shape and had a protruding drill chuck on one end. The overall size and shape of the motor was approximated by a cuboid of dimensions $10 \mathrm{~cm} \times 7.5 \mathrm{~cm} \times 5 \mathrm{~cm}$. The motor was supported on a nonconducting wooden stand. The motor was covered with aluminum foil that could be removed and weighed to determine the mass of electrospun fibers that accumulated on the motor.

The objects in the experiment volume were charged to appropriate potentials by connecting the objects to power sources or to ground via small diameter wires. 
Our interest was in the gross effect of the electric field on the path of the electrospinning jet. It is assumed that the effects of the geometric differences and the presence of the wires on the overall electric field are not significant. The validity of these assumptions will be evaluated in future work.

The polymer solution was loaded into a $5 \mathrm{ml}$ syringe and the syringe was installed in the syringe pump. The polymer solution was pumped at a continuous rate of $25 \mathrm{ml} / \mathrm{hr}$ through a Teflon tube to the charged needle. The Teflon tube provided a standoff distance of $15 \mathrm{~cm}$ between the syringe pump and the charged needle so that the syringe pump was outside of the model space and the presence of the syringe pump was neglected in the model.

The needle was located $30 \mathrm{~cm}$ from the grounded collector and held in place by a stand made of non-conducting cardboard. The needle was charged to $30 \mathrm{kV}$ using a high voltage power supply (Gamma high voltage, Ormond Beach, FL). The grounded collector was $12 \mathrm{~cm} \times 12 \mathrm{~cm}$ square of aluminum foil mounted on cardboard and located at the dimensionless position $\mathrm{Z}=0.9$ plane.

The electrospinning setup corresponding to model Case 3 is shown in Figure 5.13 (A). The geometric arrangement was the same as for Case 2 shown in Figure 5.12 plus the additional electrodes. The additional secondary electrodes were aluminum foil mounted on cardboard and charged by wires connected to high voltage power 


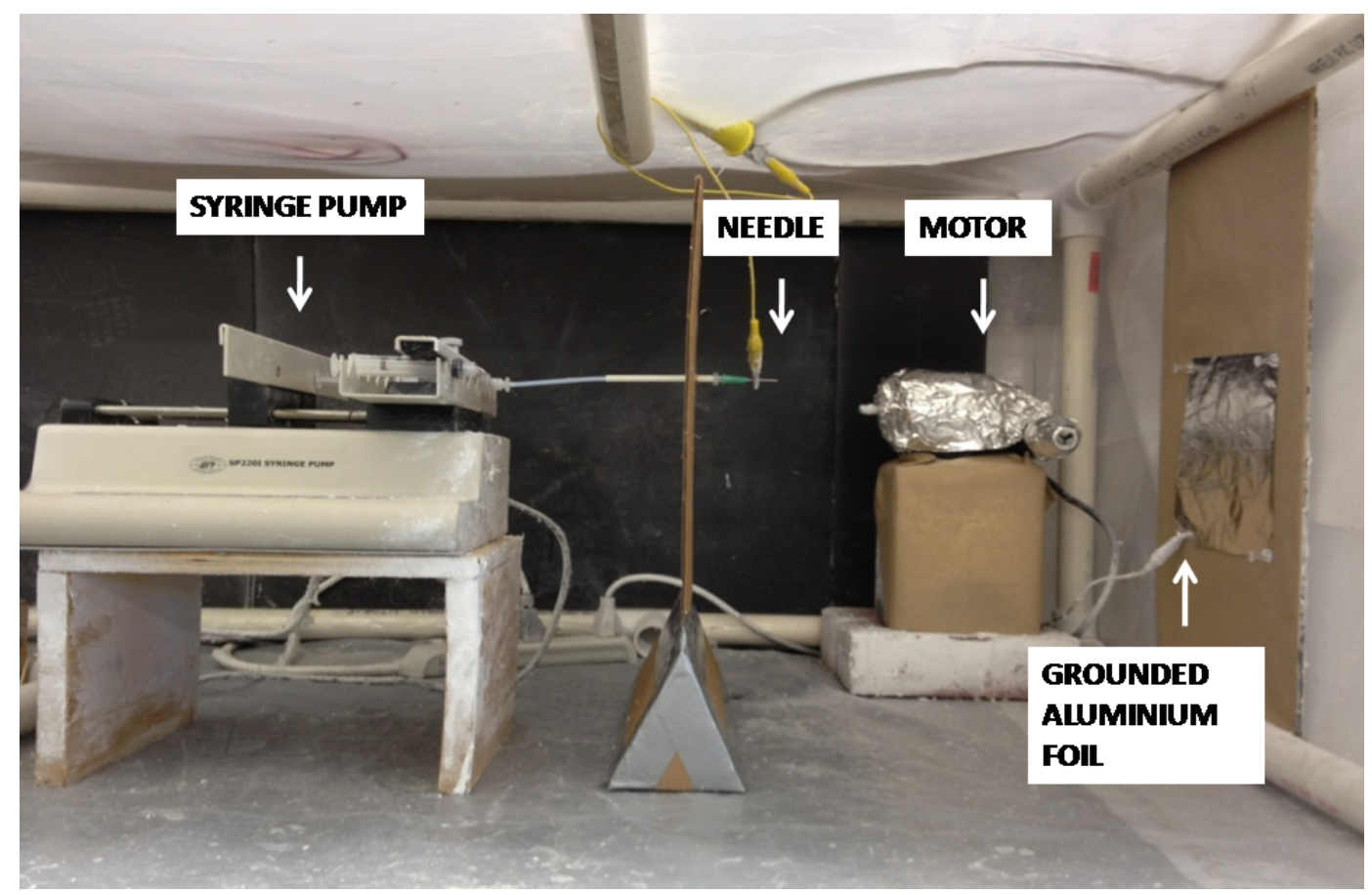

Figure 5.12: Electrospinning setup corresponding to model Case 2

supplies. The secondary electrode nearest the protruding object was $12 \mathrm{~cm} \mathrm{x} 9 \mathrm{~cm}$ charged to $18 \mathrm{kV}$ and the electrode nearest to the $\mathrm{Z}=0$ plane was $9 \mathrm{~cm} \mathrm{x} 6 \mathrm{~cm}$ and charged to $27 \mathrm{kV}$.

Experiments were conducted for comparison between the two cases. The masses of polymer accumulated on the collector and the intruding object (motor) were measured by weighing the foils to obtain a measure of the effectiveness of the secondary electrodes to divert the polymer jet. 
To evaluate the path followed by an electrospinning jet, additional experiments were conducted with sheets of non-conducting cardboard placed between the needle and the grounded collector at several Z-plane positions, as shown in Figure 5.13 (B). The electric field passed unaffected through the cardboard, but the polymer jet was collected on the cardboard. It is assumed that the presence of the cardboard had no effect on the electric field nor the path taken by the jet between the cardboard and the needle. By inspection of the fibers collected on the cardboard, the location of where the jet contacted the cardboard could be determined. The cardboard was removed and a new cardboard was positioned at a different $\mathrm{Z}$ position to obtain 3D positional information of the jet path. When the cardboards are layered on top of each other the jet path becomes obvious.

\subsection{Results and discussion}

Figure 5.14 shows photographs of the cardboard collectors at different $\mathrm{Z}$ positions overlaid to show the movement of the center of mass of the electrospinning jets in the experiments. Figure 5.15 shows the center of mass of the fibers collected on the cardboard collectors (dots) overlaid on top of the model predictions of the current density vector directions. The dominant vector directions from the model are indicated by the arrows. In Figure 5.15(A) the vector directions move towards both the intruding object and the grounded collector. The centers of masses of the fibers similarly follow a split path with some of the fibers moving towards the intruding

object and some towards the grounded collector. In Figure 5.15(B) the presence of 
the secondary electrodes changes the path of the current density lines away from the intruding object and towards the grounded collector. The centers of masses of the collected fibers similarly move towards the grounded collector and not towards the intruding object, as desired and expected.

Figure 5.16 shows the grounded collector and the secondary electrode in front of the intruding object in Case 3. Most of the fibers were observed to collect on the collector. The results of the masses of fibers collected are summarized in Table 5.1. The mass percentage of fiber collected directly on the grounded collector increased from $23 \%$ (Case 2) to $87 \%$ (Case 3).
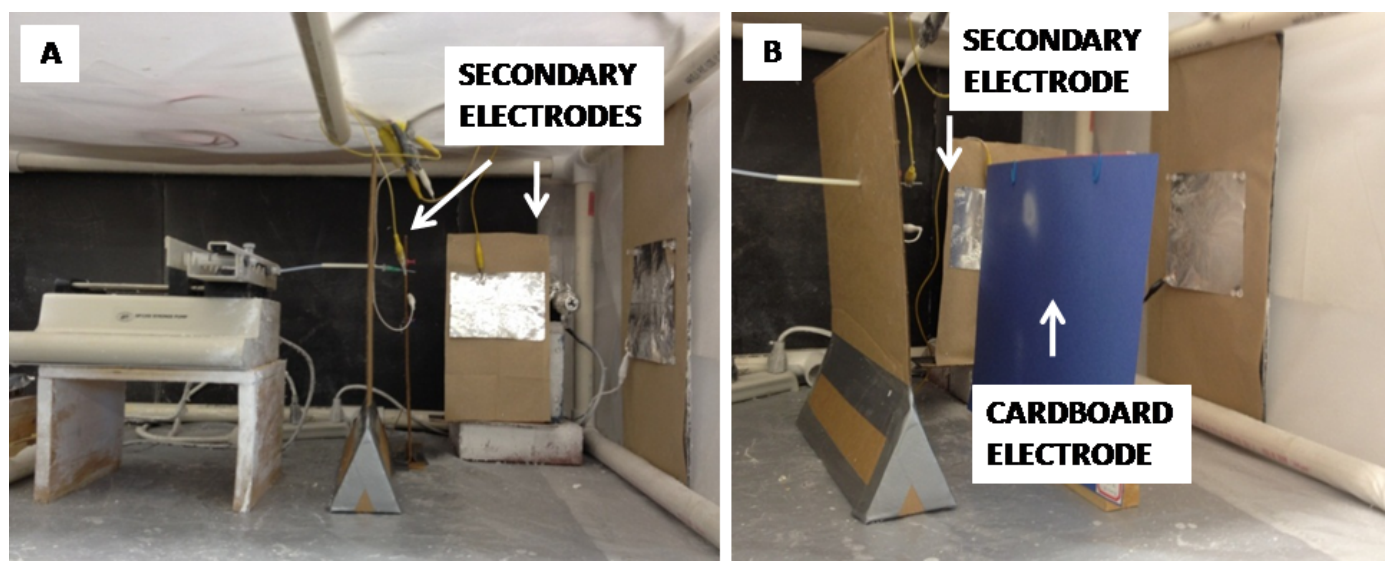

Figure 5.13: (A) Experimental setup for Case 3 with secondary flat electrodes positioned perpendicular to each other. (B) Photograph of experimental setup for Case 3 a cardboard collector positioned between the needle and the grounded aluminum foil at a particular Z plane location to collect fibers 
All the experiments were run in triplicate. Table 5.1 shows the average of the three values and the standard deviation. The percentage of fiber lost to the surroundings was determined from knowing the amount of polymer electrospun in the original solution and the mass of fibers collected on the grounded electrode or intruding object.
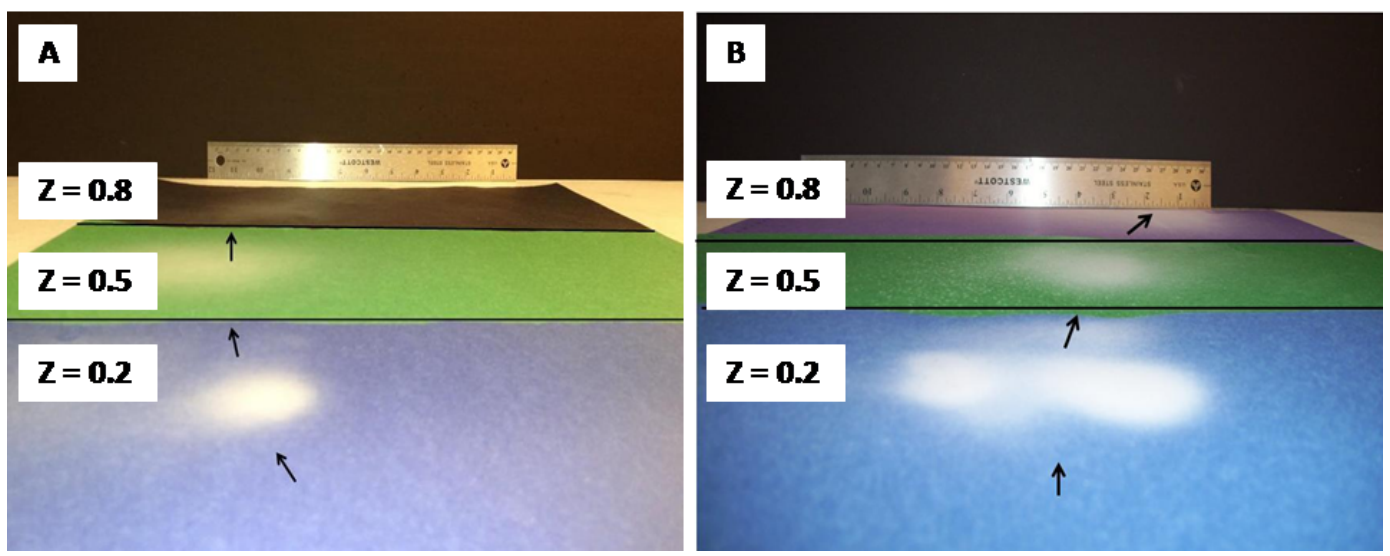

Figure 5.14: (A) Photograph of the cardboard collectors with fibers for Case 2 overlaid on top of each other to show the locations of where the fibers collected on the cardboard in the XY space at the different Z planes. (B) Photograph of the overlaid cardboard collectors with fibers for Case 3. The locations of the Z-planes were 0.2 , 0.5 and 0.8 , as labeled 

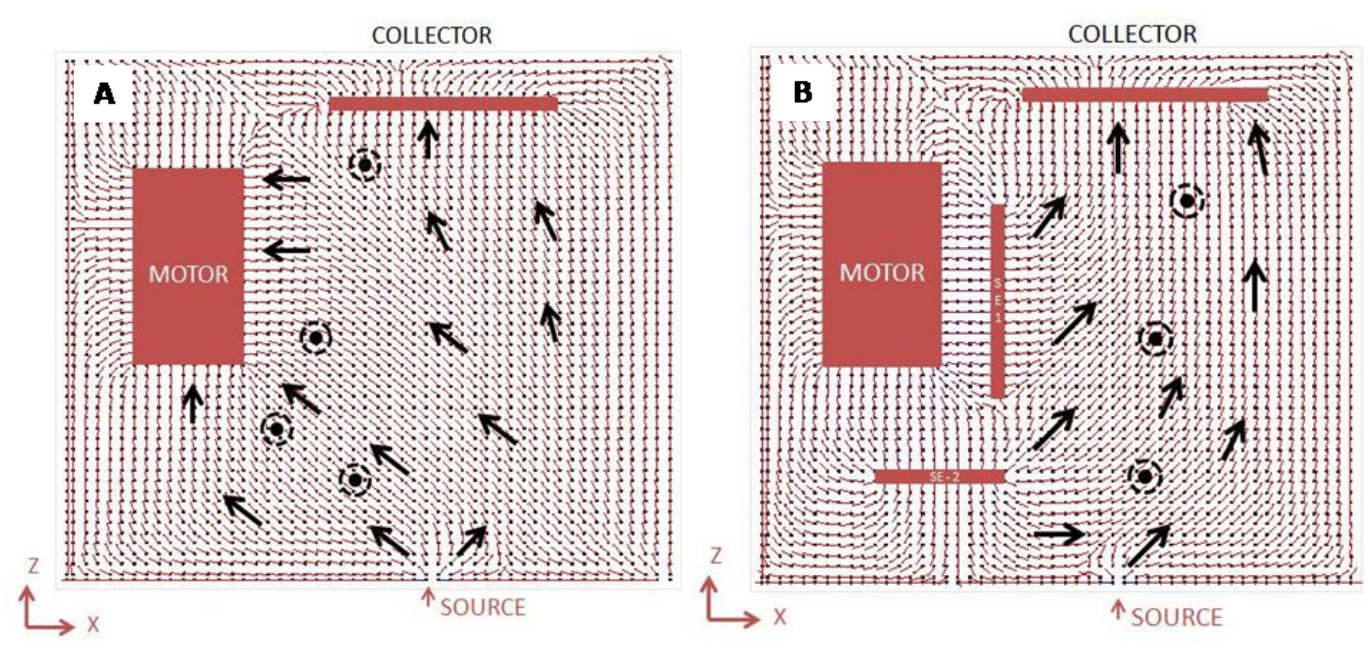

Figure 5.15: Plots showing superimposed experimental data over theoretical data for (A) Case 2 and (B) Case 3. The arrows show the general direction of electric field current density vectors at predicted by the model and the dots represent the centers of masses where fibers were collected on the cardboard collectors experimentally

Table 5.1: Experimental results

\begin{tabular}{lll}
\hline Description & Motor (case 2) & Motor \& electrodes (case 3) \\
\hline \hline Polymer on collector $(\%)$ & 23 & 87 \\
Standard deviation & 0.3 & 1.26 \\
Polymer on motor $(\%)$ & 50.1 & 1.3 \\
Polymer lost $(\%)$ & 26.9 & 11.7 \\
\hline
\end{tabular}



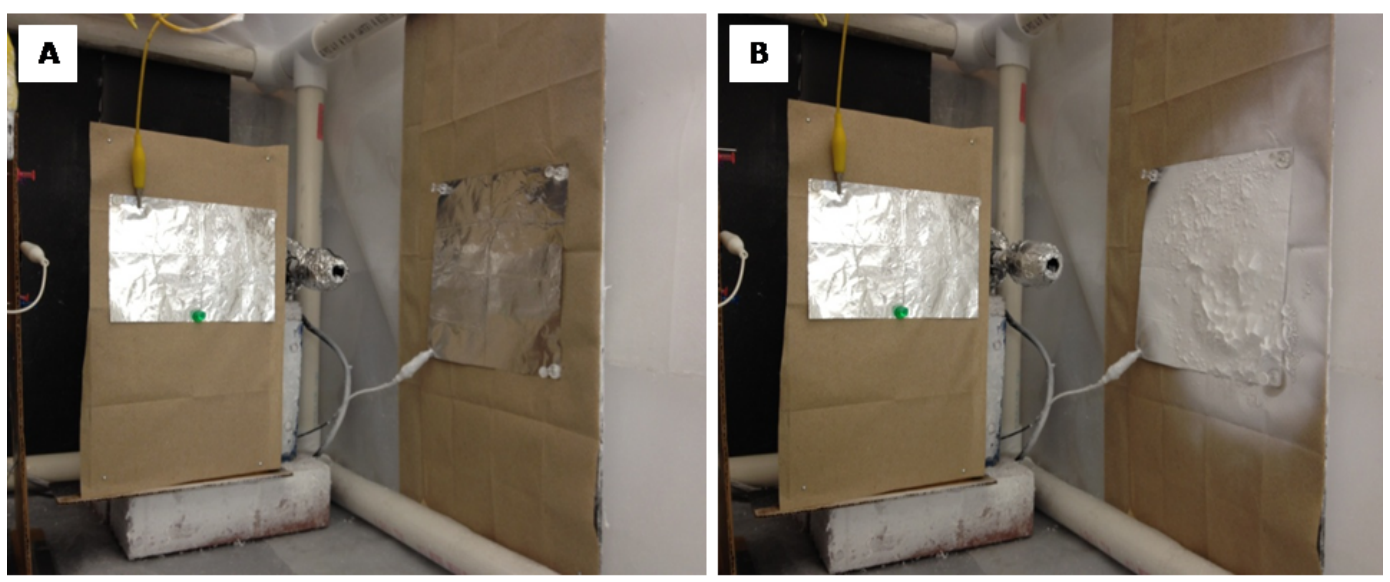

Figure 5.16: Photographs showing the secondary flat electrode and collector (A) before electrospinning and (B) after electrospinning. No nanofibers were observed to collect on the secondary electrode nor the intruding object (motor)

\subsection{Conclusion}

Experimental results show the electrospinning jets tend to follow the electric field current density lines calculated in the model. By modifying the current density lines with secondary electrodes, the electrospinning jets can be diverted away from objects in the electrospinning environment. The presence of the secondary electrodes significantly increased the percentage of polymeric fibers collected on the intended grounded collector. 


\section{CHAPTER VI}

\section{MATERIAL AND METHOD FOR THE FABRICATION OF TUBULAR AND PLANAR NANOFIBER MATS}

This chapter discusses in detail about the material and method used to fabricate tubular as well as planar nanofiber mats.

\subsection{Materials}

Syndiotactic Polypropylene (SPP, melt index: $2.20 \mathrm{~g} / 10 \mathrm{~min}$ at $230 \mathrm{C}$ with a load 2.16 Kg, ASTM D 1238) used in this study was purchased from Aldrich (Sigma Aldrich, St. Louis, MO). The weight average $\left(M_{W}\right)$ and number-average molecular weight $\left(M_{N}\right)$ were 174000 and $75000 \mathrm{~g} / \mathrm{mol}$, respectively $\left(\frac{M_{W}}{M_{N}}=2.32\right)$. SPP was dissolved in a solvent mixture of cyclohexane $(99 \%+)$, acetone and dimethylformamide (DMF) in a weight ratio of $80 / 10 / 10$ at $70 \mathrm{C}$ at a weight concentration of $2 \%$ of SPP to solvent mixture [94]. This polymer mixture was electrospun to produce fiber mats. All of the chemicals were purchased from Thermo Fisher Scientific Inc. (Waltham, MA) and used without further modification. 
6.2 Fabrication of tubular nanofiber mats

Stainless steel compression springs were used as collectors to make tubular nanofiber mats. Springs of two different diameters were used. The outer diameter (OD) of the first spring was $2.4 \mathrm{~mm}$ (0.094 inches) and $76 \mathrm{~mm}$ (3 inches) in length (Figure 6.1). The spring had a wire diameter of $0.33 \mathrm{~mm}$ (0.013 inches). The outer diameter of the second spring was $4.75 \mathrm{~mm}$ (0.187 inches) and $76 \mathrm{~mm}$ (3 inches) in length. The spring had a wire diameter of $0.58 \mathrm{~mm}$ (0.023 inches). The spring was positioned onto a stainless steel rod with the rod at the center of the spring (Figure 6.3). The rod had a diameter of about $1.7 \mathrm{~mm}$ (0.068 inches). One end of the rod was fixed to a grounded motor and rotated at $10 \mathrm{RPM}$ while the other end was suspended horizontally in the air in front of a grounded sheet of aluminum foil.

The polymer solution was loaded into a $5 \mathrm{ml}$ syringe and is pumped at a flow rate of $25 \mathrm{ml} / \mathrm{hr}$. The needle of the syringe was positioned horizontally on the syringe pump such that the needle was oriented perpendicular to the spring axis at a distance of about $25 \mathrm{~cm}$. A high voltage power supply (Gamma high voltage, Ormond Beach, FL) generated a potential difference of about $25 \mathrm{kV}$ between the syringe needle and the grounded aluminum foil, motor, and spring. A magnified view of a thin layer of electrospun SPP on the spring is shown in Figure 6.4. The thickness of SPP layer on the spring was approximately $0.6 \mathrm{~mm}$. 


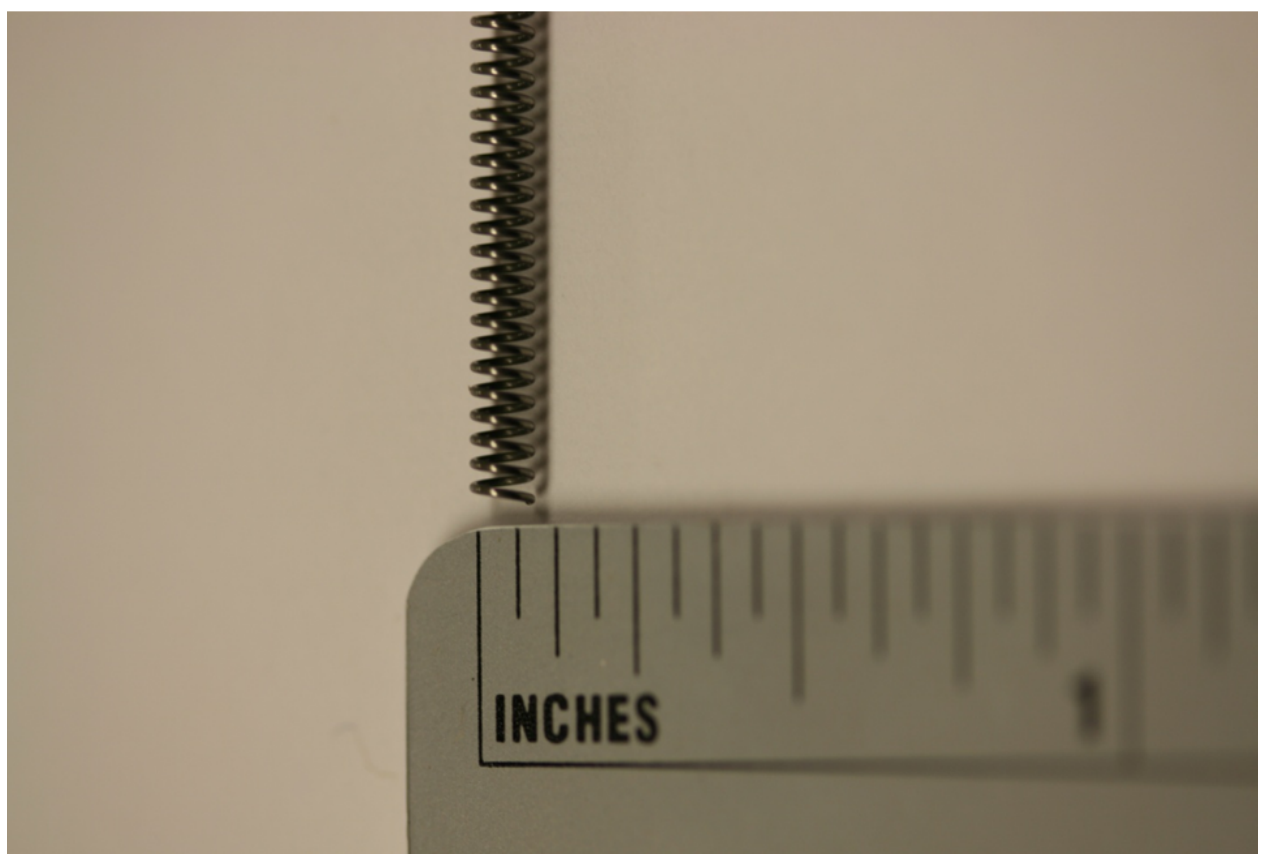

Figure 6.1: Stainless steel compression spring was used as collector to make tubular nanofiber mat

The cylindrically shaped electrospun fiber mats repelled water similar to the planar mats reported in literature. Water droplets in air sitting on a tubular mat are shown in Figure 6.5 and Figure 6.6. The water droplets are also repelled by the tubular mats when the mat is submerged in diesel fuel (Figure 6.7). The $4 \mu$ l drop shown in Figure 6.5 was placed on the tube surface by a syringe needle. Multiple attempts were required to place the droplet on the tube surface. If the drop is too small it does not detach from the needle. Drops of several microliters in volume or larger can be detached from the needle but they are unstable on the curved surface and easily roll off of the due to the low surface energy. The nanofiber mats were transparent when wetted by diesel fuel and opaque when dry in air. The water repellency of the 
tubular mats is expected to aid in separation of water from diesel fuel. The tubular mats were tested in filtration experiments described in the next chapter.

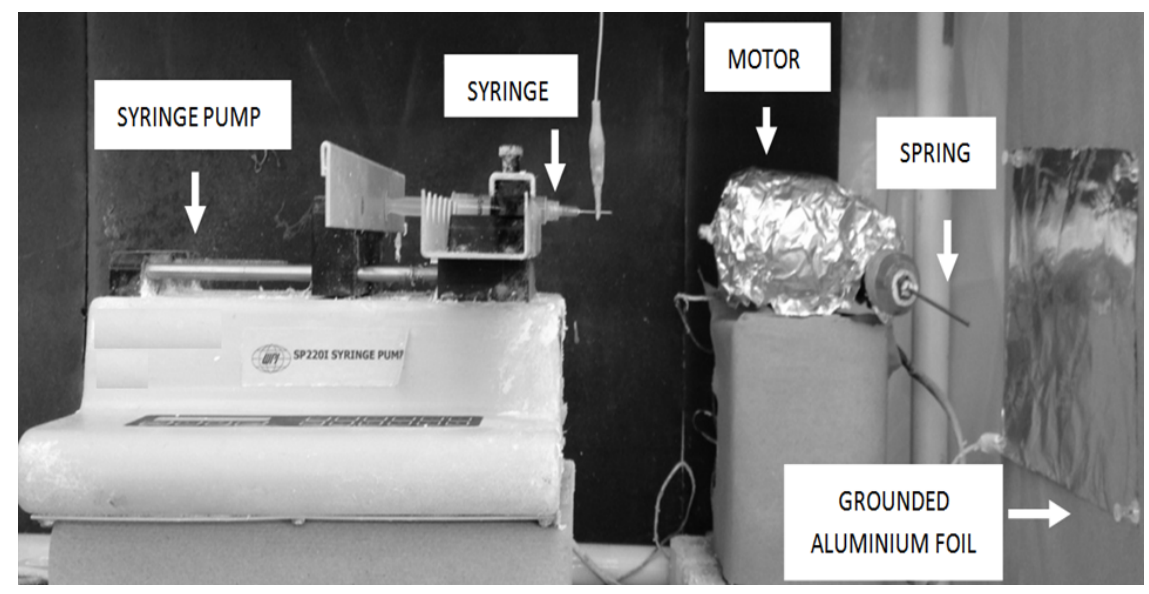

Figure 6.2: Electrospinning setup to make SPP tubular nanofiber mats

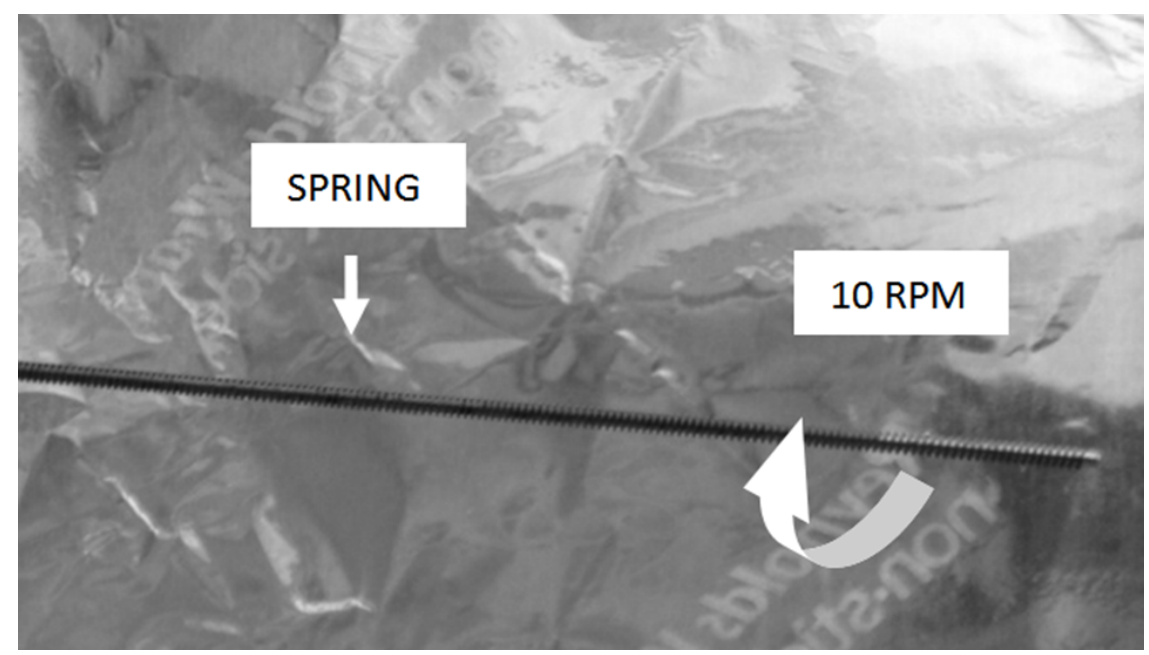

Figure 6.3: Close-up view of the spring collector $(\mathrm{OD}=2.4 \mathrm{~mm})$ 


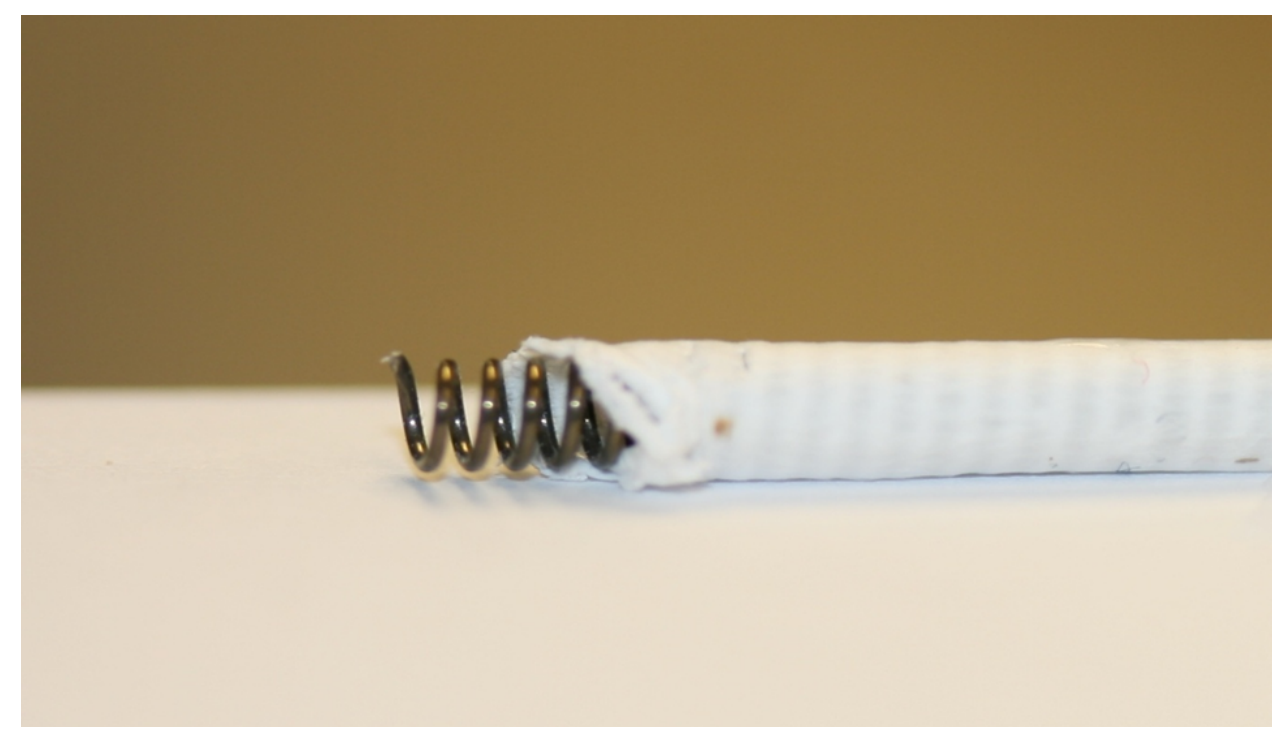

Figure 6.4: A thin SPP layer electrospun on the stainless steel compression spring of OD $2.4 \mathrm{~mm}$

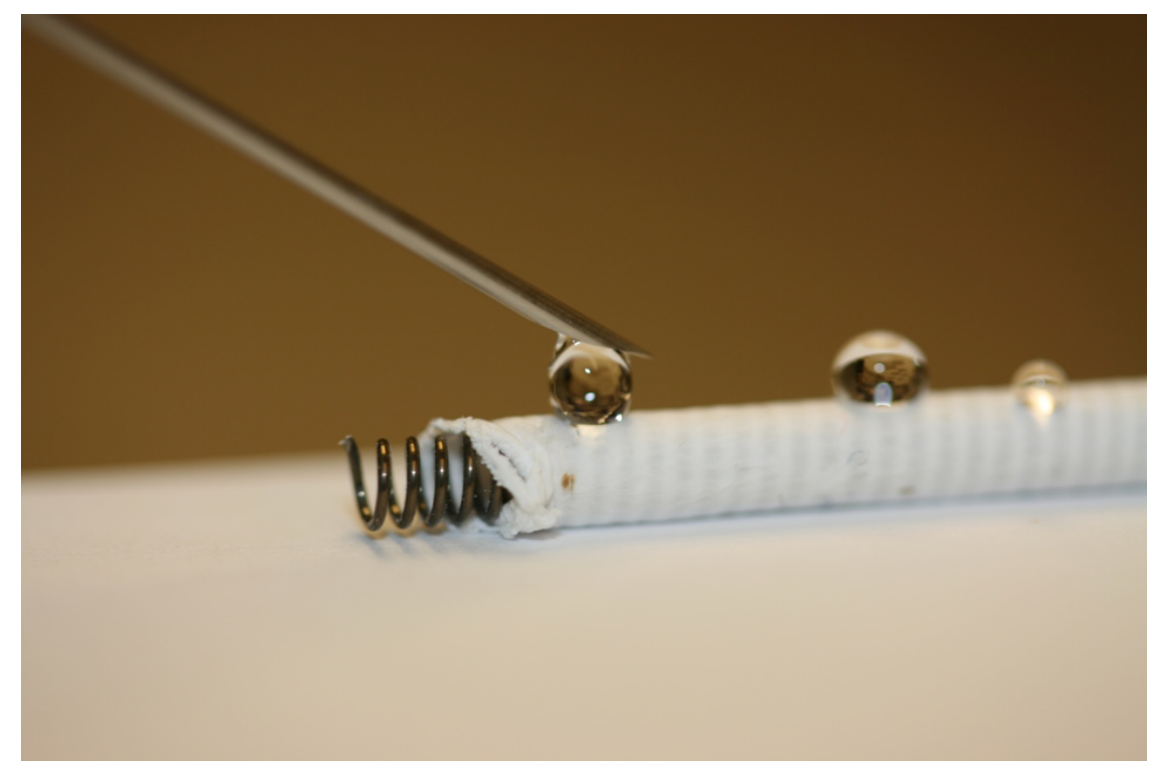

Figure 6.5: Water droplets attached to the cylindrical surface of a spring (OD $=2.4$ $\mathrm{mm}$ ) covered with SPP nanofiber layer in air. The droplet repellency is similar to that commonly reported for planar nanofiber mat surfaces 


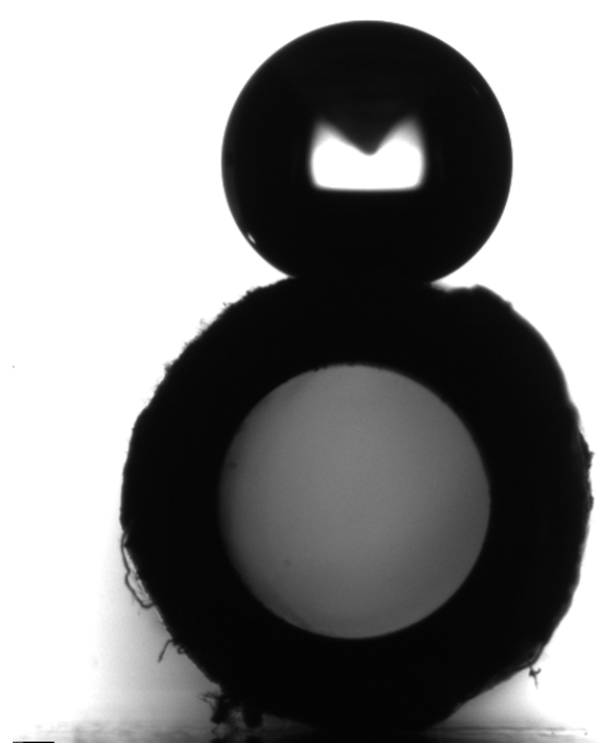

Figure 6.6: DSA photograph of a $4 \mu$ l drop sitting on a tubular filter

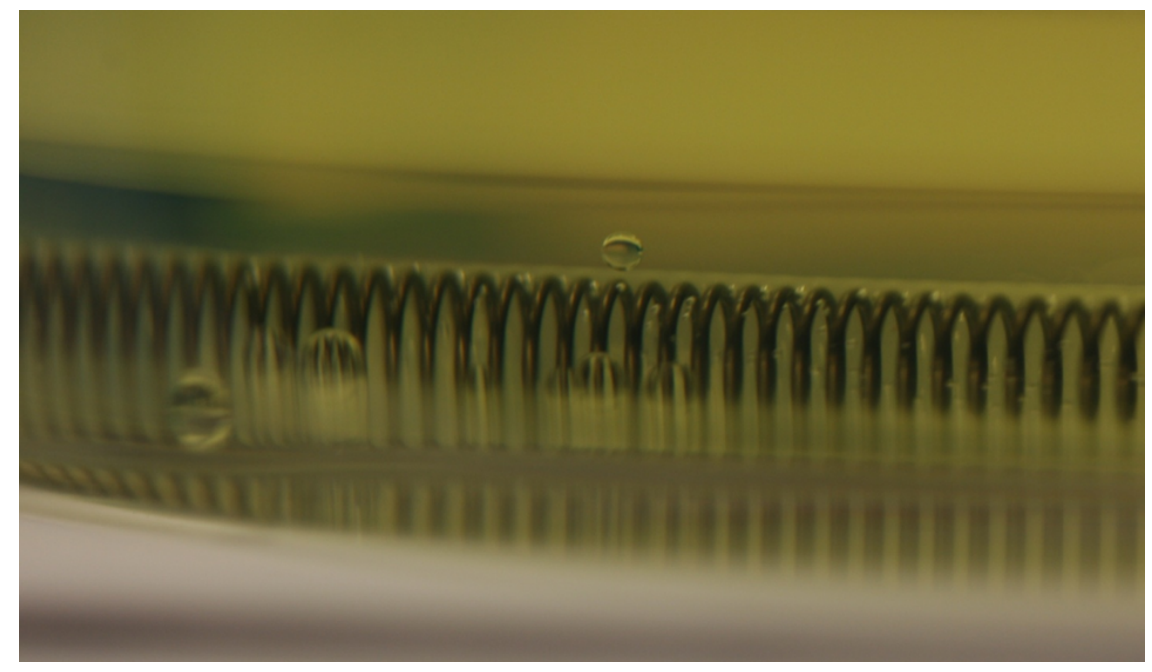

Figure 6.7: The nanofiber mats turn transparent when wetted by diesel fuel and opaque when dry in air. A 41 water droplet placed by a syringe sits on the SPP fiber mat surface on the tube while submerged in the diesel fuel showing repellency similar to that when the tube is in air 


\subsection{Preparation of planar nanofiber mats}

Planar nanofiber mats were fabricated by electrospinning SPP onto a wire mesh of area $103 \mathrm{~cm} 2$ with a pore opening of $0.01 \mathrm{~cm}^{2}$. The polymer solution was loaded into a $5 \mathrm{ml}$ syringe and is pumped at a flow rate of $25 \mathrm{ml} / \mathrm{hr}$. The needle is placed vertically at a distance of $25 \mathrm{~cm}$ from the grounded wire mesh and is connected to the syringe using Teflon tube. A high voltage power supply (Gamma high voltage, Ormond Beach, FL) generated a potential difference of about $25 \mathrm{kV}$ between the syringe needle and the grounded wire mesh. Planar nanofiber mat is shown in Figure 6.8. The thickness of SPP layer on the wire mesh was approximately $0.8 \mathrm{~mm}$. The planar nanofiber mats were tested in filtration experiments described in the next chapter.

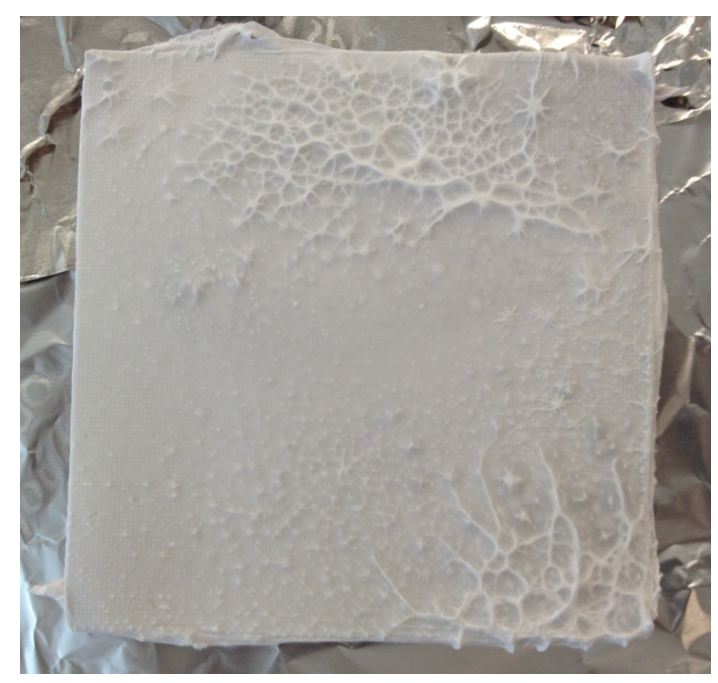

Figure 6.8: Planar nanofiber mat 


\section{CHAPTER VII}

\section{WATER-DIESEL SEPARATION EXPERIMENT AND PROCEDURE}

This chapter discusses about the filter holder design and the experimental setup used for water-diesel separation experiments.

\subsection{Filter holder design and description}

The tubular nanofiber mats were assembled in a tubular mat holder for the waterdiesel separation experiments. The holder was constructed of three Plexiglas parts (inlet, outlet, and center) as depicted in Figure 7.1. The inlet and outlet parts were fabricated with fittings for liquid flows into and out of hollow cavities machined into the Plexiglas and with vents for removal of air, as shown in Figure 7.2. The center part, shown in Figure 7.3, held one or more of the compression springs covered with the tubular nanofiber mat. The two open ends of the compression spring were placed in holes machined into the center part. The holes in the Plexiglas were sealed around the nanofiber mat and spring with epoxy (West System, G/flex 650 Epoxy). When assembled, the center part was placed between the inlet and outlet parts, as shown in Figure 7.4, such that the compression spring was inside of the inlet hollow cavity and the two open ends of the spring were exposed to the hollow cavity of the outlet cavity. 
As indicated in Figure 7.1, the water-in-diesel dispersion entered the inlet cavity, the water drops collected onto the nanofiber mat surface, and the diesel flowed through the center of the spring into the outlet cavity and out of the holder.

As the water droplets accumulated on the surface of the nanofiber mat, the drops coalesced and the enlarged drops rolled off of the tubular mat. Thus cleared of the water drops, the nanofiber mat surface became exposed for more diesel flow. This assembly could be modified to provide a means for the accumulated water to flow out of the inlet cavity, but the present holder was not fabricated with this feature. 


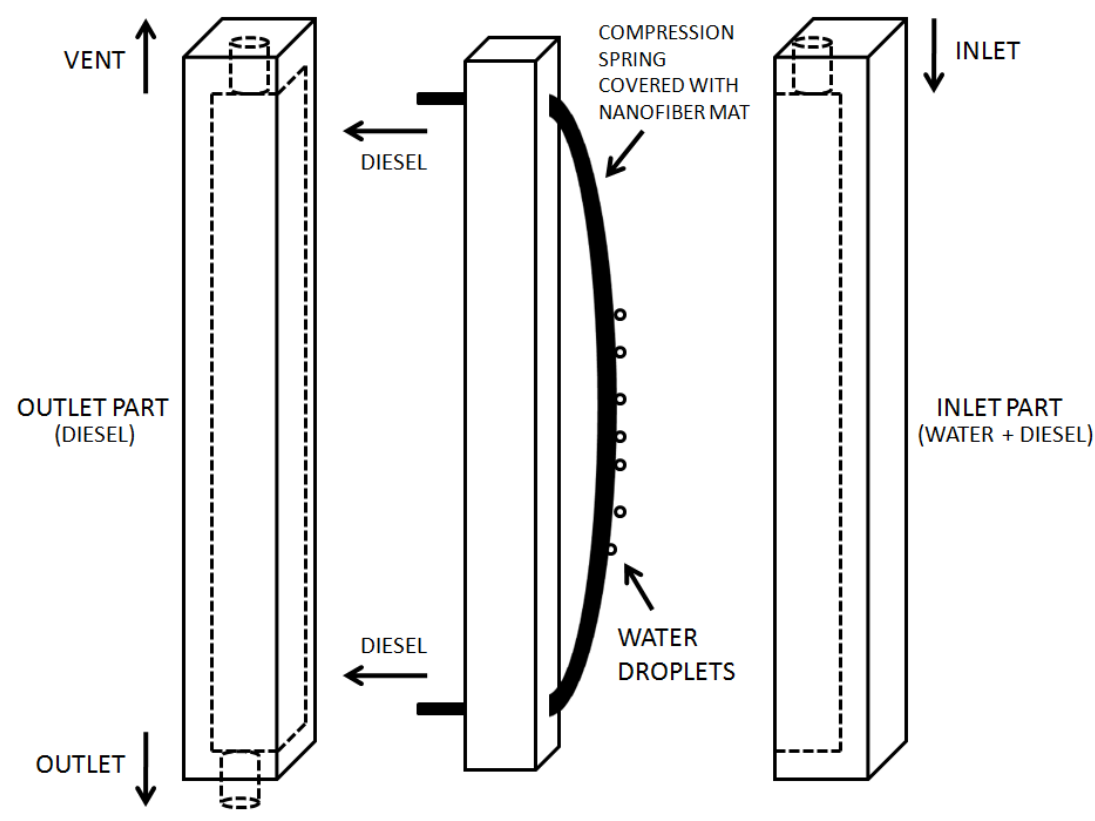

Figure 7.1: Exploded diagram of the tubular filter holder
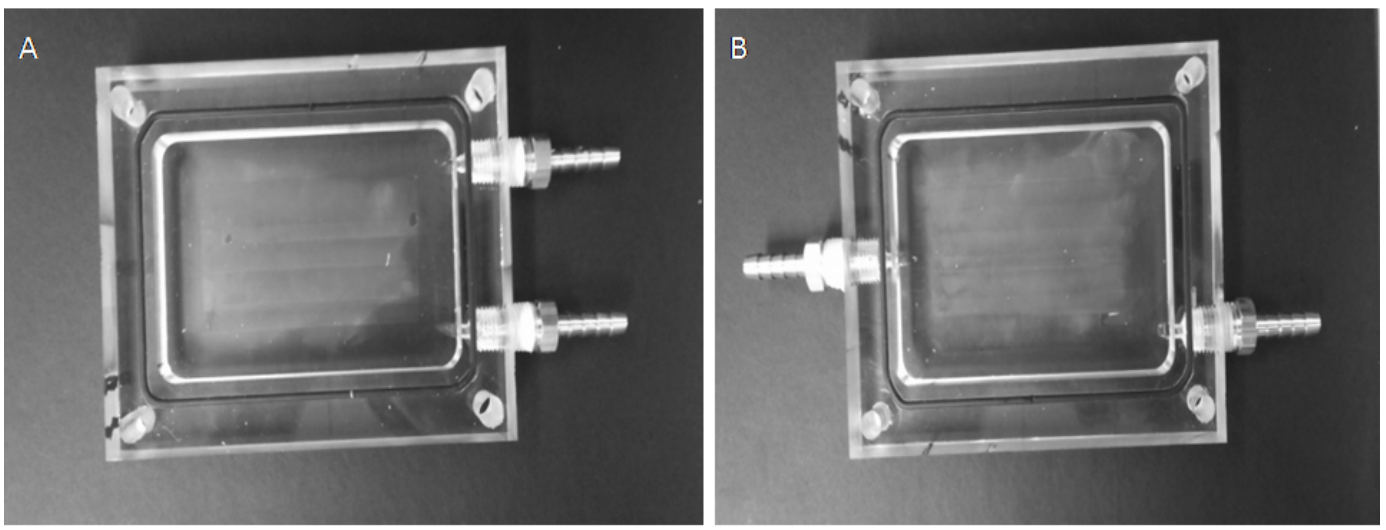

Figure 7.2: Inlet (A) and Outlet (B) parts of the tubular nanofiber filter holder 


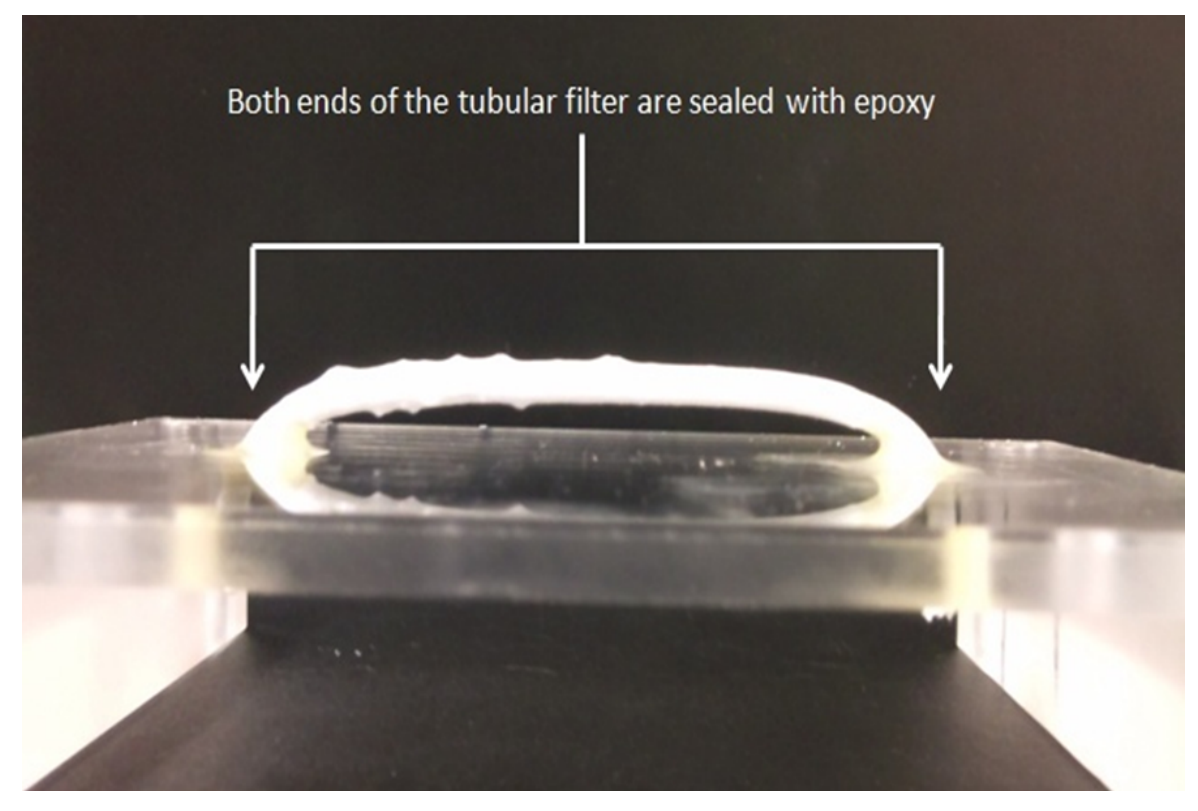

Figure 7.3: Center part of the tubular filter holder. The two open ends of the compression spring, covered with the nanofiber mat, were inserted into holes drilled into the $6.4 \mathrm{~mm}$ (0.25 inch) thick sheet of Plexiglas of the center part. The holes in the Plexiglas were sealed around the nanofiber mat with epoxy

The planar nanofiber mat was assembled in a different filter holder for the water-diesel separation experiments. The holder was constructed of two Plexiglas parts (inlet and outlet) as depicted in Figure 7.5. The inlet and outlet parts were fabricated with fittings for liquid flows into and out of hollow cavities machined into the Plexiglas, as shown in Figure 7.6. When assembled, planar nanofiber mat was placed between the inlet and outlet parts, as shown in Figure 7.7. As indicated in Figure 7.5, the water-in-diesel dispersion entered the inlet cavity, the water drops are collected onto the nanofiber mat surface, and the diesel flowed through the mat into the outlet cavity and out of the holder. 


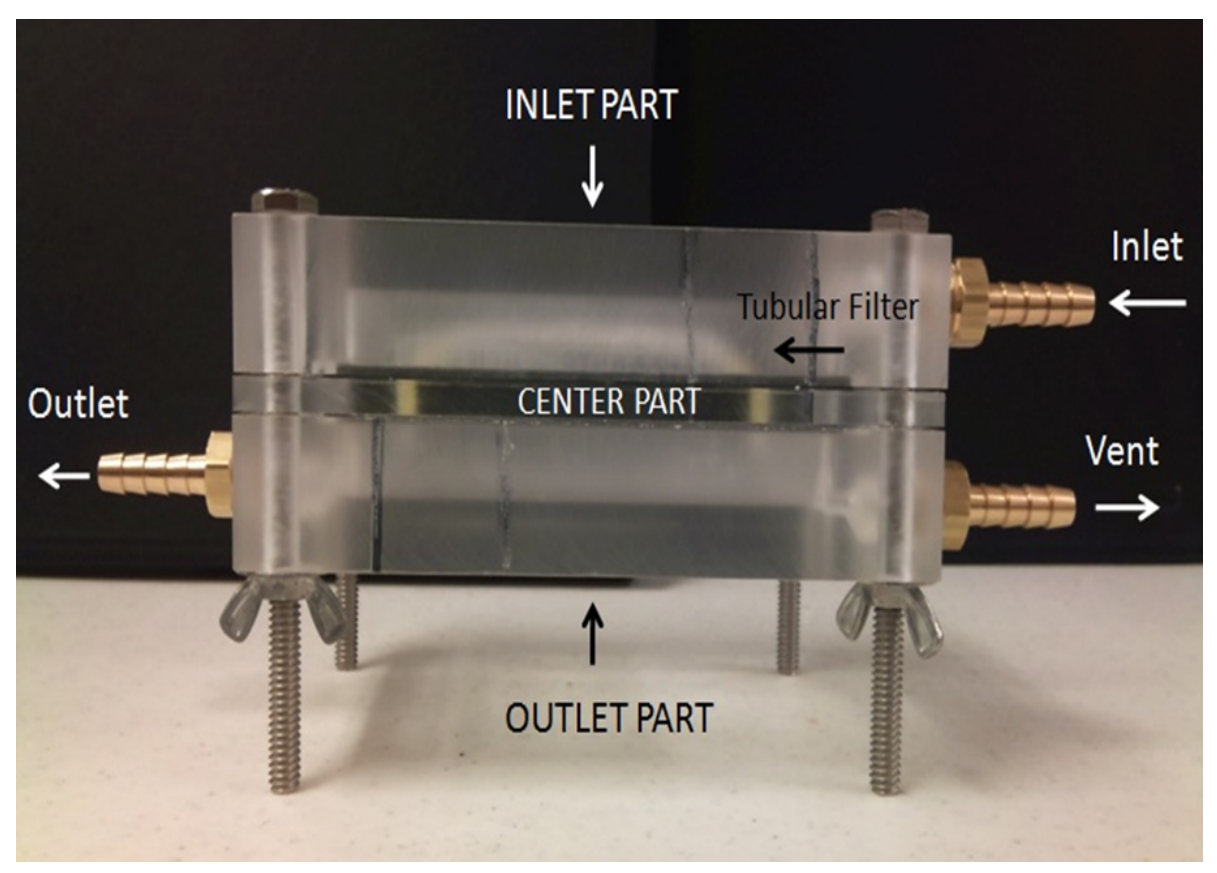

Figure 7.4: Assembled tubular filter holder

\subsection{Interfacial tension measurements}

Diesel fuel was continuously characterized for its interfacial tension. Interfacial tension of ultra low sulfur diesel fuel used was $22 \mathrm{mN} / \mathrm{m}$. Measurements were made using Pendant drop method with drop shape analyzer (Kruss Instruments, Germany). Drop shape analyzer is shown in Figure 7.8. 


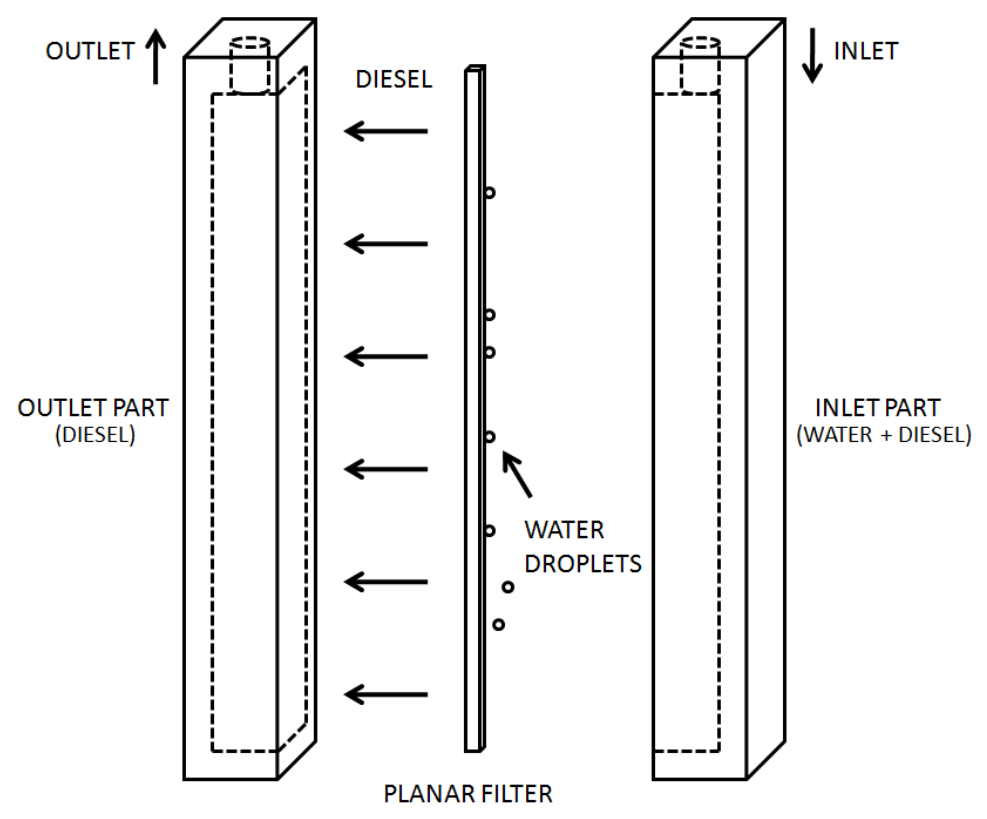

Figure 7.5: Exploded diagram of the planar filter holder
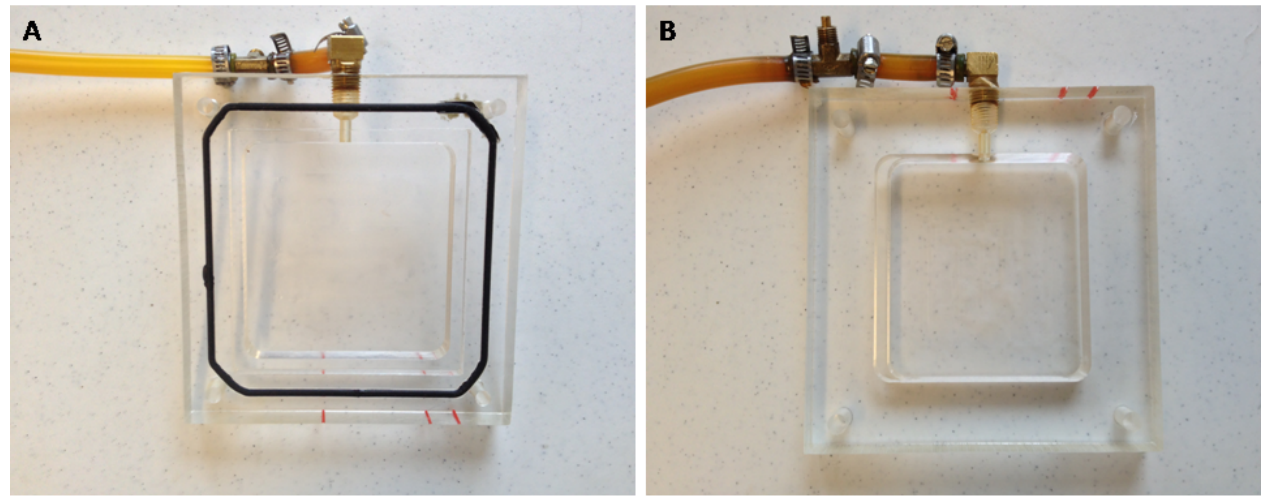

Figure 7.6: Inlet (A) and Outlet (B) parts of the planar nanofiber filter holder 

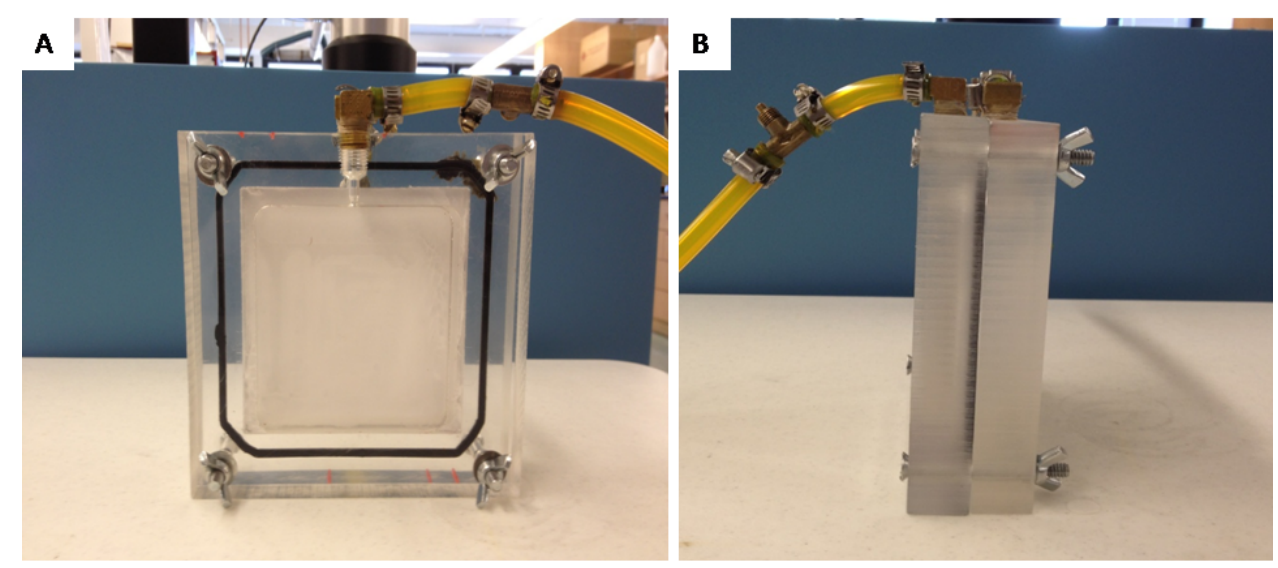

Figure 7.7: Assembled planar filter holder

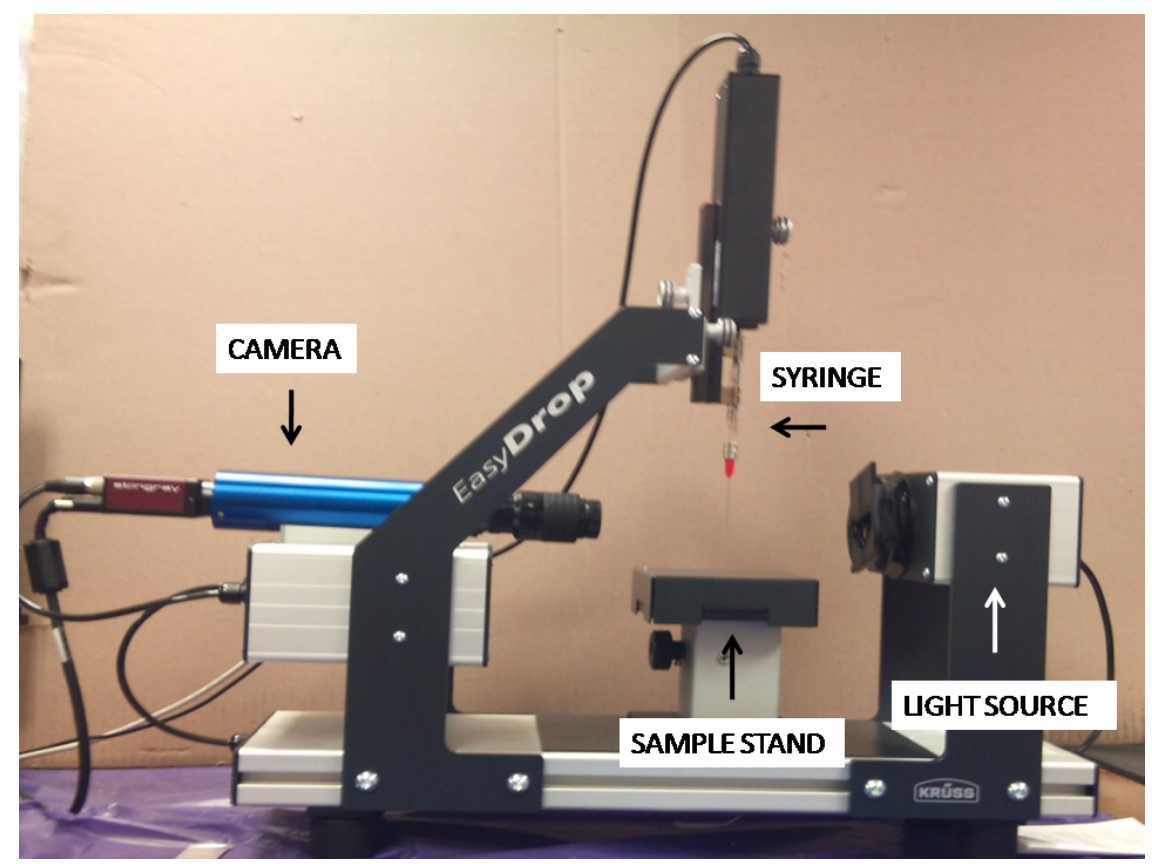

Figure 7.8: Drop shape analyzer for interfacial tension measurement 


\subsection{Water-diesel separation experiment}

The main components of the water-diesel separation experiment are shown in the diagram in Figure 7.9. Water droplets were dispersed in diesel fuel by adding measured amounts of water to the diesel fuel in the Water + Oil Tank. The tank was stirred vigorously for 10 minutes to mix the liquids together. The tank agitation by itself created relatively large water drops. A $3500 \mathrm{rpm}$ diesel fuel pump (Airtex-E3309) was used to pump the diesel mixture from the tank. Part of the mixture passed through the nanofiber mat holder and part through a recycle line back to the tank. Initially the experiment was operated with total recycle for 10 minutes to break the large drops into a dispersion of smaller droplets. After the 10 minutes of complete recycle, the valves were adjusted to maintain a constant flow rate through the tubular nanofiber mat holder.

Samples of the dispersion of the inlet stream to the nanofiber mat holder showed the fine water droplets created by the fuel pump did not settle out of the diesel fuel for at least 30 minutes. Because of the short distance between the pump and the nanofiber mat holder, the dispersion reached the nanofiber mat in a few seconds. Thus, separation of droplets by settling in the flow line was not likely.

The experiments were run for a total of 60 minutes. Samples of water in the diesel emulsion were taken at intervals of 10 to 25 minutes from the flow system 


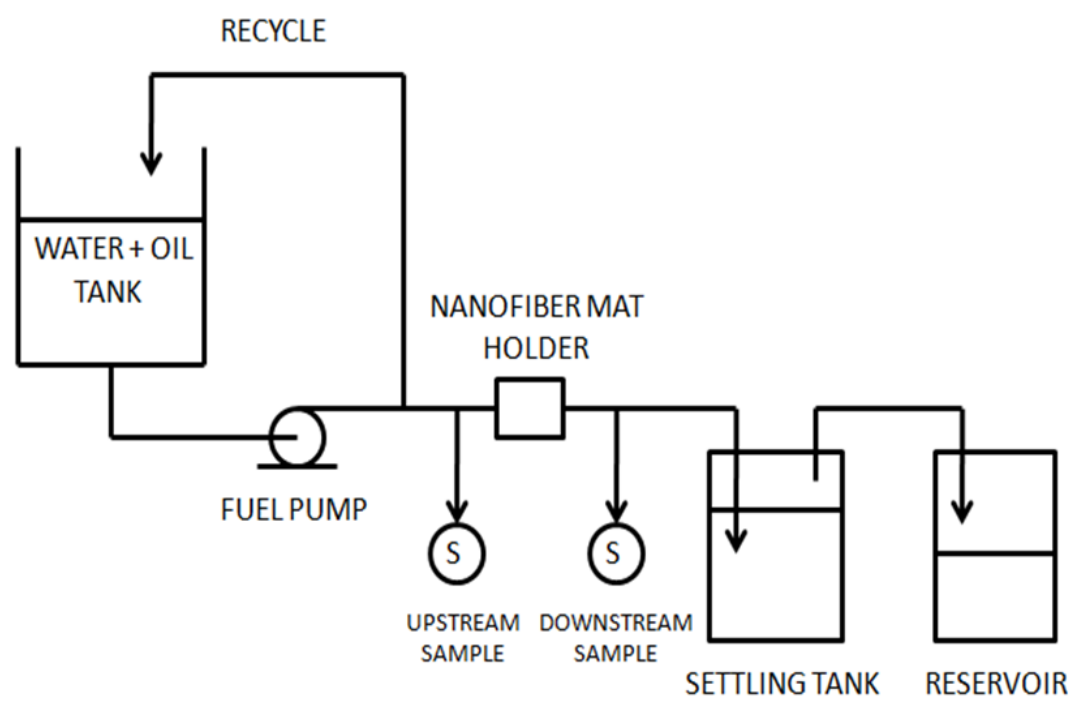

Figure 7.9: Flow diagram of the experimental apparatus for filter testing

at sample points upstream (inlet) and downstream (outlet) of the filter. The size distribution of the water droplets in the emulsion was measured using a particle size analyzer (Accusizer 780/SIS, sensor range $0.5 \mu \mathrm{m}$ to $500 \mu \mathrm{m}$ ). The Accusizer is shown in Figure 7.10. Accusizer uses a single particle optical sensing (SPOS) method which is based on the principle of laser light scattering or obscuration (blockage). Particles in gas or liquid suspension flow through a small photozone, a narrow, slab-like region of uniform illumination, produced by light from a laser diode or incandescent bulb. The particle suspension is sufficiently dilute when the particles pass, one at a time, through the illuminated region, avoiding coincidences. The passage of a particle 
through the sensing zone causes a detected pulse, the magnitude of which depends on the mean diameter of the particle. The method assumes all particles are of spherical shape and have similar optical properties. The inlet and outlet drop size distributions became relatively steady at about 30 minutes. The separation efficiency by drop size and total efficiency were calculated using the steady state inlet and outlet size distributions.

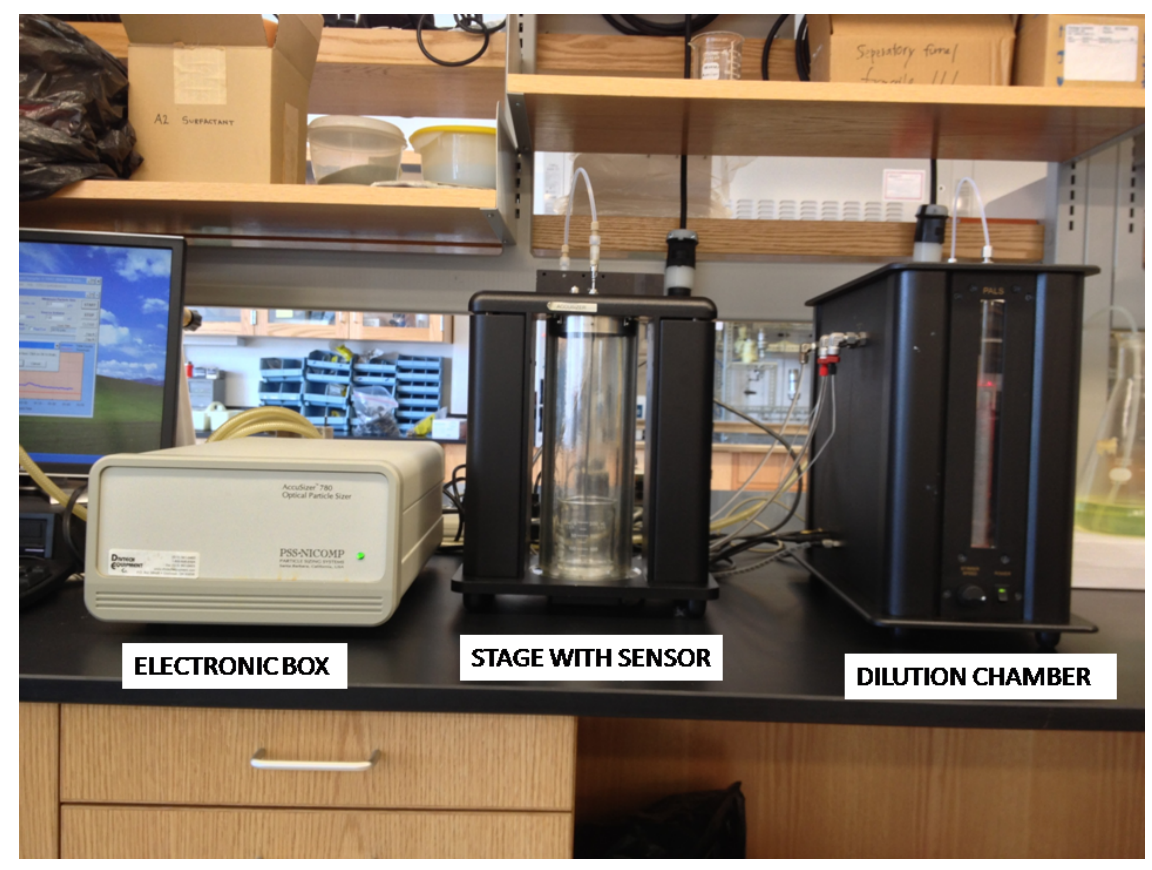

Figure 7.10: Particle size analyzer (Accusizer 780/SIS)

The separation efficiency by drop size is defined by the formula

$$
\mathrm{e}(\mathrm{x})=1-\frac{n_{o}(x)}{n_{i}(x)}
$$


Where $n_{0}(x)$ is the number count of drops per milliliter of size $\mathrm{x}$ within a size range $\Delta \mathrm{x}$ in the outlet stream and $n_{i}(x)$ is the number count of drops per milliliter of the same size and size range in the inlet stream.

The total mass of water droplets per milliliter in a flow stream is given by

$$
\mathrm{M}=\Sigma \rho \frac{\pi}{6}\left(\mathrm{D}_{\mathrm{j}}\right)^{3} \mathrm{n}_{\mathrm{j}}
$$

Where $n_{j}$ is the number of drops of diameter $D_{j}$ per milliliter and $\rho$ is the mass density of the liquid. The total separation efficiency on a mass basis is calculated from the formula

$$
\mathrm{E}_{\mathrm{TOT}}=1-\frac{M_{o}}{M_{i}}
$$

Where $M_{o}$ and $M_{i}$ are the total masses of water per milliliter in the outlet and inlet streams respectively.

\subsection{Experimental procedure}

Figure 7.11 shows the lab-scale experimental setup for the separation of water from diesel fuel. The following experimental procedure was used.

1. Clean the filter holder, place filter sample and assemble the filter holder. 
2. Connect the assembled filter holder to the inlet and outlet connections of the experimental setup.

3. Check diesel fuel level in the tank (3 gallon).

4. Add de-ionized water $(27 \mathrm{ml})$ into the tank.

5. Install a stirrer in the tank.

6. Check if the inlet valve is closed and switch on the stirrer.

7. Switch on the fuel pump and let the system run under complete recycle for 10 minutes.

8. Turn on the Accusizer and the computer connected to it.

9. Adjust the gate valve present next to the recycle stream to maintain a desired flow rate on the upstream.

10. Open the upstream sampling valve and collect $100 \mathrm{ml}$ of the sample.

11. Analyze the upstream sample using the Accusizer for drop size distribution of water.

12. Check pressure transducer connections.

13. Open the inlet and outlet valves and the experiment has started.

14. Record the pressure drop across the filter when the reading becomes constant. Constant pressure drop suggests that the system has reached steady state. 
15. Collect $100 \mathrm{ml}$ sample on the downstream of the filter holder and analyze it using the Accusizer for drop size distribution of water.

16. Turn off the Accusizer once the sample is analyzed.

17. Turn off the fuel pump, stirrer and close the inlet and outlet valves.

18. Dissemble the filter holder, remove the filter sample and clean the filter holder.

19. Close the tank to avoid falling of dust into diesel fuel.

20. Clean the area around the experimental setup.

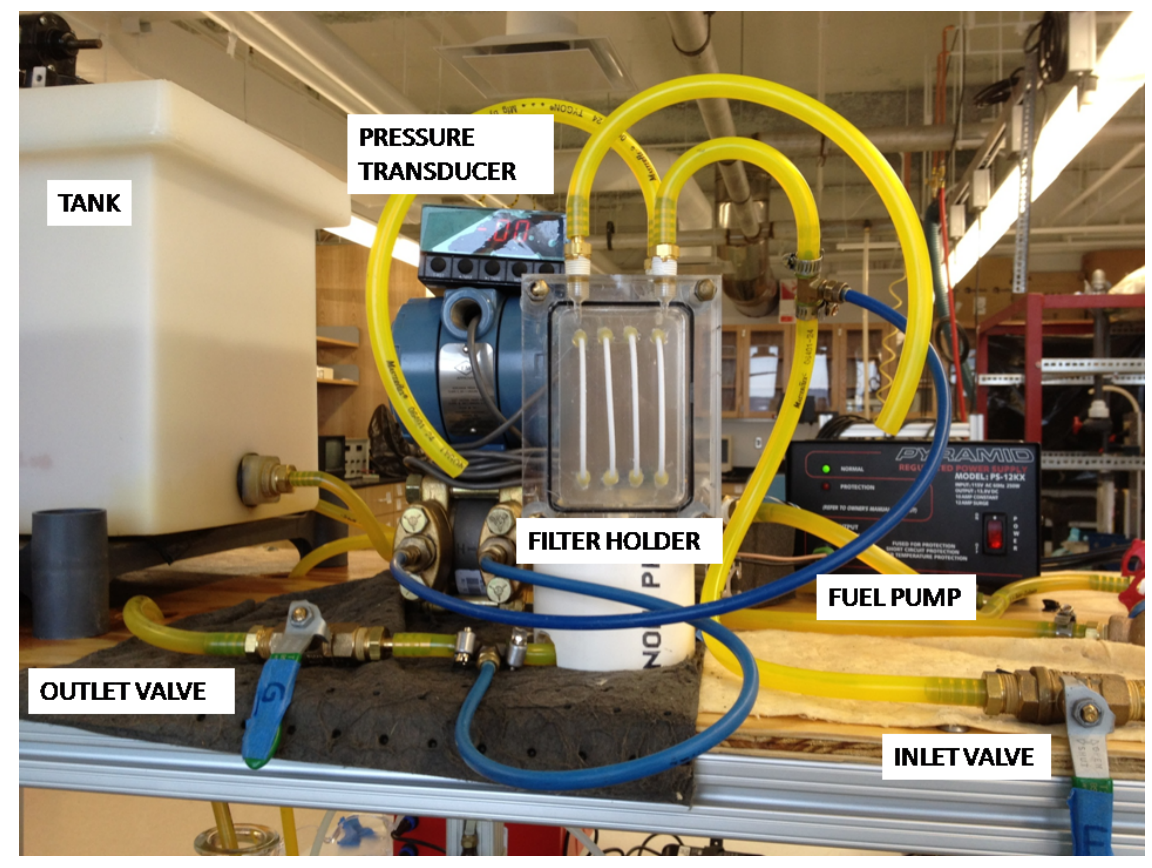

Figure 7.11: Experimental setup used to test the separation efficiency of tubular filter 


\section{CHAPTER VIII}

\section{EXPERIMENTAL RESULTS}

The objective of this work is to study the effect of surface curvature of the filter on its efficiency to separate secondary dispersion of water from diesel fuel. Tubular filters were fabricated by electrospinning polypropylene onto stainless steel compression springs. The developed filter media were characterized by measuring contact angle and later, were tested to evaluate their separation efficiency. This chapter describes the experimental results of tubular filter media tested for water-diesel separation. The effect of surface curvature and face velocity on separation efficiency of tubular filters were studied.

\subsection{Comparison of separation efficiency of a flat filter and a tubular filter}

To compare the performance of a flat filter with a tubular filter, $2 \%(\mathrm{w} / \mathrm{w})$ polypropylene was electrospun [94] onto a wire mesh of $0.01 \mathrm{~cm}^{2}$ pores as well as onto a stainless steel spring $(\mathrm{OD}=2.4 \mathrm{~mm}(0.094$ inches $))$ under the same electrospinning conditions. Example SEM images of fibers are shown in Figure 8.1. From the SEM images, beads on fibers were observed for both flat and tubular filter. The average diameters of fibers were calculated using length weighted method. The flat filter had an average fiber 
diameter of $0.489 \mu \mathrm{m}$ and the tubular filter had an average fiber diameter of 0.473 $\mu \mathrm{m}$, indicating the fiber ranges to be similar due to similar electrospinning conditions. The beads contribute to the hydrophobic nature of the fiber mat surface but because of their irregular sizes and shapes, there is not a convenient way to characterize them on the electrospun fiber mats. Length-weighted log-normal frequency fiber diameter distributions [98] are shown in Figure 8.2.
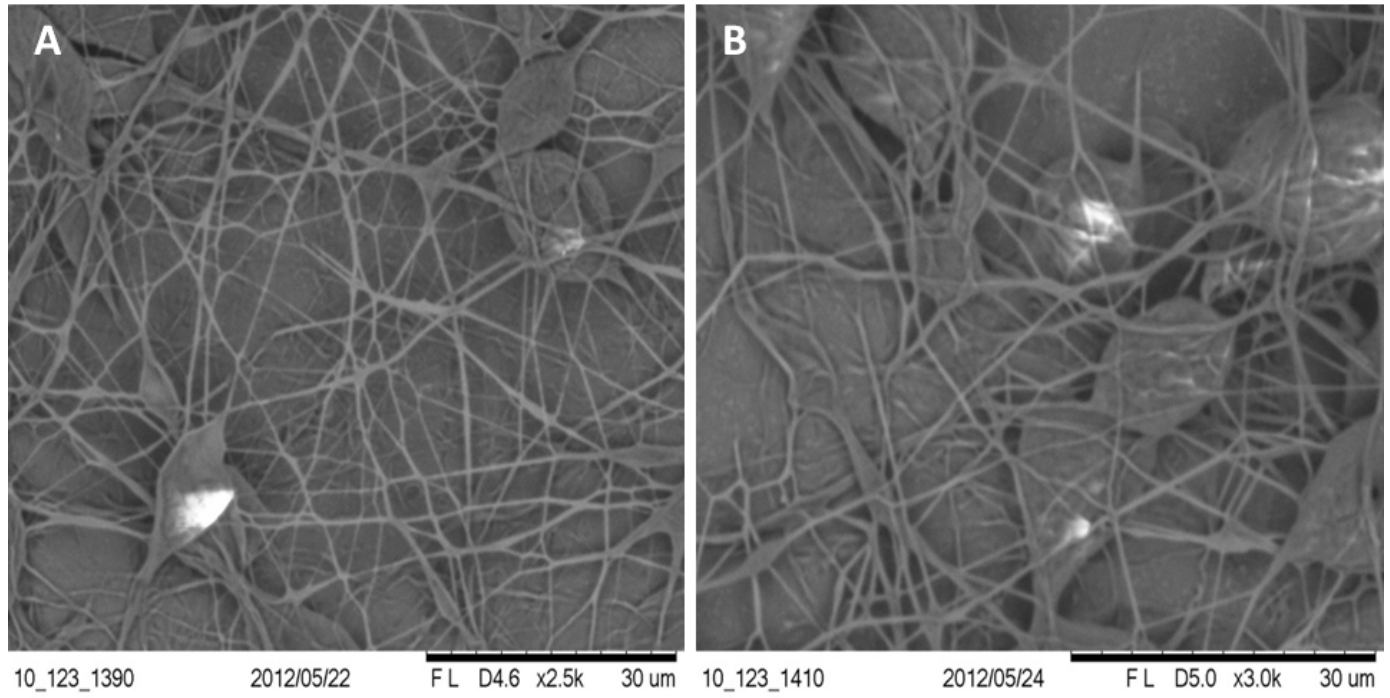

Figure 8.1: SEM pictures of nanofibers in the flat (A) and tubular (B) filter geometries 


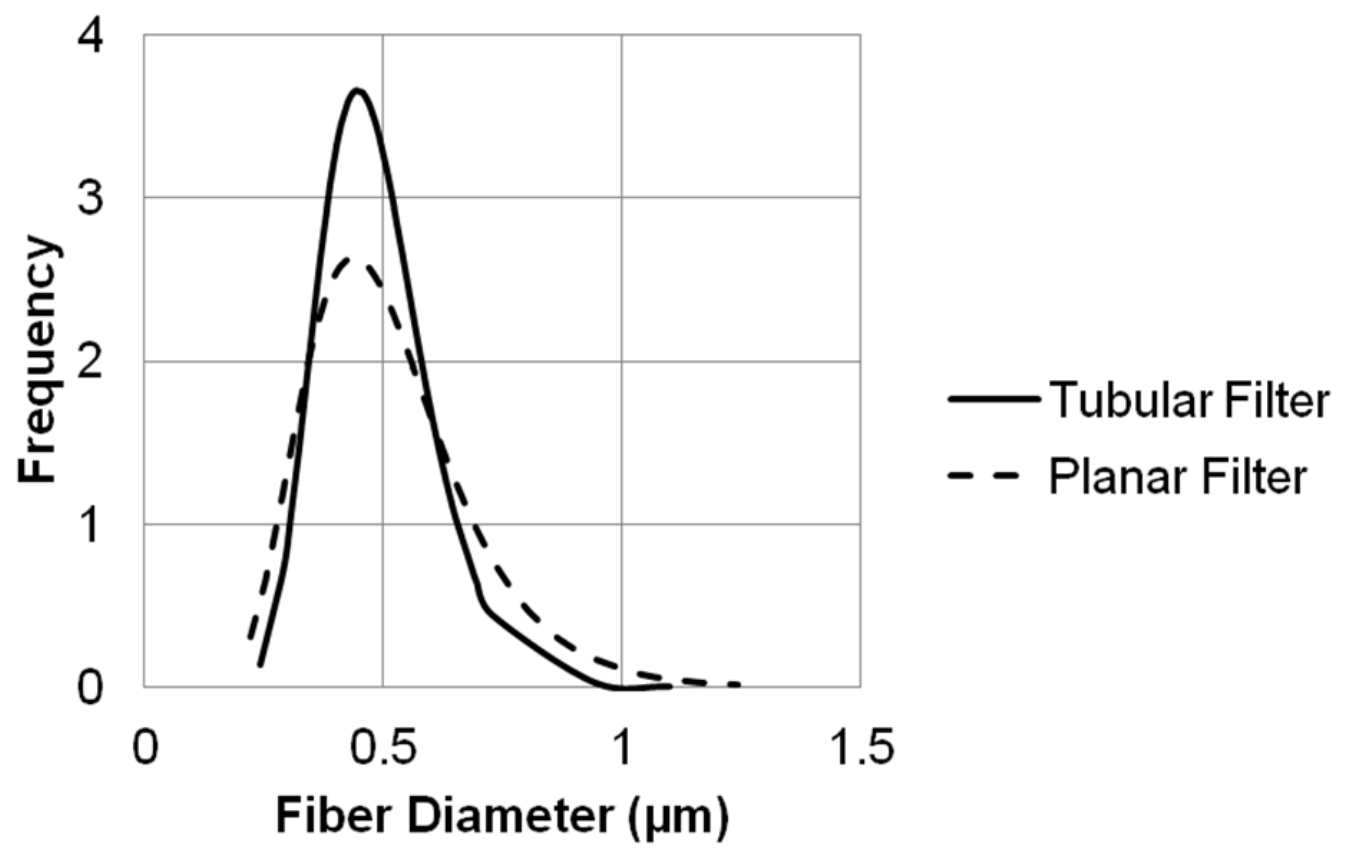

Figure 8.2: Comparison of length weighted log-normal frequency distribution of fiber diameters of the tubular and planar filters

These media were tested for their separation efficiency. The tubular filter holder was assembled with four tubular filters to provide a total filter surface area of $32.2 \mathrm{~cm}^{2}$. The filter holder was oriented with the tubular axes of the filters vertical to allow drops to roll off the surface along the length of the axis. Initially the water droplets on the nanofiber mat were observed to be very small as shown in Figure 8.3. As the experiment progressed the drops on the mat surface coalesced into larger drops. Once the drops became large, they were observed to roll off the tubular nanofiber mat due to gravity. The flat filter was held in a similar holder but the center part was replaced with Plexiglas plate with a square opening that held the flat nanofiber filter mat on a supporting rigid wire mesh (mesh openings were approximately $1 \mathrm{~mm}$ 
square). The filter holder was oriented such that the filter surface was vertical to allow drops to roll down the surface and the diesel flow was horizontal. The flat filter had a filter surface area of $103.2 \mathrm{~cm}^{2}$.

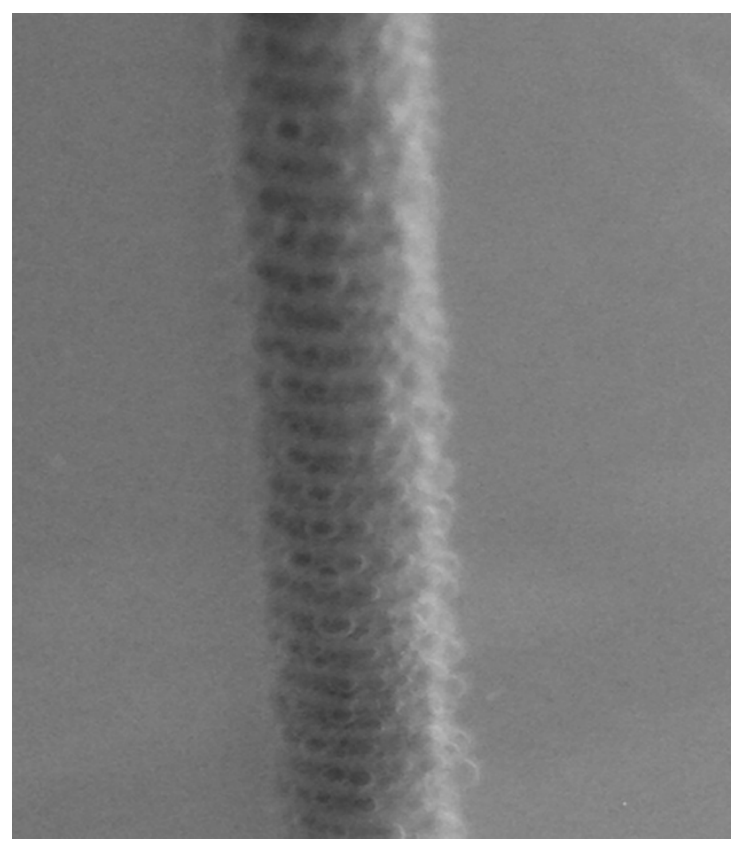

Figure 8.3: Magnified view of water droplets accumulated on the surface of the tubular nanofiber filter oriented with the axis vertical

The experimental parameters and the results obtained for the individual filters are listed in Table 8.1. Variations in the fabrication of the nanofiber mats and in the experimental conditions resulted in differences between the experiments in the thickness of the nanofiber mats the basis weights, and the face velocities. Ideally, these quantities should be the same to obtain a true comparison between the geometries, but these conditions were as close in value as could be obtained with the current 
experimental setup and electrospinning setup that gave uniform mat properties. The experimental results give an indication of how the performance of the two filters can differ.

The inlet and outlet stream steady state water droplet size distributions are shown in Figure 8.4 for the flat filter and in Figure 8.5 for the tubular filter. A comparison of the separation efficiency by drop size is shown in Figure 8.6.

Normally one would expect the flat fiber, having the thicker fiber mat media to have higher separation efficiency than the tubular filter with the thinner mat, but the opposite occurs here. The overall separation efficiency of the tubular filter was $98.9 \%$ and compared to the overall separation efficiency of $91.5 \%$ for the flat filter. We suspect the curvature of the tubular filter makes it easier for water droplets to roll off of the surface by gravity, perhaps due to a smaller contact line, than the planar filter surface. This results in less water accumulation on the surface of the tubular filter. The reduced water accumulation results in less pressure drop and less water penetration of the nanofiber mat and hence fewer and smaller droplets in the outlet stream compared to the planar filter.

The comparison between Figures 8.4 and 8.5 clearly shows the tubular filter separated more of the drops from the inlet stream. The flat filter had a significantly greater number of fine drops in the outlet stream in the of 1 - 30 micron size range 
than the tubular filter. This is more dramatically shown in Figure 8.6 where the flat filter was effective at separating drops larger than about 20 microns but the tubular filter was effective at separating drops starting at about 7 microns.

The surface tension force which resists the drop from rolling by gravity is proportional to the length of the three-phase contact line. Tubular geometry is expected to result in shorter contact lines than that for similar volume drops with the same contact angle on a planar surface. The reduction in surface force should allow smaller droplets to roll by gravity on cylindrical surfaces, thus more effectively removing the accumulated water and reducing the amount of water available to be pushed through the nanofiber layer by the pressure drop across the filter. This in turn increases the separation efficiency.

The change of efficiency with face velocity for both flat and tubular filter is shown in Figure 8.7. As expected, the separation efficiency decreases with face velocity. At higher face velocities, the filter operates at a higher pressure drop. The pressure required to push a drop through a pore is related to the pore size, the drop size, and the surface tension [33]. As the pressure drop goes up, more drops will be pushed through the filter and thus the efficiency will decrease.

In the design of water-diesel separators for diesel engine applications the face velocity can be adjusted by changing the filter area for a given flow rate range. In our 
experiments, practical considerations for sampling the flow streams to determine drop size distributions limited the tubular filter experiments to a minimum face velocity of about $1.55 \mathrm{~cm} / \mathrm{min}$. The flat filter had limitations in the maximum flow rate to avoid separation of the nanofiber membrane from the supporting wire mesh, resulting in a maximum practical face velocity of $1.55 \mathrm{~cm} / \mathrm{min}$ for the given experimental setup. The experimental results show the tubular filter performed at higher efficiency with the same face velocity than the flat filter. This means that filters with tubular geometry can be constructed more compactly with smaller filter areas for the same separation performance as compared with the flat filter geometries.

Table 8.1: Comparison of parameters and results for the two nanofiber filter geometries.

PARAMETERS

\begin{tabular}{lll}
\hline \hline Thickness of the nanofiber mat $(\mathrm{mm})$ & 0.81 & 0.49 \\
Face velocity (cm/min) & 1.55 & 1.55 \\
Pressure drop (psi) & 0.38 & 0.27 \\
Inlet filter area $\left(\mathrm{cm}^{2}\right)$ & 103.2 & 32.2 \\
Efficiency (mass basis, \%) & 91.5 & 98.7 \\
\hline
\end{tabular}




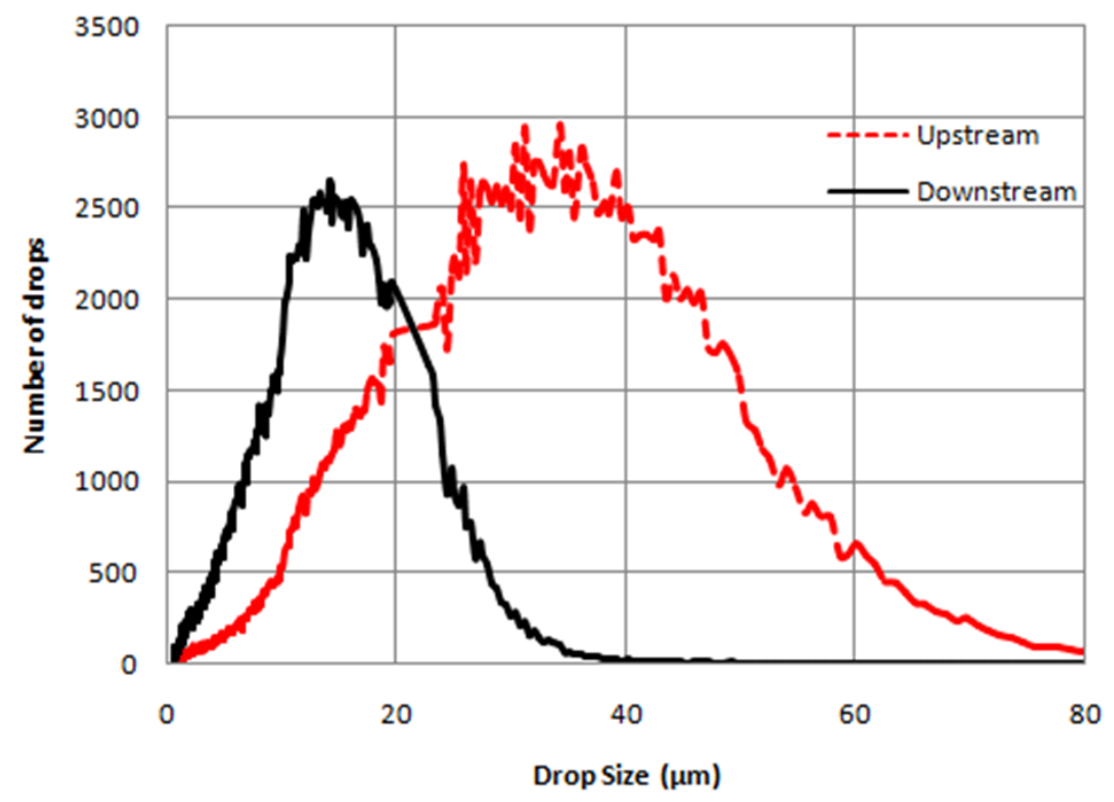

Figure 8.4: Comparison of inlet and outlet stream water droplet size distributions of the planar filter

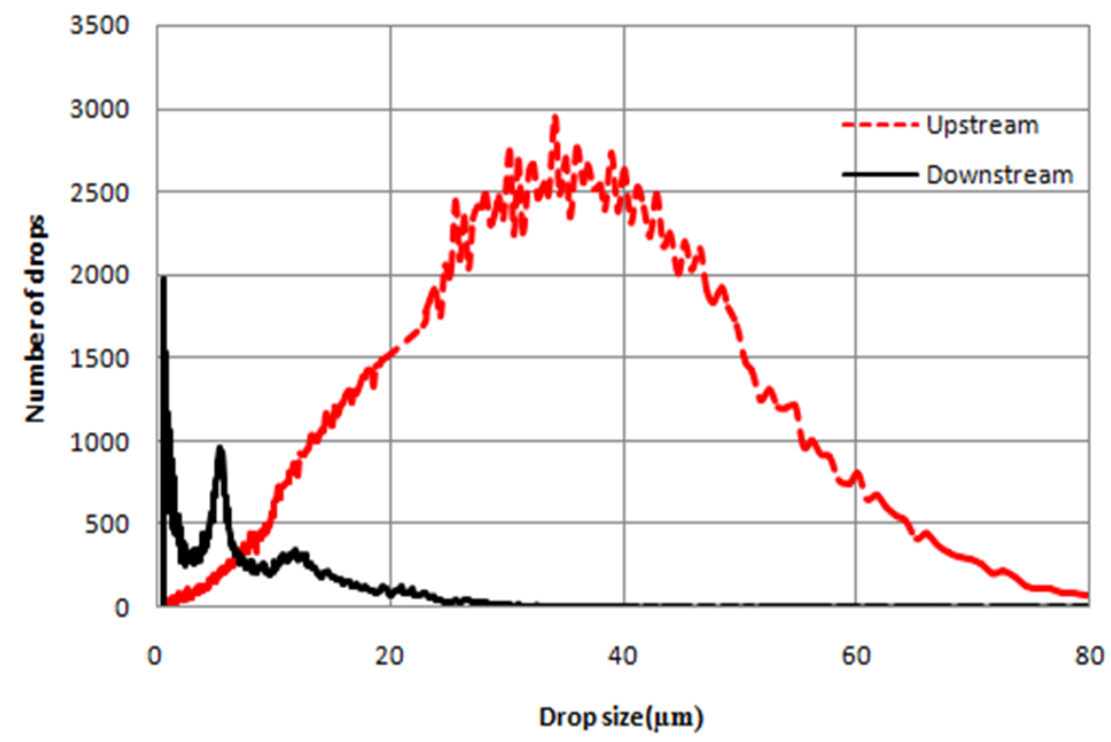

Figure 8.5: Comparison of inlet and outlet stream water droplet size distributions of the tubular filter 


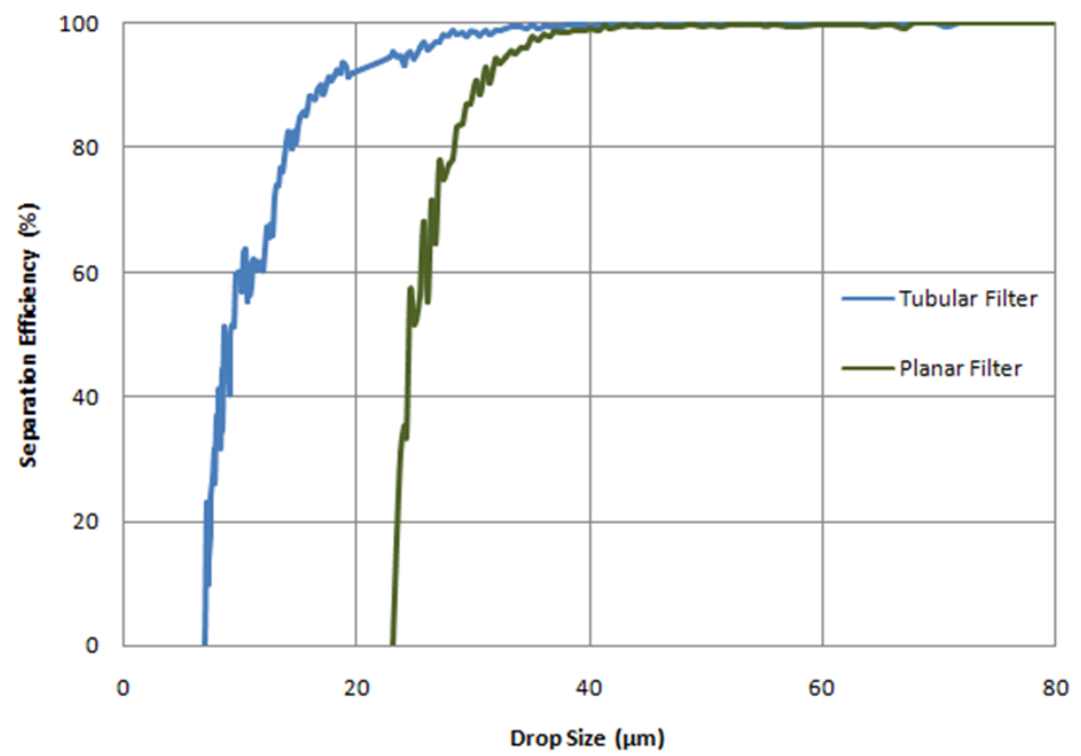

Figure 8.6: Comparison of separation efficiency by drop size

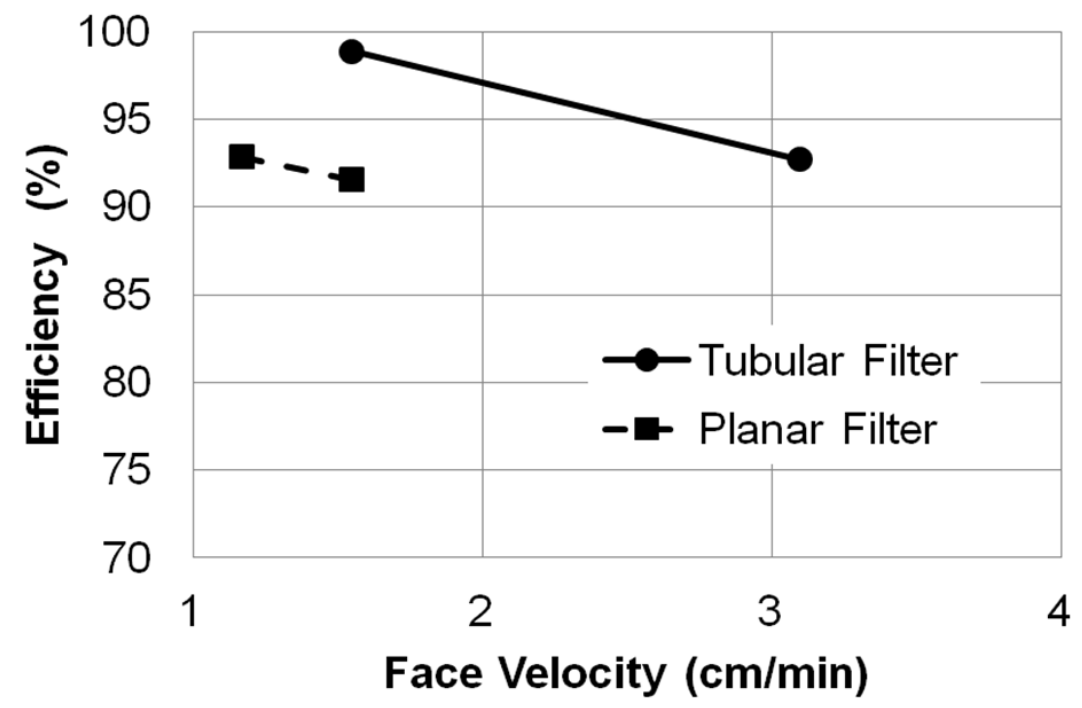

Figure 8.7: Change of efficiency with face velocity for tubular and flat filter 
8.2 Dependence of separation efficiency on the curvature of tubular filter

Tubular filters were fabricated by electrospinning $2 \%(\mathrm{w} / \mathrm{w})$ polypropylene [94] onto springs of two different diameters under the same electrospinning conditions. The first spring had an outer diameter of $2.4 \mathrm{~mm}$ (0.094 inches) and the second one had an outer diameter of $4.75 \mathrm{~mm}$ (0.187 inches). These media were tested for their separation efficiency. Tubular filter holder was assembled with tubular filters fabricated from similar springs to provide a total filter surface area of $32.2 \mathrm{~cm}^{2}$. Since the outer diameter of springs is different, the number of tubular filters in the filter holder is not the same in both the cases. The filter holder was oriented with the tubular axes of the filters vertical to allow drops to roll off the surface along the length of the axis. In all the experiments, a face velocity of $1.55 \mathrm{~cm} / \mathrm{min}$ was maintained.

Results are summarized in Figure 8.8. Experiments were run in triplicate. The average separation efficiency is reported and the error bar corresponds to one standard deviation. The inlet and outlet stream steady state water droplet size distributions are shown in Figure 8.9 for tubular filter with spring outer diameter $2.4 \mathrm{~mm}$ and in Figure 8.10 for tubular filter with spring outer diameter $4.75 \mathrm{~mm}$. A comparison of the separation efficiency by drop size is shown in Figure 8.11. 


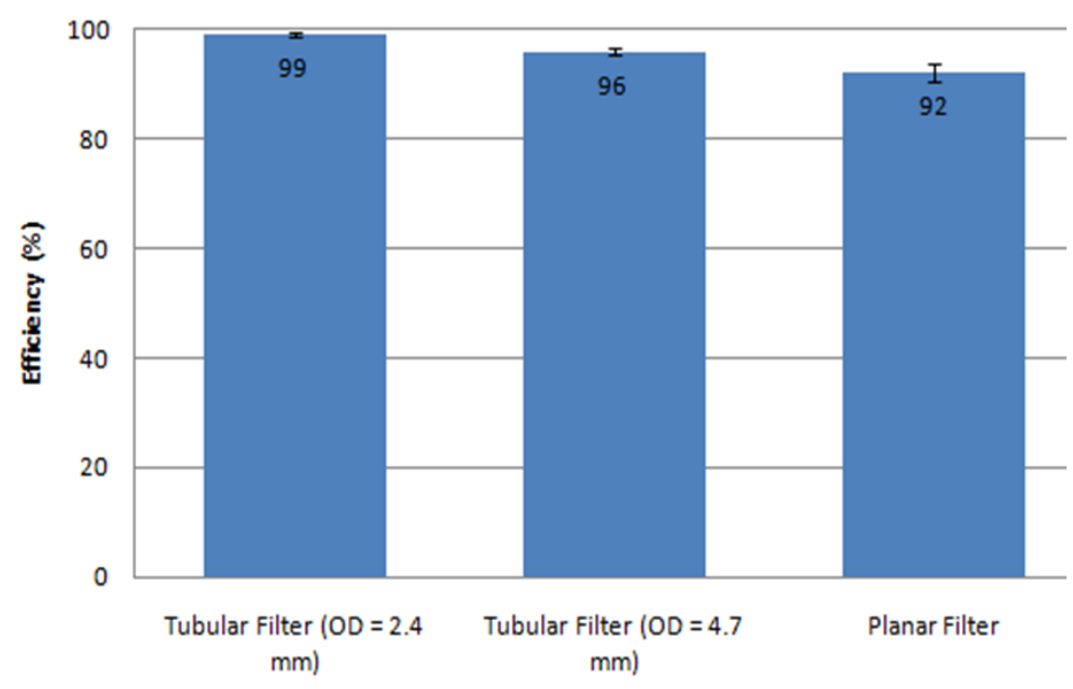

Figure 8.8: Effect of curvature on the separation efficiency of filter media. The average separation efficiency is reported and the error bar corresponds to one standard deviation

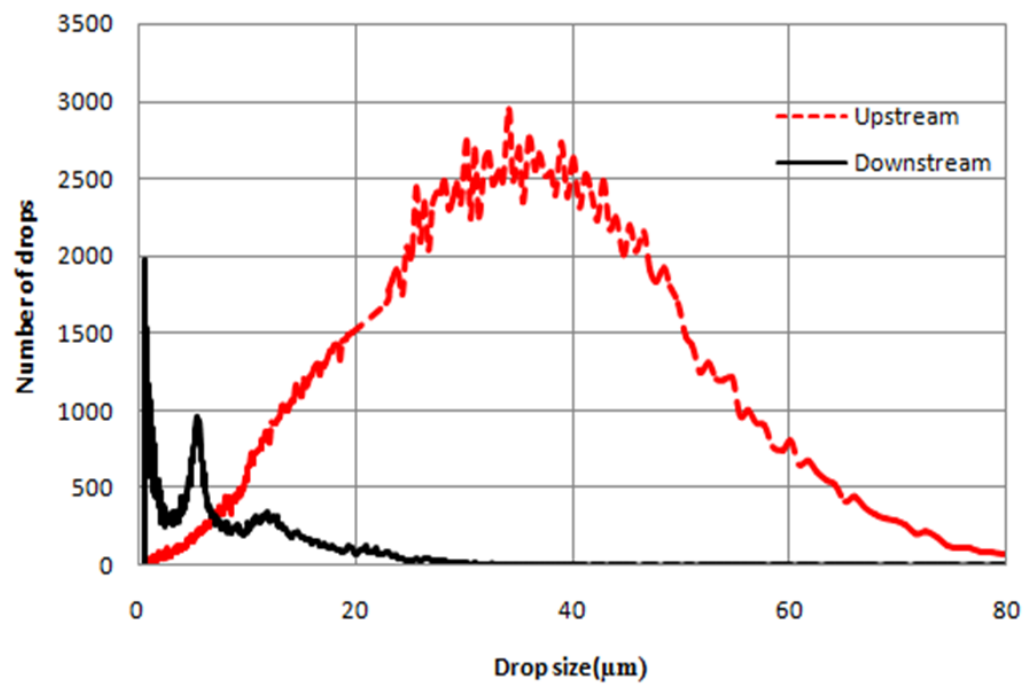

Figure 8.9: Comparison of inlet and outlet stream water droplet size distributions of the tubular filter with spring outer diameter $2.4 \mathrm{~mm}$ 


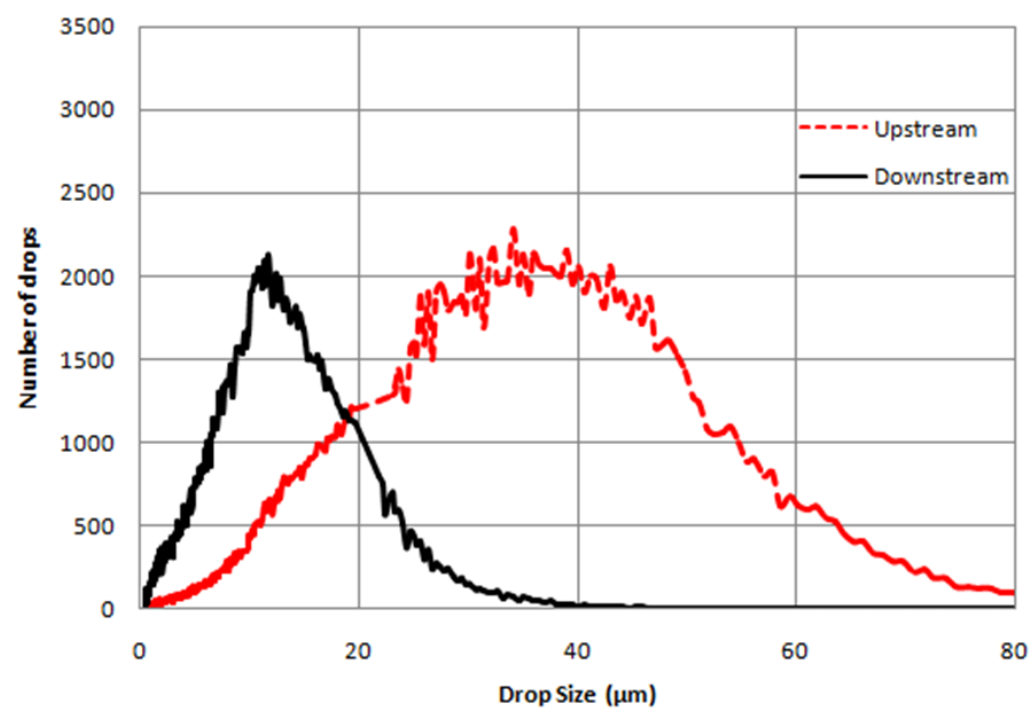

Figure 8.10: Comparison of inlet and outlet stream water droplet size distributions of the tubular filter with spring outer diameter $4.7 \mathrm{~mm}$

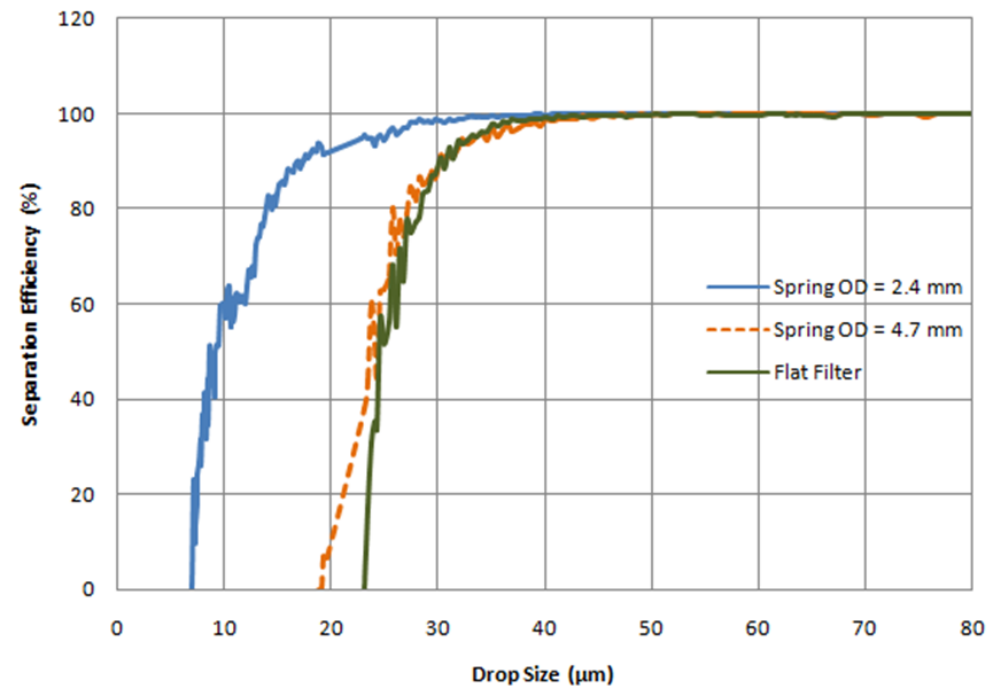

Figure 8.11: Comparison of separation efficiency by drop size 


\subsection{Dependence of separation efficiency of tubular filter on face velocity}

Tubular filters were fabricated by electrospinning $2 \%(\mathrm{w} / \mathrm{w})$ polypropylene [94] onto stainless steel compression springs under the same electrospinning conditions. The outer diameter of the spring was $2.4 \mathrm{~mm}$ (0.094 inches) and $76 \mathrm{~mm}$ (3 inches) in length. The spring had a wire diameter of $0.33 \mathrm{~mm}$ (0.013 inches). These media were tested for their separation efficiency. Tubular filter holder was assembled with tubular filters. The filter holder was oriented with the tubular axes of the filters vertical to allow drops to roll off the surface along the length of the axis.

The face velocity is defined as the ratio of volumetric flow rate to the area of the filter

$$
\mathrm{F}=\frac{Q}{A}
$$

Where, $\mathrm{Q}=$ volumetric flow rate and $\mathrm{A}=$ area of the filter. From the definition of face velocity, its value can be varied by either changing the volumetric flow rate or the area of the filter. Dependence of separation efficiency on the face velocity is studied in two different cases. In the first case, the total filter area is kept constant while the volumetric flow rate is varied. In the second case, the volumetric flow rate is kept constant while the total area of the filter, i.e the number of tubular filters in the filter holder is varied. 
In the first case, experiments were run at different face velocities and the separation efficiency of tubular filter was evaluated. The total filter area, i.e the number of tubular filters in the filter holder is maintained constant in all the experiments while the upstream flow rate was varied. The tubular filter holder was assembled with four tubular filters to provide a total filter surface area of $32.2 \mathrm{~cm}^{2}$. Results are summarized in Figure 8.12. Experiments were run in triplicate. The average separation efficiency is reported and the error bar corresponds to one standard deviation.

In the second case, experiments were run at two different face velocities (25 $\mathrm{cm} / \mathrm{min}$ and $12.5 \mathrm{~cm} / \mathrm{min}$ ) and the separation efficiency of the tubular filter was evaluated. The upstream flow rate is maintained constant in all the experiments (Flow rate $=200 \mathrm{ml} / \mathrm{min})$ while the total area of the filter, i.e the number of tubular filters in the filter holder was varied. Tubular filter in both the cases were made by electrospinning equal volumes of polypropylene solution onto stainless steel compression springs under the similar electrospinning conditions. Results are summarized in Figure 8.13. The average separation efficiency is reported and the error bar corresponds to one standard deviation. Comparison of water droplet size distribution on the upstream and downstream of the filter media at different face velocities for both the cases are as shown in Figures 8.14 - 8.20. 


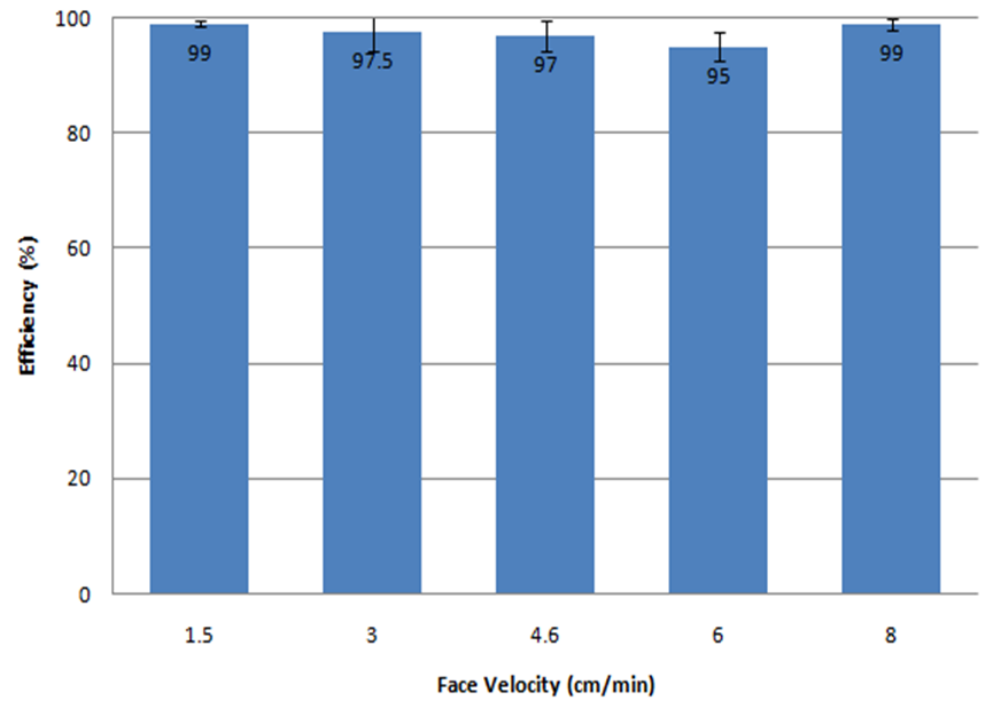

Figure 8.12: Effect of face velocity on separation efficiency for tubular filter (filter area is constant)

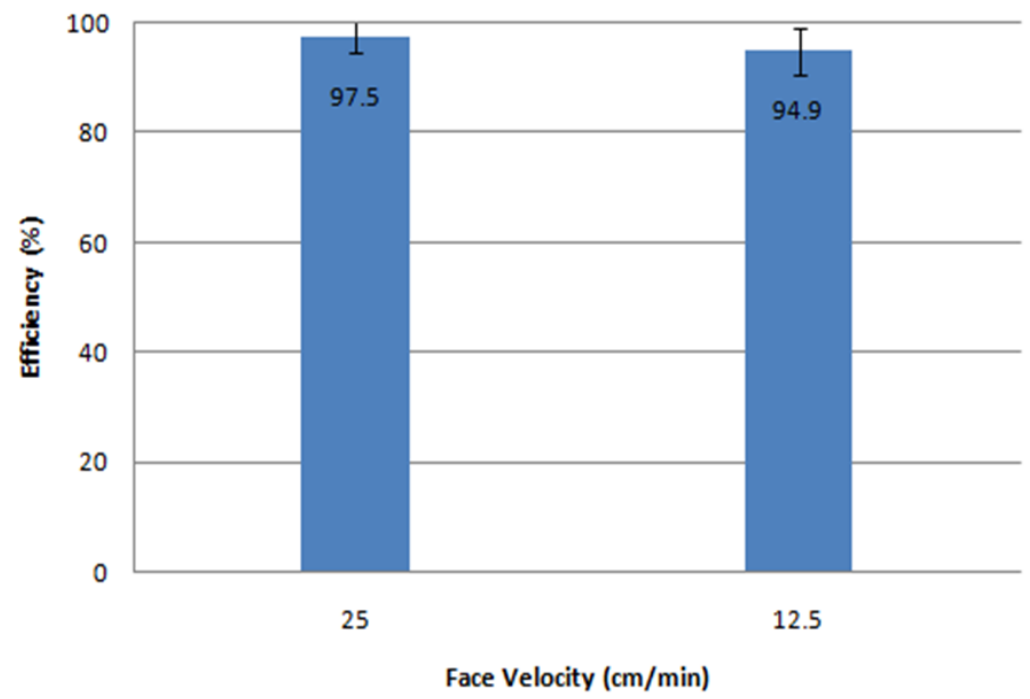

Figure 8.13: Effect of face velocity on separation efficiency for tubular filter (upstream flow rate is constant) 


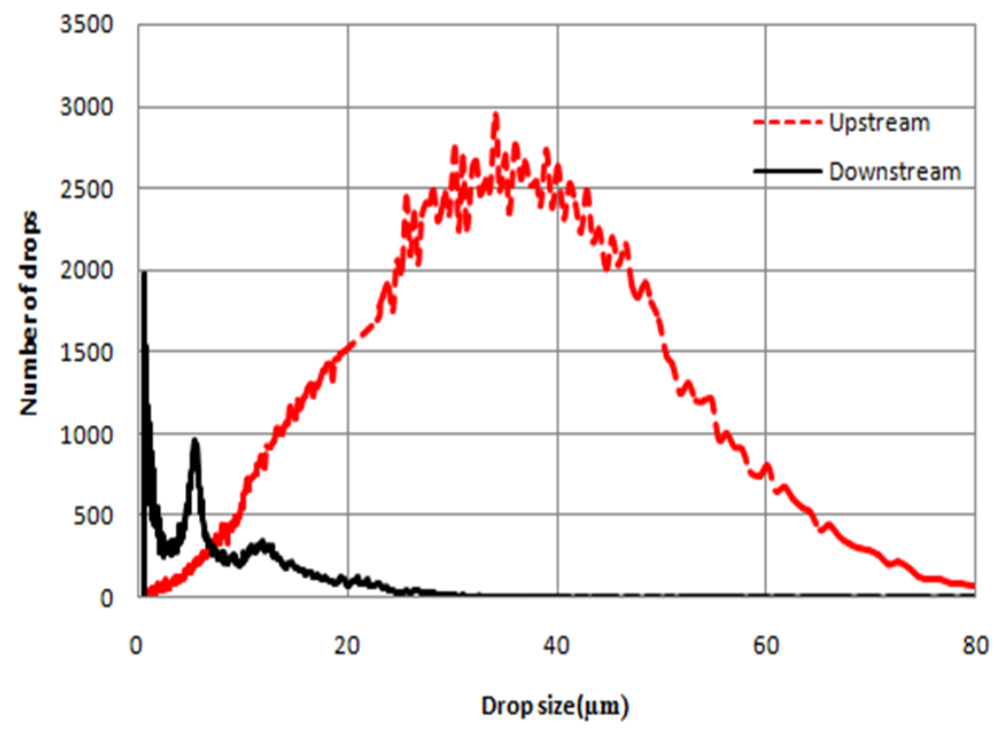

Figure 8.14: Comparison of inlet and outlet stream water droplet size distributions of the tubular filter at a face velocity of $1.55 \mathrm{~cm} / \mathrm{min}$

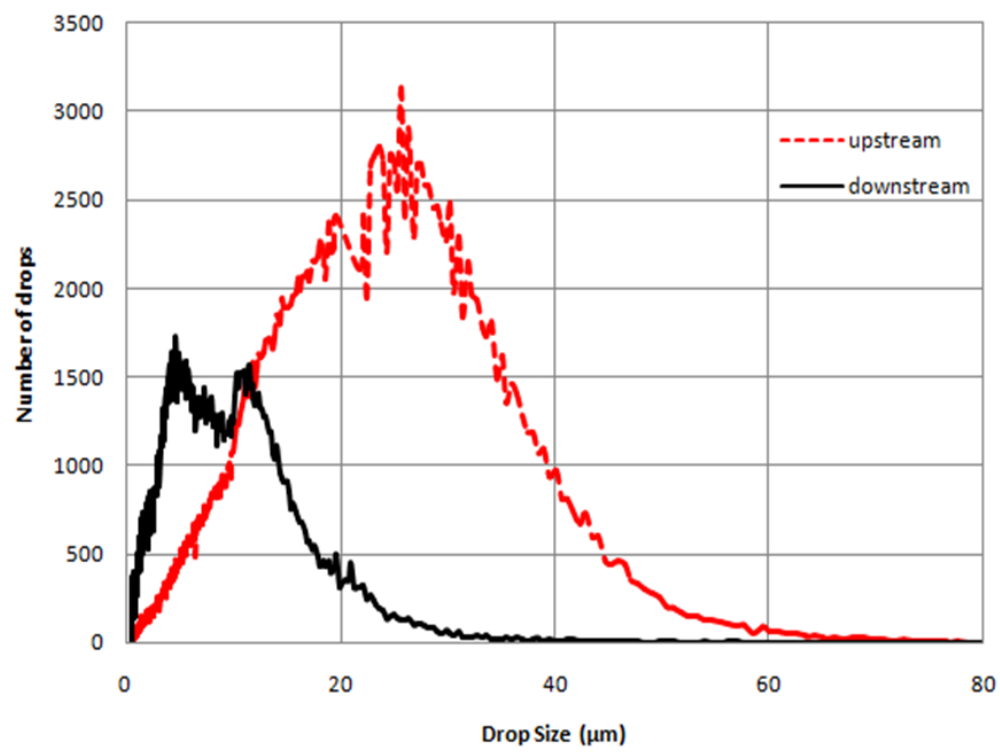

Figure 8.15: Comparison of inlet and outlet stream water droplet size distributions of the tubular filter at a face velocity of $3 \mathrm{~cm} / \mathrm{min}$ 


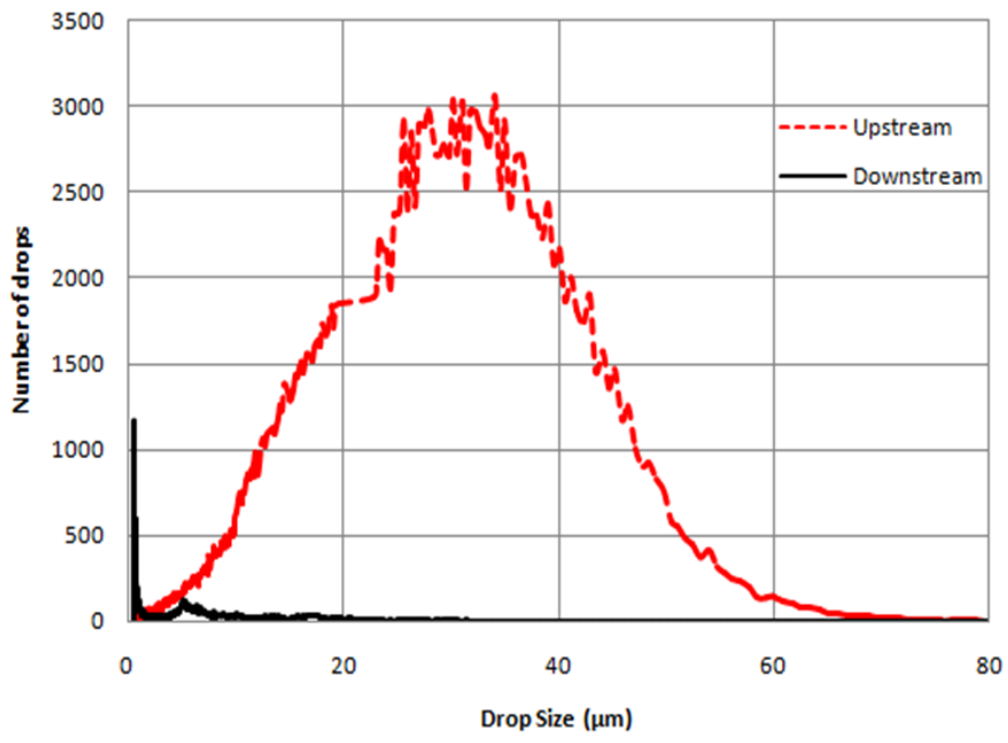

Figure 8.16: Comparison of inlet and outlet stream water droplet size distributions of the tubular filter at a face velocity of $4.6 \mathrm{~cm} / \mathrm{min}$

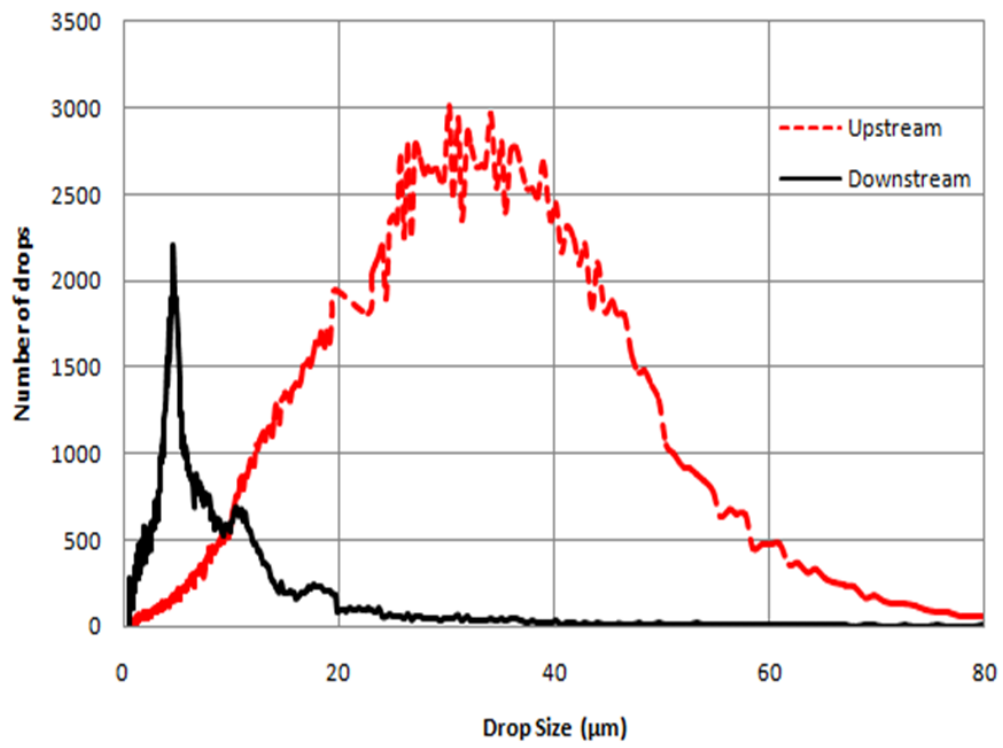

Figure 8.17: Comparison of inlet and outlet stream water droplet size distributions of the tubular filter at a face velocity of $6 \mathrm{~cm} / \mathrm{min}$ 


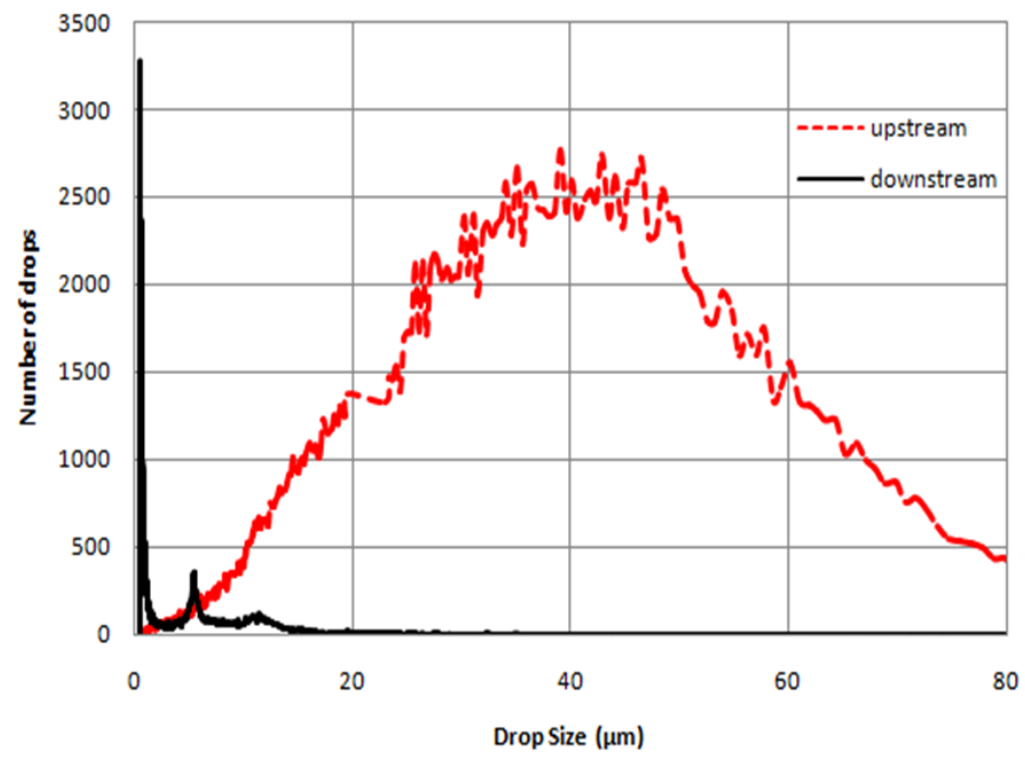

Figure 8.18: Comparison of inlet and outlet stream water droplet size distributions of the tubular filter at a face velocity of $8 \mathrm{~cm} / \mathrm{min}$

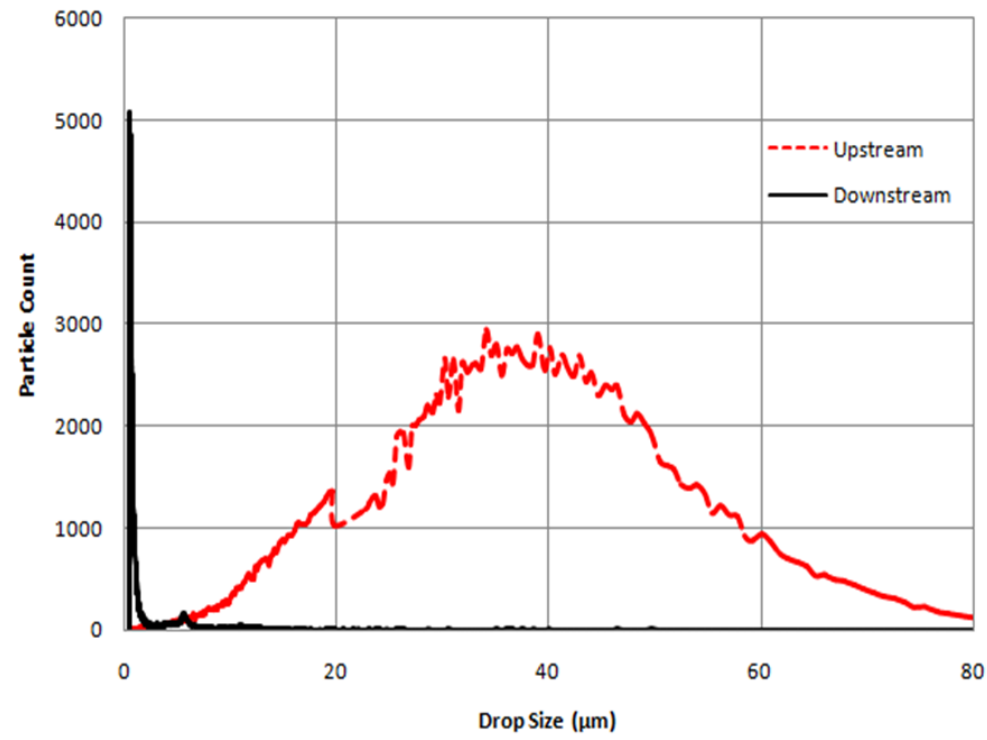

Figure 8.19: Comparison of inlet and outlet stream water droplet size distributions of the tubular filter at a face velocity of $12.5 \mathrm{~cm} / \mathrm{min}$ 


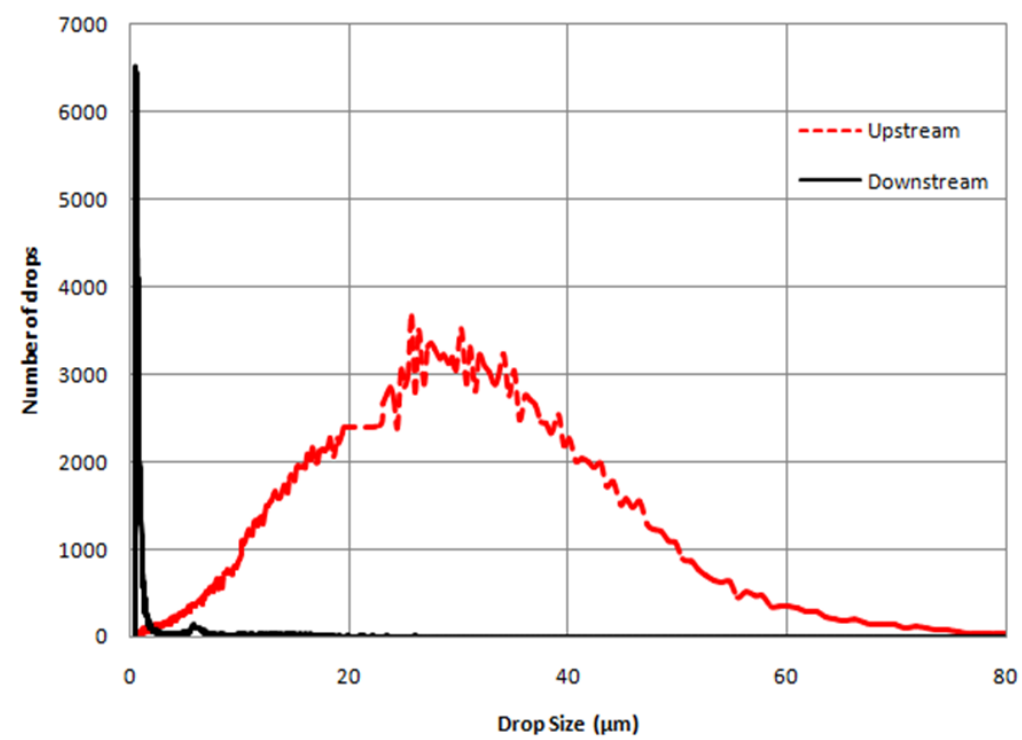

Figure 8.20: Comparison of inlet and outlet stream water droplet size distributions of the tubular filter at a face velocity of $25 \mathrm{~cm} / \mathrm{min}$

\subsection{Conclusion}

In this work, electrospun fiber mats were created on compression springs to form superhydrophobic tubular filters. The tubular filter was tested for separation of water from a water-in-diesel dispersion. The tubular filter performed much more efficiently than a flat filter of the same material under similar conditions showing that surface curvature of the filter media has an effect on its performance. The tubular filter performed with high separation efficiency at very high face velocity. This work shows practical nanofiber mat filters for separation of water-diesel dispersions can be constructed in compact tubular geometries. 


\section{CHAPTER IX}

\section{CONCLUSIONS}

Superhydrophobic surfaces have contact angles that exceed 150 degrees and are known to reduce surface fouling, protect surfaces, and improve liquid-liquid separations. Superhydrophobic behavior is typically measured on planar surfaces whereas applications may require curved surfaces. In this work, an equation is derived that relates the radius of curvature of spherical and cylindrical surfaces and drop size to the observed contact angle on the curved surfaces. Electrospun sub-micron fiber mats can perform as superhydrophobic surfaces. Experiments are conducted with drops on superhydrophobic curved surfaces fabricated from mats of electrospun fibers. The measurement of water contact angles on curved surfaces is described in Chapter III. The derived equation agrees reasonably well with the experimental data for both cylindrical and spherical surfaces and can be used to study the effect of curvature on the contact angle. The effect of liquid drop volume on the contact angle for a curved surface can also determined. This equation can be useful to estimate the effects of surface curvature on apparent contact angles.

Superhydrophobic surfaces can be used as barriers to separate secondary dispersions of water from organic liquids. Water droplets accumulate on the surface and 
coalesce into larger drops. Once they become large enough, gravity pulls the drop down vertical surfaces and uncovers surface area for organic fluid flow and capture of additional water droplets. The surface tension force that holds a drop to the surface is proportional to the length of the three phase contact line. In this work, the hypothesis that curved surface results in shorter contact lines when compared to a planar surface is applied. Equations are derived to calculate the length of three phase contact line of a drop on planar as well as spherical surface. Experiments are conducted with drops on hydrophobic spherical and planar surfaces fabricated from mats of electrospun fibers. The measurement of water contact angles on these surfaces is described in Chapter IV. The derived equations agree reasonably well with the experimental data for both planar and spherical surfaces. Results show that similar drops have shorter contact lines on curved surfaces when compared to planar surfaces. Hence, this work shows that the force holding a drop to a vertical curved surface (such as a cylinder) will be less than the force holding a drop to a planar surface. This reduction in force should allow smaller drops to roll off of curved surfaces than flat surfaces. This is expected to increase the efficiency of water - oil separation.

Electrospinning is a well known process for fabricating sub-micron size fibers. A high voltage potential is used in electrospinning to launch a polymer jet from a droplet of polymer solution towards a grounded collector. Most of the electrospun fibers collect on the grounded collector, but depending on the design of the electrospinning apparatus and the environment, some of the fibers drift away from the 
collector and are captured on other objects. In this work, the hypothesis that the electrospinning jet follows the path of the electric fields current density lines is applied. By controlling the direction of the current density lines one can control the path of the electrospinning jet and hence can control the location of where the fibers are collected. The static electric field was modeled by numerically solving Laplaces equation for the potential field. Electrospinning experiments were conducted with the same geometric arrangement of electrodes for comparison as described in Chapter V. Experimental results show the electrospinning jets tend to follow the electric field current density lines calculated in the model. By modifying the current density lines with secondary electrodes, the electrospinning jets diverted away from objects in the electrospinning environment. The presence of the secondary electrodes significantly increased the percentage of polymeric fibers collected on the intended grounded collector. This work shows it is possible to direct the electrospinning jets away from undesired objects by use of secondary electrodes.

In many industrial applications water-in-oil dispersions are separated for safety, ecological and economic reasons. Water droplets with diameters greater than 100 microns are normally easy to separate using gravity settling. Separation of secondary dispersions with droplets smaller than 100 microns are more difficult. Recent developments in fabrication of submicron sized fiber mats by electrospinning offer opportunities to improve the separations of secondary dispersions. The electrospun membranes have large surface area-to-mass ratios and small pores, making them 
ideal materials for use in filtration applications. Previous investigations of superhydrophobic nanofiber membranes generally consider flat planar surfaces. In this work, electrospun fiber mats were created on compression springs to form superhydrophobic tubular filters as described in Chapter VI. The compression spring covered with the syndiotactic polypropylene nanofiber mat repelled water in air and when submerged in diesel fuel. Electrospun fiber mats were created on a flat wire mesh to form superhydrophobic planar filters. The tubular filter and planar filter were tested for separation of water from a water-in-diesel dispersion as described in Chapter VII. The cylindrical nanofiber filters performed with separation efficiency as high as $98 \%$ on a total mass basis for water drops in the range of 7-50 microns in ultra low sulphur diesel fuel (ULSD) with a face velocity of $1.55 \mathrm{~cm} / \mathrm{min}$. The flat filter geometry performed at about $92 \%$ separation efficiency at a similar face velocity. The tubular filter performed much more efficiently than a flat filter of the same material under similar conditions showing that surface curvature of the filter media has an effect on its performance. The effect of face velocity on the separation efficiency of tubular filter is studied and it performed with high efficiency at very high face velocity. This work shows that practical nanofiber mat filters for separation of water-diesel dispersions can be constructed in compact tubular geometries. 


\section{CHAPTER X}

\section{FUTURE WORK}

The recommendations for future work are as below:

1. The effect of surface curvature on the separation efficiency of tubular filter was studied with Ultra low sulfur diesel (ULSD) of interfacial tension (IFT) 22 $\mathrm{mN} / \mathrm{m}$. This study can be extended by lowering the IFT of ULSD to a value below $15 \mathrm{mN} / \mathrm{m}$. The IFT can be lowered by the use of surfactants. At low IFT, water drops show resistance to coalescence and it would be of interest as to observe how the tubular filter would perform.

2. During the evaluation of performance of the tubular filter, the average diameter of water drops on the upstream was maintained at 35 microns. Water-diesel emulsion was created using a fuel pump. Initially, the system was run under complete recycle for 10 minutes. The high RPM of the fuel pump sheared the bigger drops into finer drops. This helped to obtain a steady emulsion on the upstream. This study could be extended by lowering the average diameter of water drops on the upstream. By lowering the average diameter, the tubular filter is challenged with a finer emulsion and it would be interesting to observe its performance. One recommendation to lower the average diameter would be 
to increase the recycling time at the beginning of the experiment. This would give the drops sufficient time to be broken down into tiny droplets. Second recommendation would be to lower the concentration of water in the waterdiesel mixture.

3. In this work, the effect of face velocity on the separation efficiency of tubular filter was studied. The maximum face velocity maintained was $25 \mathrm{~cm} / \mathrm{min}$. The tubular filter performed with an average separation efficiency of $97.5 \%$. This study could be extended to higher face velocity to evaluate the performance of the tubular filter.

4. Biodiesel is emerging as an alternative fuel to ULSD. This leads to the modification of current filtration techniques in diesel engines. This work could be extended to study the performance of tubular filter when challenged with waterbiodiesel emulsion.

5. Equation C.13 (Appendix C) was derived to calculate the length of three phase contact line of drops on hydrophobic spherical surfaces. This study could be extended to derive an equation to calculate the length of three phase contact line of drops on cylindrical surfaces. This would help to understand and improve the behavior of tubular filter.

6. The electric field model was applied to improve the collection of fibers on the collector during the fabrication of tubular filters. The study could be extended to model the electric field to get uniform thickness of polymer on curved sur- 
faces. The electric field model was studied for one particular situation but this work could be extended to different electrospinning scenarios like the multi-jet or the nano yarn. 


\section{BIBLIOGRAPHY}

[1] C. Stanfel. Fuel filtration: Protecting the diesel engine. Filtration + Separation, pages 22-24, 2009.

[2] J. Combest. Fuel filtration in the automotive industry. Filtration and Separation, pages 309-312, 1992.

[3] Y. Li and J. Schnable. Solving water contamination problems in lubrication oil. Filtration + Separation, pages 18-21, 2000.

[4] X. Ma, A. Zhou, and C. Song. A novel method for oxidative desulfurization of liquid hydrocarbon fuels based on catalytic oxidation using molecular oxygen coupled with selective adsorption. Catalysis Today, 123:276-284, 2007.

[5] W. F. De Souza, L. R. Guimaraes, M. C. Guerreiro, and L. C. A. Oliveira. Catalytic oxidation of sulfur and nitrogen compounds from diesel fuel. Applied Catalysis A: General, pages 205-209, 2009.

[6] http://www.dieselfuelfilterings.com/process.cause.html. (accessed March, 2011).

[7] http://www.afssociety.org/articles/automotive/water-contamination-in-fuel-causeand-effect. (accessed March, 2011).

[8] C. H. May. The separation of water from oil by principle of coalescence. Journal of the American Society of Lubrication Engineers, 18th ASLE Annual Meeting:327332, 1963.

[9] R. Magiera. Separation of liquid-liquid dispersions by flow through fibre beds. Filtration and Separation, pages 369-375, 1997.

[10] J. H. Raistrick. Fibrous material for the filtration of liquids. Composites, pages 206-208, 1979.

[11] R. C. Brown. Air Filtration: An integrated approach to the theory and applications of fibrous filters. Pergamon Press, New York, 1993. 
[12] C. Shin and G. G. Chase. The effect of nanofibers on liquid-liquid coalescence filter performance. AIChE Journal, 51:3109-3113, 2005.

[13] C. Shin and G. G. Chase. Water in oil coalescence in micro nanofiber composite filters. AIChE Journal, 50:343-350, 2004.

[14] K. Moorthy. Effect of surface energy of fibers on coalescence filtration. Masters thesis, The University of Akron, 2007.

[15] P. S. Kulkarni. Mixed hydrophilic/hydrophobic fiber media for liquid-liquid coalescence. Phd thesis, The University of Akron, 2011.

[16] X. Yao, Y. Song, and L. Jiang. Applications of bio-inspired special wettable surfaces. Advanced Materials, 23:719-734, 2011.

[17] P. S. Kulkarni, S. U. Patel, and G. G. Chase. Layered hydrophilic/hydrophobic fiber media for water-in-oil coalescence. Separation and Purification Technology, 85:157-164, 2012.

[18] U. Daiminger, W. Nitsch, P. Plucinski, and S. Hoffmann. Novel techniques for oil/water separation. Journal of Membrane Science, pages 197-203, 1997.

[19] N. Bhardwaj and S. C. Kundu. Electrospinning: A fascinating fiber fabrication technique. Biotechnology Advances, 28:325-347, 2010.

[20] C. Burger, B. S. Hsiao, and B. Chu. Nanofibrous materials and their applications. Annu. Rev. Mater, 36:333-368, 2006.

[21] X. H. Qin and S. Y. Wang. Filtration properties of electrospinning nanofibers. Journal of Applied Polymer Science, 102:1285-1290, 2006.

[22] S. Agarwal, J. H. Wendroff, and A. Greiner. Use of electrospinning technique for biomedical applications. Polymer, 49:5603-5621, 2008.

[23] L. Buttafoco, N. G. Kolkman, P. E. Buijtenhujis, A. A. Poot, P. J. Dijkstra, I. Vermes, and J. Feijen. Electrospinning of collagen and elastin for tissue engineering applications. Biomaterials, 27:724-734, 2006.

[24] R. Dersch, M. Steinhart, U. Boudriot, A. Greiner, and J. H. Wendorff. Nanoprocessing of polymers-applications in medicine, sensors, catalysis and photonics. Polym. Adv. Tech, 16:276-282, 2005. 
[25] Z. Dong, S. J. Kennedy, and Y. Wu. Electrospinning materials for energy-related applications and devices. Journal of Power Sources, 196:4886-4904, 2011.

[26] C. W. Extrand and Y. Kumagai. Liquid drops on an inclined plane: The retention between contact angles, drop shape, and retentive force. Journal of Colloid and Interface Science, 170:515-521, 1995.

[27] F. Milinazzo and M. Shinbrot. A numerical study of a drop on a vertical wall. Journal of Colloid and Interface Science, 121:254-264, 1988.

[28] A. I. Elsherbini and A. M. Jacobi. Liquid drops on vertical and inclined surfaces i. an experimental study of drop geometry. Journal of Colloid and Interface Science, 273:556-565, 2004.

[29] C. W. Extrand and A. N. Gent. Retention of liquid drops by solid surfaces. Journal of Colloid and Interface Science, 138:431-442, 1990.

[30] L. Leger. Liquid spreading. Rep. Prog. Phys, pages 431-486, 1992.

[31] C. Dorrer and J. Ruhe. Some thoughts on superhydrophobic wetting. Soft matter, 5:51-61, 2009.

[32] A. W. Admson. Physical chemistry of surfaces. 5th Edition, 1990.

[33] R. N. Wenzel. Resistance of solid surfaces to wetting by water. Industrial and Engineering Chemistry, 28:988-994, 1936.

[34] A. B. D. Cassie and S. Baxter. Wettability of porous surfaces. Trans. Faraday Soc., 40:546-551, 1944.

[35] L. Cao, A. K .Jones, V. K. Sikka, J. Wu, and D. Gao. Anti icing superhydrophobic coatings. Langmuir, 25:12444-12448, 2009.

[36] L. Feng, Z. Zhang, Z. Mai, Y. Ma, B. Liu, L. Jiang, and D. Zhu. A superhydrophobic and superoleophilic coating mesh film for the separation of oil and water. Angew. Chem. Int. Ed, 43:2012-2014, 2004.

[37] C. Neinhuis and W. Barthlott. Characterization and distribution of waterrepellent, self-cleaning plant surfaces. Annals of Botany, 79:667-677, 1997.

[38] X. Gao and L. Jiang. Water repellent legs of water striders. Nature, 432:36, 2004. 
[39] W. Lee, M. K. Jin, W. C. Yoo, and J. K. Lee. Nanostructuring of a polymeric substrate with well defined nanometer scale topography and tailored surface wettability. Langmuir, 20:7665-7669, 2004.

[40] M. Ma, R. M. Hill, and G. Rutledge. A review of recent results on superhydrophobic materials based on micro and nanofibers. Journal of Adhesion Science and Technology, 22:1799-1817, 2008.

[41] S. H. Kim. Fabrication of superhydrophobic surfaces. Journal of Adhesion Science and Technology, 22:235-250, 2008.

[42] J. Zhang, J. Li, and Y. Han. Superhydrophobic ptfe surfaces by extension. Macromol. Rapid Commun, 25:1105-1108, 2004.

[43] H. Yabu and M. Shimomura. Single-step fabrication of transparent superhydrophobic porous polymer films. Chem. Mater., 17:5231-5234, 2005.

[44] L. Xu, W. Chen, A. Mulchandani, and Y. Yan. Reversible conversion of conducting polymer films from superhydrophobic to superhydrophilic. Angew. Chem. Int. Ed, 44:6009-6012, 2005.

[45] J. Zhang, X. Lu, W. Huang, and Y. Han. Reversible superhydrophobicity to superhydrophilicity transition by extending and unloading an elastic polyamide film. Macromol. Rapid Commun., 26:477-480, 2005.

[46] N. Zhao, J. Xu, Q. Xie, L. Weng, X. Gao, X. Zhang, and L. Shi. Fabrication of biomimetic superhydrophobic coating with a micro-nano-binary structure. Macromol. Rapid Commun., 26:1075-1080, 2005.

[47] R. Mohammadi, J. Wassink, and A. Amirfazli. Effect of surfactants on wetting of superhydrophobic surfaces. Langmuir, 20:9657-9662, 2004.

[48] B. Qian and Z. Shen. Fabrication of superhydrophobic surfaces by dislocation, selective chemical etching on aluminum, copper, and zinc substrates. Langmuir, 21:9007-9009, 2005.

[49] K. Tadanaga, K. Kitamuro, A. Matsuda, and T. Minami. Formation of superhydrophobic alumina coating films with high transparency on polymer substrates by the sol-gel process. Journal of Sol-Gel Science and Technology, 26:705-708, 2003.

[50] M. Kang, R. Jung, H.S. Kim, and H. J. Jin. Fabrication of superhydrophobic surfaces. Journal of Adhesion Science and Technology, 22:235-250, 2008. 
[51] J. F. Cooley. Apparatus for electrically dispersing fluids. US 692631, February 1902.

[52] A. Formhals. Processing and apparatus for preparing artificial threads. US 1975504, October 1934.

[53] A. Formhals. Artificial fiber construction. US 2109333, February 1938.

[54] A. Formhals. Method of producing artificial fibers. US 2158415, May 1939.

[55] A. Formhals. Method and apparatus for spinning. US 2160962, May 1939.

[56] A. Formhals. Artificial thread and method of producing same. US 2187306, January 1940.

[57] A. Formhals. Production of artificial fibers from fiber forming liquids. US 2323025, January 1943.

[58] A. Formhals. Method and apparatus for spinning. US 2349950, May 1944.

[59] J. Doshi and D. H. Reneker. Electrospinning process and application of electrospun fibers. Journal of Electrostatics, 35:151-160, 1995.

[60] D. H. Reneker, A. L. Yarin, H. Fong, and S. Koombhongse. Bending instability of electrically charged liquid jets of polymer solutions in electrospinning. Journal of applied physics, 87:4531-4547, 2000.

[61] A. L. Yarin, S. Koombhongse, and D. H. Reneker. Bending instability in electrospinning of nanofibers. Journal of applied physics, 89:3018-3026, 2001.

[62] V. Beachley and X. Wen. Effect of electrospinning parameters on the nanofiber diameter and length. Materials Science and Engineering C, 29:663-668, 2009.

[63] C. J. Thompson, G. G. Chase, A. L. Yarin, and D. H. Reneker. Effects of parameters on nanofiber diameter determined from electrospinning model. Polymer, 48:6913-6922, 2007.

[64] D. Halliday and R. Resnick. Fundamentals of Physics. Wiley, 1974.

[65] P. Katta, M. Alessandro, R. D. Ramsier, and G. G. Chase. Continuous electrospinning of aligned polymer nanofibers onto a wire drum collector. Nano Letters, 4:2215-2218, 2004 
[66] A. F. Lotus, S. Bhargava, E. T. Bender, E. A. Evans, R. D. Ramsier, D. H. Reneker, and G. G. Chase. Electrospinning route for the fabrication of p-n junction using nanofiber yarns. Journal of Applied Physics, 106:014303/1-014303/4, 2009 .

[67] L. S. Carnell, E. J. Siochi, N. M. Holloway, R. M. Stephens, C. Rhim, L. E. Niklason, and R. L. Clark. Aligned mats from electrospinning single fibers. Macromolecules, 41:5345-5349, 2008.

[68] H. Pan, L. Li, L. Hu, and X. Cui. Continuous aligned polymer fibers produced by a modified electrospinning method. Polymer, 47:4901-4904, 2006.

[69] Y. Wu, L. A. Carnell, and R. L. Clark. Control of electrospun mat width through the use of parallel auxilary electrodes. Polymer, 48:5653-5661, 2007.

[70] W. E. Teo, M. Kotaki, X. M. Mo, and S. Ramakrishna. Porous tubular structures with controlled fiber orientation using a modified electrospinning method. Nanotechnology, 16:918-924, 2005.

[71] A. Theron, E. Zussman, and A. L. Yarin. Electrostatic field assisted alignment of electrospun nanofibers. Nanotechnology, 12:384-390, 2001.

[72] D. Li, Y. Wang, and Y. Xia. Electrospinning of polymeric and ceramic nanofibers as uniaxially aligned arrays. Nanotechnology, 3:1167-1171, 2003.

[73] W. E. Teo and S. Ramakrishna. A review on electrospinning design and nanofiber assemblies. Nanotechnology, 17:R89-R106, 2006.

[74] G. G. Chase, J. S. Varabhas, and D. H. Reneker. New methods to electrospin nanofibers. Journal of Engineered Fibers and Fabrics, 6:32-38, 2011.

[75] J. M. Deitzel, J. D. Kleinmeyer, J. K. Hirvonen, and N. C. Beck Tan. Controlled deposition of electrospun poly(ethylene oxide) fibers. Polymer, 42:8163-8170, 2001.

[76] S. J. Kwoun, R. M. Lec, R. A. Cairncross, P. Shah, and C. J. Brinker. Characterization of superhydrophobic materials using multiresonance acoustic shear wave sensors. IEEE Trans. Ultrasonics, Ferroelectrics, and Frequency control, 53:1400-1403, 2006.

[77] C. R. Crick and I. P. Parkin. Preparation and characterisation of superhydrophobic surfaces. Chem. Eur. J, 16:3568-3588, 2010. 
[78] R. J. Good and M. N. Koo. Effect of drop size on contact angle. Journal of colloid and interface science, 71:283-292, 1979.

[79] E. L. Decker, B. Frank, Y. Suo, and S. Garoff. Physics of contact angle measurements. Colloids and Surfaces, 156:177-189, 1997.

[80] R. Holyst. Wetting on a spherical surface. Phys. Rev. B, 36:5628, 1987.

[81] P. J. Upton, J. O. Indekeu, and J. M. Yeomans. Wetting on spherical and cylindrical substrates. Phys. Rev. B, 40:666, 1989.

[82] A. Marmur and B. Krasovitski. Line tension on curved surfaces: Liquid drops on solid micro and nanospheres. Langmuir, 18:8919-8923, 2002.

[83] H. B. Eral, G. Manukyan, and J. M. Oh. Wetting of a drop on a sphere. Langmuir, 27:5340-5346, 2011.

[84] L. M. Alarcon, D. C. Malaspina, E. P. Schulz, M. A. Frechero, and G. A. Appignanesi. Structure and orientation of water molecules at model hydrophobic surfaces with curvature: From graphene sheets to carbon nanotubes and fullerenes. Chemical Physics, 388:47-56, 2011.

[85] C. Choi, Y. Yoon, D. Hong, K. S. Brammer, K. Noh, Y. Oh, S. Oh, F. E. Talke, and S. Jin. Strongly superhydrophobic silicon nanowires by supercritical carbon dioxide drying. Electronic Materials Letters, 6:59-64, 2010.

[86] M. Nosonovsky and B. Bhushan. Superhydrophobic surfaces and emerging applications: Non-adhesion, energy, green engineering. Current Opinion in Colloid and Interface Science, 14:270-280, 2009.

[87] J. Genzer and K. Efimenko. Recent developments in superhydrophobic surfaces and their relevance to marine fouling: a review. Biofouling, 22:339-360, 2006.

[88] X. H. Xu, Z. Z. Zhang, J. Yang, and X. Zhu. Study of the corrosion resistance and loading capacity of superhydrophobic meshes fabricated by spraying method. Colloids and Surfaces A: Physiochemical and Engineering Aspects, 377:70-75, 2011.

[89] B. Grignard, A. Vaillant, J. D. Coninck, M. Piens, A. M. Jonas, C. Detrembleur, and C. Jerome. Electrospinning of a functional perfluorinated block copolymer as a powerful route for imparting superhydrophobicity and corrosion resistance to aluminum substrates. Langmuir, 27:335-342, 2011. 
[90] J. W. Gibbs. On the equilibrium of heterogeneous substances. Yale University Press, 1961.

[91] J. F. Oliver, C. Huh, and S. G. Mason. Resistance to spreading of liquids by sharp edges. Journal of Colloid and Interface Science, 59:568-581, 1977.

[92] J. Sjoblom. Emulsions and emulsion stability. Marcel Dekker, Inc, 1996.

[93] C. W. Extrand and S. I. Moon. Contact angles on spherical surfaces. Langmuir, 24:9470-9473, 2008.

[94] K. H. Lee, O. Ohsawa, K. Watanabe, I. S. Kim, S. R. Givens, B. Chase, and J. F. Rabolt. Electrospinning of syndiotactic polypropylene from a polymer solution at ambient temperatures. Macromolecules, 42:5215-5218, 2009.

[95] J. S. Varabhas, G. G. Chase, and D. H. Reneker. Electrospun nanofibers from a porous hollow tube. Polymer, 49:4226-4229, 2008.

[96] X. M. Li, D. Reinhoudt, and M. C. Calama. What do we need for a superhydrophobic surface? a review on the recent progress in the preparation of superhydrophobic surfaces. Chemical Society Reviews, 36:1350-1368, 2007.

[97] Press. Numerical Recipes in FORTRAN. 2nd Edition, Cambridge University Press, Cambridge, 1992.

[98] O. O. Dosunmu, G. G. Chase, W. Kataphinan, and D. H. Reneker. Electrospinning of polymer nanofibers from multiple jets on a porous tubular surface. Nanotechnology, 17:1123-1127, 2006.

[99] C. J. Angammana and S. H. Jayaram. The effects of electric field on the multijet electrospinning process and fiber morphology. IEEE Transactions on Industry Applications, 47:1028-1035, 2011. 
APPENDICES 


\section{APPENDIX A \\ RELATION BETWEEN INTRINSIC CONTACT ANGLE, DROP SIZE AND RADIUS OF CURVATURE TO THE APPARENT CONTACT ANGLE}

Consider a sessile liquid drop of volume $\mathrm{V}$ on a spherical surface in such a way that the drop is symmetric on the y axis which passes through the center of the sphere as well as the drop. Assuming the drop to spread along the curved surface to produce an intrinsic advancing contact angle $\left(\theta_{o}\right)$, as shown in Figure A.1, which would be the angle made by the liquid drop on a flat surface of the same material and composition. Due to the curvature of the sphere, the apparent advancing contact angle $(\theta)$, relative to the horizontal is greater than the intrinsic value $\theta_{o}$.

In Figure A.1, line segments $\mathrm{CB}$ and $\mathrm{CD}$ equal the radius of the sphere, $\mathrm{R}$. Line segments $\mathrm{AB}$ and $\mathrm{AD}$ equal $\mathrm{r}$, the radius of the liquid drop. In triangle $\mathrm{FCB}$,

$$
\mathrm{a}=\mathrm{R} \sin \alpha
$$

And in triangle FAB,

$$
\mathrm{a}=\mathrm{r} \sin \beta
$$




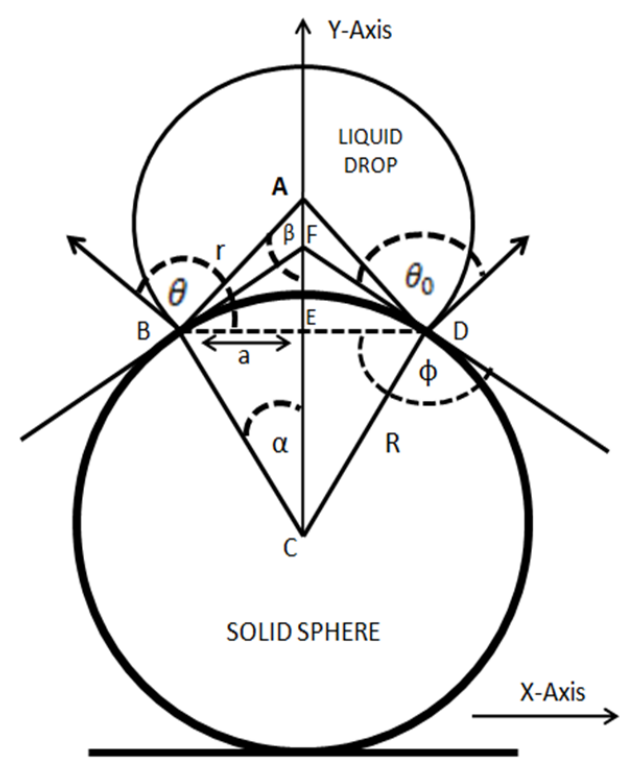

Figure A.1: Schematic diagram of a liquid droplet sitting on top of a solid sphere

Combining Equations A.1 and A.2 gives

$$
\frac{R}{r}=\frac{\sin \beta}{\sin \alpha}
$$

By inspection of the angles and the lines described in Figure A.1, the following relations are obtained

$$
\begin{gathered}
\alpha=\pi-\phi \\
\alpha+\beta+\theta_{o}=\pi
\end{gathered}
$$


Combining Equations A.3, A.4 and A.5, it is possible to derive

$$
\frac{R}{r}=\frac{\sin \left(\phi-\theta_{o}\right)}{\sin \phi}
$$

Gibb's equation is given by

$$
\theta=\theta_{o}+\pi-\phi
$$

Where, $\phi$ is the edge angle

Combining Equation A.6 and Equation A.7

$$
\frac{R}{r}=\frac{\sin \theta}{\sin \left(\theta-\theta_{o}\right)}
$$

Equation A.8 can be rearranged to calculate the apparent contact angle $(\theta)$, with help of a trig identity, to the form

$$
\theta=\arctan \left[\frac{\sin \theta_{o}}{\cos \theta_{o}-\left(\frac{r}{R}\right)}\right]
$$

The apparent contact angle $(\theta)$, due to the effect of curved surface, can be calculated for a given droplet size, radius of curvature of the sphere and the contact angle on a flat surface. Equation A.9 is derived for a droplet sitting on a spherical surface. For a drop sitting on the surface of a cylinder, the axial view is analogous to the view shown in Figure A.1. Therefore, the equation for the apparent contact 
angle for the axial view of a drop sitting on a cylindrical surface is by analogy the same as Equation A.9. 


\section{APPENDIX B}

\section{EQUATION TO CALCULATE THE LENGTH OF THREE PHASE CONTACT LINE OF A DROP ON A HYDROPHOBIC PLANAR SURFACE}

Consider a water droplet of volume $\mathrm{V}$ sitting on a hydrophobic flat surface as shown in Figure B.1. Because the drop is small, we assume the drop has a spherical surface.

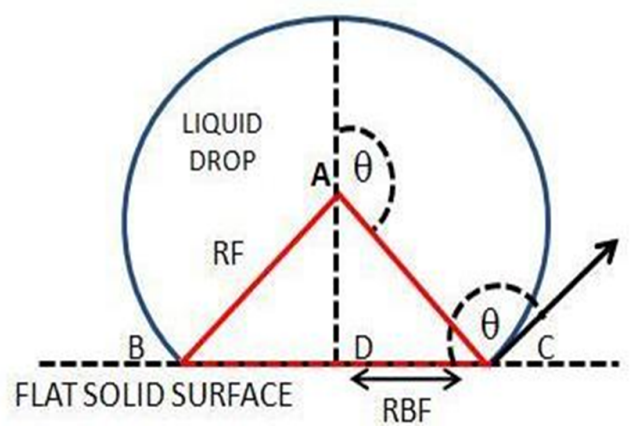

Figure B.1: Schematic diagram of a liquid droplet on a planar surface

The total volume of the drop is equal to the sum of spherical part and the conical part.

$$
\mathrm{V}=\mathrm{V}_{\mathrm{S}}+\mathrm{V}_{\mathrm{C}}
$$


Where

$$
\begin{gathered}
\mathrm{V}_{\mathrm{S}}=\iiint r^{2} d r \mathrm{~d} \alpha d \beta \\
\mathrm{V}_{\mathrm{S}}=\frac{2 \pi R_{F}^{3}(1-\cos \theta)}{3} \\
\mathrm{~V}_{\mathrm{C}}=\frac{-\pi R_{F}^{3} \sin ^{2} \theta \cos \theta}{3}
\end{gathered}
$$

Substituting Equation B.2 and Equation B.3 in Equation B.1 gives

$$
\mathrm{R}_{\mathrm{F}}=\left[\frac{3 V}{2 \pi(1-\cos \theta)-\pi \sin ^{2} \theta \cos \theta}\right]^{1 / 3}
$$

Where, $R_{F}=$ Radius of the drop on flat surface

$$
\theta=\text { Contact angle }
$$

Radius of the circular contact line is

$$
\mathrm{R}_{\mathrm{BF}}=\mathrm{R}_{\mathrm{F}} \sin \theta
$$

And hence the length of contact line of a drop on a flat surface is

$$
\mathrm{L}_{\mathrm{F}}=2 \pi R_{F} \sin \theta
$$




\begin{abstract}
APPENDIX C
EQUATION TO CALCULATE THE LENGTH OF THREE PHASE CONTACT LINE OF A DROP ON A HYDROPHOBIC SPHERE
\end{abstract}

Consider a water droplet of volume $\mathrm{V}$ sitting on a hydrophobic spherical surface as shown in Figure C.1. The drop is assumed to be small enough that the surface forces are strong enough to cause the drop to have a spherical shape.

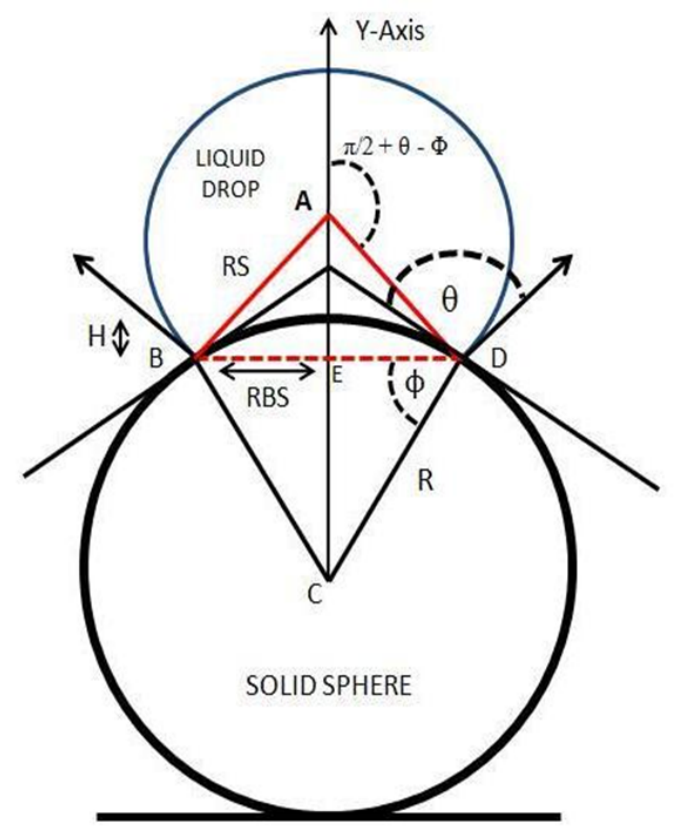

Figure C.1: Schematic diagram of a liquid droplet on a solid sphere 
Area of the spherical cap of the solid sphere is given by

$$
\mathrm{A}=2 \pi R H
$$

Rearranging Equation C.1

$$
\mathrm{H}=\frac{A}{2 \pi R}
$$

Where

$$
\begin{aligned}
& \mathrm{R}=\text { Radius of the solid sphere } \\
& \mathrm{H}=\text { Height of the spherical cap }
\end{aligned}
$$

In Figure C.1, $\triangle \mathrm{ECD}$,

$$
\phi=\sin ^{-1} \frac{R-H}{R}
$$

From observation, angle $(\mathrm{ADE})=\theta-\phi$

In Figure C.1, $\Delta \mathrm{ECD}$,

$$
\cos \phi=\frac{R_{B S}}{R}
$$

In Figure C.1, $\Delta \mathrm{ADE}$,

$$
\cos (\theta-\phi)=\frac{R_{B S}}{R_{S}}
$$


Where, $R_{B S}=$ Radius of the circular contact line of the drop

$$
R_{S}=\text { Radius of the drop on the solid sphere }
$$

Dividing Equations C.4 and C.5

$$
\begin{aligned}
& \frac{\cos \phi}{\cos (\theta-\phi)}=\frac{R_{S}}{R} \\
& \mathrm{R}_{\mathrm{S}}=\frac{R \cos \phi}{\cos (\theta-\phi)}
\end{aligned}
$$

Where, $\theta=$ Contact angle

The volume of drop on solid sphere is equal to

$$
\mathrm{V}=\mathrm{V}_{\mathrm{S}}+\mathrm{V}_{\mathrm{C}}-\mathrm{V}_{\mathrm{SC}}
$$

Where, $V_{S}=$ Volume of the spherical part

$$
\begin{aligned}
& V_{C}=\text { Volume of the conical part } \\
& V_{S C}=\text { Volume of the spherical cap of the solid sphere }
\end{aligned}
$$

$$
\begin{gathered}
\mathrm{V}_{\mathrm{S}}=\frac{2 \pi R_{S}^{3}(1+\sin (\theta-\phi))}{3} \\
\mathrm{~V}_{\mathrm{C}}=\frac{\pi R_{S}^{3} \cos ^{2}(\theta-\phi) \sin (\theta-\phi)}{3} \\
\mathrm{~V}_{\mathrm{SC}}=\frac{\pi H^{2}(3 R-H)}{3}
\end{gathered}
$$


Radius of the circular contact area is

$$
\mathrm{R}_{\mathrm{BS}}=\mathrm{R} \cos \phi
$$

And hence the length of contact line of a drop on a sphere is

$$
\mathrm{L}_{\mathrm{S}}=2 \pi R \cos \phi
$$




\section{APPENDIX D \\ FORTRAN CODE TO CALCULATE THE THEORETICAL LENGTH OF THREE PHASE CONTACT LINE OF A DROP ON A SPHERE}

For a given volume of a drop and its intrinsic contact angle on a solid surface, this program calculates the radius of the drop on a planar as well as a spherical surface.

! CREATED: AUG 07,2012

! GOUTHAM VISWANADAM

$! \mathrm{R}=$ RADIUS OF THE SPHERE

! R0 $=$ RADIUS OF THE DROP IN AIR

$!$ RF $=$ RADIUS OF THE DROP ON FLAT SURFACE WITH CONTACT ANGLE TETA

$!$ RS = RADIUS OF THE DROP ON A SPHERE OF RADIUS 'R' WITH INTRINSIC CONTACT ANGLE TETA

$! \mathrm{V}=$ VOLUME OF THE DROP

! VSS = VOLUME OF SPHERICAL SEGMENT OF THE DROP

! VC = VOLUME OF CONICAL SEGMENT OF THE DROP 
$!$ VCAP $=$ VOLUME OF SPHERICAL CAP WHEN DROP SITS ON A SPHERE

! AREA $=$ CONTACT AREA ON THE CURVED SURFACE

$!$ AREA1 $=$ CONTACT AREA ON THE FLAT SURFACE

$!$ CLF $=$ LENGTH OF CONTACT LINE ON A FLAT SURFACE

$!$ CLS $=$ LENGTH OF CONTACT LINE ON A SPHERICAL SURFACE

$!$ RBF $=$ RADIUS OF THE CONTACT AREA ON A FLAT SURFACE

$!$ RBS $=$ RADIUS OF THE CONTACT AREA ON A SPHERICAL SURFACE

IMPLICIT NONE

DOUBLE PRECISION V,R,R0,RF,RS,A,B,C,D,H

DOUBLE PRECISION TOL,DELTA,AREA,AREA1

DOUBLE PRECISION RBF,CLF,RBS,CLS

DOUBLE PRECISION PHI,TETA,ALPHA

DOUBLE PRECISION VSS,VC,VCAP,VS

INTEGER I

WRITE $\left(6,{ }^{*}\right)$ 'ENTER THE VOLUME OF THE DROP(MICRO LITERS) :'

$\operatorname{READ}\left(5,{ }^{*}\right) \mathrm{V}$

WRITE $\left(6,{ }^{*}\right)$ 'ENTER THE DROP CONTACT ANGLE(DEGREES) : '

$\operatorname{READ}\left(5,{ }^{*}\right)$ TETA

WRITE $\left(6,{ }^{*}\right)$ 'ENTER THE RADIUS OF SPHERE(MM) : ' 
$\operatorname{READ}(5, *) \mathrm{R}$

$\mathrm{PHI}=22 \cdot \mathrm{d} 0 / 7 . \mathrm{d} 0$

DELTA $=1 . d-7$

$\mathrm{TOL}=1 . \mathrm{d}-8$

! CONVERTING DEGREES INTO RADIANS

$\mathrm{TETA}=(\mathrm{PHI} * \mathrm{TETA}) / 180 . \mathrm{d} 0$

! CALCULATING THE RADIUS OF DROP IN AIR

$\mathrm{R} 0=\left(\left(3^{*} \mathrm{~V}\right) /\left(4^{*} \mathrm{PHI}\right)\right)^{* *}(1 . \mathrm{d} 0 / 3 . \mathrm{d} 0)$

$\operatorname{WRITE}\left(6,{ }^{*}\right)$ 'RADIUS OF THE DROP IN $\operatorname{AIR}(\mathrm{MM})={ }^{\prime}, \mathrm{R} 0$

! CALCULATING THE RADIUS OF DROP ON FLAT SURFACE

$$
\begin{aligned}
& \mathrm{A}=2 \cdot \mathrm{d} 0 *(1 . \mathrm{d} 0-\mathrm{COS}(\mathrm{TETA})) \\
& \mathrm{B}=\mathrm{SIN}(\mathrm{TETA}){ }^{* *} 2 . \mathrm{d} 0 \\
& \mathrm{~B}=\mathrm{B}^{*} \operatorname{COS}(\mathrm{TETA}) \\
& \mathrm{C}=\mathrm{A}-\mathrm{B} \\
& \mathrm{D}=\left(3 . \mathrm{d} 0^{*} \mathrm{~V}\right) /\left(\mathrm{PHI}{ }^{*} \mathrm{C}\right) \\
& \mathrm{RF}=\mathrm{D}^{* *}(1 . \mathrm{d} 0 / 3 \cdot \mathrm{d} 0)
\end{aligned}
$$

$\operatorname{WRITE}\left(6,{ }^{*}\right)$ 'RADIUS OF THE DROP ON FLAT SURFACE(MM) $=$ ',RF

$\mathrm{RBF}=\mathrm{RF}^{*} \mathrm{COS}(\mathrm{TETA}-(\mathrm{PHI} / 2 . \mathrm{d} 0))$

$\mathrm{CLF}=2 * \mathrm{PHI} * \mathrm{RBF}$ 
$\mathrm{AREA} 1=\mathrm{PHI}\left(\mathrm{RBF}^{* *} 2\right)$

! CALCULATING THE RADIUS OF DROP ON CURVED SURFACE

$\mathrm{AREA}=$ DELTA

$\mathrm{VS}=0 . \mathrm{d} 0$

$\mathrm{I}=1$

DO WHILE (VS.LT.V)

$\operatorname{WRITE}\left(6,{ }^{*}\right)$ 'ITERATION $={ }^{,}, \mathrm{I}$

$\mathrm{H}=\mathrm{AREA} /(2 * \mathrm{PHI} * \mathrm{R})$

!EQUATION RELATING H AND RADIUS OF SPHERE TO ALPHA

$\mathrm{ALPHA}=\operatorname{ASIN}(1-(\mathrm{H} / \mathrm{R}))$

!CALCULATING THE RADIUS OF THE DROP

$\mathrm{RS}=\left(\mathrm{R}^{*} \operatorname{COS}(\mathrm{ALPHA})\right) / \mathrm{COS}(\mathrm{TETA}-\mathrm{ALPHA})$

!VOLUME OF THE SPHERICAL PART

$\operatorname{VSS}=(2 . \mathrm{d} 0 / 3 . \mathrm{d} 0) * \mathrm{PHI} *\left(\mathrm{RS}^{* *} 3\right) *(1 . \mathrm{d} 0-\mathrm{COS}(\mathrm{TETA}-\mathrm{ALPHA}+(\mathrm{PHI} / 2 . \mathrm{d} 0)))$

!VOLUME OF THE CONICAL PART

$\mathrm{VC}=(\mathrm{PHI} / 3 . \mathrm{d} 0) *\left(\mathrm{RS}^{* *} 3\right) *(\operatorname{SIN}(\mathrm{ALPHA}-\mathrm{TETA}+(\mathrm{PHI} / 2 . \mathrm{d} 0)))^{* *} 2$

$\mathrm{VC}=\mathrm{VC} * \operatorname{COS}($ ALPHA-TETA $+(\mathrm{PHI} / 2 . \mathrm{d} 0))$

!VOLUME OF SPHERICAL CAP

$\mathrm{VCAP}=(\mathrm{PHI} / 3 \cdot \mathrm{d} 0)^{*}\left(\mathrm{H}^{* *} 2\right) *((3 * \mathrm{R})-\mathrm{H})$

!VOLUME OF THE DROP SITTING ON CURVED SURFACE

$\mathrm{VS}=\mathrm{VSS}+\mathrm{VC}-\mathrm{VCAP}$ 
RBS $=\mathrm{R}^{*} \mathrm{COS}(\mathrm{ALPHA})$
$\mathrm{CLS}=2^{*}$ PHI ${ }^{*} \mathrm{RBS}$
IF ((V-VS).LE.TOL) THEN

WRITE $\left(6,{ }^{*}\right)$ 'CONVERGENCE REACHED AFTER',I,' ITERATIONS'

$\operatorname{WRITE}\left(6,{ }^{*}\right)$ 'RADIUS OF THE DROP IN AIR(MM) $={ }^{\prime}, \mathrm{R} 0$

$\operatorname{WRITE}\left(6,{ }^{*}\right)$ 'RADIUS OF THE DROP ON FLAT SURFACE $(\mathrm{MM})=$

',RF

WRITE $\left(6,{ }^{*}\right)$ 'RADIUS OF THE DROP ON CURVED SURFACE(MM)

$={ }^{\prime}, \mathrm{RS}$

$\operatorname{WRITE}\left(6,{ }^{*}\right)$ 'THE HEIGHT OF SPHERICAL CAP $=$ ',H

$\operatorname{WRITE}\left(6,{ }^{*}\right)$ 'CONTACT AREA ON FLAT SURFACE(MM2) = ',AREA1

$\operatorname{WRITE}\left(6,{ }^{*}\right)$ 'CONTACT AREA ON SPHERICAL SURFACE(MM2)=

',AREA

WRITE $\left(6,{ }^{*}\right)$ 'LENGTH OF CONTACT LINE ON FLAT SURFACE $=$

',CLF

$\operatorname{WRITE}\left(6,{ }^{*}\right)$ 'RADIUS OF THE CIRCULAR CONTACT AREA $(\mathrm{MM})=$ ',RBS

$\operatorname{WRITE}\left(6,{ }^{*}\right)$ 'LENGTH OF CONTACT LINE ON SPHERE(MM) =

',CLS

ELSE

$\mathrm{AREA}=\mathrm{AREA}+\mathrm{DELTA}$

ENDIF 
$\mathrm{I}=\mathrm{I}+1$

ENDDO

PAUSE

END

$==\mathrm{I}=\mathrm{=}=\mathrm{=}=\mathrm{=}=\mathrm{=}=\mathrm{=}=\mathrm{=}=\mathrm{=}=\mathrm{=}=\mathrm{=}=\mathrm{=}=\mathrm{=}=\mathrm{=}=\mathrm{=}=\mathrm{=}$ 


\section{APPENDIX E \\ EQUATION TO CALCULATE THE POTENTIAL AT EACH POINT IN THE GRID}

Gauss's law, or the conservation of charge [64][99], models the current density vector, $\mathrm{j}$, for a static electric system in a continuum by setting the gradient of the current density to zero

$$
\underline{\nabla} \cdot \underline{j}=0
$$

The electrical conductivity, $\sigma$, relates the current density to the potential gradient as

$$
\underline{j}=-\sigma \underline{\nabla} \phi
$$

Where, $\phi$ is the electrical potential (voltage) and $\sigma$ is the conductivity of the medium.

For constant conductivity, Equation E.1 and Equation E.2 combine to form Laplace's equation of potential

$$
\nabla^{2} \phi=0
$$


In rectangular co-ordinates, Equation E.3 is

$$
\frac{\partial^{2} \phi}{\partial^{2} x}+\frac{\partial^{2} \phi}{\partial^{2} y}+\frac{\partial^{2} \phi}{\partial^{2} z}=0
$$

The derivatives in Equation E.4 may be approximated by Taylor series expansion over equal positional steps in the three directions

$$
\mathrm{h}=\Delta x=\Delta y=\Delta z
$$

To obtain the equivalent of Equation E.4 in discretized form as

$$
\frac{\phi_{i+1 j k}-2 \phi_{i j k}+\phi_{i-1 j k}}{h^{2}}+\frac{\phi_{i j+1 k}-2 \phi_{i j k}+\phi_{i j-1 k}}{h^{2}}+\frac{\phi_{i j k+1}-2 \phi_{i j k}+\phi_{i j k-1}}{h^{2}}
$$

Equation E.6 simplifies to

$$
\phi_{i j k}=\frac{1}{6}\left[\phi_{\mathrm{i}+1 \mathrm{jk}}+\phi_{i-1 j k}+\phi_{i j+1 k}+\phi_{i j-1 k}+\phi_{i j k+1}+\phi_{i j k-1}\right]
$$

In a 3-D rectangular grid geometry, Equation E.7 says the potential at the point with indices ijk is equal to the average of the six surrounding grid point potentials, indicated in Figure E.1, and indicated by $\mathrm{i} \pm 1, \mathrm{j} \pm 1, \mathrm{k} \pm 1$ indices. 


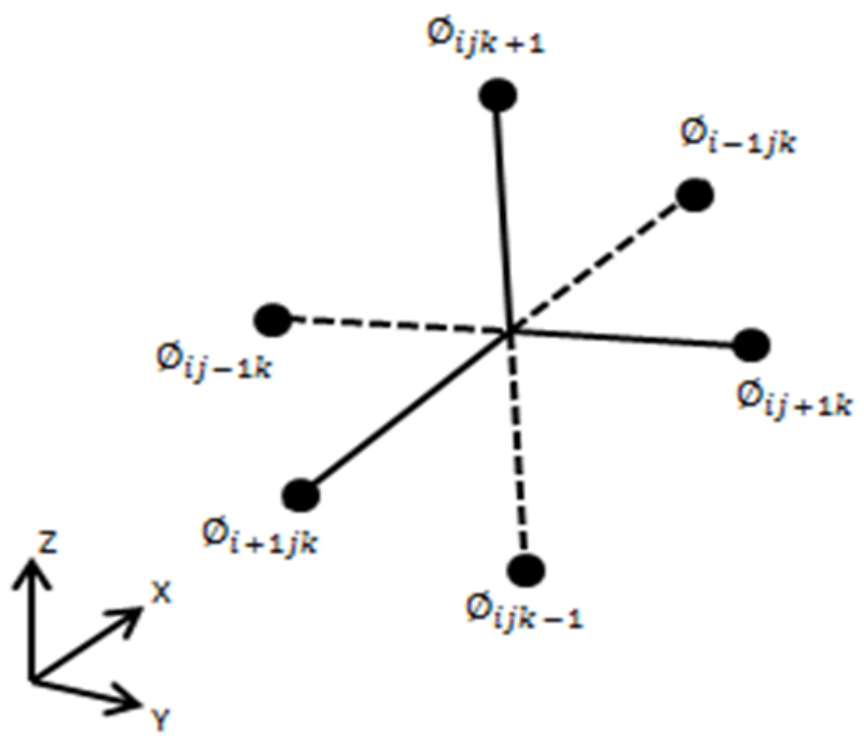

Figure E.1: Notation showing voltage potential at a local point in a rectangular grid and the surrounding points 


\section{APPENDIX F \\ FORTRAN CODE FOR ELECTRIC FIELD MODELLING WITH TWO PERPENDICULAR ELECTRODES}

This program calculates the electric potential flux fields for a 3D system with source, collector, motor and two secondary electrodes

! CREATED 14OCT2010

! GEORGE G CHASE

! MODIFIED AUG 2011

! GOUTHAM VISWANADAM

! MAIN PROGRAM

PARAMETER $(\mathrm{NI}=100, \mathrm{NJ}=100, \mathrm{NK}=100)$

IMPLICIT INTEGER $(\mathrm{I}, \mathrm{N})$

IMPLICIT REAL (A-H, O-Z)

COMMON QX(0:NI,0:NJ,0:NK),QY(0:NI,0:NJ,0:NK), QZ(0:NI,0:NJ,0:NK)

COMMON T(0:NI,0:NJ,0:NK),L(0:NI,0:NJ,0:NK) 
COMMON RELAX,TOL,TSR,TMR,TGR,TER1,TER2

COMMON DX,DY,DZ,QTOT,FQTOT

COMMON FSX0,FSX1,FSY0,FSY1,FSZ0,FSZ1

COMMON FGX0,FGX1,FGY0,FGY1,FGZ0,FGZ1

COMMON FMX0,FMX1,FMY0,FMY1,FMZ0,FMZ1

COMMON FE1X0,FE1X1,FE1Y0,FE1Y1,FE1Z0,FE1Z1

COMMON FE2X0,FE2X1,FE2Y0,FE2Y1,FE2Z0,FE2Z1

COMMON FPLANE

COMMON MMAX,IPLANE

CALL INIT1

5 CALL MENU

CALL INIT2

CALL CALCT

CALL CALCQ

GOTO 5

END 
! THIS SUBROUTINE INITIALIZES VARIABLE VALUES

SUBROUTINE INIT1

PARAMETER $(\mathrm{NI}=100, \mathrm{NJ}=100, \mathrm{NK}=100)$

IMPLICIT INTEGER $(\mathrm{I}, \mathrm{N})$

IMPLICIT REAL (A-H, O-Z)

COMMON QX(0:NI,0:NJ,0:NK),QY(0:NI,0:NJ,0:NK), QZ(0:NI,0:NJ,0:NK)

COMMON T(0:NI,0:NJ,0:NK),L(0:NI,0:NJ,0:NK)

COMMON RELAX,TOL,TSR,TMR,TGR,TER1,TER2

COMMON DX,DY,DZ,QTOT,FQTOT

COMMON FSX0,FSX1,FSY0,FSY1,FSZ0,FSZ1

COMMON FGX0,FGX1,FGY0,FGY1,FGZ0,FGZ1

COMMON FMX0,FMX1,FMY0,FMY1,FMZ0,FMZ1

COMMON FE1X0,FE1X1,FE1Y0,FE1Y1,FE1Z0,FE1Z1

COMMON FE2X0,FE2X1,FE2Y0,FE2Y1,FE2Z0,FE2Z1

COMMON FPLANE

COMMON MMAX,IPLANE

! SET PROGRAM PARAMETERS

RELAX $=1.2 \quad$ !RELAXATION PARAMETER FOR CONVERGENCE

TOL $=1 . \mathrm{E}-5 \quad$ !CONVERGENCE TOLERANCE FOR CALCULATIONS

MMAX $=5000 \quad$ !MAXIMUM NUMBER OF ITERATIONS 


\section{! SET BOUNDARY POTENTIAL VALUES \\ $\mathrm{TSR}=1.0 \quad$ !SOURCE POTENTIAL \\ TGR $=0.0 \quad$ !GROUND POTENTIAL \\ $\mathrm{TMR}=0.0 \quad$ !MOTOR POTENTIAL \\ TER $1=0.6 \quad$ !FIRST ELECTRODE POTENTIAL \\ TER $2=0.9 \quad$ !SECOND ELECTRODE POTENTIAL}

! SET POSITION STEP SIZES
$\mathrm{X}=\mathrm{NI}$
$\mathrm{DX}=1 / \mathrm{X}$
$\mathrm{Y}=\mathrm{NJ}$
$\mathrm{DY}=1 / \mathrm{Y}$
$\mathrm{Z}=\mathrm{NK}$
$\mathrm{DZ}=1 / \mathrm{Z}$

! INITIALIZE T AND L VALUES

$! \mathrm{T}=$ POTENTIAL FIELD

$! \mathrm{L}=$ LOGICAL VARIABLE

! L=1 IF POTENTIAL IS CALCULATED AT POINT

! L=0 IF POTENTIAL IS FIXED VALUE 
$\mathrm{DO} \mathrm{K}=0, \mathrm{NK}$

$\mathrm{Z}=\mathrm{K}$

$\mathrm{Z}=\mathrm{Z}^{*} \mathrm{DZ} \quad$ ! FRACTIONAL POSITION IN Z DIR

DO $\mathrm{J}=0, \mathrm{NJ}$

$\mathrm{DO} \mathrm{I}=0, \mathrm{NI}$

$\mathrm{T}(\mathrm{I}, \mathrm{J}, \mathrm{K})=(\mathrm{TGR}-\mathrm{TSR}) * \mathrm{Z}+\mathrm{TSR}$

$\mathrm{L}(\mathrm{I}, \mathrm{J}, \mathrm{K})=1$

ENDDO

ENDDO

ENDDO

! FRACTIONAL POSITIONS FOR GROUND (AT K = NK BOUNDARY)

! THESE FRACTIONAL POSITIONS ARE THE CORNERS OF A RECTANGU-

LAR BOX ON THE K=NK SURFACE.

$\mathrm{FGX0}=0.4$

$\mathrm{FGX} 1=0.8$

$\mathrm{FGY0}=0.3$

$\mathrm{FGY} 1=0.7$

$\mathrm{FGZ0}=0.9$

$\mathrm{FGZ1}=0.9$ 
! FRACTIONAL POSITIONS FOR SOURCE (AT K $=0$ BOUNDARY)

! THESE FRACTIONAL POSITIONS ARE THE CORNERS OF A RECTANGULAR BOX ON THE K=0 SURFACE

$\mathrm{FSX} 0=0.6$

$\mathrm{FSX} 1=0.6$

$\mathrm{FSY} 0=0.5$

$\mathrm{FSY} 1=0.5$

$\mathrm{FSZ0}=0.0$

$\mathrm{FSZ1}=0.0$

! FRACTIONAL POSITIONS FOR MOTOR

! THESE FRACTIONAL POSITIONS ARE THE CORNERS OF A CUBE INSIDE OF THE COMPUTATION SPACE

! ALL ZEROS MEANS THERE IS NO MOTOR

$\mathrm{FMX} 0=0.1$

$\mathrm{FMX} 1=0.3$

$\mathrm{FMY0}=0.3$

$\mathrm{FMY} 1=0.6$

$\mathrm{FMZ0}=0.4$

$\mathrm{FMZ1}=0.8$ 
! FRACTIONAL POSITION FOR FIRST ELECTRODE

!THESE FRACTIONAL POSITIONS ARE THE CORNERS OF A CUBE INSIDE OF THE COMPUTATION SPACE

!ALL ZEROS MEANS THERE IS NO ELECTRODE

$\mathrm{FE} 1 \mathrm{X} 0=0.4$

$\mathrm{FE} 1 \mathrm{X} 1=0.4$

$\mathrm{FE} 1 \mathrm{Y} 0=0.3$

$\mathrm{FE} 1 \mathrm{Y} 1=0.6$

$\mathrm{FE} 1 \mathrm{Z} 0=0.3$

$\mathrm{FE} 1 \mathrm{Z} 1=0.7$

! FRACTIONAL POSITION FOR SECOND ELECTRODE

!THESE FRACTIONAL POSITIONS ARE THE CORNERS OF A CUBE INSIDE OF THE COMPUTATION SPACE

!ALL ZEROS MEANS THERE IS NO ELECTRODE

$\mathrm{FE} 2 \mathrm{X} 0=0.2$

$\mathrm{FE} 2 \mathrm{X} 1=0.4$

$\mathrm{FE} 2 \mathrm{Y0}=0.3$

$\mathrm{FE} 2 \mathrm{Y} 1=0.6$

$\mathrm{FE} 2 \mathrm{Z} 0=0.2$

$\mathrm{FE} 2 \mathrm{Z} 1=0.2$ 
! INITIALIZE PLANE AND POSITION FOR WRITING RESULTS

IPLANE $=1 \quad ! 1=\mathrm{X}, 2=\mathrm{Y}, 3=\mathrm{Z}$

FPLANE $=0.5$

! FRACTIONAL POSITION OF Z PLANE FOR CALCULATING QTOT $\mathrm{QTOT}=0.0$

FQTOT $=0.2$

RETURN

END

SUBROUTINE INIT2

PARAMETER $(\mathrm{NI}=100, \mathrm{NJ}=100, \mathrm{NK}=100)$

IMPLICIT INTEGER (I,N)

IMPLICIT REAL (A-H, O-Z)

COMMON QX(0:NI,0:NJ,0:NK),QY(0:NI,0:NJ,0:NK), QZ(0:NI,0:NJ,0:NK)

COMMON T(0:NI,0:NJ,0:NK),L(0:NI,0:NJ,0:NK)

COMMON RELAX,TOL,TSR,TMR,TGR,TER1,TER2

COMMON DX,DY,DZ,QTOT,FQTOT

COMMON FSX0,FSX1,FSY0,FSY1,FSZ0,FSZ1

COMMON FGX0,FGX1,FGY0,FGY1,FGZ0,FGZ1 


\author{
COMMON FMX0,FMX1,FMY0,FMY1,FMZ0,FMZ1 \\ COMMON FE1X0,FE1X1,FE1Y0,FE1Y1,FE1Z0,FE1Z1 \\ COMMON FE2X0,FE2X1,FE2Y0,FE2Y1,FE2Z0,FE2Z1 \\ COMMON FPLANE \\ COMMON MMAX,IPLANE
}

! SET L=0 FOR THE SOURCE, GROUND, MOTOR, SECONDARY ELECTRODE

\title{
! SOURCE
}

$$
\begin{aligned}
& \mathrm{X}=\mathrm{NI} \\
& \mathrm{X}=\mathrm{FSX} 0^{*} \mathrm{X} \\
& \mathrm{I} 0=\mathrm{X} \\
& \mathrm{X}=\mathrm{NI} \\
& \mathrm{X}=\mathrm{FSX} 1^{*} \mathrm{X} \\
& \mathrm{I} 1=\mathrm{X} \\
& \mathrm{Y}=\mathrm{NJ} \\
& \mathrm{Y}=\mathrm{FSY} 0^{*} \mathrm{Y} \\
& \mathrm{J} 0=\mathrm{Y} \\
& \mathrm{Y}=\mathrm{NJ} \\
& \mathrm{Y}=\mathrm{FSY} 1^{*} \mathrm{Y} \\
& \mathrm{J} 1=\mathrm{Y}
\end{aligned}
$$




$$
\begin{aligned}
& \mathrm{Z}=\mathrm{NK} \\
& \mathrm{Z}=\mathrm{FSZ} 0 * \mathrm{Z} \\
& \mathrm{K} 0=\mathrm{Z} \\
& \mathrm{Z}=\mathrm{NK} \\
& \mathrm{Z}=\mathrm{FSZ1}{ }^{*} \mathrm{Z} \\
& \mathrm{K} 1=\mathrm{Z} \\
& \text { DO I=I0,I1 } \\
& \text { DO J=J0,J1 } \\
& \text { DO } \mathrm{K}=\mathrm{K} 0, \mathrm{~K} 1 \\
& \mathrm{~L}(\mathrm{I}, \mathrm{J}, \mathrm{K})=0 \\
& \mathrm{~T}(\mathrm{I}, \mathrm{J}, \mathrm{K})=\mathrm{TSR} \\
& \text { END DO } \\
& \text { ENDDO }
\end{aligned}
$$

\section{ENDDO}

$$
\begin{aligned}
& \begin{array}{l}
\text { GROUND } \\
\mathrm{X}=\mathrm{NI}
\end{array} \\
& \mathrm{X}=\mathrm{FGX} 0^{*} \mathrm{X} \\
& \mathrm{I} 0=\mathrm{X} \\
& \mathrm{X}=\mathrm{NI} \\
& \mathrm{X}=\mathrm{FGX} 1 * \mathrm{X} \\
& \mathrm{I} 1=\mathrm{X}
\end{aligned}
$$




$$
\begin{aligned}
& \mathrm{Y}=\mathrm{NJ} \\
& \mathrm{Y}=\mathrm{FGY} 0 * \mathrm{Y} \\
& \mathrm{J} 0=\mathrm{Y} \\
& \mathrm{Y}=\mathrm{NJ} \\
& \mathrm{Y}=\mathrm{FGY} 1{ }^{*} \mathrm{Y} \\
& \mathrm{J} 1=\mathrm{Y} \\
& \mathrm{Z}=\mathrm{NK} \\
& \mathrm{Z}=\mathrm{FGZ} 0^{* \mathrm{Z}} \\
& \mathrm{K} 0=\mathrm{Z} \\
& \mathrm{Z}=\mathrm{NK} \\
& \mathrm{Z}=\mathrm{FGZ} 1 * \mathrm{Z} \\
& \mathrm{K} 1=\mathrm{Z} \\
& \mathrm{DO} \mathrm{I}=\mathrm{I} 0, \mathrm{I} 1
\end{aligned}
$$$$
\text { DO J=J0,J1 }
$$$$
\text { DO } \mathrm{K}=\mathrm{K} 0, \mathrm{~K} 1
$$

$$
\begin{aligned}
& \mathrm{L}(\mathrm{I}, \mathrm{J}, \mathrm{K})=0 \\
& \mathrm{~T}(\mathrm{I}, \mathrm{J}, \mathrm{K})=\mathrm{TGR}
\end{aligned}
$$

\section{END DO}

\section{ENDDO}

\section{ENDDO}


! MOTOR

$\mathrm{X}=\mathrm{NI}$

$\mathrm{X}=\mathrm{FMX} 0 * \mathrm{X}$

$\mathrm{I} 0=\mathrm{X}$

$\mathrm{X}=\mathrm{NI}$

$\mathrm{X}=\mathrm{FMX} 1 * \mathrm{X}$

$\mathrm{I} 1=\mathrm{X}$

$\mathrm{Y}=\mathrm{NJ}$

$\mathrm{Y}=\mathrm{FMY} 0^{*} \mathrm{Y}$

$\mathrm{J} 0=\mathrm{Y}$

$\mathrm{Y}=\mathrm{NJ}$

$\mathrm{Y}=\mathrm{FMY} 1^{*} \mathrm{Y}$

$\mathrm{J} 1=\mathrm{Y}$

$\mathrm{Z}=\mathrm{NK}$

$\mathrm{Z}=\mathrm{FMZ} * \mathrm{Z}$

$\mathrm{K} 0=\mathrm{Z}$

$\mathrm{Z}=\mathrm{NK}$

$\mathrm{Z}=\mathrm{FMZ1}{ }^{*} \mathrm{Z}$

$\mathrm{K} 1=\mathrm{Z}$ 


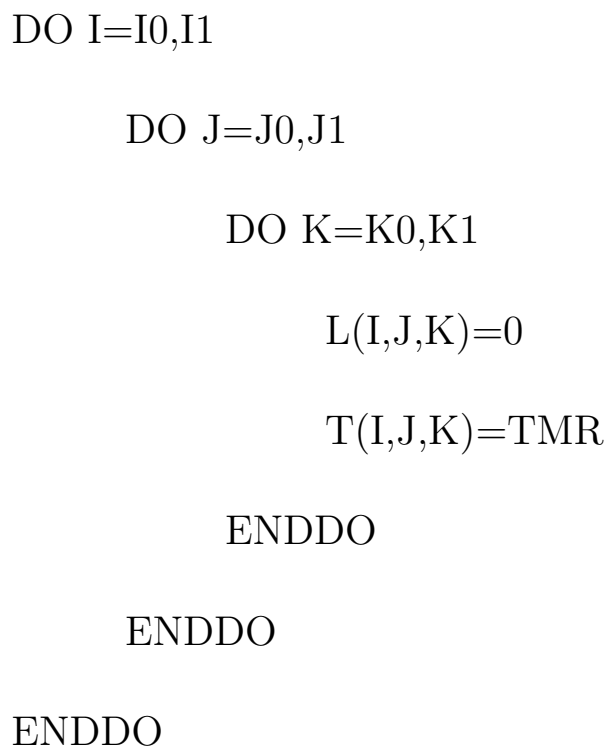




$$
\begin{aligned}
& \mathrm{Z}=\mathrm{NK} \\
& \mathrm{Z}=\mathrm{FE} 1 \mathrm{Z} 0 * \mathrm{Z} \\
& \mathrm{K} 0=\mathrm{Z} \\
& \mathrm{Z}=\mathrm{NK} \\
& \mathrm{Z}=\mathrm{FE} 1 \mathrm{Z} 1 * \mathrm{Z} \\
& \mathrm{K} 1=\mathrm{Z} \\
& \text { DO I=I0,I1 } \\
& \text { DO J=J0,J1 } \\
& \text { DO } \mathrm{K}=\mathrm{K} 0, \mathrm{~K} 1 \\
& \mathrm{~L}(\mathrm{I}, \mathrm{J}, \mathrm{K})=0 \\
& \mathrm{~T}(\mathrm{I}, \mathrm{J}, \mathrm{K})=\mathrm{TER} 1 \\
& \text { ENDDO } \\
& \text { ENDDO }
\end{aligned}
$$

\section{ENDDO}

!SECOND ELECTRODE

$$
\begin{aligned}
& \mathrm{X}=\mathrm{NI} \\
& \mathrm{X}=\mathrm{FE} 2 \mathrm{X} 0 * \mathrm{X} \\
& \mathrm{I} 0=\mathrm{X} \\
& \mathrm{X}=\mathrm{NI} \\
& \mathrm{X}=\mathrm{FE} 2 \mathrm{X} 1 * \mathrm{X}
\end{aligned}
$$




$$
\begin{aligned}
& \mathrm{I} 1=\mathrm{X} \\
& \mathrm{Y}=\mathrm{NJ} \\
& \mathrm{Y}=\mathrm{FE} 2 \mathrm{Y} 0 * \mathrm{Y} \\
& \mathrm{J} 0=\mathrm{Y} \\
& \mathrm{Y}=\mathrm{NJ} \\
& \mathrm{Y}=\mathrm{FE} 2 \mathrm{Y} 1 * \mathrm{Y} \\
& \mathrm{J} 1=\mathrm{Y} \\
& \mathrm{Z}=\mathrm{NK} \\
& \mathrm{Z}=\mathrm{FE} 2 \mathrm{Z} 0 * \mathrm{Z} \\
& \mathrm{K} 0=\mathrm{Z} \\
& \mathrm{Z}=\mathrm{NK} \\
& \mathrm{Z}=\mathrm{FE} 2 \mathrm{Z} 1 * \mathrm{Z} \\
& \mathrm{K} 1=\mathrm{Z} \\
& \text { DO I=I0,I1 } \\
& \text { DO J=J0,J1 } \\
& \text { DO } \mathrm{K}=\mathrm{K} 0, \mathrm{~K} 1 \\
& \mathrm{~L}(\mathrm{I}, \mathrm{J}, \mathrm{K})=0 \\
& \mathrm{~T}(\mathrm{I}, \mathrm{J}, \mathrm{K})=\mathrm{TER} 2 \\
& \text { ENDDO }
\end{aligned}
$$

\section{ENDDO}


RETURN

END

SUBROUTINE MENU

PARAMETER $(\mathrm{NI}=100, \mathrm{NJ}=100, \mathrm{NK}=100)$

IMPLICIT INTEGER (I,N)

IMPLICIT REAL (A-H, O-Z)

COMMON QX(0:NI,0:NJ,0:NK),QY(0:NI,0:NJ,0:NK), QZ(0:NI,0:NJ,0:NK)

COMMON T(0:NI,0:NJ,0:NK),L(0:NI,0:NJ,0:NK)

COMMON RELAX,TOL,TSR,TMR,TGR,TER1,TER2

COMMON DX,DY,DZ,QTOT,FQTOT

COMMON FSX0,FSX1,FSY0,FSY1,FSZ0,FSZ1

COMMON FGX0,FGX1,FGY0,FGY1,FGZ0,FGZ1

COMMON FMX0,FMX1,FMY0,FMY1,FMZ0,FMZ1

COMMON FE1X0,FE1X1,FE1Y0,FE1Y1,FE1Z0,FE1Z1

COMMON FE2X0,FE2X1,FE2Y0,FE2Y1,FE2Z0,FE2Z1

COMMON FPLANE

COMMON MMAX,IPLANE

WRITE $(*, *)$ 'MENU FOR 3D POTENTIAL FIELD’ 
WRITE $(*, *)^{‘}$ 'INPUT INDICATED NUMBER’

WRITE $(*, *)^{‘}[0]$ STOP PROGRAM'

$\operatorname{WRITE}(*, *)^{‘}[1]$ CALCULATE POTENTIAL FIELD'

$\operatorname{WRITE}\left(*,{ }^{*}\right)^{6}[2]$ NUMBER OF ITERATIONS $={ }^{\prime}$, MMAX

$\operatorname{WRITE}(*, *)^{\prime}[3]$ LOCATION OF MOTOR'

WRITE $\left(*,{ }^{*}\right)^{‘}[4]$ POTENTIAL OF MOTOR =',TMR

$\operatorname{WRITE}(*, *)^{‘}[5]$ LOCATION OF SOURCE’

WRITE $(*, *)^{6}[6]$ POTENTIAL OF SOURCE $=$ ',TSR

WRITE $(*, *)^{6}[7]$ LOCATION OF GROUND'

WRITE $(*, *)^{6}[8]$ POTENTIAL OF FIRST ELECTRODE $=$ ',TER1

$\operatorname{WRITE}(*, *)^{*}[9]$ LOCATION OF FIRST ELECTRODE’

WRITE $(*, *)^{‘}[10]$ POTENTIAL OF SECOND ELECTRODE $=$ ',TER2

WRITE $(*, *)^{‘}[11]$ LOCATION OF SECOND ELECTRODE’

WRITE $(*, *)^{‘}[12]$ WRITE PLANAR POTENTIALS AND CURRENTS'

WRITE $\left(*,{ }^{*}\right)^{‘}[13]$ LOAD PREVIOUS POTENTIAL FIELD’

WRITE $(*, *)^{*}[14]$ SAVE CURRENT POTENTIAL FIELD'

WRITE $(*, *)^{‘}[15]$ WRITE SELECT VALUES TO SCREEN'

$\operatorname{READ}(*, *) \mathrm{M}$

IF(M.EQ.0)THEN

STOP

ELSE IF(M.EQ.1)THEN 


\section{RETURN}

ELSE IF(M.EQ.2)THEN

$$
\begin{aligned}
& \text { WRITE }\left(*,{ }^{*}\right) \text { 'INPUT NUMBER OF ITERATIONS' } \\
& \operatorname{READ}(*, *) \text { MMAX }
\end{aligned}
$$

ELSE IF(M.EQ.3)THEN

30 WRITE $\left(*,{ }^{*}\right)^{`}$ INPUT FOR FRACTIONAL POSITION OF MOTOR’

$$
\begin{aligned}
& \operatorname{WRITE}(*, *)^{‘}[1] \text { XLOW }={ }^{\prime}, \text { FMX0 } \\
& \operatorname{WRITE}(*, *)^{‘}[2] \mathrm{XHIGH}={ }^{\prime}, \mathrm{FMX} 1 \\
& \text { WRITE }(*, *)^{‘}[3] \text { YLOW }={ }^{\prime}, \text { FMY0 } \\
& \operatorname{WRITE}(*, *)^{6}[4] \text { YHIGH }={ }^{\prime}, \text { FMY1 } \\
& \operatorname{WRITE}(*, *)^{6}[5] \mathrm{ZLOW}={ }^{\prime}, \mathrm{FMZ0} \\
& \operatorname{WRITE}\left(*,{ }^{*}\right)^{‘}[6] \mathrm{ZHIGH}={ }^{\prime}, \mathrm{FMZ1} \\
& \text { WRITE }(*, *)^{*}[0] \text { RETURN TO MAIN MENU' }
\end{aligned}
$$

$\operatorname{READ}(*, *) \mathrm{N}$

IF(N.EQ.1)THEN

$$
\begin{aligned}
& \operatorname{WRITE}(*, *)^{‘} \text { 'INPUT XLOW' } \\
& \operatorname{READ}(*, *) \text { FMX0 }
\end{aligned}
$$

ELSE IF(N.EQ.2)THEN

$$
\begin{aligned}
& \operatorname{WRITE}\left(*,{ }^{*}\right)^{‘} \operatorname{INPUT} \text { XHIGH'} \\
& \operatorname{READ}\left(*,{ }^{*}\right) \mathrm{FMX} 1
\end{aligned}
$$

ELSE IF(N.EQ.3)THEN

$$
\text { WRITE }(*, *)^{`} \text { 'INPUT YLOW' }
$$


$\operatorname{READ}(*, *)$ FMY0

ELSE IF(N.EQ.4)THEN

$$
\begin{aligned}
& \text { WRITE }\left(*, *{ }^{*}\right) \text { INPUT YHIGH' } \\
& \operatorname{READ}\left(*,{ }^{*}\right) \text { FMY1 }
\end{aligned}
$$

ELSE IF(N.EQ.5)THEN

$$
\begin{aligned}
& \operatorname{WRITE}(*, *){ }^{‘} \text { INPUT ZLOW' } \\
& \operatorname{READ}\left(*,{ }^{*}\right) \text { FMZ0 }
\end{aligned}
$$

ELSE IF(N.EQ.6)THEN

$$
\begin{aligned}
& \operatorname{WRITE}\left(*,{ }^{*}\right)^{‘} \text { INPUT ZHIGH' } \\
& \operatorname{READ}(*, *) \text { FMZ1 }
\end{aligned}
$$

\section{ENDIF}

IF(N.NE.0)

GOTO 30

ELSE IF(M.EQ.4)THEN

$$
\begin{aligned}
& \text { WRITE }(*, *) \text { 'INPUT MOTOR POTENTIAL' } \\
& \operatorname{READ}(*, *) \text { TMR }
\end{aligned}
$$

ELSE IF(M.EQ.5)THEN

50 WRITE $\left(*,{ }^{*}\right)$ 'INPUT FOR FRACTIONAL POSITION OF SOURCE'

$$
\begin{aligned}
& \operatorname{WRITE}\left(*,{ }^{*}\right)^{‘}[1] \text { XLOW }={ }^{\prime}, \mathrm{FSX} 0 \\
& \operatorname{WRITE}\left(*,{ }^{*}\right)^{6}[2] \mathrm{XHIGH}={ }^{\prime}, \mathrm{FSX} 1 \\
& \operatorname{WRITE}\left(*,{ }^{*}\right)^{6}[3] \text { YLOW }={ }^{\prime}, \text { FSY0 } \\
& \operatorname{WRITE}(*, *)^{6}[4] \text { YHIGH }=\text { ',FSY1 }
\end{aligned}
$$


$\operatorname{WRITE}(*, *)^{*}[5] \mathrm{ZLOW}={ }^{\prime}$, FSZ0

$\operatorname{WRITE}\left({ }^{*},{ }^{*}\right)^{\natural}[6] \mathrm{ZHIGH}={ }^{,}, \mathrm{FSZ1}$

WRITE $(*, *)^{‘}[0]$ RETURN TO MAIN MENU'

$\operatorname{READ}(*, *) \mathrm{N}$

IF(N.EQ.1)THEN

WRITE $(*, *) \cdot I N P U T$ XLOW'

$\operatorname{READ}(*, *) \operatorname{FSX} 0$

ELSE IF(N.EQ.2)THEN

$\operatorname{WRITE}\left(*,{ }^{*}\right)^{‘}$ INPUT XHIGH'

$\operatorname{READ}(*, *) F S X 1$

ELSE IF(N.EQ.3)THEN

WRITE $(*, *)^{‘}$ 'INPUT YLOW’

$\operatorname{READ}(*, *)$ FSY0

ELSE IF(N.EQ.4)THEN

WRITE $(*, *)^{*}$ 'INPUT YHIGH'

$\operatorname{READ}(*, *)$ FSY1

ELSE IF(N.EQ.5)THEN

WRITE $(*, *)$ 'INPUT ZLOW'

$\operatorname{READ}(*, *) \operatorname{FSZ} 0$

ELSE IF(N.EQ.6)THEN

WRITE $(*, *)^{‘}$ 'INPUT ZHIGH’

$\operatorname{READ}(*, *)$ FSZ1 


\section{ENDIF}

IF(N.NE.0)

GOTO 50

ELSE IF(M.EQ.6)THEN

WRITE $\left(*,{ }^{*}\right)^{‘}$ INPUT SOURCE POTENTIAL’

$\operatorname{READ}(*, *) \operatorname{TSR}$

ELSE IF(M.EQ.7)THEN

60 WRITE $\left(*,{ }^{*}\right)^{‘}$ INPUT FOR FRACTIONAL POSITION OF GROUND’

$\operatorname{WRITE}(*, *)^{‘}[1] \mathrm{XLOW}={ }^{\prime}, \mathrm{FGX} 0$

$\operatorname{WRITE}\left(*,{ }^{*}\right)^{\cdot}[2] \mathrm{XHIGH}={ }^{\prime}, \mathrm{FGX} 1$

$\operatorname{WRITE}(*, *)^{6}[3] \mathrm{YLOW}={ }^{\prime}, \mathrm{FGY0}$

$\operatorname{WRITE}(*, *)^{6}[4]$ YHIGH $={ }^{\prime}, \mathrm{FGY} 1$

$\operatorname{WRITE}\left(*,{ }^{*}\right)^{6}[5]$ ZLOW $={ }^{\prime}$, FGZ0

$\operatorname{WRITE}\left(*,{ }^{*}\right)^{`}[6] \mathrm{ZHIGH}={ }^{\prime}, \mathrm{FGZ1}$

WRITE $\left(*,{ }^{*}\right)^{‘}[0]$ RETURN TO MAIN MENU'

$\operatorname{READ}(*, *) \mathrm{N}$

IF(N.EQ.1)THEN

WRITE $(*, *)^{‘}$ 'INPUT XLOW’

$\operatorname{READ}(*, *)$ FGX0

ELSE IF(N.EQ.2)THEN

WRITE $(*, *)^{\prime}$ INPUT XHIGH'

$\operatorname{READ}(*, *)$ FGX1 
ELSE IF(N.EQ.3)THEN

$$
\begin{aligned}
& \text { WRITE }(*, *) \text { 'INPUT YLOW' } \\
& \operatorname{READ}(*, *) \text { FGY0 }
\end{aligned}
$$

ELSE IF(N.EQ.4)THEN

$$
\begin{aligned}
& \text { WRITE }\left(*,{ }^{*}\right)^{‘} \text { INPUT YHIGH' } \\
& \operatorname{READ}(*, *) \text { FGY1 }
\end{aligned}
$$

ELSE IF(N.EQ.5)THEN

$$
\begin{aligned}
& \operatorname{WRITE}(*, *) ‘ \text { 'INPUT ZLOW’ } \\
& \operatorname{READ}(*, *) \text { FGZ0 }
\end{aligned}
$$

ELSE IF(N.EQ.6)THEN

$$
\begin{aligned}
& \operatorname{WRITE}(*, *)^{‘} \text { 'INPUT ZHIGH' } \\
& \operatorname{READ}(*, *) \text { FGZ1 }
\end{aligned}
$$

ENDIF

IF(N.NE.0)

\section{GOTO 60}

ELSE IF(M.EQ.8)THEN

$$
\begin{aligned}
& \text { WRITE }\left(*,{ }^{*}\right)^{‘} \text { INPUT FIRST ELECTRODE POTENIAL' } \\
& \operatorname{READ}(*, *) \text { TER1 }
\end{aligned}
$$

ELSE IF(M.EQ.9)THEN

70 WRITE $\left(*,{ }^{*}\right)^{`}$ INPUT FOR FRACT POSN OF FIRST ELECTRODE’

$$
\begin{aligned}
& \operatorname{WRITE}(*, *)^{‘}[1] \text { XLOW }={ }^{\prime}, \text { FE1X0 } \\
& \operatorname{WRITE}(*, *)^{\circ}[2] \text { XHIGH }={ }^{\prime}, \text { FE1X1 }
\end{aligned}
$$




$$
\begin{aligned}
& \operatorname{WRITE}(*, *)^{\cdot}[3] \text { YLOW }={ }^{\prime}, \mathrm{FE} 1 \mathrm{Y} 0 \\
& \operatorname{WRITE}(*, *)^{‘}[4] \mathrm{YHIGH}={ }^{\prime}, \mathrm{FE} 1 \mathrm{Y} 1 \\
& \operatorname{WRITE}(*, *)^{`}[5] \mathrm{ZLOW}={ }^{,}, \mathrm{FE} 1 \mathrm{ZL} \\
& \operatorname{WRITE}(*, *)^{‘}[6] \mathrm{ZHIGH}={ }^{\prime}, \mathrm{FE} 1 \mathrm{Z1} \\
& \text { WRITE }(*, *)^{*}[0] \text { RETURN TO MAIN MENU' }
\end{aligned}
$$

$\operatorname{READ}(*, *) \mathrm{N}$

IF(N.EQ.1)THEN

$$
\begin{aligned}
& \operatorname{WRITE}(*, *)^{‘} \text { INPUT XLOW’ } \\
& \operatorname{READ}(*, *) \text { FE1X0 }
\end{aligned}
$$

ELSE IF(N.EQ.2)THEN

$$
\begin{aligned}
& \operatorname{WRITE}(*, *)^{‘} \operatorname{INPUT} \text { XHIGH’} \\
& \operatorname{READ}\left(*,{ }^{*}\right) \mathrm{FE} 1 \mathrm{X} 1
\end{aligned}
$$

ELSE IF(N.EQ.3)THEN

$$
\begin{aligned}
& \operatorname{WRITE}(*, *)^{‘} \text { INPUT YLOW' } \\
& \operatorname{READ}(*, *) \text { FE1Y0 }
\end{aligned}
$$

ELSE IF(N.EQ.4)THEN

$$
\begin{aligned}
& \operatorname{WRITE}\left(*,{ }^{*}\right) \text { 'INPUT YHIGH' } \\
& \operatorname{READ}(*, *) \text { FE1Y1 }
\end{aligned}
$$

ELSE IF(N.EQ.5)THEN

$$
\begin{aligned}
& \operatorname{WRITE}(*, *)^{‘} \text { 'INPUT ZLOW' } \\
& \operatorname{READ}\left(*,{ }^{*}\right) \text { FE1Z0 }
\end{aligned}
$$

ELSE IF(N.EQ.6)THEN 
WRITE $\left(*,{ }^{*}\right)^{‘}$ INPUT ZHIGH’

$\operatorname{READ}\left({ }^{*},{ }^{*}\right)$ FE1Z1

ENDIF

IF(N.NE.0)GOTO 70

ELSE IF(M.EQ.10)THEN

WRITE $\left(*,{ }^{*}\right)^{‘}$ INPUT SECOND ELECTRODE POTENIAL'

$\operatorname{READ}(*, *) \operatorname{TER} 2$

ELSE IF(M.EQ.11)THEN

80 WRITE $\left(*,{ }^{*}\right)^{‘}$ INPUT FOR FRACT POSN OF SECOND ELECTRODE’

$\operatorname{WRITE}\left(*,{ }^{*}\right)^{‘}[1]$ XLOW $={ }^{,}, \mathrm{FE} 2 \mathrm{X} 0$

$\operatorname{WRITE}(*, *)^{\cdot}[2] \mathrm{XHIGH}={ }^{\prime}, \mathrm{FE} 2 \mathrm{X} 1$

$\operatorname{WRITE}\left(*,{ }^{*}\right)^{‘}[3]$ YLOW $={ }^{\prime}$, FE2Y0

$\operatorname{WRITE}(*, *)^{*}[4]$ YHIGH $={ }^{\prime}$, FE2Y1

$\operatorname{WRITE}(*, *)^{‘}[5]$ ZLOW $={ }^{\prime}$, FE2Z0

$\operatorname{WRITE}\left(*,{ }^{*}\right)^{*}[6]$ ZHIGH $={ }^{\prime}$, FE2Z1

WRITE $(*, *)^{‘}[0]$ RETURN TO MAIN MENU'

$\operatorname{READ}(*, *) \mathrm{N}$

IF(N.EQ.1)THEN

WRITE $(*, *)$ 'INPUT XLOW'

$\operatorname{READ}\left(*,{ }^{*}\right) \operatorname{FE} 2 \mathrm{X0}$

ELSE IF(N.EQ.2)THEN

WRITE $\left(*,{ }^{*}\right)^{‘}$ INPUT XHIGH’ 
$\operatorname{READ}(*, *)$ FE2X1

ELSE IF(N.EQ.3)THEN

$$
\begin{aligned}
& \operatorname{WRITE}\left(*,{ }^{*}\right)^{‘} \text { INPUT YLOW' } \\
& \operatorname{READ}\left(*,{ }^{*}\right) \text { FE2Y0 }
\end{aligned}
$$

ELSE IF(N.EQ.4)THEN

$$
\begin{aligned}
& \operatorname{WRITE}(*, *)^{\prime} \text { INPUT YHIGH' } \\
& \operatorname{READ}\left(*,{ }^{*}\right) \mathrm{FE} 2 \mathrm{Y} 1
\end{aligned}
$$

ELSE IF(N.EQ.5)THEN

$$
\begin{aligned}
& \operatorname{WRITE}(*, *)^{‘} \text { 'INPUT ZLOW' } \\
& \operatorname{READ}(*, *) \text { FE2Z0 }
\end{aligned}
$$

ELSE IF(N.EQ.6)THEN

$$
\begin{aligned}
& \operatorname{WRITE}\left(*,{ }^{*}\right)^{‘} \text { INPUT ZHIGH' } \\
& \operatorname{READ}(*, *) \text { FE2Z1 }
\end{aligned}
$$

ENDIF

IF(N.NE.0)

GOTO 80

ELSE IF(M.EQ.12)THEN

$$
\begin{aligned}
& \operatorname{WRITE}(*, *)^{‘} \operatorname{INPUT} \text { CHOICE OF PLANE }(1=\mathrm{X}, 2=\mathrm{Y}, 3=\mathrm{Z})^{\prime} \\
& \operatorname{READ}(*, *) \operatorname{IPLANE} \\
& \operatorname{WRITE}\left(*, *{ }^{‘}\right. \text { 'INPUT FRAC LOCATION OF PLANE' } \\
& \operatorname{READ}(*, *) \text { FPLANE }
\end{aligned}
$$

CALL RESULTS 
ELSE IF(M.EQ.13)THEN

CALL OLDFILE

ELSE IF(M.EQ.14)THEN

CALL SAVEFILE

ELSE IF(M.EQ.15)THEN

WRITE $\left(*{ }^{*}\right)^{`}$ 'INPUT PLANE TO WRITE TO SCREEN’

$\operatorname{WRITE}\left(*{ }^{*}\right)^{6} 1=\mathrm{X}, 2=\mathrm{Y}, 3=\mathrm{Z}$

$\operatorname{READ}(*, *) \operatorname{IP}$

WRITE $(*, *)^{‘}$ INPUT PLANE POSITION IN I,J,OR K'

$\operatorname{READ}(*, *) \operatorname{IIJK}$

WRITE $(*, *)^{‘}$ INPUT RANGES TO WRITE TO SCREEN'

IF(IP.EQ.1)THEN

$\mathrm{I}=\mathrm{IIJK}$

$\operatorname{WRITE}(*, *)^{`} \mathrm{~J} 0, \mathrm{~J} 1^{\prime}$

$\operatorname{READ}(*, *) \mathrm{J} 0, \mathrm{~J} 1$

$\operatorname{WRITE}(*, *) \cdot \mathrm{K} 0, \mathrm{~K} 1$ ’

$\operatorname{READ}(*, *) \mathrm{K} 0, \mathrm{~K} 1$

$\operatorname{WRITE}(*, *)^{‘} \mathrm{~J}, \mathrm{~K}, \mathrm{~T}, \mathrm{QX}$ ’

DO J=J0,J1

$\mathrm{DO} \mathrm{K}=\mathrm{K} 0, \mathrm{~K} 1$

WRITE $\left(*{ }^{*}\right)^{`}$ 'J,K, T(I,J,K), QX(I,J,K)'

ENDDO 


\section{ENDDO}

ELSE IF(IP.EQ.2)THEN

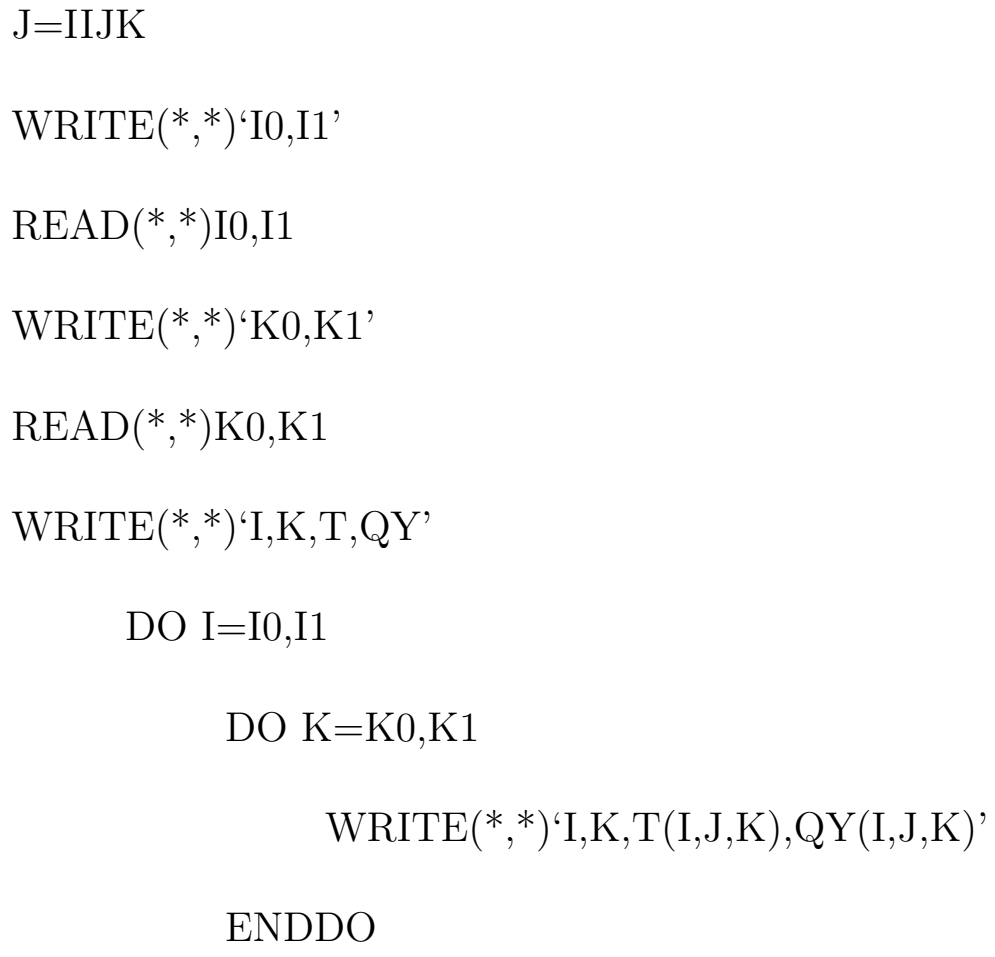




\section{ENDDO}

ENDDO

ENDIF

PAUSE

ENDIF

GOTO 5

END

$=\mathrm{E}=\mathrm{=}=\mathrm{=}=\mathrm{=}=\mathrm{=}=\mathrm{=}=\mathrm{=}=\mathrm{=}=\mathrm{=}=\mathrm{=}=\mathrm{=}=\mathrm{=}=\mathrm{=}=\mathrm{=}=\mathrm{=}=\mathrm{=}$

SUBROUTINE CALCT

!THIS SUBROUTINE CALCULATES THE POTENTIAL FIELD IT APPLIES A GAUSS-SIEDEL ITERATIVE PROCEDURE AND CHECKS EACH POINT FOR CONVERGENCE

PARAMETER $(\mathrm{NI}=100, \mathrm{NJ}=100, \mathrm{NK}=100)$

IMPLICIT INTEGER (I,N)

IMPLICIT REAL (A-H, O-Z)

COMMON QX(0:NI,0:NJ,0:NK),QY(0:NI,0:NJ,0:NK), QZ(0:NI,0:NJ,0:NK)

COMMON T(0:NI,0:NJ,0:NK),L(0:NI,0:NJ,0:NK)

COMMON RELAX,TOL,TSR,TMR,TGR,TER1,TER2 


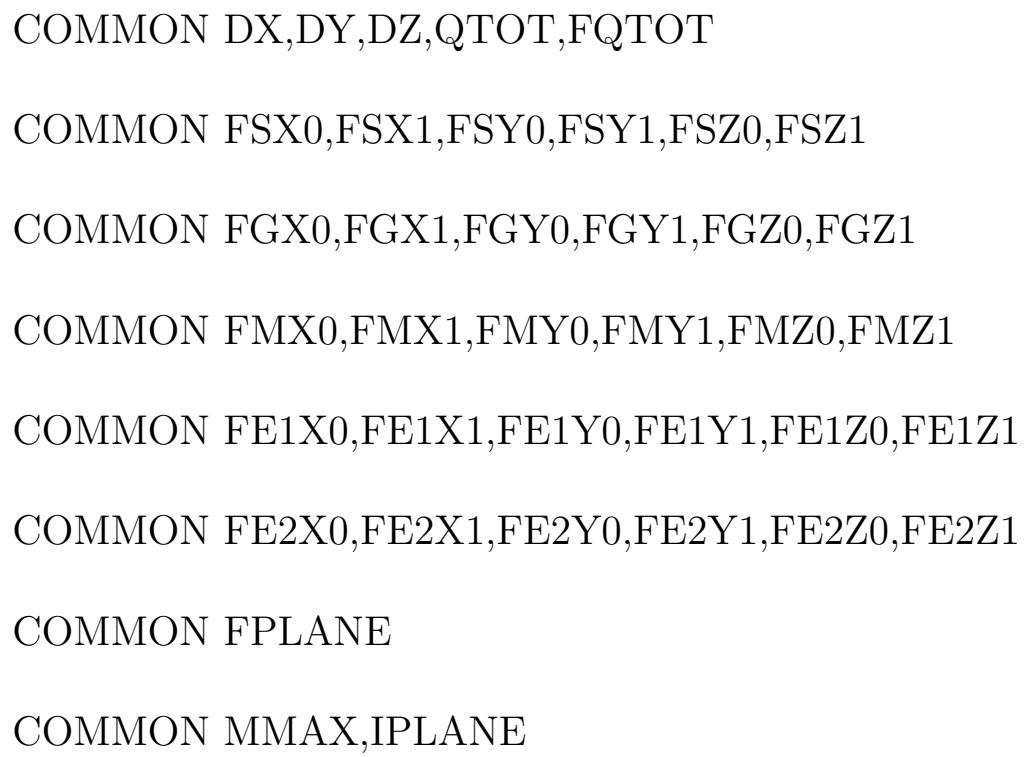




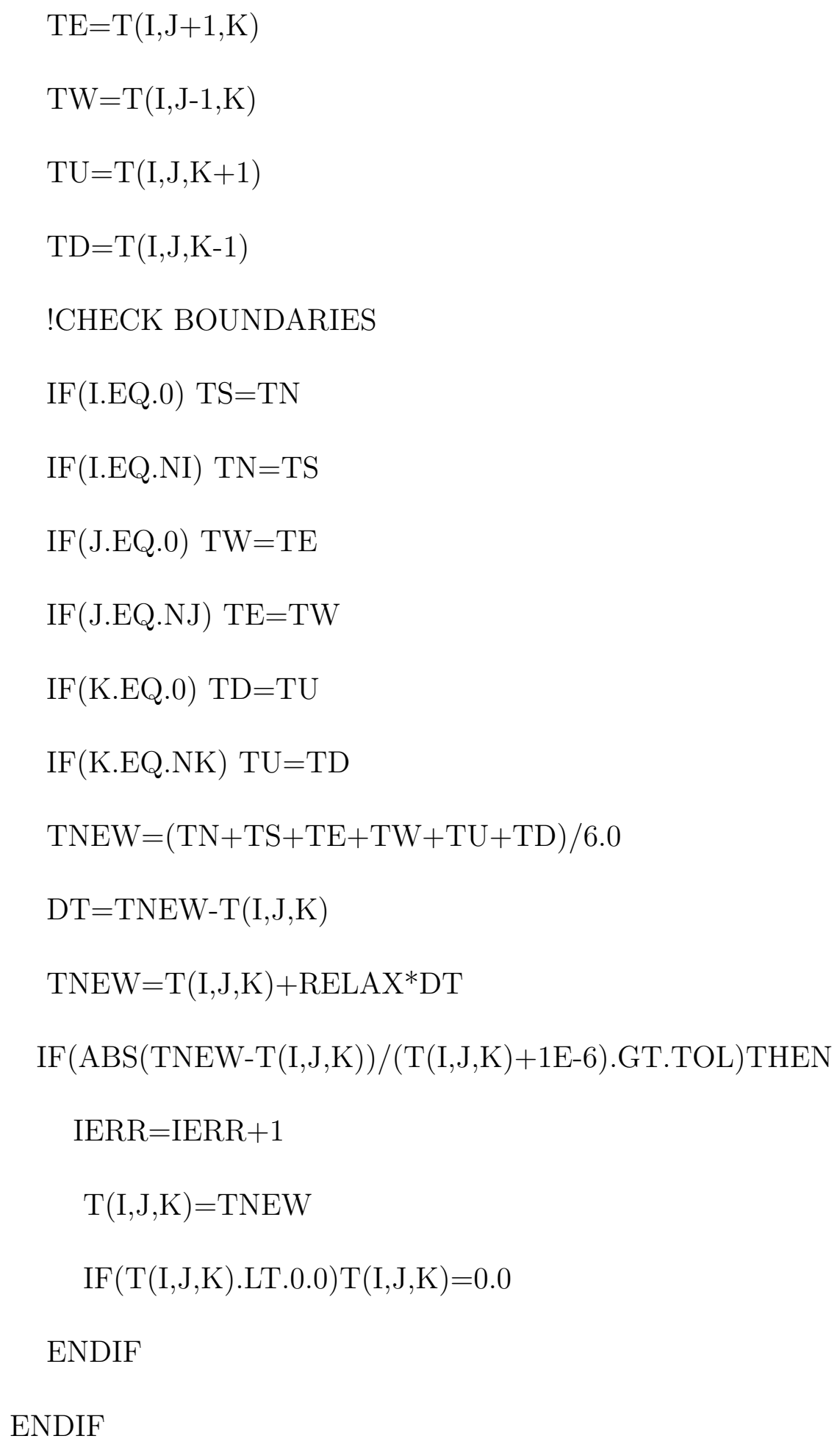


ENDDO

IF(IERR.EQ.0)MCONVG=M

ENDIF

ENDDO

IF(MCONVG.GT.0)THEN

WRITE $\left(*,{ }^{*}\right)^{\prime}$ CONVERGENCE REACHED AFTER ',MCONVG,' ITERATIONS'

ELSE

WRITE $(*, *)^{`}$ CONVERGENCE NOT REACHED’

ENDIF

! WRITE POTENTIAL FIELD TO FILE HERE... CALL SAVE

RETURN

END

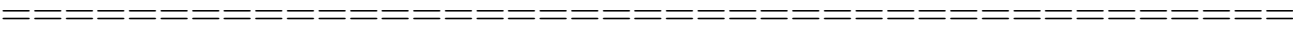

SUBROUTINE CALCQ

!THIS SUBROUTINE CALCUATES THE CURRENT FLUX X,Y,Z COMPONENTS USING A SECOND ORDER SLOPE ESTIMATE FOR THE INTERIOR POINTS AND FIRST ORDER ESTIMATE FOR BOUNDARY POINTS 


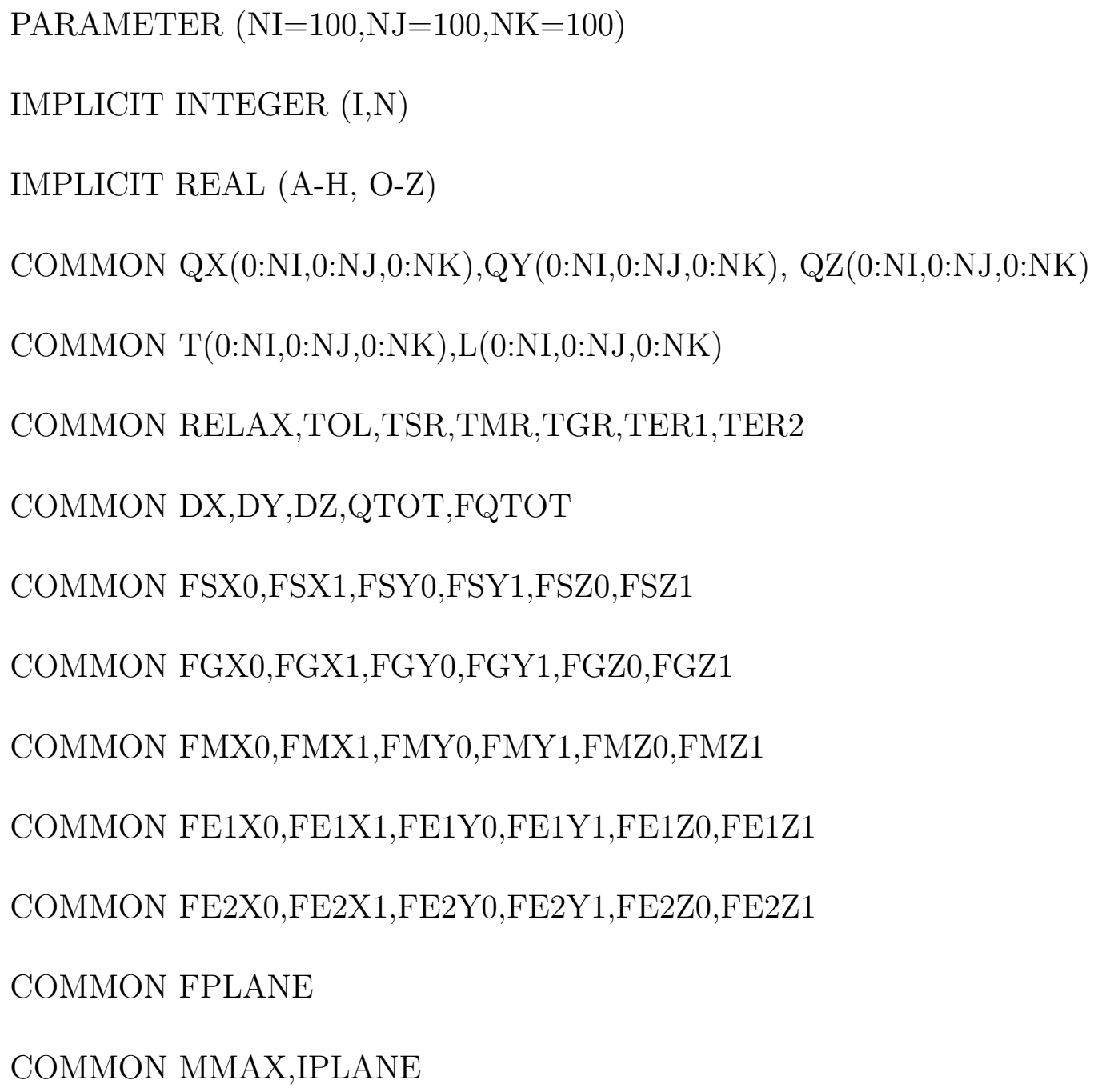




$$
\begin{aligned}
& \mathrm{SY}=2.0 \\
& \mathrm{SZ}=2.0 \\
& \mathrm{TN}=\mathrm{T}(\mathrm{I}+1, \mathrm{~J}, \mathrm{~K}) \\
& \mathrm{TS}=\mathrm{T}(\mathrm{I}-1, \mathrm{~J}, \mathrm{~K}) \\
& \mathrm{TE}=\mathrm{T}(\mathrm{I}, \mathrm{J}+1, \mathrm{~K}) \\
& \mathrm{TW}=\mathrm{T}(\mathrm{I}, \mathrm{J}-1, \mathrm{~K}) \\
& \mathrm{TU}=\mathrm{T}(\mathrm{I}, \mathrm{J}, \mathrm{K}+1) \\
& \mathrm{TD}=\mathrm{T}(\mathrm{I}, \mathrm{J}, \mathrm{K}-1) \\
& \text { !CHECK BOUNDARIES } \\
& \text { IF(I.EQ.0) THEN } \\
& \mathrm{TS}=\mathrm{TN} ! \mathrm{FOR} \text { INSULATOR } \\
& \mathrm{SX}=1.0 \\
& \operatorname{IF}(\mathrm{L}(\mathrm{I}, \mathrm{J}, \mathrm{K}) \cdot \mathrm{EQ} .0) \mathrm{TS}=\mathrm{T}(\mathrm{I}, \mathrm{J}, \mathrm{K}) \\
& \text { ELSE IF(I.EQ.NI)THEN } \\
& \mathrm{TN}=\mathrm{TS} \\
& \mathrm{SX}=1.0 \\
& \text { IF(L(I,J,K).EQ.0)TN=T(I,J,K) } \\
& \text { ENDIF } \\
& \text { IF(J.EQ.0) THEN } \\
& \mathrm{TW}=\mathrm{TE} \\
& \mathrm{SY}=1.0 \\
& \text { IF(L(I,J,K).EQ.0)TW=T(I,J,K) }
\end{aligned}
$$




$$
\begin{aligned}
& \text { ELSE IF(J.EQ.NJ)THEN } \\
& \mathrm{TE}=\mathrm{TW} \\
& \mathrm{SY}=1.0 \\
& \mathrm{IF}(\mathrm{L}(\mathrm{I}, \mathrm{J}, \mathrm{K}) \cdot \mathrm{EQ} .0) \mathrm{TE}=\mathrm{T}(\mathrm{I}, \mathrm{J}, \mathrm{K}) \\
& \text { ENDIF } \\
& \text { IF(K.EQ.0) THEN } \\
& \mathrm{TD}=\mathrm{TU} \\
& \mathrm{SZ}=1.0 \\
& \mathrm{IF}(\mathrm{L}(\mathrm{I}, \mathrm{J}, \mathrm{K}) . \mathrm{EQ} .0) \mathrm{TD}=\mathrm{T}(\mathrm{I}, \mathrm{J}, \mathrm{K}) \\
& \text { ELSE IF(K.EQ.NK)THEN } \\
& \mathrm{TU}=\mathrm{TD} \\
& \mathrm{SZ}=1.0 \\
& \text { IF(L(I,J,K).EQ.0)TU=T(I,J,K) } \\
& \text { ENDIF } \\
& \mathrm{QX}(\mathrm{I}, \mathrm{J}, \mathrm{K})=(\mathrm{TS}-\mathrm{TN}) / \mathrm{SX} / \mathrm{DX} \\
& \mathrm{QY}(\mathrm{I}, \mathrm{J}, \mathrm{K})=(\mathrm{TW}-\mathrm{TE}) / \mathrm{SY} / \mathrm{DY} \\
& \mathrm{QZ}(\mathrm{I}, \mathrm{J}, \mathrm{K})=(\mathrm{TD}-\mathrm{TU}) / \mathrm{SZ} / \mathrm{DZ}
\end{aligned}
$$

\section{ENDDO}

\section{ENDDO}

\section{ENDDO}


! CALCUlate TOTAL Q IN Z DIRECTION AT Z PLANE AT FRACTIONAL POSITION Z $=0.2$

! THIS Q CAN BE USED TO DETERMINE THE OVERALL CALCULATION ACCURACY AND CONVERGENCE

$\mathrm{Z}=\mathrm{NK}$

$\mathrm{Z}=\mathrm{FQTOT}^{*} \mathrm{Z}$

$\mathrm{K}=\mathrm{Z}$

$\mathrm{QTOT}=0.0$

DO I $=0, \mathrm{NI}$

DO J $=0, \mathrm{NJ}$

$$
\begin{aligned}
& \mathrm{DQ}=\mathrm{QZ}(\mathrm{I}, \mathrm{J}, \mathrm{K}) * \mathrm{DX} * \mathrm{DY} \\
& \mathrm{IF}((\mathrm{I} . \mathrm{EQ} .0) . \mathrm{OR} .(\mathrm{I} \cdot \mathrm{EQ} . \mathrm{NI})) \mathrm{DQ}=\mathrm{DQ} / 2.0 \\
& \mathrm{IF}((\text { J.EQ.0).OR.(J.EQ.NJ) }) \mathrm{DQ}=\mathrm{DQ} / 2.0 \\
& \text { QTOT=QTOT }+\mathrm{DQ}
\end{aligned}
$$

ENDDO

ENDDO

$\operatorname{WRITE}\left(*,{ }^{*}\right)^{‘} \mathrm{QTOT}=$ ', QTOT

PAUSE 
RETURN

END

SUBROUTINE RESULTS

PARAMETER $(\mathrm{NI}=100, \mathrm{NJ}=100, \mathrm{NK}=100)$

IMPLICIT INTEGER (I,N)

IMPLICIT REAL (A-H, O-Z)

COMMON QX(0:NI,0:NJ,0:NK),QY(0:NI,0:NJ,0:NK), QZ(0:NI,0:NJ,0:NK)

COMMON T(0:NI,0:NJ,0:NK),L(0:NI,0:NJ,0:NK)

COMMON RELAX,TOL,TSR,TMR,TGR,TER1,TER2

COMMON DX,DY,DZ,QTOT,FQTOT

COMMON FSX0,FSX1,FSY0,FSY1,FSZ0,FSZ1

COMMON FGX0,FGX1,FGY0,FGY1,FGZ0,FGZ1

COMMON FMX0,FMX1,FMY0,FMY1,FMZ0,FMZ1

COMMON FE1X0,FE1X1,FE1Y0,FE1Y1,FE1Z0,FE1Z1

COMMON FE2X0,FE2X1,FE2Y0,FE2Y1,FE2Z0,FE2Z1

COMMON FPLANE

COMMON MMAX,IPLANE

DIMENSION XT(0:NI),YT(0:NJ),ZT(0:NK) 
! CALCULATE POSITIONS

DO I $=0, \mathrm{NI}$

$$
\mathrm{X}=\mathrm{I}
$$

$$
\mathrm{XT}(\mathrm{I})=\mathrm{DX} * \mathrm{X}
$$

ENDDO

DO J $=0, \mathrm{NJ}$

$$
\begin{aligned}
& \mathrm{Y}=\mathrm{J} \\
& \mathrm{YT}(\mathrm{J})=\mathrm{DY}^{*} \mathrm{Y}
\end{aligned}
$$

\section{ENDDO}

DO $\mathrm{K}=0, \mathrm{NK}$

$$
\begin{aligned}
& \mathrm{Z}=\mathrm{K} \\
& \mathrm{ZT}(\mathrm{K})=\mathrm{DZ} * \mathrm{Z}
\end{aligned}
$$

\section{ENDDO}

! WRITE TO FILES

IF(IPLANE.EQ.1)THEN！X PLANE (I IS FIXED)

$$
\begin{aligned}
& \mathrm{X}=\mathrm{NI} \\
& \mathrm{X}=\mathrm{FPLANE} \text { } \mathrm{X} \\
& \mathrm{I}=\mathrm{X} \quad \text { ! LOCATION OF X PLANE } \\
& \text { OPEN(UNIT=2,FILE='YZ.DAT',STATUS='UNKNOWN') } \\
& \text { OPEN(UNIT=3,FILE='QYZ.DAT',STATUS='UNKNOWN') } \\
& \text { OPEN(UNIT=4,FILE='TYZ.DAT',STATUS='UNKNOWN') } \\
& ! \text { WRITE POTENTIALS TO FILE TO PLOT IN MSEXCEL }
\end{aligned}
$$


$\operatorname{WRITE}\left(4,{ }^{*}\right)^{‘} \mathrm{XPLANE},(\mathrm{YT}(\mathrm{J}), \mathrm{J}=0, \mathrm{NJ})$

DO $\mathrm{K}=0, \mathrm{NK}$

$\operatorname{WRITE}\left(4,{ }^{*}\right) \mathrm{ZT}(\mathrm{K}),(\mathrm{T}(\mathrm{I}, \mathrm{J}, \mathrm{K}), \mathrm{J}=0, \mathrm{NJ})$

ENDDO

! WRITE FLUX FIELDS TO FILE TO PLOT IN VECTOR PLOT

DO J $=0, \mathrm{NJ}$

$\mathrm{DO} \mathrm{K}=0, \mathrm{NK}$

$\mathrm{Z}=\mathrm{K}$

$\mathrm{Z}=\mathrm{DZ} * \mathrm{Z}$

$\operatorname{WRITE}\left(2,{ }^{*}\right) \mathrm{YT}(\mathrm{J}), \mathrm{Z}$

$\operatorname{WRITE}\left(3,{ }^{*}\right) \mathrm{QY}(\mathrm{I}, \mathrm{J}, \mathrm{K}), \mathrm{QZ}(\mathrm{I}, \mathrm{J}, \mathrm{K})$

ENDDO

ENDDO

$\operatorname{CLOSE}(\mathrm{UNIT}=2)$

CLOSE(UNIT $=3)$

ELSE IF(IPLANE.EQ.2)THEN! Y PLANE (J IS FIXED)

$$
\begin{aligned}
& \mathrm{Y}=\mathrm{NJ} \\
& \mathrm{Y}=\mathrm{FPLANE} \text { ' } \mathrm{T} \\
& \mathrm{J}=\mathrm{Y} \quad ! \mathrm{LOCATION} \text { OF Y PLANE } \\
& \text { OPEN(UNIT=2,FILE='XZ.DAT',STATUS='UNKNOWN') } \\
& \text { OPEN(UNIT=3,FILE='QXZ.DAT',STATUS='UNKNOWN') } \\
& \text { OPEN(UNIT=4,FILE='TXZ.DAT',STATUS='UNKNOWN') }
\end{aligned}
$$


! WRITE POTENTIALS TO FILE TO PLOT IN MSEXCEL

$\operatorname{WRITE}\left(4,{ }^{*}\right)^{‘} \mathrm{YPLANE},(\mathrm{XT}(\mathrm{I}), \mathrm{I}=0, \mathrm{NI})$

$\mathrm{DO} \mathrm{K}=0, \mathrm{NK}$

$\operatorname{WRITE}\left(4,{ }^{*}\right) \mathrm{ZT}(\mathrm{K}),(\mathrm{T}(\mathrm{I}, \mathrm{J}, \mathrm{K}), \mathrm{I}=0, \mathrm{NI})$

ENDDO

! WRITE FLUX FIELDS TO FILE TO PLOT IN VECTOR PLOT

DO I $=0, \mathrm{NI}$

$\mathrm{X}=\mathrm{I}$

$\mathrm{X}=\mathrm{X}^{*} \mathrm{DX}$

DO K=0,NK

$\mathrm{Z}=\mathrm{K}$

$\mathrm{Z}=\mathrm{DZ} * \mathrm{Z}$

$\operatorname{WRITE}\left(2,{ }^{*}\right) \mathrm{X}, \mathrm{Z}$

WRITE $\left(3,{ }^{*}\right) \mathrm{QX}(\mathrm{I}, \mathrm{J}, \mathrm{K}), \mathrm{QZ}(\mathrm{I}, \mathrm{J}, \mathrm{K})$

ENDDO

ENDDO

ELSE ! Z PLANE (K IS FIXED)

$\mathrm{Z}=\mathrm{NK}$

$\mathrm{Z}=\mathrm{FPLANE} * \mathrm{Z}$

$\mathrm{K}=\mathrm{Z} \quad$ ! LOCATION OF Z PLANE

OPEN $(\mathrm{UNIT}=2, \mathrm{FILE}=$ 'XY.DAT',STATUS='UNKNOWN')

OPEN(UNIT=3,FILE='QXY.DAT',STATUS='UNKNOWN') 
OPEN $($ UNIT=4,FILE='TXY.DAT',STATUS='UNKNOWN')

! WRITE POTENTIALS TO FILE TO PLOT IN MSEXCEL

$\operatorname{WRITE}\left(4,{ }^{*}\right)^{`}$ ZPLANE',(XT $\left.(\mathrm{J}), \mathrm{I}=0, \mathrm{NI}\right)$

DO J $=0, \mathrm{NJ}$

$\operatorname{WRITE}\left(4,{ }^{*}\right) \mathrm{YT}(\mathrm{J}),(\mathrm{T}(\mathrm{I}, \mathrm{J}, \mathrm{K}), \mathrm{I}=0, \mathrm{NI})$

ENDDO

! WRITE FLUX FIELDS TO FILE TO PLOT IN VECTOR PLOT

DO I $=0, \mathrm{NI}$

$\mathrm{X}=\mathrm{I}$

$\mathrm{X}=\mathrm{X}^{*} \mathrm{DX}$

DO J $=0, \mathrm{NJ}$

$\mathrm{Y}=\mathrm{J}$

$\mathrm{Y}=\mathrm{Y}^{*} \mathrm{DY}$

$\operatorname{WRITE}\left(2,{ }^{*}\right) \mathrm{X}, \mathrm{Y}$

WRITE $\left(3,{ }^{*}\right) \mathrm{QX}(\mathrm{I}, \mathrm{J}, \mathrm{K}), \mathrm{QY}(\mathrm{I}, \mathrm{J}, \mathrm{K})$

ENDDO

ENDDO

ENDIF

CLOSE(UNIT $=2$ )

CLOSE(UNIT $=3$ )

CLOSE(UNIT $=4$ )

RETURN 
END

SUBROUTINE SAVEFILE

PARAMETER $(\mathrm{NI}=100, \mathrm{NJ}=100, \mathrm{NK}=100)$

IMPLICIT INTEGER (I,N)

IMPLICIT REAL (A-H, O-Z)

COMMON QX(0:NI,0:NJ,0:NK),QY(0:NI,0:NJ,0:NK), QZ(0:NI,0:NJ,0:NK)

COMMON T(0:NI,0:NJ,0:NK),L(0:NI,0:NJ,0:NK)

COMMON RELAX,TOL,TSR,TMR,TGR,TER1,TER2

COMMON DX,DY,DZ,QTOT,FQTOT

COMMON FSX0,FSX1,FSY0,FSY1,FSZ0,FSZ1

COMMON FGX0,FGX1,FGY0,FGY1,FGZ0,FGZ1

COMMON FMX0,FMX1,FMY0,FMY1,FMZ0,FMZ1

COMMON FE1X0,FE1X1,FE1Y0,FE1Y1,FE1Z0,FE1Z1

COMMON FE2X0,FE2X1,FE2Y0,FE2Y1,FE2Z0,FE2Z1

COMMON FPLANE

COMMON MMAX,IPLANE

OPEN (UNIT=7, FILE='3DFIELD.DAT',STATUS='REPLACE',ERR=99)

WRITE(7,900) NI,NJ,NK

DO $\mathrm{I}=0, \mathrm{NI}$ 


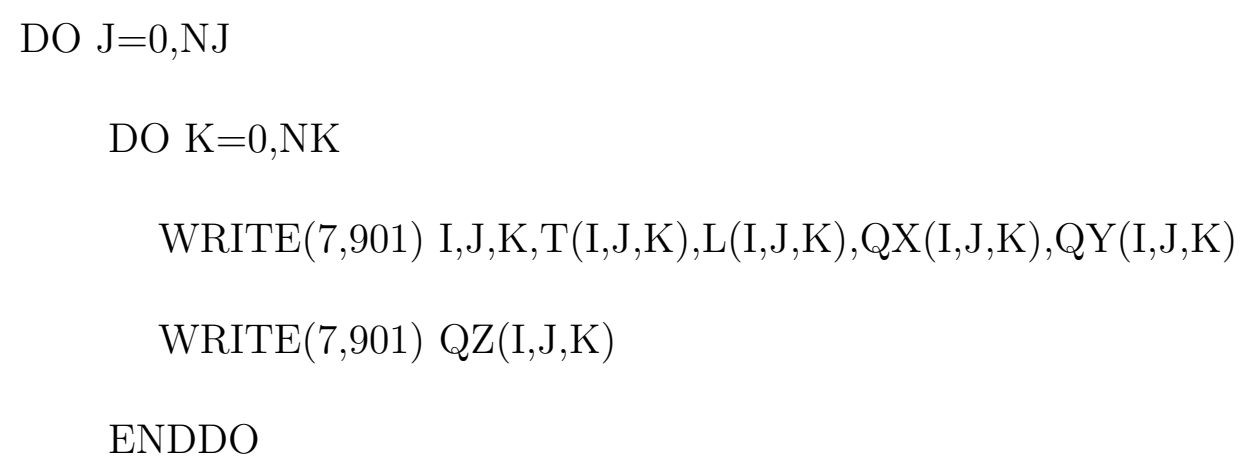

\section{ENDDO}

\section{ENDDO}

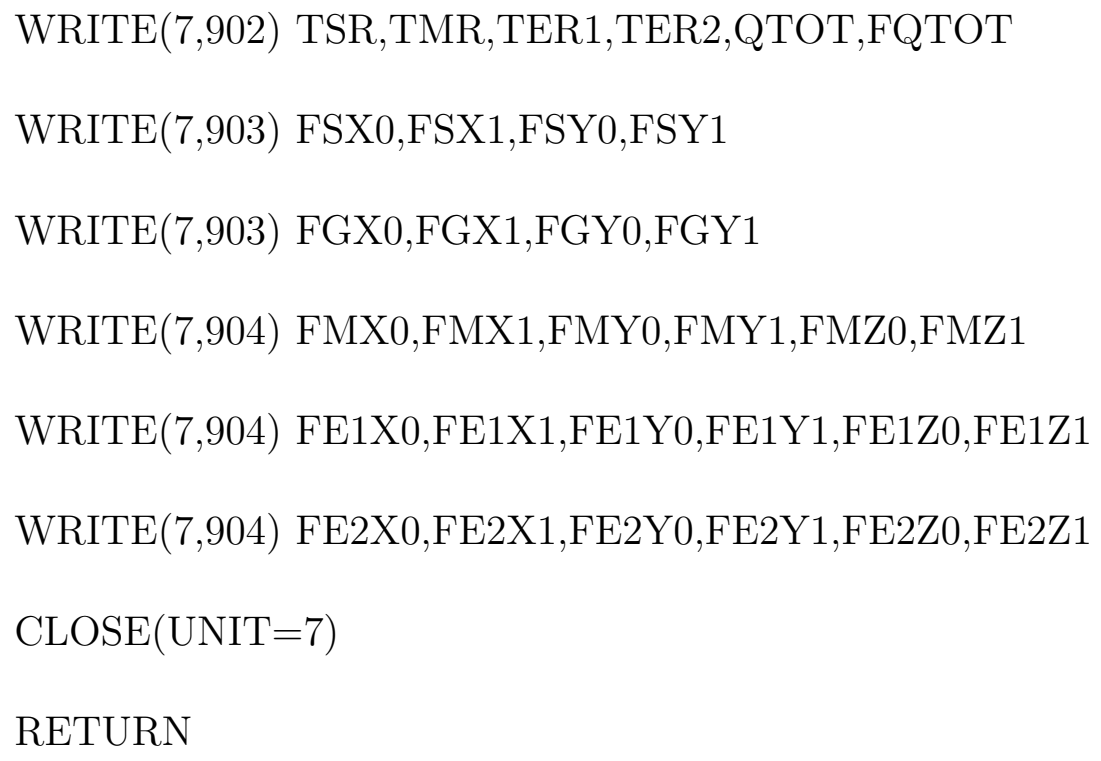


901 FORMAT(1X,3(I8,','),F12.8,',',I8,3(',',F12.8))

902 FORMAT(1X,5(F12.8,','))

903 FORMAT(1X,4(F12.8,','))

904 FORMAT(1X,6(F12.8,','))

END

SUBROUTINE OLDFILE

! THIS SUBROUTINE LOADS VALUES FROM AN OLD DATA FILE

PARAMETER $(\mathrm{NI}=100, \mathrm{NJ}=100, \mathrm{NK}=100)$

IMPLICIT INTEGER $(\mathrm{I}, \mathrm{N})$

IMPLICIT REAL (A-H, O-Z)

COMMON QX(0:NI,0:NJ,0:NK),QY(0:NI,0:NJ,0:NK), QZ(0:NI,0:NJ,0:NK)

COMMON T(0:NI,0:NJ,0:NK),L(0:NI,0:NJ,0:NK)

COMMON RELAX,TOL,TSR,TMR,TGR,TER1,TER2

COMMON DX,DY,DZ,QTOT,FQTOT

COMMON FSX0,FSX1,FSY0,FSY1,FSZ0,FSZ1

COMMON FGX0,FGX1,FGY0,FGY1,FGZ0,FGZ1

COMMON FMX0,FMX1,FMY0,FMY1,FMZ0,FMZ1 
COMMON FE1X0,FE1X1,FE1Y0,FE1Y1,FE1Z0,FE1Z1

COMMON FE2X0,FE2X1,FE2Y0,FE2Y1,FE2Z0,FE2Z1

COMMON FPLANE

COMMON MMAX,IPLANE

OPEN (UNIT=8, FILE='3DFIELD.DAT',STATUS='OLD',ERR=99)

! MUST CHECK THAT NI,NJ,NK ARE SAME SIZE

$\operatorname{READ}(8,900, \mathrm{ERR}=90, \mathrm{END}=92) \mathrm{NI} 1, \mathrm{NJ} 1, \mathrm{NK} 1$

IF(NI.NE.NI1.OR.NJ.NE.NJ1.OR.NK.NE.NK1)THEN

WRITE $\left(*,{ }^{*}\right)$ 'SYSTEM DIMENSIONS ARE DIFFERENT’

WRITE $(*, *)^{`}$ CAANNOT READ DATA FROM FILE’

$\operatorname{WRITE}(*, *)^{`} \mathrm{NI}=$ ',NI,' NIFILE $=$ ',NI1

$\operatorname{WRITE}(*, *)^{`} \mathrm{NJ}={ }^{\prime}, \mathrm{NJ},{ }^{\prime} \operatorname{NIFILE}={ }^{\prime}, \mathrm{NJ} 1$

$\operatorname{WRITE}(*, *)^{6} \mathrm{NK}={ }^{\prime}, \mathrm{NK},{ }^{\prime}$ NIFILE $={ }^{\prime}, \mathrm{NK} 1$

PAUSE

RETURN

ENDIF

! DIMENSIONS OK TO READ

DO I $=0, \mathrm{NI}$

$$
\begin{aligned}
& \text { DO J }=0, \mathrm{NJ} \\
& \text { DO K=0,NK } \\
& \quad \text { READ }(8,901) \mathrm{I} 1, \mathrm{~J} 1, \mathrm{~K} 1, \mathrm{~T}(\mathrm{I}, \mathrm{J}, \mathrm{K}), \mathrm{L}(\mathrm{I}, \mathrm{J}, \mathrm{K}), \mathrm{QX}(\mathrm{I}, \mathrm{J}, \mathrm{K}), \mathrm{QY}(\mathrm{I}, \mathrm{J}, \mathrm{K})
\end{aligned}
$$




\author{
$\operatorname{READ}(8,901) \mathrm{QZ}(\mathrm{I}, \mathrm{J}, \mathrm{K})$ \\ ENDDO \\ ENDDO
}

\title{
ENDDO
}

$\operatorname{READ}(8,902, \mathrm{ERR}=90, \mathrm{END}=92)$

TSR,TMR,TER1,TER2,QTOT,FQTOT

READ $(8,903, \mathrm{ERR}=90, \mathrm{END}=92) \mathrm{FSX} 0, \mathrm{FSX} 1, \mathrm{FSY} 0, \mathrm{FSY} 1$

READ $(8,903, \mathrm{ERR}=90, \mathrm{END}=92)$ FGX0,FGX1,FGY0,FGY1

$\operatorname{READ}(8,904, \mathrm{ERR}=90, \mathrm{END}=92)$

FMX0,FMX1,FMY0,FMY1,FMZ0,FMZ1

READ $(8,904, E R R=90, E N D=92)$ FE1X0,FE1X1,FE1Y0,FE1Y1,FE1Z0,FE1Z1

READ $(8,904, E R R=90, E N D=92)$ FE2X0,FE2X1,FE2Y0,FE2Y1,FE2Z0,FE2Z1

CLOSE(UNIT $=8)$

RETURN

90 WRITE $(*, *)^{‘}$ AN ERROR OCCURED WHILE READING FILE’

WRITE $(*, *)^{*}$ CHECK TO SEE IF FILE IS OPENED IN MSEXCEL'

GO TO 100

92 WRITE $\left(*,{ }^{*}\right)^{‘}$ AN END OCCURED WHILE READING FILE’

GO TO 100

99 WRITE $(*, *)^{‘}$ AN ERROR OCCURED WHILE OPENING FILE’

$100 \quad$ PAUSE

RETURN 
900 FORMAT(1X,I8, ', , I8, ', ', I8)

901 FORMAT(1X,3(I8, ', '),F12.8, ', ',I8,3(',',F12.8))

902 FORMAT(1X,5(F12.8, ','))

903 FORMAT(1X,4(F12.8, ','))

904 FORMAT(1X,6(F12.8, ','))

END

$==\overline{=}=\mathrm{=}=\mathrm{=}=\mathrm{=}=\mathrm{=}=\mathrm{=}=\mathrm{=}=\mathrm{=}=\mathrm{=}=\mathrm{=}=\mathrm{=}=\mathrm{=}=\mathrm{=}=\mathrm{=}=$ 